\title{
Designing incentive mechanisms for sustainable land management: Empirical evidence from Indonesia
}

\author{
Dissertation \\ to obtain the Ph. D. degree \\ in the International Ph. D. Program for Agricultural Sciences in Goettingen (IPAG) \\ at the Faculty of Agricultural Sciences, \\ Georg-August-University Göttingen, Germany \\ presented by \\ Miriam Vorlaufer \\ born in Frankfurt/ Main
}


1. Name of supervisor: Prof. Dr. Meike Wollni

2. Name of co-supervisor: Prof. Dr. Marcela Ibañez-Diaz

Date of dissertation: 12.05.2015 


\section{Summary}

Over the last five decades, the growing demand for ecosystem services, such as food, water and fuel has led to the most rapid and extensive changes in ecosystems in human history. Examples for these transformations include the agricultural intensification at the habitat and landscapes scale. In the coming decades this pressure on ecosystems will continue to rise due to an expected further increase in global population and GDP. While these changes in ecosystems have induced substantial net gains in human wellbeing, they also entail a degradation of regulating and supporting ecosystem services (e.g. water purification, regulation of regional and local climate) that is often greater than what is socially optimal. To address this externality problem, Payments for Environmental Services (PES) are increasingly proposed as an efficient market-based policy instrument.

Previous studies on PES have primarily been based on the Coasean approach. However, practitioners can rarely find or establish the conditions that underlie the Coasean approach, such as perfect information. Critics thus postulate a new conceptualization of PES that accounts for the complexities that characterize the real-world implementation of PES. In this context, the management of uncertainty associated with heterogeneity in the environmental, socio-economic, and socio-cultural background (contextual factors) are of major concern, as well as strategic decisions regarding trade-offs in the PES outcomes, where measures of efficiency are not the sole rationale.

The aim of this thesis hence is to contribute to a better understanding of the relationships among contextual background, PES policy design and PES outcomes. More specifically, three research objectives were addressed. First, we assessed the relation between ecological outcomes (bird diversity, bird abundance) and economic outcomes (yields, revenue) of remnant or planted trees in smallholder oil palm plantations, along a management intensity gradient. Second, we investigated the crowding effect, induced by the 
framing of incentives as PES. Third, the conservation and distributional outcomes of two alternative PES schemes, adopting different implicit fairness criteria, were analyzed.

The empirical analyses were based on survey and ecological data (120 observations), as well as data from framed field experiments (360 observations). The data collection was conducted in the Province of Jambi, Sumatra, Indonesia, between November 2012 and April 2013. In the study region tropical lowland rainforest and extensive traditional production systems have been almost completely transformed into monoculture rubber and oil palm plantations with severe impacts on ecosystem service provision. To mitigate this degradation, wildlife-friendly strategies in which monoculture plantations are enriched with trees planted in gaps within the plantation or with agroforestry buffer zones to surrounding natural vegetation have been proposed.

In the first part of the study we assessed at what cost species diversity (abundance) can be conserved and identified along which section of the management intensity gradient cost-effective options for wildlife-friendly farming systems arise. Focusing on birds, results showed that the restoration of wildlife-friendly oil palm plantations, containing mixed tree stands, can mitigate the loss of diversity (abundance) with respect to edgetolerant, open habitat and generalist bird species with low conservation status. This gain in diversity (abundance) comes along with a loss in yields and revenue. Since this relationship is non-linear, the marginal shadow price of bird species richness (abundance) changes depending on the initial level of management intensity. In relatively extensively managed oil palm plantations, environmental additionality -in terms of bird species richness- can only be achieved at the cost of relatively high revenue penalties, whereas in relatively intensively managed oil palm plantations the same increase in bird species richness can be achieved at a considerably lower loss in revenue. Results hence suggested that there is room for tree-based enrichment of intensively managed oil palm plantations.

In the second part of this thesis we investigated the extent to which contextual manipulations of a policy intervention, such as the explicit framing of an incentive as PES, affect conservation behavior using data from a framed field experiment. The results showed that the PES framing significantly crowds in conservation behavior. Furthermore, re- 
sults of a zero-one inflated beta regression suggested that this crowding-in effect does not hold for the entire range of participants with different social preferences; the conservation behavior of participants with very weak preferences is not affected by the framing. To further identify mechanisms that can be abstracted from crowding effects, we controlled for social experimenter demand effects. Findings suggested that framing effects are driven by pro-social motives, such as the desire for social conformism or respect rather than by the activation of pro-nature motives. The results of this part highlight the importance for policymakers to take into consideration the contextual manipulations associated with the implementation of a policy and to carefully assess the heterogeneity in the existing preferences for the desired conservation activity.

The last part of this thesis explored the trade-off between conservation and equity considerations in the use of PES. In particular, we investigated the impact of two alternative PES schemes, which are implicitly associated with different fairness principles, on conservation and distributional outcomes under endowment and productivity heterogeneity (differences in opportunity costs of conservation). We tested an equal PES scheme, where a fixed flat rate per conserved hectare is paid, and a discriminatory PES scheme, where redistribution is explicitly considered as a strategic objective. Keeping the conservation fund constant, in the latter scheme the total payment is redistributed by offering higher payments per conserved land unit to low-endowed participants than to highendowed participants. Results indicated that with the introduction of PES, the conservation behavior at group level significantly increases, indicating that environmental additionality in terms of conservation area can be achieved. Moreover, findings suggested that the introduction of a discriminatory PES scheme can function as a multi-purpose instrument that not only provides environmental additionality similar to an equal PES scheme, but also realigns the income distribution in favor of low-endowed participants and reduces inequality among group members (as measured by the gini index).

In the light of increasingly degraded ecosystems, this thesis illustrated empirically the complexities and context-dependencies associated with the implementation of marketbased instruments, such as PES. Further collaborations between ecologists and economists are needed to specify the uncertainties associated with the environmental con- 
text. Moreover, inducing general principles from observed psychological response patterns to the introduction of PES is essential for further research. 


\section{Acknowledgement}

This dissertation would not have been possible without the outstanding support of many people in Germany and Indonesia. First and foremost, I would like to express my deep gratitude to my supervisor, Meike Wollni, for her professional guidance and encouragement during the three years course of my dissertation. Her valuable advice and comments have greatly improved the quality of this work and her confidence in me has given me the freedom to shape the dissertation according to my interests. I am also sincerely grateful to Marcela Ibañez, my co-supervisor, for introducing me "the world of experimental economics". I would also like to express my gratitude and appreciation to Yann Clough for his mentorship and guidance. This cooperation has led me to discover other perspectives and approaches. I would like to acknowledge Ulrich Brose, for his very valuable comments and hosting me at his chair. Finally, I am also grateful to Oliver Mußhoff for serving on my examination committee.

I would like to thank the German Research Foundation (DFG) through the CRC990 "Ecological and Socio-Economic functions of tropical lowland rainforest transformation systems" for providing me the financial support. To the fellow doctoral students at the Chair of International Agricultural Economics, I am very grateful for the motivation and all the academic and non-academic discussions, which always inspired me. To the colleagues from the CRC990, I will always esteem the special moments and experiences we shared together, especially, in Indonesia. My special thanks go to Mimi Teuscher for the great cooperation and for catching my interest in "ZilpZalps".

The field work in Indonesia would not have been possible without the exceptional support of many people from the University of Bogor (IPB) and the University of Jambi.

In particular, I would like to thank Pak Bambang Juanda and Ibu Rosyani who were always willing to share their experience and knowledge with me and provided support whenever possible. I am very grateful to the whole CRC coordination team in Indonesia, Wolfram, Mira, Risky, Mega, Yuking for their great administrative support. Furthermore, 
my thanks go to the enumerators for their great work in ensuring the quality of the data and for introducing me Indonesian culture. Moreover, I would like to thank the village heads and interviewed farmers in the villages, Karmeo, Pulau Betung, Bukit Harapan and Bukit Harapan for their willingness to take time out of their schedules to participate in the workshops and their great hospitality - Termina kasih!-.

Finally, I would like express my heartfelt gratitude to my friends and family, who provided endless moral support during my PhD years. I am very grateful to my parents, for their loving encouragement and their confidence in me. In particular, I am greatly indebted to Fabi, for his love and unconditional support. 


\section{Table of contents}

1 General Introduction

1.1 The degradation of ecosystem services 1

1.2 Oil palm 4

1.2.1 Biodiversity conservation in oil-palm-dominated landscapes 5

1.2.2 Incentive mechanisms for biodiversity conservation in oil-palmdominated landscapes

1.3 Toward a new conceptualization of Payments for Environmental

Services

1.3.1 Uncertainty regarding environmental additionality 9

$\begin{array}{ll}\text { 1.3.2 Motivation crowding } & 10\end{array}$

$\begin{array}{ll}\text { 1.3.3 Equity considerations } & 11\end{array}$

1.4 Problem statement 12

$\begin{array}{lll}1.5 & \text { Research objectives } & 14\end{array}$

$\begin{array}{lll}1.6 & \text { Outline } & 15\end{array}$

2 Trade-off between bird diversity and abundance, yields and revenue in smallholder oil palm plantations

$\begin{array}{lll}2.1 & \text { Introduction } & 18\end{array}$

2.2 Material and methods $\quad 21$

$\begin{array}{lll}2.2 .1 & \text { Study site } & 21\end{array}$

$\begin{array}{lll}2.2 .2 & \text { Household survey } & 23\end{array}$

$\begin{array}{lll}2.2 .3 & \text { Bird sampling } & 24\end{array}$

2.2.4 Vegetation assessment 24

2.2.5 Data analysis $\quad 25$

$\begin{array}{lll}2.3 & \text { Results } & 28\end{array}$

2.3.1 Household survey: trees 28

2.3.2 Bird species composition and abundance 29

2.3.3 Determinants of yields 32

$\begin{array}{lll}2.3 .4 & \text { Trees and revenue } & 32\end{array}$

2.3.5 Bird diversity and abundance - revenue relationship 33

2.3.6 Marginal shadow price of bird species richness and abundance $\begin{array}{ll}\text { tree relationship } & 34\end{array}$

$\begin{array}{lll}2.4 & \text { Discussion } & 35\end{array}$

2.4.1 Implications for conservation 38

2.5 Conclusion 41

3 Frame-shifting and motivation crowding: A public good experiment on Payments for Environmental Services 
3.1 Introduction 44

3.2 Background on land use transformation 46

3.3 Conceptual Framework 48

$\begin{array}{lll}3.3 .1 & \text { Pay-offs } & 48\end{array}$

$\begin{array}{ll}\text { 3.3.2 Crowding effects } & 49\end{array}$

$\begin{array}{ll}3.4 & \text { Experimental Treatments } \\ 3.5\end{array}$

$3.5 \quad$ Experimental Procedure 53

3.6 Sample characteristics 53

3.7 Assessment of the framing effect 56

3.7.1 Descriptive analyses $\quad 56$

3.7.2 Econometric analyses $\quad 59$

Methodology $\quad 59$

$\begin{array}{ll}\text { Model specification } & 61\end{array}$

Results $\quad 62$

3.8 Assessment of the motivational factors $\quad 65$

$\begin{array}{lll}\text { 3.8.1 Descriptive analyses } & 65\end{array}$

$\begin{array}{ll}3.8 .2 & \text { Econometric analyses }\end{array}$

$\begin{array}{lll}3.9 & \text { Conclusion } & 70\end{array}$

4 Conservation vs. Equity: Can Payments for Environmental Services achieve both?

$\begin{array}{lll}4.1 & \text { Introduction } & 74\end{array}$

$\begin{array}{lll}4.2 & \text { Background } & 78\end{array}$

$\begin{array}{lll}4.3 & \text { Conceptual framework } & 81\end{array}$

$\begin{array}{ll}\text { The producer problem } & 81\end{array}$

The social planner problem $\quad 83$

Payments for Environmental Services (PES) 83

4.4 Experimental Design and Procedures 86

$\begin{array}{lll}4.5 & \text { Results } & 96\end{array}$

4.5.1 Socioeconomic characteristics of the sample 90

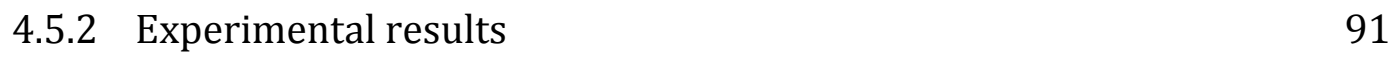

Descriptive results $\quad 91$

$\begin{array}{ll}\text { Econometric results } & 94\end{array}$

Impact of endowment status on conservation behavior 94

Impact of alternative PES schemes on distributional outcome $\quad 97$

Impact of alternative PES schemes on environmental additionality at group level 99

$\begin{array}{lll}4.6 \text { Conclusion } & 100\end{array}$

5 General Conclusion $\quad 104$

$\begin{array}{lll}5.1 & \text { Summary of findings } & 104\end{array}$

$\begin{array}{ll}5.2 \text { Policy recommendations } & 107\end{array}$

$\begin{array}{ll}5.3 & \text { Limitations and further research } \\ & 110\end{array}$

Declaration on the proportion of own work performed $\quad 114$ 
$\begin{array}{ll}\text { Declarations } & 116\end{array}$

$\begin{array}{ll}\text { Bibliography } & 117\end{array}$

$\begin{array}{lr}\text { Appendices } & 129\end{array}$

Appendix I: Recorded bird species $\quad 129$

Appendix II: Principal Component Analysis (PCA) 130

Appendix III: BayesX estimation results (framing effects) 131

Appendix IV: GAMLSS estimation results (framing effects) 132

Appendix V: Q-Q plots 133

Appendix VI: Random assignment test $\quad 134$

Appendix VII: Random effects Tobit model 135

Appendix VIII: Questionnaire “tree enrichment” 136

Appendix IX: “Warm-up” questions 155

Appendix X: Instructions Public good game 158

Appendix: XI: Questionnaire “ Post-Experimental Survey" 179

Appendix XII: Questionnaire "General Household Survey" 185 


\section{List of Tables}

Table 1: Explanatory variables considered in the full models to explain bird abundance, bird diversity, yields and revenue ..............................................25

Table 2: Coefficients of variables included in the bird and economic models ....................30

Table 3: Relative profit of rubber agroforestry $(a+\delta)$ by payment set..................................52

Table 4: Descriptive results of socioeconomic indicators by treatment ...............................54

Table 5: Share participants with zero investment in rubber agroforestry by payment level and treatment for hypothetical and incentivized

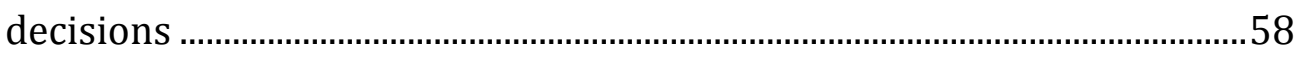

Table 6: Explanatory variables entering into full model .........................................................62

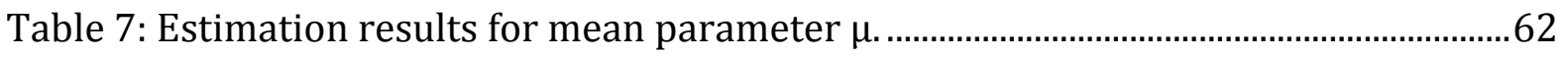

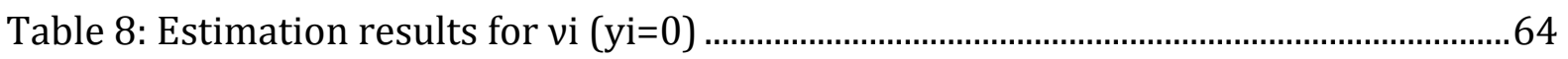

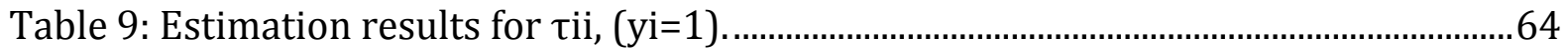

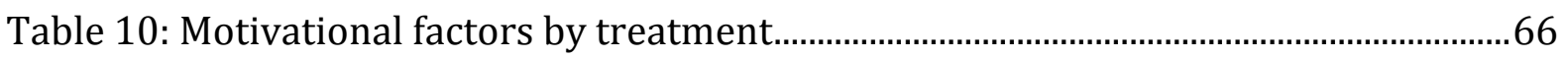

Table 11: GAMLSS estimation results for mean parameter $\mu$.................................................68

Table 12: Relative profit of rubber agroforestry $(a+\delta)$ by PES scheme, payment set, payment level, and endowment status ...................................................8

Table 13: Socio-economic characteristics of participants........................................................ 90

Table 14: Random effects Tobit model on the share of endowment conserved under equal and discriminatory PES schemes..............................................95

Table 15: Random effects Tobit model on the share of total group earnings and

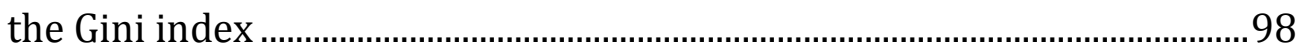

Table 16: Random effects Tobit model on the share of endowment conserved at group level 


\section{List of Figures}

Figure 1: Conceptualization of PES. PES outcomes with non-dashed frames are considered in the Coasean approach; contextual factors and PES outcomes with a dashed frame are based on the new conceptualization of PES; contextual factors with a grey frame are not addressed in this study.

Figure 2 Map of the study area: (a) Sumatra (b) Location of the study plots in the four study villages Bukit Harapan (yellow), Bukit Sari (blue), Pulau Betung (green) and Karmeo (red) in the Jambi province.

Figure 3: Effects of trees within oil palm plantations on bird species richness (a), as well as bird abundance (c). The marginal gain in bird species (b) and bird abundance conditional on the number of trees are given. Grey dots indicate original observations.

Figure 4: Effects of trees within oil palm plantations on oil palm yields (a). The marginal loss in revenue (b) conditional on the number of trees are given. Grey dots indicate original observations.

Figure 5: Relationship between predicted revenue and predicted bird diversity (a) and predicted bird abundance, respectively (c). Marginal loss in revenue with every one-unit change in bird diversity (b) and bird abundance (d), respectively, conditional on the tree stands within or at the border of the oil palm plantation.

Figure 6: Average share endowment contributed to conservation by treatment and payment level (for both hypothetical and incentivized decisions).

Figure 7: Predicted share of endowment allocated to rubber agroforestry (sh_jrn) due to an increase in payment level (sh_pes_n) conditional on perceived expectations and treatment (PES=framed treatment)....

Figure 8: Average share of endowment contributed to rubber agroforestry by PES scheme, endowment status and payment level.

Figure 9: Average share of total group earnings held by individual by PES scheme, payment level, and endowment status. 


\section{List of Abbreviations}

AIC

BEINF

CA

CPO

CVM

DIE

EDE

ES

FAO

FIC

FONAFIFO

GAM

GAMLSS

GDP

GLM

GPS

HCV

ICDP

ICRAF

IDR

IFAD

INS

IPB
Akaike Information Criterion

Beta-inflated distribution

Conservation agreement

Crude palm oil

Contingent Valuation Method

Deutsches Institut für Entwicklungsforschung

Experimenter demand effects

Ecosystem services

Food and Agriculture Organization of the United Nations

Food information to consumers

Fondo Nacional de Financiamiento Forestal

Generalized additive model

Generalized additive model for location, scale and shape

Gross domestic product

Generalized linear model

Global Positioning System

High conservation value

Integrated conservation and development program

World Agroforestry Centre

Indonesian Rupiah

International Fund for Agricultural Development

Inclusion of nature in the self

University of Bogor 
IUCN

MA

MRT

MRV

NES

NGO

OLS

PCA

PES

PWC

REDD+

RSPO

RUPES

SMBC

SOFI

UN

UNCTAD

UNDP

UNEP

UN-FCCC

WTO

WWF
International Union for Conservation of Nature

Millenium ecosystem assessment

Marginal rate of transformation

Information Monitoring and Measurement, Reporting, and Verification

Nucleus Estates and Smallholder

Non-governmental organization

Ordinary least square

Principal Component Analysis

Payments for Environmental Services

PricewaterhouseCoopers

Reducing Emissions from Deforestration and Forest Degradation

Roundtable on Sustainable Palm oil

Rewarding Upland Poor for Environmental Services

Smithsonian Migratory Bird Centre

State of Food Insecurity in the World

United Nations

United Nations Conference on Trade and Development

United Nations Development Programme

United Nations Environment Programme

United Nations Framework Convention on Climate Change

World Trade Organization

World Wildlife Fund 


\section{General Introduction}

\subsection{The degradation of ecosystem services}

Human well-being depends considerably on the Earth's ecosystem services, including commodities (e.g., food) as well as regulating (e.g., water purification), supporting (e.g., nutrient cycling), and cultural services (e.g., aesthetic beauty) (MA, 2005; Jack et al., 2008; Engel et al., 2008). Over the last 50 years, the demand for ecosystem services has increased significantly as the world population has doubled to 7 billion and the global economy has grown more than six-fold, inducing, for example, changes in eating habits toward meat and dairy products (MA, 2005; Engel et al., 2008). In response, food production increased by $250 \%$, water use by $100 \%$, and timber production by $50 \%$ (MA, 2005). In the coming decades, this pressure on ecosystems will continue to rise due to an expected three- to six-fold increase in global GDP by 2050 and considerable but weakening population growth to 9 billion. Accordingly, the International Fund for Agricultural Development (IFAD) estimates that global food production will have to increase by $70 \%$ until 2050 to ensure food security (IFAD, 2010).

The growing demand for ecosystem services over the last five decades has led to the most rapid and extensive changes in ecosystems in human history. The increase in food production was accomplished by agricultural intensification at the habitat and landscape scales, made possible by the use of new technologies (e.g., crop varieties, fertilization) and the transformation of natural or semi-natural habitats into agricultural production areas. These changes to ecosystems have led to substantial net gains in human well-being, such as the significant reduction of undernourished persons by 209 million since 1990-92 (FAO, 2014b). However, the increase in global food production has been achieved at the expense of increasingly degraded regulating and supporting ecosystem services, including water purification, disease regulation, and the regulation of the regional and local climate. The Millennium Ecosystem Assessment estimates that approximately $60 \%$ of ecosystem services are "being degraded or used unsustainably" (MA, 2005, p.6). These forms of ecosystem service degradation entail consequences for hu- 
mans, such as the rapid spread of crop diseases (e.g., Rustus fungus strain Ug99), abrupt alterations in water quality, shifts in regional climate, and increases in soil depletion and erratic water supply (MA, 2005; Godfray et al., 2010). Poor communities are particularly vulnerable to the impacts of ecosystem degradation. Approximately $76 \%$ of the world's poor live in rural areas. A large majority of them are small-scale farmers or agricultural wage laborers who rely on the provision of ecosystem services (World Bank, 2014; Dercon, 2009). Thus, fostered by limited informal and formal insurance systems linked to, for example changing weather patterns, ecosystem degradation threatens to undermine the progress that has been made in poverty alleviation. Going beyond the material aspects of human well-being, ecosystem degradation also negatively affects the personal security of the poor and the social relations among individuals (e.g., social cohesion) (UNEP, 2007). Considering the increasing competition for natural capital and emerging resource bottlenecks, the Food and Agriculture Organization of the United Nations (FAO, 2015) has called for a paradigm shift from input-intensive agricultural development toward a more sustainable agriculture system that uses ecosystem services more efficiently.

Since the benefits of regulating and supporting ecosystem services, such as water purification, primarily flow to others, the valuation of the ecological dimension in the decision-making processes of resource users and the public interest might be misaligned. This difference in private and social benefits leads to a greater depletion of regulating and supporting ecosystem services than would be socially optimal, thus indicating market failure (Engel et al., 2008; Jack et al., 2008; Gómez-Baggethun et al., 2010). To address this externality problem, a number of potential policy solutions exist, including command-and-control regulations, voluntary agreements and market-based instruments.

Payments for Environmental/Ecosystem Services (PES) are increasingly proposed as a market-based instrument that translate non-market values of ecosystems into financial incentives. These icentives are at least equal to the private benefits forgone for the ecosystem service provider (Engel et al., 2008; Tacconi, 2012). Muradian et al. (2010, p. 2010) define PES as "a transfer of resources between social actors, which aim to create incentives to align individual and/or collective land use decisions with the social inter- 
est in the management of natural resources." Hundreds of PES initiatives have emerged over the last decades (Jack et al., 2008; Landell-Mills, 2002). Examples include the wellknown forest conservation program in Costa Rica (FONAFIFO) (Pagiola, 2008) and the PES scheme for carbon sequestration in Mexico (Corbera et al., 2007).

To date, the conceptualization and analysis of PES has primarily been based on the Coasean approach. Given well-defined property rights and relatively low transaction costs, the Coase theorem states that through bargaining over rights (e.g., the right to commercialize the service provided by a natural asset) a Pareto-efficient outcome can be achieved regardless of the initial allocation of property rights over the assets (Muradian et al, 2010; Engel et al, 2008; Muradian et al., 2013). Adherents of the Coasean approach propose the creation of market transactions for environmental goods through the implementation of market-based policy instruments to address the undersupply of ecosystem services. However, practitioners can rarely find or establish the conditions that underlie the Coasean approach, such as clear property rights, perfect information and competition (Muradian et al., 2010). Critics thus postulate a new conceptualization of PES that accounts for the complexities that characterize the real-world implementation of PES. In this context, the management of uncertainty associated with heterogeneity in the environmental, socio-economic, and socio-cultural background are of major concern, as well as strategic decisions regarding trade-offs in the PES outcomes, where measures of efficiency are not the sole rationale (Jack et al., 2008; Muradian et al., 2010).

Given the complexities faced by practitioners, the aim of this study is to contribute to a better understanding of the relationships among PES outcome, PES policy design and contextual factors (environmental, socio-economic, and socio-cultural background) and thereby to contribute to the design of PES. We do so by focusing on oil-palm-dominated landscapes in Indonesia. 


\subsection{0il palm}

Palm oil is one of the most important vegetable oils globally. "Hidden in the shopping basket," (Paddison, 2014) it can be found in an estimated one in ten products in US grocery stores, such as margarine, detergents and cosmetics (Koh et al., 2009). It accounts for 25\% of global vegetable oil consumption (World Bank, 2010; UNEP, 2011). Furthermore, oil palm (Elaeis guineensis) is currently one of the most relevant cultivated feedstocks for the biodiesel production (Koh et al., 2009). The relatively high demand for palm oil for food, oleochemistry and biofuel production is primarily driven by its higher yields at lower cost relative to competing vegetable oils (e.g., soybean Glycine max; rapeseed Brassica napus) ${ }^{1}$. Over the last 25 years, the total oil palm plantation area has tripled (Gilbert, 2012), making it the most rapidly increasing perennial crop in the tropics (Phalan et al., 2013). Currently, oil palm is cultivated on approximately 17 million ha worldwide (FAO, 2014a). This expansion will likely continue due to increasing food demand, especially in Asian countries such as India and China (IFAD, 2010). Oil palm is grown in zones naturally occupied by the most biologically diverse terrestrial ecosystems on earth, which provide important regulatory and supporting ecosystem services, including carbon storage and water filtration (Fitzherbert et al., 2008; Koh et al., 2011). The Southeast Asian countries of Malaysia and Indonesia account for more than $80 \%$ of global palm oil production (Sodhi et al., 2004). In Indonesia, the area under oil palm cultivation nearly doubled from 4.2 million ha in 2000 to approximately 8 million ha in 2010, making Indonesia one of the world's leaders in palm oil production (Obidzinski et al., 2012).

The expansion of the oil palm area in Indonesia has fostered economic development alongside conflicts over land use and extensive ecosystem degradation. Oil palm cultivation is an attractive way out of poverty for many rural households (Feintrenie et al., 2010; McCarthy et al., 2012), although smallholders only exploit a limited amount of the crop's genetic yield potential (Lee et al., 2013). Furthermore, the expansion of cultivation significantly affects social relations and land ownership. In 2010, there were approximately 630 land disputes between oil palm companies and local communities due to, for example, failure to recognize customary rights (Colchester, 2010; Obidzinski et

\footnotetext{
1 The average productivity of oil palm is approximately 4 tons of crude palm oil (CPO) ha- $1 \mathrm{y}-1$, whereas substitute crops produce on average less than 0.8t ha-1y-1 (UNCTAD, 2014).
} 
al., 2012). In addition to its economic and social implications, the expansion of oil palm cultivation has severe impacts on the provision of ecosystem services. Its expansion is one of the largest causes of deforestation (Koh et al., 2011). For the period from 1990 to 2005, Indonesia ranked second among countries facing a significant decline in forested area (World Trade Organization, 2010). In addition, oil palm has replaced complex extensive cultivation systems, such as rubber agroforestry (hutan karet) (Ekadinata and Vincent, 2011; Gouyon et al., 1993).

The conversion of natural rainforest into oil palm entails a severe loss of multitrophic biodiversity and ecosystem functioning. Oil palm plantations hold significantly fewer vertebrate and invertebrate taxa than do primary or disturbed (logged or secondary) forests because of low habitat complexity and landscape fragmentation (Fitzherbert et al., 2008; Foster et al., 2011). The loss of ecosystem functioning accompanying the loss of biodiversity is proportionately stronger in oil palm plantations than in low-intensity ecosystems, such as hutan karet (Barnes et al., 2014). Several studies report that bird functional diversity significantly decreases as forests are converted into oil palm (Edwards et al., 2010; Azhar et al., 2013). To mitigate this loss in biodiversity and ecosystem functioning, scholars increasingly discuss various conservation strategies for oilpalm-dominated landscapes.

\subsubsection{Biodiversity conservation in oil-palm-dominated landscapes}

Various strategies have been discussed to mitigate ecosystem degradation in oil-palmdominated landscapes. These include designer plantation landscapes in which monocultural plantations are enriched with trees planted in gaps within the plantation or with agroforestry buffer zones bordering surrounding natural vegetation (Edwards et al., 2010; Koh et al., 2009; Fitzherbert et al., 2008; Bhagwat and Willis, 2008). Particularly in Indonesia, where the forests have been nearly completely converted into agricultural land, leaving only fragmented habitats, designer landscapes that offer the potential for conservation within the landscape matrix are theoretically feasible solutions. In this context, agricultural landscapes that exhibit habitat complexity comparable to that of natural habitats, such as agroforestry systems, may contribute significantly to the mitigation of biodiversity loss. In particular, open-habitat bird species, which are dependent on heterogeneous human-made habitats, might be maintained by extensifi- 
cation (Benton et al., 2003). These species provide a range of regulatory ecosystem services, such as pest control, seed dispersal and pollination (Karp et al., 2013; Van Bael et al., 2008). For designer plantations, the planting of trees is crucial. They provide habitats for foraging, nesting, or roosting and attract seed-dispersing bird species (Chazdon, 2008).

Ample evidence shows that the extensification of agricultural production toward wildlife friendly farming systems comes at the cost of lower yields (Green et al., 2005; Perfecto et al., 2005; Steffan-Dewenter et al., 2007; Phalan et al., 2011a; Tscharntke et al., 2012b). Given this trade-off, self-regarding utility-maximizing farmers with no further preferences for wildlife-friendly farming systems do not have an incentive to extensify their production. Hence, incentives that compensate for the forgone yields are needed to encourage conservation in oil-palm-dominated landscapes.

\subsubsection{Incentive mechanisms for biodiversity conservation in oil-palm-dominated landscapes}

Market-based instruments, such as certification schemes or PES, are intended to compensate for the forgone benefits induced by agricultural extensification.

Several campaigns (e.g., Orang Utan) led by non-governmental organizations (NGOs) have raised awareness among concerned consumers regarding the threats that oil palm cultivation poses for nature. This has led to the establishment of sustainability standards and certification schemes (DIE, 2012). The most relevant standard is the Roundtable on Sustainable Palm Oil (RSPO), initiated in 2004 by the World Wildlife Fund (WWF) and the company Unilever. It is an international, multi-stakeholder initiative involving palm oil producers, food producers, retailers, banks, and environmental and development NGOs. Currently, 18\% of global palm oil production is RSPO certified (RSPO, 2014a). Among eight principles and criteria, RSPO members agree to the conservation of natural resources and biodiversity. Thus, linked to the strategy of forest fragment conservation, oil palm producers are required to identify and conserve habitats of high conservation value (HCV) within or surrounding their plantations (Koh et al., 2009). However, RSPO lacks clear guidelines on the HCV identification process and related auditing (Koh et al., 2009). The RSPO label on products, which is used by a rela- 
tively small number of RSPO members, is not associated with the payment of price premiums due to insufficient consumer demand for certified palm oil (RSPO, 2014b). This lack of demand for certification is in large part the result of the untransparent labeling of palm oil as generic vegetable oil in processed food. In 2014, the EU introduced the law on food information to consumers (FIC), which determined that concealing ingredients using generic titles was no longer permitted. Whether the labeling of palm oil will translate into a change in the willingness to pay for eco-certified oil palm remains to be seen (Smedley, 2014).

The implementation of PES schemes, such as Reducing Emissions from Deforestation and Forest Degradation (REDD ${ }^{+}$), represents further efforts to create incentives to reduce ecosystem service degradation from forested land and to invest in certain wildlifefriendly cultivation systems, such as agroforestry buffer zones ${ }^{2}$. In 2005, REDD was first discussed within the United Nations Framework Convention on Climate Change (UNFCCC) at the request of Cost Rica and Papua New Guinea. Seven years later, in 2012, three UN agencies of the UN-REDD Program (FAO, UNDP, and UNEP) and the Indonesian Ministry of Forestry completed the Indonesian readiness phase that was intended, for example, to develop a strategy for Information, Monitoring and Measurement, Reporting, and Verification (MRV), which is a condition for REDD implementation. In the next phase, pilot studies of five REDD ${ }^{+}$activities will be implemented in Central Sulawesi, where the readiness phase was also conducted (Klaver, 2013).

To prepare villagers to implement market-based policy instruments, such as rubber eco-certification and REDD+, in 2002 the World Agroforestry Centre (ICRAF) launched the Rewarding Upland Poor for Environmental Services (RUPES) program in Indonesia. The aim of this initiative was to develop conservation agreements (CA) to preserve rubber agroforestry, which may function as complex habitats in oil-palm-dominated landscapes (ICRAF, 2014) ${ }^{3}$.

\footnotetext{
${ }^{2}$ For further discussion on the role of agroforestry in REDD+ programs, see Minang et al., 2014.

3 For a discussion of whether to allow rubber agroforestry through hutan desa (village forest) to be included as a land use in the REDD+ scheme, see Pramova et al., 2013, Villamor et al., 2011.
} 


\subsection{Toward a new conceptualization of Payments for Environmental Ser- vices}

Figure 1 depicts the extension of the Coasean approach, in which contextual factors interact with PES policy design and thereby determine the PES outcomes.

The Coasean policy approach implies the normative vision of assessing a policy based on its economic efficiency as the sole relevant PES outcome. Efficiency in this context is principally defined as social efficiency, whereby social economic welfare is maximized. In this equilibrium, the social marginal benefits of an intervention equal the social marginal costs. The social marginal costs include, for example, the marginal opportunity cost of foregone benefits of resource use and the marginal transaction costs of a policy intervention. A policy intervention is environmentally effective, but not necessarily socially efficient, if it provides environmental additionality, meaning that it incentivizes the provision of additional ecosystem services that would not have been provided otherwise (Engel et al., 2008; Jack et al., 2008).

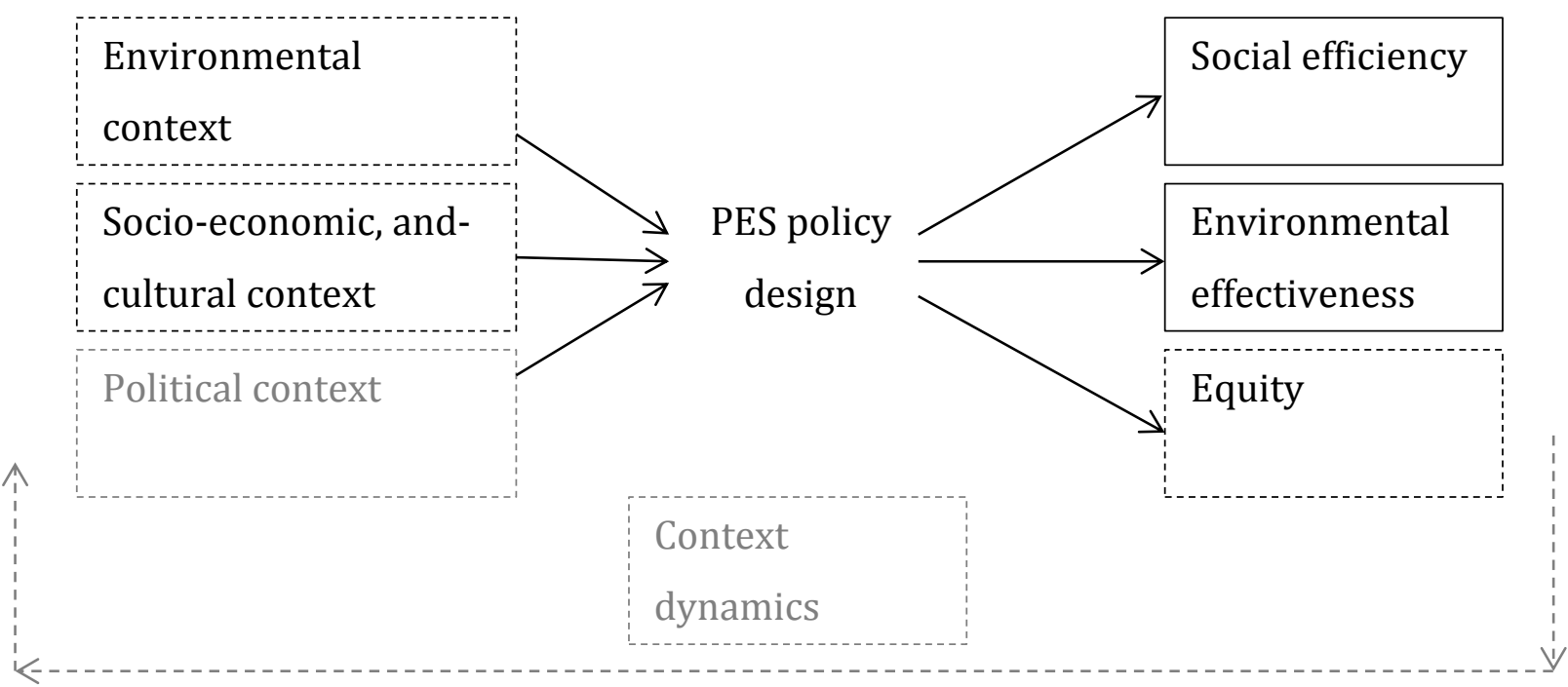

Figure 1: Conceptualization of PES. PES outcomes with non-dashed frames are considered in the Coasean approach; contextual factors and PES outcomes with a dashed frame are based on the new conceptualization of PES; contextual factors with a grey frame are not addressed in this study. 
Critics of conventional economic theory argue that contextual factors, which are generally disregarded under the Coasean approach, interact with the policy design and hence determine the PES outcome. Jack et al. (2008) and Muradian et al. (2010) identify four groups of contextual factors: environmental context, socio-economic and socio-cultural context, political context and context dynamics. In this study, we address aspects of the environmental, socio-economic and socio-cultural context, whereas we disregard the political context and context dynamics ${ }^{4}$. With respect to PES outcomes, we extend the Coasean approach by assessing the equity considerations of PES implementation.

\subsubsection{Uncertainty regarding environmental additionality}

The provision of environmental additionality induced by a policy is a necessary condition for PES implementation. However, practitioners and policy makers face substantial uncertainty regarding environmental additionality due to the considerable complexity of conservation activities (management intensity), ecosystem functioning and ecosystem service provision (Muradian et al., 2010; Jack et al., 2008; Pascual et al., 2010). This uncertainty can be partly explained by the non-linearity of the marginal benefits of ecosystem service provision (Jack et al., 2008).

Marginal environmental benefits are constant when, for example, the first tree on a monoculture plantation provides the same amount of ecosystem service provision, such as pest control (through an increase in bird diversity), as the $50^{\text {th }}$ tree. This would imply that environmental additionality does not depend on the initial conditions; hence, the implementation of a uniform per-unit payment is a feasible PES scheme to achieve a conservation goal. However, for many ecosystem services, changes in management intensity induce a non-linear change in environmental benefits due to, for example, threshold effects in ecosystems (Jack et al., 2008). The level of environmental additionality thus depends on the initial properties of the ecosystem (environmental context). The complexity in the PES policy design with respect to non-linearity is further fostered by the fact that the marginal opportunity costs of conservation are also non-constant. For example, the forgone benefits due to the first tree planted on a monoculture plantation are not identical to those of the $50^{\text {th }}$ tree. Assuming that it is possible to discriminate among resource users with respect to the compensation level, the non-linearity

${ }^{4}$ For further discussion of the political context, see Jack et al., 2008. 
makes it possible to identify sections of the management intensity gradient at which cost-effective options for conservation activities arise (Clough et al., 2011; Pascual et al., 2010; Jack et al., 2008).

\subsubsection{Motivation crowding}

In addition to the increasing relevance of PES in practice, a growing number of scholars criticize the utilitarian, market-based rationales for conservation underlying the Coasean approach, in which ecosystem values are reduced to a single exchange value. In this context, socio-economic and socio-cultural aspects associated with the provision of ecosystem services are denied (Muradian et al., 2010; Kosoy and Corbera, 2010 see also McCauley, 2006). One of the most common arguments of critics is that incentives such as PES may undermine social and ethical motives to conserve ecosystem services and hence may lead to a counterproductive or less efficient outcome than that predicted by conventional economic theory (Frey and Jegen, 2001; Bowles, 2008). Critics primarily refer to the motivation crowding theory (Frey, 1994; Frey, 1997; Frey and OberholzerGee, 1997), which states that monetary incentives affect the outcome not only by altering the costs and benefits of providing the desired activity (price effect) but also by shaping the intrinsic motivation to contribute to the desired outcome (crowding effect). Accordingly, monetary incentives may either strengthen social and ethical motives (crowding in) or undermine such motives (crowding out).

Empirical evidence has identified a number of psychological mechanisms that may explain crowding effects in the provision of public goods that are induced by monetary incentives (Narloch et al., 2012; Rodriguez-Sickert et al., 2008; Cardenas et al., 2000; Vollan, 2008; for an overview, see Rode et al., 2014). One line of literature assumes that incentives are part of the way a situation is represented and that these contextual manipulations affect behavior (Tversky and Kahnemann, 1981; Bowles, 2008). In the short run, PES may serve as frame shifting by changing the cognitive concept of the conservation logic toward economic reasoning, thus disregarding pro-nature and social motives (Bowles, 2008; Gómez-Baggethun et al., 2010; Vatn et al., 2010; García-Amado et al., 2013). In the long run, this frame shifting might diminish environmental values and mindsets (Rode et al. 2014). Besides these forms of crowding out, frame shifting might also result in crowding in. With respect to pro-social motives, frame shifting may serve 
as a signal, highlighting that conservation activities are socially esteemed and enforcing social norms. With respect to pro-nature motives, frame shifting may activate environmental considerations in the short run and strengthen environmental values and mindsets in the long run (Sommerville et al., 2010).

\subsubsection{Equity considerations}

Ignoring the role of the initial allocation of property rights to achieve efficiency gains, the Coasean policy approach disregards equity considerations in the implementation of PES. Driven by the normative vision of efficiency improvements as a guiding principle, the "pro-poor" targeting of PES has been investigated with regard to the required conditions (such as secure property rights, reduced transaction costs, and an increased capacity for market participation) for poor landowners to become efficient providers of ecosystem services and hence to participate in the PES program (Pascual et al., 2010; Grieg-Gran et al., 2005; Landell-Mills, 2002; Pagiola et al., 2005). Critics argue that this $a$ priori rationale of efficiency as the sole outcome precludes a better understanding of the relationship between equity and efficiency (Pascual et al., 2010; Muradian et al., 2010; Muradian et al., 2013; Landell-Mills and Porras, 2002). Evidence shows that in the majority of PES schemes, poor landholders tend to be excluded from participation (procedural justice) or lack adequate benefits generated through program participation (distributional justice) (Zbinden and Lee. 2005; Grieg-Gran et al., 2005; Sommerville et al., 2010; Corbera et al., 2007). Thus, practitioners (e.g., NGOs, government agencies) increasingly contend that PES should function as a multipurpose instrument for both ecosystem conservation and poverty alleviation to secure the political and social legitimacy of the intervention (Landell-Mills and Porras, 2002; Pagiola et al., 2005; Grieg-Gran et al., 2005; Corbera et al., 2007; Muradian et al., 2010; Corbera and Pascual, 2012; Narloch et al., 2013; Muradian et al., 2013). Because PES schemes are often framed within broader development interventions that are explicitly intended to target vulnerable groups, practitioners are confronted with the need to consider equity and fairness when designing PES schemes. Moreover, the implicit fairness criteria of the PES scheme (Pascual et al., 2010) and the distribution of benefits and costs among landholders might be perceived as unfair by members of society or other stakeholders, thus decreasing the social legitimacy of the program (Sommerville et al., 2010; Corbera et al., 2007; Kosoy et al., 2007; Petheram and Campbell, 2010). 
Pascual et al. (2010) conceptualize the interdependency between efficiency and equity and elaborate the role of different implicit fairness criteria in PES schemes. As depicted in the previous section, incentives are embedded in complex social systems and interact with ethical and social motives (Bowles, 2008; Frey and Jegen, 2001; Cardenas and Carpenter, 2008; Pascual et al., 2010). The social notion of what distributive rule (implicit fairness criterion) is perceived as fair may thus determine conservation behavior and, ultimately, the equity/ efficiency relationship. Because the perception of fairness is substantially determined by the socio-economic (e.g., status in society) and socio-cultural contexts, manifold fairness criteria exist that may vary significantly across agents (Pascual et al., 2010). Pascual et al. (2010) identify a number of PES design principles that differ considerably in their implicit fairness criterion or in the relative weights that they assign to equity and efficiency concerns. Policy designs range from PES schemes that primarily favor equity concerns at the cost of efficiency to schemes that primarily focus on efficiency concerns at the expense of equity.

\subsection{Problem statement}

The nearly complete transformation of natural or semi-natural habitats into oil palm plantations has serious consequences for the provision of ecosystem services. Hence, the implementation of PES schemes that incentivize the establishment of wildlifefriendly farming systems is a potential approach to mitigate ecosystem degradation.

To address the question of at what cost diversity (abundance) of bird species can be conserved and at what section of the management intensity gradient cost-effective options for wildlife-friendly farming systems arise, the species diversity (abundance) yield function has to be estimated (Green et al., 2005; Perfecto et al., 2005; Steffan-Dewenter et al., 2007; Phalan et al., 2011a; Tscharntke et al., 2012b). To best of our knowledge, studies that integrate biodiversity and yield data in the context of wildlife-friendly strategies in oil-palm-dominated landscapes are lacking. Previous ecological (economic) studies on the relationship between management options that enhance habitat complexity and bird species diversity (yield) are inconclusive (Nájera and Simonetti, 2010; Aratrakorn et al., 2006; Azhar et al., 2011; Bhagwat and Willis, 2008; Miccolis et al., 
2014) as they miss a clear definition of the degree of habitat complexity. Despite the relevance of non-linearity in the marginal benefits and costs of methods for enhancing habitat complexity, studies offering insights into how biodiversity and yields respond to quantitative changes in management options in oil-palm-dominated landscapes are lacking (Koh and Ghazoul, 2008).

To understand the mechanisms that underlie crowding effects is of essential relevance when it comes to the design of policy instruments (Rode et al., 2014). In the last decade, a growing number of studies have investigated motivation crowding induced by PESlike schemes meant to encourage biodiversity conservation in a development country context. Narloch et al. (2012) investigate the effectiveness of collective vs. individual rewards linking it to the motivation crowding theory by applying an experimental approach (see also Vollan, 2008; Travers et al., 2011). Others use case studies to examine qualitatively the relation between PES and motivational factors (Fisher, 2012; GarcíaAmado et al., 2013; Sommerville et al., 2010). These studies are inconclusive as they provide only suggestive comments on the mechanisms that underlie the crowding effect. To best of our knowledge, studies that explicitly aim to investigate the crowding effect induced by framing in the context of PES schemes are lacking.

The potential interdependency between efficiency and equity is determined by the fairness criteria adopted in the PES scheme. Despite the relevance of this issue, to date, few scholars have addressed the distributional implications, such as the distribution of benefits and losses between different landholders, induced by alternative PES schemes. Both Alix-Garcia et al. (2008) and Börner et al. (2010) highlight equity and efficiency/cost-effectiveness implications by applying micro-simulation models. Simulations allow the researcher to control for various determinants of PES outcomes, (e.g., differences in opportunity costs, spatial patterns, ecosystem service provision and land tenure, experimental approaches). However, experimental approaches, such as framed field experiments are needed to control for the context-dependent impacts of applying different fairness criteria (through different social notions of distributional justice). To the best of our knowledge, studies that apply a framed field experiment to assess the distributional outcomes of alternative PES schemes are scarce (Narloch et al., 2013; Jindal et al., 2013). Narloch et al. (2013) investigate the distributional outcomes of three 
alternative payment rules that implicitly incorporate different fairness criteria by applying an agro-biodiversity conservation auction in Bolivia and Peru.

The introduction of heterogeneous participants in public goods games is a relevant extension because strong evidence exists that preferences associated with the provision of a public good and the valuation of intangible factors associated with the PES design (e.g. implicit fairness criteria) are largely determined by the relative position of an individual within a group (Cardenas et al., 2002; Janssen et al., 2012; Schilizzi, 2011). The experimental literature on public goods games generally only considers one type of heterogeneity, such as endowment heterogeneity (Cherry et al., 2005; Narloch et al., 2012; Reuben and Riedl, 2013) or productivity heterogeneity (Reuben and Riedl, 2013; Cardenas et al. 2002), instead of accounting for both types of heterogeneity (Chan and Mesterlman, 1999). To best of our knowledge, studies that apply a public good game with heterogenous participants (endowment and productivity heterogeneity) to investigate the distributional outcome of alternative PES schemes have not yet been conducted.

\subsection{Research objectives}

The aim of this study is to assess the relationships among PES outcomes, policy design and environmental and socio-cultural context. We do so by focusing on oil-palmdominated landscapes in Indonesia. Our aim is to contribute to the scientific basis for designing incentive mechanims for structurally complex oil palm landscapes. Given the research gaps in the literature identified above, the objectives of the study are as follows:

- To assess the trade-off between ecological (bird diversity, bird abundance) and economic outcomes (yields, revenue) of remnant or planted trees in smallholder oil palm plantations along a management intensity gradient.

- To assess the crowding effect induced by the framing of incentives as PES.

- To assess the conservation and distributional outcomes of two alternative PES schemes, which adopt different implicit fairness criteria, by using a modified public goods experiment with heterogeneous participants (both in terms of endowment and productivity). 
The analyses of the objective rely on two datasets. The investigation of the first research question is based on the analysis of survey and ecological data from 120 smallholder oil palm plantations. To assess the second and third research question, a modified public good experiment was implemented. The experiment was conducted with 360 oil palm/rubber cultivating farmers in Indonesia. The household questionnaire, instructions and post-experimental questionnaire are attached in the Appendix at the end of the dissertation.

\subsection{Outline}

The rest of the dissertation is organized as follows. Chapter II presents the first manuscript titled "Trade-off between bird diversity and abundance, and yields and revenue". This study employs a mixed model approach to assess the ecological-economic trade-off of remnant or planted trees in smallholder oil palm plantations. In addition, the marginal shadow price of bird species richness (abundance) conditional on the initial level of management intensity is illustrated.

Chapter III present the second manuscript titled "Frame-shifting and motivation crowding: a public good experiment on Payments for Enviromental Services". This study applies a zero-one inflated beta regression to explicitly investigate framing effects conditional on the level of preferences for conservation. This chapter also explores the psychological mechanisms behind framing effects by taking into account social experimenter demand effects.

Chapter IV presents the third manuscript titled "Conservation vs. Equity. Can Payments for Environmental Services achieve both? ". It uses the data from a modified public good game with heterogeneous participants to investigate the conservation outcome at individual and group level of two alternative PES schemes. In addition, the distributional outcome is analyzed with respect to the income distribution at individual level and the Gini Index.

Finally, Chapter V summarizes the main findings and concludes with policy recommendations and suggestions for further research. 


\title{
2 Trade-off between bird diversity and abundance, yields and revenue in smallholder oil palm plantations 5
}

\begin{abstract}
Global land-use change has drastic consequences for biodiversity leading to losses of ecological functioning, ecosystem services and human well-being. While species dependent on undisturbed natural habitat are most affected by conversion to agriculture, even populations of disturbance-tolerant species can be endangered in landscapes dominated by high-input mono-cultural cropping systems. This has raised the question of how, and at what cost, a diversity of species can be conserved in such habitats. Focusing on birds of smallholder oil palm-dominated landscapes, we investigated the relationship between the ecological and economic outcomes of remnant or planted trees in smallholder oil palm plantations. The study comprised a household and a field component. We gathered plot specific data on yields, revenue and inputs from 120 households owning productive oil palm plantations in the Jambi Province, Sumatra, Indonesia. Bird diversity and abundance as well as vegetation structure was assessed on the same oil palm plots. We tested the effects of a set of economic and ecological variables on measures of bird diversity, bird abundance, oil palm yield, and total revenue. Our results show that a gain in bird diversity and bird abundance conditional on increases in number of trees comes along with a loss in revenue for farmers indicating that there is a win-lose relationship between ecological and economic functions. However, since the relationship is non-linear, costs for bird species gain or gain in bird abundance change depending on the number of trees within an oil palm plantation: in a relatively extensively managed oil palm plantation (high number of trees, low oil palm yields), a further
\end{abstract}

\footnotetext{
${ }_{5}^{5}$ Published: Teuscher, M., Vorlaufer, M., Wollni, M., Brose, U., Mulyani, Y. \& Clough, Y. (2015). Trade-off between bird diversity and abundance, yields and revenue in smallholder oil palm plantations, Biological Conservation, 186, 306-318
} 
increase in the number of bird species or individuals leads to a relatively high loss in total revenue, whereas in an intensively managed oil palm plantation the same increase in number of bird species results in a smaller loss in revenue. An increase in bird abundance can be fostered at smaller costs when compared to the costs for increasing biodiversity. This suggests that there is room for tree-based enrichment of intensively managed oil palm plantations, where a relatively high increase in bird species richness or bird abundance could be achieved at relatively low cost.

Keywords: ecological-economic trade-off, bird diversity, agro-ecosystems, oil palm, Southeast Asia 


\subsection{Introduction}

Land-use change is globally the most important cause for biodiversity loss (Immerzeel et al., 2014; Sala, 2000). Both the transformation of natural or semi-natural habitats into mono-cultural annual or perennial cropping as well as agricultural intensification at local and landscape-scale lead to losses in biodiversity and ecosystem functioning of species communities (Edwards et al., 2014; Sala, 2000; Sodhi et al., 2004; SteffanDewenter et al., 2007; Wilcove et al., 2013), with a risk of negative effects on human well-being (Cardinale et al., 2012; but see Raudsepp-Hearne et al., 2010). In the next few decades, the pressure on biodiversity will proceed or even amplify due to an increasing demand for food (Tilman et al., 2002) and biofuels (Corley, 2009; Field et al., 2008; Koh and Ghazoul, 2008; Koh and Wilcove, 2007). The mitigation of the loss of biodiversity and of land degradation is therefore one of the major challenges in the current decade (UN's 'decade of biodiversity') (Tscharntke et al., 2012a).

Almost two-third of the cropland expansion in tropical countries in the last decade can be attributed to the expansion of annual crops, such as soybean and maize. Oil palm (Elaeis guineensis), ranking the fifth of the most rapidly expanding crops in harvested area, is the most rapidly expanding perennial crop in the tropics (Phalan et al., 2013). Within 25 years, the total plantation area of oil palm has tripled, with current global estimates of over 15 million ha (Gilbert, 2012). In Indonesia, the area under oil palm cultivation almost doubled from 4.2 million ha in 2000 to around 8 million ha in 2010, which account for $46 \%$ of the world's crude oil production (Obidzinski et al., 2012). In 2009 , the Indonesian government claimed that the oil palm area can be nearly doubled to 18 million ha "without disturbing [...] forest preservation efforts" (The Jakarta Post, 2009).

On the one hand, oil palm cultivation is an attractive pathway out of poverty for many rural households (The World Bank, 2011) even though smallholder productivity (in $2010,38 \%$ of the total oil palm area was managed by smallholders (Rianto et al., 2012)) is approximately $35-40 \%$ lower than yields in the private and government sectors (Lee et al., 2013) and varies considerably conditional on institutional, agronomic and biophysical factors (Budidarsono, 2012; Koh and Ghazoul, 2010; Lee et al., 2013; McCarthy, 2010; Rist et al., 2010). On the other hand, oil palm cultivation is also a pervasive threat to biodiversity (Belcher and Schreckenberg, 2007; Fitzherbert et al., 2008). Large areas of Southeast Asia, where around $80 \%$ of palm oil are produced, belong to the most bio- 
logically diverse terrestrial ecosystems on earth, characterized by a high degree of endemicity (Fitzherbert et al., 2008). It is estimated that between 1990 and 2005 around $57 \%$ of the oil palm expansion occurred at the expense of tropical rainforest (Koh and Wilcove, 2008; Wilcove and Koh, 2010). Between 1990 and 2005, Indonesia reported an absolute decline in forested area of $280,000 \mathrm{~km}^{2}$, ranking second among the countries which face a significant decline in forested area (World Trade Organization, 2010). Oil palm plantations are also often established on extensive complex smallholder production systems, such as "jungle rubber" (hutan karet), which is characterized by rubber trees mixed with other tree species forming a stand structure similar to secondary forest (Ekadinata and Vincent, 2011; Gouyon et al., 1993). Both, forest and jungle rubber, are valuable habitats for conservation. Jambi Province in Indonesia is one of the provinces with the fastest and most complete transformation of tropical lowland rainforest and extensive traditional production systems into rubber or oil palm plantations worldwide (Laumonier et al., 2010). Compared to jungle rubber as a complex agroforestry system, oil palm production is characterized by a high degree of intensification at the landscape and habitat scale, including landscape simplification (Foster et al., 2011) and rather low structural habitat complexity (uniform stand age; low canopy; low ground layer vegetation cover; low-stability micro-climate).

Oil palm landscapes are among the poorest habitats for biodiversity in tropical regions (Fitzherbert et al., 2008) and the conversion of natural or logged forest to oil palm plantations leads to dramatic losses in biodiversity in the majority of taxonomic groups (Foster et al., 2011). Fayle et al. (2010), for example, report a decline of forest ant species of $81 \%$ as forest is converted to oil palm. This loss of species is mainly caused by a loss in habitat heterogeneity. Moreover, conversion of tropical forests into oil-palm can lead to a loss in ecosystem functions that disproportionately exceeds the decline in species diversity (Barnes et al., 2014). Edwards et al. (2013) showed that functional diversity of birds experiences severe declines along a gradient from unlogged forest to logged forest to oil palm. Similar results were found by Azhar et al. (2013) who found reduced bird functional diversity in oil palm compared to peat swamp forest. Species that dominantly colonized oil palm landscapes after conversion are mainly generalist disturbance-tolerant species with large geographical ranges and low conservation status (Edwards et al., 2013; Peh et al., 2006). 
However, it has been highlighted that even in such impoverished landscapes, there can be significant variation in abundance and diversity of species, dependent on the management of the vegetation and the presence of nearby forests (Azhar et al., 2011; Koh, 2008), suggesting that the - from many species' perspective - inhospitable monoculture landscape can be softened up to some degree. Achieving this is valuable, not only in order to maintain populations of disturbance-tolerant species, which have been shown to keep declining elsewhere long after major changes in land use (e.g. farmland birds in Europe), but also to ensure ecosystem functions such as pest control. Birds, for instance, play an important role in an ecosystem as they maintain a wide range of ecosystem functions such as pest control, seed dispersal and pollination (Karp et al., 2013; Sekercioğlu et al., 2002; Sekercioğlu et al., 2004; Van Bael et al., 2008). Birds were shown to contribute to the control of leaf-eating oil palm pests (Koh, 2008) and have a beneficial impact on agroforestry crops as they effectively suppressed arthropod densities leading to an increase of yield by about a third (Maas et al., 2013).

One wildlife-friendly option are designer plantation landscapes in which mono-cultural plantations are enriched with trees planted in gaps within the plantation or with agroforestry buffer zones to surrounding natural vegetation. They are proposed as a means to maintain livelihood needs while increasing biodiversity and ecological functions and thus to alleviate the negative environmental impacts of intensively managed transformation systems such as oil palm (Bhagwat and Willis, 2008; Bhagwat et al., 2008; Clough et al., 2011; Koh et al., 2009). In particular, tree planting is considered an important measure. Planted trees are likely to attract seed dispersing animals by providing habitat for foraging, nesting, or roosting and thus increase seed rain and allow natural succession (Chazdon, 2008). Even within small stands, trees may alleviate stressful conditions and thus facilitate seedling establishment by creating a more favourable microclimate and amelioration of the soil (Cole et al., 2010; Fischer et al., 2010; Herrera and García, 2009; Manning et al., 2006; Zahawi and Augspurger, 2006).

The evaluation of management options that aim to conserve biodiversity, both at the landscape and habitat scale, depends on the shape of relationship between ecological and economic outcomes (Green et al., 2005; Perfecto et al., 2005; Steffan-Dewenter et al., 2007; Phalan et al., 2011a; Tscharntke et al., 2012b). The effect of mixed trees in oil palm plantations, controlling for management regimes (e.g. fertilizer and herbicides 
application) and habitat complexity (ground vegetation, shrubs) on yields and revenue has rarely been studied. On the one hand, oil palm yields most probably decrease with increasing number of other trees within the plantation because of competition for light and nutrients (Corley and Tinker, 2003), and depending on the method of establishment, on space forgone for planting oil palm. On the other hand, Miccolis et al. (2014) show, based on a study of oil palm grown in trial plots of ecologically diverse agroforestry systems in northern Brazil, that after five years oil palm yields in agroforestry systems were on average higher than those in mono-cultural systems. Thus, agro forests managed to be more "wildlife-friendly" do not necessarily result in a decrease in agricultural output.

Here, we investigate the relationship between the ecological and economic outcomes of remnant or planted trees in smallholder oil palm plantations, as a contribution towards the scientific basis for designing incentives for structurally complex oil palm plantations for enhanced species diversity. This study comprises a field and a household survey component. We conducted a bird and vegetation assessment and a socio-economic household survey from the same 120 smallholder oil palm plantations in four villages in the province of Jambi, Sumatra, Indonesia, along a gradient of habitat complexity and management intensity. This study aims to answer the following research questions: (1) Do remnant or planted trees within oil palm plantations affect bird diversity and bird abundance? (2) Do remnant or planted trees within oil palm plantations affect economic outcome variables, such as yield and revenue? (3) Is there a trade-off between ecological and economic functions? (4) What is the shape of the relationship between ecological and economic functions?

\subsection{Material and methods}

\subsubsection{Study site}

The survey was conducted in four villages (Bukit Harapan $1^{\circ} 31^{\prime} 25.9746^{\prime \prime} \mathrm{S}, 102^{\circ} 56^{\prime}$ 3.3864" E; Bukit Sari 1 31' 59.7606" S, 103 10' 16.8882" E; Karmeo 1 47' 39.7242" S, $103^{\circ} 2^{\prime}$ 38.1402"; Pulau Betung 1³3' 41.4216" S, 103²5' 41.6958" E) in the Batanghari region in the Province of Jambi, Sumatra, Indonesia, between February and April 2013. A map of the study area is provided in Figure 2. Total area of all 101 plots used in 
the analyses (excluding missing data points) was 164 ha (70 ha in Bukit Harapan; 53 ha in Bukit Sari; 27 ha in Karmeo; 14 ha in Pulau Betung). The climate is humid tropical, with a mean temperature range from $25.9-26.8^{\circ} \mathrm{C}$ and an annual rainfall of $2268.3 \mathrm{~mm}$ year $^{-1}$ (1960-1990 average). To establish mono-cultural oil palm and rubber cultivation area, natural lowland rainforest was cut massively in the 1970's and 1980's by concession logging. Hence, large areas of lowland rainforest do no longer exist in the $\mathrm{Ba}$ tanghari region but only small patches of jungle rubber or secondary forest. This transformation of lowland rainforest into mono-cultural rubber and oil palm plantations was fostered by the transmigration program, which was launched by the Indonesian government in the 1980's (Elmhirst, 1999; Fearnside, 1997). Within the framework of this program, households were resettled from the over-populated islands of Java or Bali to the less-populated islands of Kalimantan and Sumatra. These settlements were established in Nucleus Estates and smallholder plantations (NES), where a company-owned refinery and estate is surrounded by smallholder-owned plantations. Besides access to credit and oil palm technology, early transmigrant households obtained certified land entitlements, which include 2 ha of already established oil palm plantation within the NES plantation (McCarthy et al., 2012). Transmigrant smallholder oil palm plantations intend to be intensively used agricultural systems characterized by high input use and contribute to landscape homogenization. Oil palm plantations within one NES plantation are similar in terms of oil palm age, oil palm density, and management practices and form a large mono-cultural oil palm plantation by bordering each other.

In the last 10 years, however, the expansion of smallholder oil palm area has been mainly driven by independent smallholders, who are located in autochthonous, rather than transmigrant villages (Ekadinata and Vincent, 2011). These independent smallholders are either locals or spontaneous migrants (e.g. from other parts of the Jambi province). Autochthonous oil palm plots are considerably different compared to the transmigrant ones in terms of oil palm age, oil palm density and management practices. The landscape of autochthonous villages is characterized by oil palm plantations that incorporate a management intensity gradient and small patches with different land use types (e.g. rubber mono-culture, jungle rubber, bush fallow land, home garden etc.).

To capture a wide range of variability in structural complexity on the habitat and landscape scale among oil palm plantations and accounting for the gradient in agricultural 
intensity in that region, the survey was carried out in two autochthonous villages (Pulau Betung, Karmeo) and two transmigrant villages (Bukit Sari, Bukit Harapan).

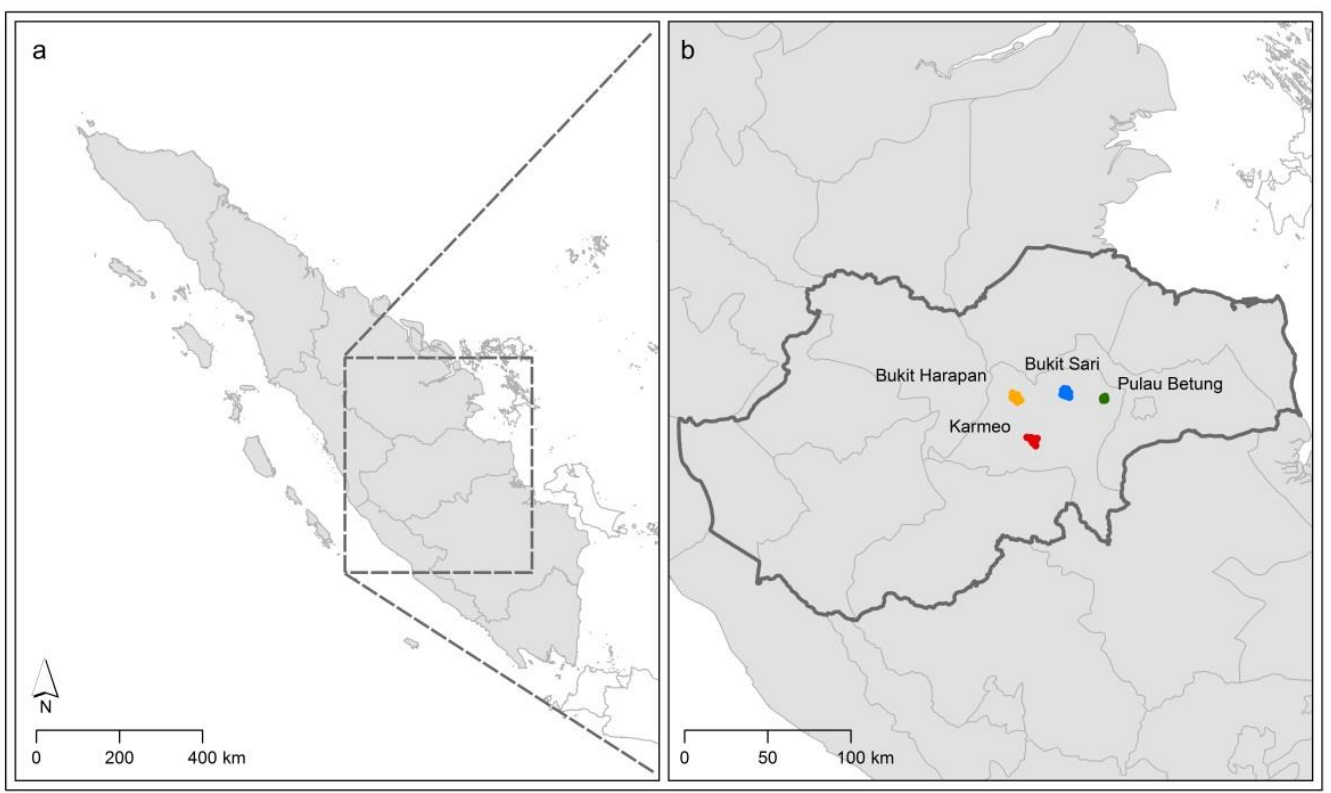

Figure 2 Map of the study area: (a) Sumatra (b) Location of the study plots in the four study villages Bukit Harapan (yellow), Bukit Sari (blue), Pulau Betung (green) and Karmeo (red) in the Jambi province.

\subsubsection{Household survey}

Based on a village census, a total of 120 households that individually manage productive oil palm plots were randomly selected. In the case that a household owned more than one productive oil palm plot, the largest oil palm plot was selected for further consideration. In the transmigrant villages, 70 oil palm cultivating households were interviewed. Due to the lower number of households owning productive oil palms, only 50 plots were selected in the autochthonous villages. Information on farm and household characteristics including plot specific data was obtained from the household heads. The standardized questionnaire contains information on plot characteristics (plot size, oil palm age, oil palm density, location etc.), abundance and use of trees within or along the border of the specific plot, costs and benefits of oil palm cultivation and cultivation of trees, respectively. All plot characteristics and management related information refer to the calendar year 2012. Afterwards, we accompanied the farmer to the plot that he/she was interviewed about to take GPS coordinates and tracked the borders of each plot by sur- 
rounding it with a GPS device. Plots sizes ranged from 0.19 ha to 9.26 ha (mean plot size: $1.62 \pm 0.98)$.

\subsubsection{Bird sampling}

Birds were recorded visually and acoustically, and by systematic tape recordings in accordance with a standardized observation method using 15 minutes point counts at the centre of each plot. We did only one point count per plot, independent of the plot size, as we only wanted to assess the local bird diversity and the sum of observations at the centre of each plot. Each plot was visited twice from 6 am to 10.30 am and there was a minimum of six days between the first and the second sampling period on plots within each of the villages. Point counts were only done when weather conditions were appropriate (no rain). For every species, we recorded the maximum number of individuals present simultaneously on the plot. Individuals flying only above the canopy were excluded from analyses. Migratory species were not recorded. For taxonomy we followed MacKinnon et al. (1993). To get a standardized measure for all plots for the analyses, we used bird observations within a 25 m radius only, as this was the maximum area that could fit into every plot. For vulnerability status, we used the species' IUCN (International Union for Conservation of Nature) classification (IUCN, 2014).

\subsubsection{Vegetation assessment}

Vegetation structure was assessed on $100 \mathrm{~m}$ x $6 \mathrm{~m}$ transects on each plot starting from the centre of the plot proceeding into northerly, southerly, westerly and easterly direction. We distinguished between trees and shrubs and noted the distance of each vegetation structure from the centre. The height and percentage cover of ground vegetation was assessed within circles (radius=3 $\mathrm{m}$ ) at the centre point and along each of the four transects at $50 \mathrm{~m}$ and $100 \mathrm{~m}$ distance from the centre. Density measures for vegetation variables were calculated only from data that was collected within each plot. Vegetation data collected outside the plot were not considered. 


\subsubsection{Data analysis}

Using mixed effects models, we tested the effect of a set of economic and ecological variables on bird diversity, bird abundance (sum of bird observations in two sampling periods), yields (ton year ${ }^{-1}$ ha $^{-1}$ ) and revenue (US\$ year-1 ha-1), with village as a random effect to control for unobserved heterogeneity between the four study villages. Table 1 depicts the set of variables used, as well as their range.

Table 1: Explanatory variables considered in the full models to explain bird abundance, bird diversity, yields and revenue

\begin{tabular}{|c|c|c|c|c|}
\hline Variable name & Description & Min & Mean & Max \\
\hline Village & $\begin{array}{l}\text { Factor with four levels, Bukit Hara- } \\
\text { pan, Bukit Sari, Karmeo and Pulau } \\
\text { Betung, entered the model as ran- } \\
\text { dom effect }\end{array}$ & - & - & - \\
\hline $\begin{array}{l}\text { Number of trees } \\
\text { (ecology models) }\end{array}$ & $\begin{array}{l}\text { Number of all trees }>2 \mathrm{~m} \text { per ha, } \log \\
\text { transformed (offset: } 2.51 \text { ) }\end{array}$ & 0 & 27.93 & 314.72 \\
\hline $\begin{array}{l}\text { Number of trees } \\
\text { (economic models, } \\
\text { negative input) }\end{array}$ & $\begin{array}{l}\text { Number of trees per ha, log trans- } \\
\text { formed (offset: } 0.22 \text { ) }\end{array}$ & 0 & 12.26 & 125.67 \\
\hline Number of oil palms & $\begin{array}{l}\text { Number of oil palms per ha, log } \\
\text { transformed }\end{array}$ & 86.98 & 159.26 & 349.99 \\
\hline Forest border & $\begin{array}{l}\text { Factor with two levels, forest patch } \\
\text { bordering the oil palm plot (1) and } \\
\text { no forest patch at the border of the } \\
\text { plot }(0)\end{array}$ & 0 & - & 1 \\
\hline Shrubs & $\begin{array}{l}\text { Number of shrubs }>1.5 \mathrm{~m} \text { per ha, } \\
\text { untransformed }\end{array}$ & 0 & 30.63 & 193.72 \\
\hline $\begin{array}{l}\text { Height ground ve- } \\
\text { getation }\end{array}$ & $\begin{array}{l}\text { Factor with five levels: (1) } 0-15 \mathrm{~cm} \text {, } \\
\text { (2) } 16-30 \mathrm{~cm},(3) 31-50 \mathrm{~cm}, \text { (4) } 51- \\
100 \mathrm{~cm}, \text { (5) } 101-150 \mathrm{~cm}\end{array}$ & 0 & - & 5 \\
\hline Age & Age of oil palms & 1 & 12.39 & 21 \\
\hline Age, squared & $\begin{array}{l}\text { Age of oil palms, squared trans- } \\
\text { formed }\end{array}$ & 1 & 189.41 & 441 \\
\hline $\begin{array}{l}\text { Quantity of fertili- } \\
\text { zer }\end{array}$ & $\begin{array}{l}\text { Total amount of applied fertilizer } \\
\text { (kg) per ha and year, log trans- } \\
\text { formed (offset: } 1.14 \text { ) }\end{array}$ & 0 & 771.10 & 2493.22 \\
\hline Value of herbicides & $\begin{array}{l}\text { Total value of applied herbicides } \\
\text { (IDR) per ha and year, log trans- } \\
\text { formed (offset: } 14127.2 \text { ) }\end{array}$ & 0 & 184094.6 & 3461947 \\
\hline Labour hours & $\begin{array}{l}\text { Total working hours of family and } \\
\text { non-family labourers per ha and } \\
\text { year, log transformed }\end{array}$ & 32.43 & 286.31 & 2190.72 \\
\hline Marehat & $\begin{array}{l}\text { Factor with two levels, marehat } \\
\text { clones plantes (1) and no marehat } \\
\text { clones planted (0) }\end{array}$ & 0 & - & 1 \\
\hline
\end{tabular}

Transformed values in parentheses. Offsets used for log transformation of variables including zeros in parentheses. 
For the bird models, we pooled the observations from the two sampling periods and ran a glmm with a Poisson distribution and a log-link function using the "glmer" function (R Core Team, 2014). There was no over-dispersion in the bird diversity model whereas the bird abundance model was highly over-dispersed. To deal with the over-dispersion in the abundance model, we included an observation level random effect.

For the economic models, we estimated a Cobb-Douglas production function, which was specified as a linear relationship between the log-transformed outcome variables and a range of log-transformed input variables. The "lme" function was used assuming a normal distribution and fitting the models by maximum likelihood estimation (R Core Team, 2014).

Oil palm yields were calculated as the total output of oil palm bunches divided by oil palm area. The total revenue comprises the revenue generated both from marketed oil palm bunches and from fruit and timber products of the remnant or planted trees within or at the border of the oil palm plantation. In addition, the opportunity costs of fruits and timber products generated from remnant or planted trees and consumed by the household were valued using the respective market prices. For the oil palm revenue, for each individual farmer the average fresh oil palm bunch price was calculated based on the average fresh oil palm bunch price received in the dry and in the rainy season weighted by the length of each season.

The choice of explanatory variables considered in the economic models was guided by the production technologies and practices hypothesized to influence oil palm output and output generated from remnant or planted tree stands. Oil palm smallholders use three main discretionary inputs: herbicides, fertilizer and labour. Since herbicides are partly used as concentrates, we considered the total value of the applied herbicides in the analyses, assuming a positive correlation between the concentration of active substances and price. For fertilizers, it was feasible to use the total amount of applied fertilizer. Labour reflects the total working hours of family and hired labourers spent on weeding of ground layer vegetation and epiphytes, herbicide, fertilizer and soil amendment applications and harvesting. All management-related explanatory variables are given per hectare and year. Previous studies have shown that the yield potential is determined by the quality of the seedlings (Phalan et al., 2009) and that transmigrant smallholders tended to receive better quality seedlings (McCarthy et al., 2012). While most of the transmigrant oil palm plantations in our sample were planted with Marehat 
clones, the variety can be found on a significantly lower share of the autochthonous plots. To control for differences in yields and revenues conditional on the seedling quality, we considered a dummy for Marehat clones.

As for the ecological predictors, besides height and percentage cover of ground vegetation as well as number of trees, a forest factor describing whether or not a forest patch ( $>1 \mathrm{ha}$ ) was bordering the plot was included because we assumed that forest patches at the border should function as source habitats and influence bird diversity and abundance on the plot (Anand et al., 2008; Clough et al., 2009). Nearest fragment distance or nearest forest fragment size could not be adequately assessed as there were neither suitable maps with a detailed enough land-use classification, nor recent enough aerial pictures available from which size and distance of forest fragments could have been derived. Collecting this information in the field was not possible due to time and labour constraints.

We used two different tree variables - one for the economic models and one for the bird models - because in the economic survey all the information (e.g. number of oil palms, amount of fertilizer) relates to an entire plot, whereas the ecological variables were derived from only part of a plot (100 × $6 \mathrm{~m}$ transects for vegetation, $25 \mathrm{~m}$ radius for birds). As the tree variable is our determining factor and links the economic and ecological parts of the study, we decided to maintain the same scales for the tree variable as for the corresponding response variables (data on bird diversity and abundance for only part of the plot; data on yield and revenue for the whole plot). Hence, for the bird models we used the tree densities that were derived from data collected on transects. In the economic models we included a tree variable, which was based on household survey data and related to the area of the whole plot; it is the number of trees which the farmer recalled having within his plot. The field and household based data on number of trees is significantly correlated $(p=0.008)$. In the economic models we included the tree variable as a negative input given that this better described the data (lower AIC). Additionally, we multiplied the tree variable with a constant term (1.05), as this better approximated the correct shape of the function. In the case of the bird models, the tree variable was entered as a positive input.

Due to incomplete data we only considered 101 of the originally 120 observations in the analysis (37 plots in autochthonous villages, 64 plots in transmigrant villages). 
We checked for correlations between the explanatory variables. Not surprisingly, correlation between percentage cover and height of ground vegetation was relatively high (Pearson's $r=0.59$ ). Both variables are known to be important structural parameters for birds (Atkinson et al., 2005; Azhar et al., 2013; Clough et al., 2006), but due to the correlation we only included height of ground vegetation. All of the other variable pairs were not strongly correlated (Pearson's $r<0.5$ ).

Number of oil palms, number of trees (both variables), labour hours, amount of fertilizer, and value of herbicides were log-transformed. As those variables - except for number of oil palms - contained zeros, we added the smallest value of each variable divided by two to each value of the variable in order to be able to do the log-transformation. Age of oil palms entered the model untransformed and with an additional squared term, as we expected optimal yields at intermediate palm age. All other terms entered the models without transformation. To avoid a leverage effect of some explanatory variables as compared to others, we normalized all predictors by subtracting the mean and dividing by the standard deviation (Schielzeth, 2010).

We checked for spatial autocorrelation by calculating Moran's I values for each of the model's residuals. Using the Moran's I standard deviate in the 'spdep' package in R (R Core Team, 2014), we tested for spatial autocorrelation but found no support for spatial autocorrelation of variation in any of the response variables (Moran's I test results yielded $\mathrm{p}>0.1$ ).

Model adequacy of full and best models, including normality, homoscedasticity of the residuals, and whether a linear relationship was likely to be appropriate, was checked graphically using diagnostic plots. A forward and backward selection was done with each full model. The best models were chosen on the basis of the Akaike Information Criterion (AIC). All analyses were conducted in R (R Core Team, 2014), with additional functions provided by the packages lme4 and nlme.

\subsection{Results}

\subsubsection{Household survey: trees}

For almost half of the sampled oil palm plantations (47.9\%) trees were reported by the respondents. 1843 trees were recorded on all plots in total. The five most common tree species in the oil palm plantations were rubber Hevea brasiliensis ( $\mathrm{N}=1495)$, banana 
Musa spec. $(\mathrm{N}=120)$, durian Durio zibethinus $(\mathrm{N}=46)$, langsat Lansium domesticum $(\mathrm{N}=42)$ and alstonia Alstonia scholaris $(\mathrm{N}=30)$, which account for $94 \%$ of the total number of trees. Some other species occurred infrequently; overall 35 species of trees were found. Of those, 19 tree species could be classified as fruit trees and 15 tree species as timber trees (and rubber). When considering only the plantations with trees, on average $1.9286(\mathrm{SD}=0.1817$ ) different tree species were cultivated, indicating a rather low level of tree species diversity. Even though the number of trees and the number of tree species are significantly correlated, the strength of the relationship is relatively weak (Pearson's $r=0.31$ ). Respondents indicated that $85.8 \%$ of the trees were planted, while the remaining $14.2 \%$ are remnants from former cultivation systems. Unfortunately, the data does not contain information on the age of the trees to assess whether the trees were planted before or after the establishment of the oil palm plantation. With respect to the management of the trees, results revealed that $40 \%$ of the trees were pruned, herbicides were applied to $27.9 \%$ of the trees and only $2.7 \%$ of the trees received fertilizer application. Manure and pesticides were not used.

\subsubsection{Bird species composition and abundance}

727 birds of 33 species were detected across all plots within a $25 \mathrm{~m}$ radius around the centre point of each plot. The Yellow-Vented Bulbul Pycnonotus goiavier was the most common species ( $\mathrm{N}=197)$, followed by the Olive-Winged Bulbul Pycnonotus plumosus ( $N=156)$ and the Bar-Winged Prinia Prinia familiaris $(\mathrm{N}=127)$. There was one observation of the Green Iora Aegitina viridissima, which was the only recorded species listed as "nearly threatened" according to the IUCN. All other recorded species are listed as "least concern" (IUCN, 2014) (Table A1). 
Table 2: Coefficients of variables included in the bird and economic models

\begin{tabular}{|c|c|c|c|c|}
\hline & $\begin{array}{l}\text { Bird } \\
\text { species }\end{array}$ & $\begin{array}{l}\text { Bird } \\
\text { abundance }\end{array}$ & Yield & Revenue \\
\hline Village & random & random & random & random \\
\hline $\begin{array}{l}\text { Number of trees } \\
\text { (ecology models, positive input) }\end{array}$ & $\begin{array}{l}0.243 \\
(0.059)\end{array}$ & $\begin{array}{l}0.277 \\
(0.093)\end{array}$ & - & - \\
\hline $\begin{array}{l}\text { Number of trees } \\
\text { (economic models, negative in- } \\
\text { put) }\end{array}$ & - & - & $\begin{array}{l}0.404 \\
(0.053)\end{array}$ & $\begin{array}{l}0.256 \\
(0.143)\end{array}$ \\
\hline Number of oil palms & - & $\begin{array}{l}-0.205 \\
(0.099)\end{array}$ & - & - \\
\hline Forest border & - & - & - & - \\
\hline Shrubs & - & - & $\begin{array}{l}-0.068 \\
(0.049)\end{array}$ & - \\
\hline Height ground vegetation & $\begin{array}{l}0.144 \\
(0.056)\end{array}$ & $\begin{array}{l}0.194 \\
(0.097)\end{array}$ & $\begin{array}{l}-0.123 \\
(0.051)\end{array}$ & $\begin{array}{l}-0.131 \\
(0.052)\end{array}$ \\
\hline Age & & & $\begin{array}{l}1.247 \\
(0.272)\end{array}$ & $\begin{array}{l}1.655 \\
(0.299)\end{array}$ \\
\hline (Age productive oil palm) ${ }^{2}$ & - & - & $\begin{array}{l}-1.016 \\
(0.271)\end{array}$ & $\begin{array}{l}-1.226 \\
(0.297)\end{array}$ \\
\hline Quantity of fertilizer & - & - & & - \\
\hline Value of herbicides & - & - & - & - \\
\hline Labour hours & - & - & $\begin{array}{l}0.309 \\
(0.053)\end{array}$ & $\begin{array}{l}0.344 \\
(0.056)\end{array}$ \\
\hline Marehat & $\begin{array}{l}-0.227 \\
(0.141)\end{array}$ & - & $\begin{array}{l}0.212 \\
(0.127)\end{array}$ & - \\
\hline
\end{tabular}

Standard errors in parentheses

The three most important parameters for explaining variation in bird diversity were number of trees, height of ground vegetation and whether or not high quality oil palm seedlings (Marehat) were planted on the plot, as depicted in Table 2. The number of trees and height of ground vegetation had a positive effect on species richness, whereas the presence of high quality seedlings had a negative effect on species diversity. Similar results were found for bird abundance, which was also positively affected by number of trees and height of ground vegetation. However, the Marehat variable did not enter the model. Instead, the number of oil palms was included and had a negative effect on the number of bird observations.

The predicted bird diversity conditional on the number of trees ranged from 2.58 species $\left(\mathrm{N}\right.$ tree $\left.\mathrm{ha}^{-1}=0\right)$ to 5.15 species $(\mathrm{N}$ tree ha-1 $=125)($ Figure $3 \mathrm{a})$. Predicted sums of bird observations ranged from 3.66 individuals $(\mathrm{N}$ tree ha-1 $=0)$ to 8.05 individuals $(\mathrm{N}$ tree ha-1 $=125$ ) (Figure $3 \mathrm{c}$ ). Bird diversity and the sum of bird observations showed a positive nonlinear response to an increase in the number of trees (Figure 3 a and Figure 3 c), with a decrease in the marginal effect of trees on bird diversity and abundance, 
respectively, with increasing number of trees (Figure $3 \mathrm{~b}$ and Figure $3 \mathrm{~d}$ ). This implies that a further increase in the number of trees in a plantation with low numbers of remnant or planted trees has a larger effect on bird diversity and abundance than the same increase in the number of trees on an oil palm plot with high numbers of remnant or planted trees.
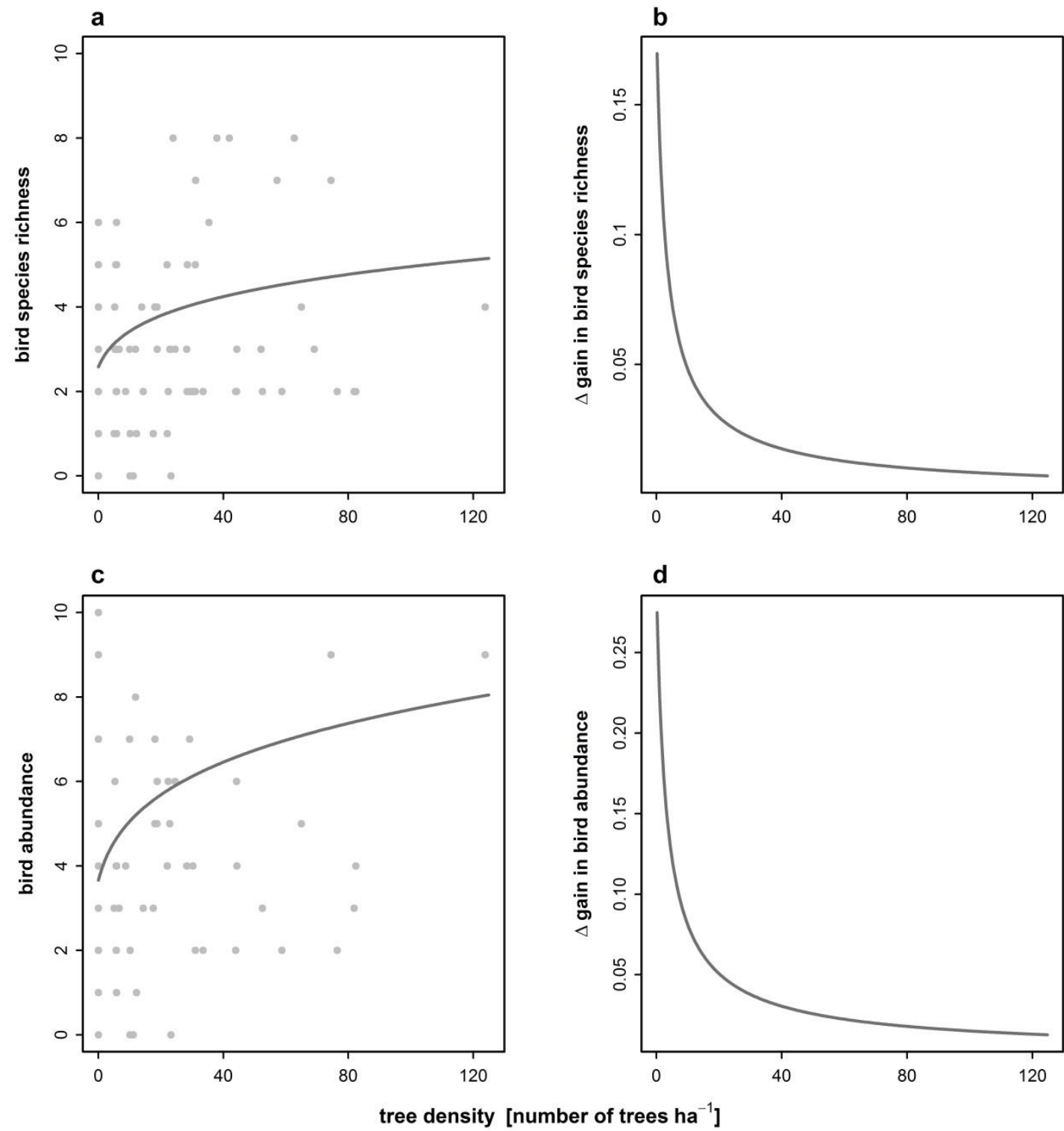

Figure 3: Effects of trees within oil palm plantations on bird species richness (a), as well as bird abundance (c). The marginal gain in bird species (b) and bird abundance conditional on the number of trees are given. Grey dots indicate original observations. 


\subsubsection{Determinants of yields}

As expected, yields were highest at intermediate oil palm age, as both the age of the oil palm plantation and its squared value were significant in the best model, as depicted in Table 2. Oil palm yields were positively affected by the amount of labour hours (family and hired labour hours) spent on weeding of ground layer vegetation and epiphytes, herbicide, fertilizer and soil amendment applications and harvesting. The cultivation of Marehat clones (improved oil palm seedlings) positively affected oil palm yields. Further management parameters such as the amount of applied fertilizers and the value of applied herbicides did not enter the best model. Yields were not affected by landscape variables, such as the dummy for neighbouring forest patches, which was not considered in the best model. In contrast, both variables capturing the habitat complexity determined the yields of the oil palm plantation; the height of the ground vegetation layer and the number of shrubs $>1.5 \mathrm{~m}$ negatively affected the yields. We found the number of trees within or at the border of the oil palm plantation to negatively affect yields, too. The predicted oil palm yields conditional on the number of trees ranged from 11.15 ton $\mathrm{ha}^{-1} \mathrm{y}^{-1}(\mathrm{~N}$ tree ha-1 $=0)$ to 1.80 ton $\mathrm{ha}^{-1} \mathrm{y}^{-1}(\mathrm{~N}$ tree ha-1 $=125)$ (Figure $\left.4 \mathrm{a}\right)$. Testing for the functional form of the relation between yields and number of trees, results indicated that the predicted yields conditional on the number of trees follow a non-linear pattern, with an increase of the marginal effect of trees on yields with increasing numbers of trees.

\subsubsection{Trees and revenue}

To test whether or not the benefits generated from trees compensated for the loss in oil palm yield, we tested the effect of the set of predictors on total revenue (US\$ ha-1 $\mathrm{y}^{-1}$ ) (Phalan et al., 2011b). Again, results outlined in Table 2 revealed that the total revenue was highest at intermediate age of the oil palm as both, the age and the squared term of age, entered the model. Similar to yields, revenue was not affected by neighbouring forest patches, the amount of applied fertilizer or the value of applied herbicides. Revenue was positively affected by the amount of labour hours (considering family and hired labour hours) and negatively by height of ground vegetation, being one of the proxies for habitat complexity As opposed to the yield model, the cultivation of Marehat clones and shrubs were not important parameters to explain variation in revenue. Again, we 
found that the number of trees within or at the border of the oil palm plantation negatively affected the total revenue. The predicted revenue conditional on the number of trees ranged from 1010.83 US $\$ h^{-1} \mathrm{y}^{-1}\left(\mathrm{~N}\right.$ tree ha- $\left.{ }^{-1}=0\right)$ to 222.87 US $\$$ ha $^{-1} \mathrm{y}^{-1}(\mathrm{~N}$ tree ha-1 $=125$ ). Similar to the functional form of the production function for yield, the relation between predicted revenue and number of trees is non-linear, with an increase in the marginal effect of trees on predicted revenue with increasing tree stands (Figure $4 \mathrm{~b}$ ).

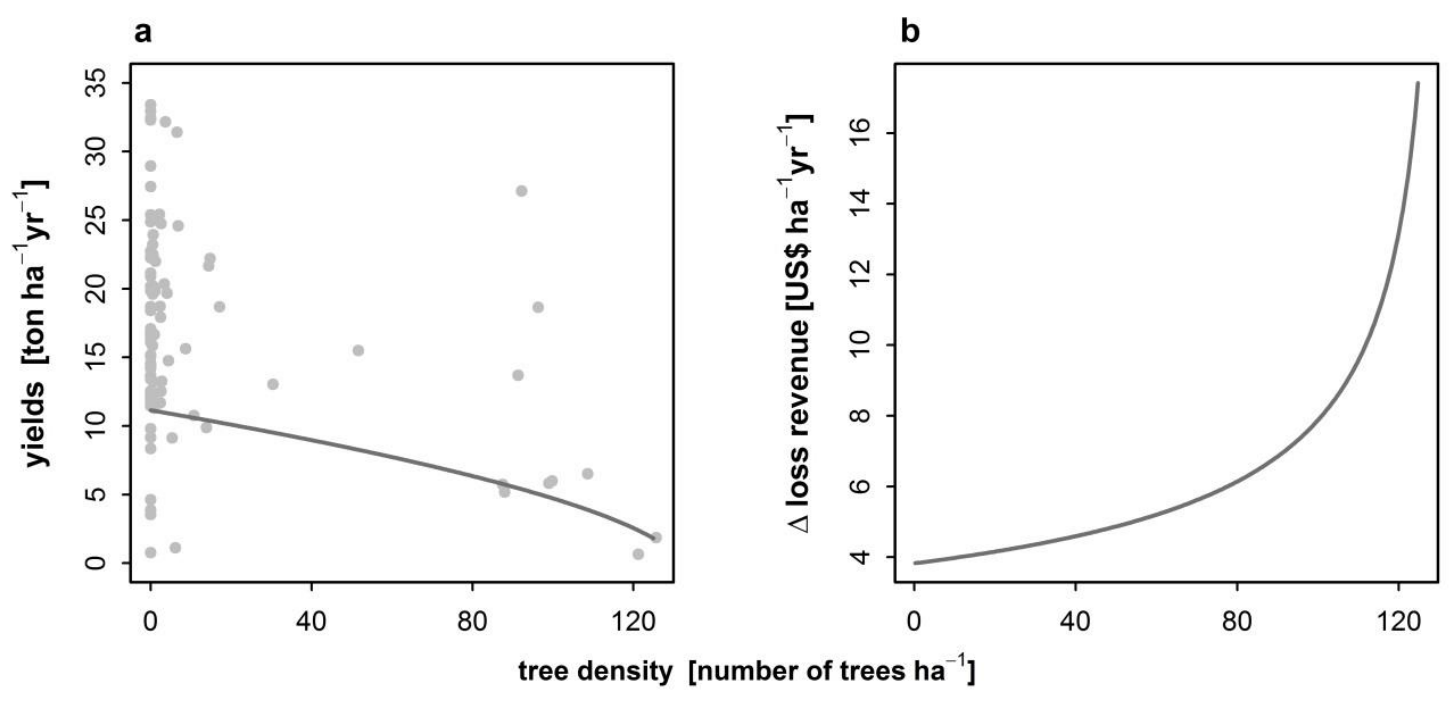

Figure 4: Effects of trees within oil palm plantations on oil palm yields (a). The marginal loss in revenue (b) conditional on the number of trees are given. Grey dots indicate original observations.

\subsubsection{Bird diversity and abundance - revenue relationship}

The predicted bird diversity and the predicted revenue can be defined as a "yield set", since both outcome variables can be parameterized with respect to trees (Perfecto et al., 2005). The functional form of the "yield set" revealed a trade-off between the revenue and the bird diversity (Figure 5 a). Thus, the bird diversity loss can only be mitigated at the cost of revenue. It implies that external incentives have to be provided to encourage profit-maximizing farmers to conserve (Kragt and Robertson, 2014). The slope, also called marginal rate of transformation (MRT), measures how much of revenue is given up for one more unit of bird diversity or vice versa. It also reflects the (marginal) shadow prices of bird diversity (the shadow prices of bird diversity in terms of revenue at the margin). The "yield set" curve is convex, indicating that the MRT increases with increasing revenue (agricultural intensification). Given a relatively extensively managed 
oil palm plantation (high number of trees, low revenue), a further increase in number of bird species leads to a distinct loss in revenue. In contrast, given a relatively intensively managed oil palm plantation (relatively low number of tree stands and high revenue), the same increase in number of bird species results in a smaller revenue loss. Thus, up to a certain level of intensification, bird diversity shows a relatively low sensitivity to an increase in intensification.

Similar results were found for the bird abundance - revenue relationship. There was also a trade-off between bird abundance and revenue (Figure $5 \mathrm{c}$ ) with distinct losses in revenue when bird abundance is increased on relatively extensively managed oil palm plantations and only small losses in revenue with increases in bird abundances on intensively managed plantations. However, in general, the revenue loss for additional bird individuals is smaller than for additional bird species, meaning that for the same amount of funds more individuals could be locally conserved compared to species.

\subsubsection{Marginal shadow price of bird species richness and abundance - tree rela- tionship}

To evaluate potential target groups of conservation programs that aim to foster bird diversity and abundance by giving external incentives to establish or expand the number of trees within oil palm plantations, we illustrate the marginal loss in revenue with every unit increase in bird diversity (Figure $5 \mathrm{~b}$ ) and bird abundance (Figure $5 \mathrm{~d}$ ) conditional on the trees within or at the border of the oil palm plantation. Results revealed that the marginal loss in revenue induced by a one unit increase in bird diversity, and hence the shadow price of bird diversity expansion, increases with increasing numbers of trees (extensification of oil palm cultivation). We calculated the percentage of revenue that has to be given up for an additional bird species exemplified for a plantation with 10 and 50 trees per ha, respectively. A farmer that has ten trees within his/her plantation experiences a $20 \%$ loss of total revenue for an additional bird species, whereas on a plantation with 50 remnant or planted trees the same increase in bird species results in a $67 \%$ loss of total revenue. Similarly, for every unit increase in bird abundance, the marginal loss in revenue increased with increasing number of trees. However, a farmer that has ten trees within his/her plantation experiences a $12 \%$ loss of total revenue for an additional bird individual, whereas on a plantation with 50 remnant or planted trees the same increase in bird individuals results in a 39\% loss of total 
revenue. This shows, that an increase in bird abundance can be enhanced at smaller costs when compared to the costs for increasing bird diversity.
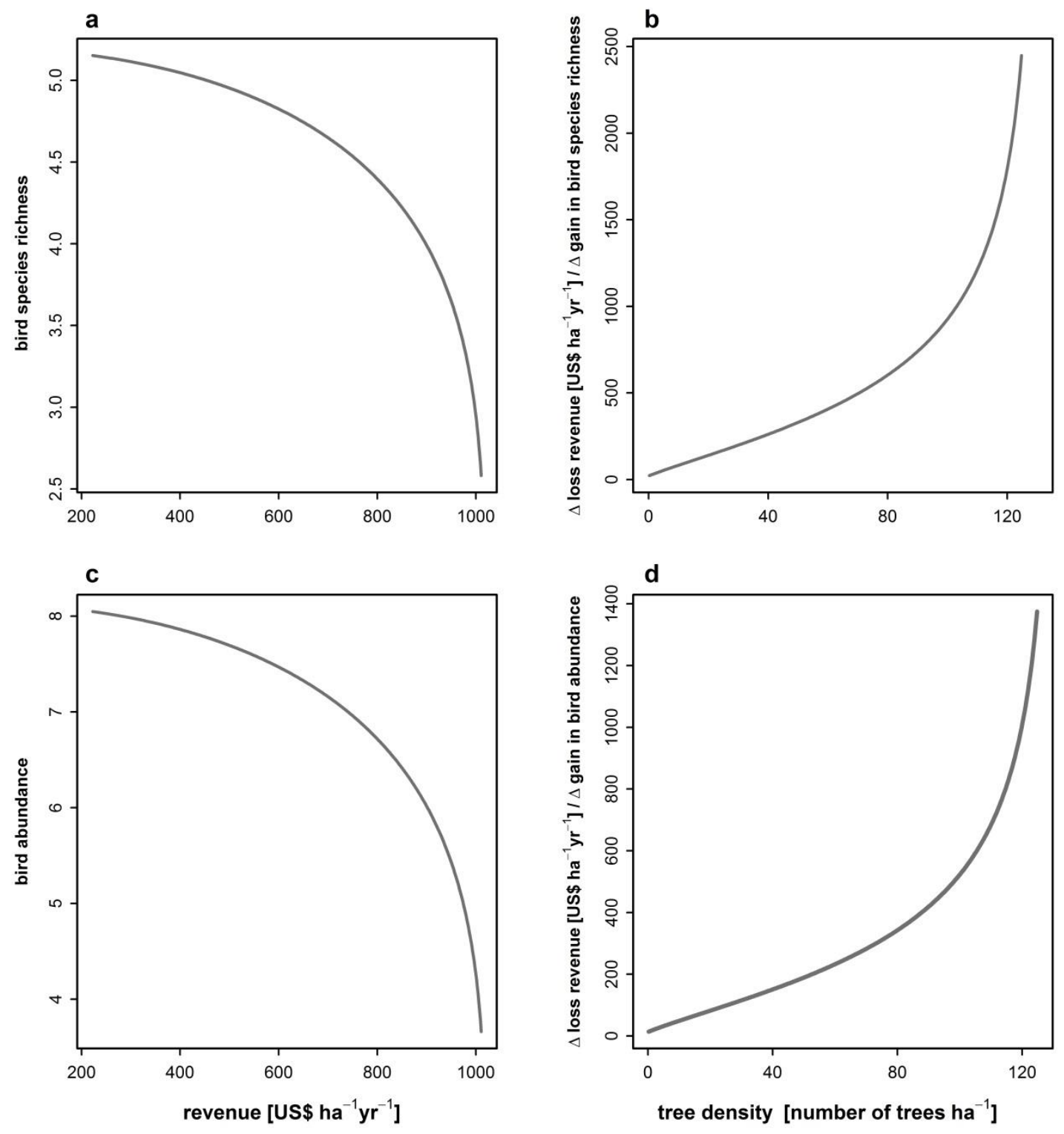

Figure 5: Relationship between predicted revenue and predicted bird diversity (a) and predicted bird abundance, respectively (c). Marginal loss in revenue with every one-unit change in bird diversity (b) and bird abundance (d), respectively, conditional on the tree stands within or at the border of the oil palm plantation.

\subsection{Discussion}

Forests and traditional cultivation systems with a high degree of habitat complexity in Southeast Asia are being converted to oil palm plantations at high rate and there is growing interest in oil palm agriculture in other tropical regions, such as South America and Western Africa. Besides the obvious need to conserve large expanses of natural 
habitats, this raises the question on how to maintain a baseline level of biodiversity in oil palm-dominated landscapes. Focusing thus on a "wildlife-friendly" strategy of having remnant or planted trees within or at the border of oil palm plantations, we investigated the relationship of bird diversity and bird abundance with oil palm yields and total revenue along a gradient from low-intensity oil palm plantations enriched with trees to intensively managed mono-cultural oil palm plantations. Consistent with our expectations, we found a win-lose relationship between these ecological and economic functions indicating that a gain in bird diversity and bird abundance conditional on an increase in the number of trees comes along with a loss in revenue for farmers. It implies that profit-maximizing farmers do not have a private incentive to conserve. However, incremental increases in bird diversity and bird abundance come at different costs depending on the initial number of trees (and therefore the initial level of bird species diversity or bird abundance).

Overall, our study confirmed that bird communities supported by oil palm plantations are extremely impoverished in comparison to natural forests (Peh et al., 2006). Only a few common and widespread species are found in this type of habitat and there is a loss of species with high conservation status and restricted ranges. We observed one forest species and five edge-tolerant species besides mostly edge-tolerant, open habitat and generalist species (for definitions see Rotenberg and Stouffer, 2007) (see Table A1). With one exception, all sampled bird species had low conservation status. Oil palm sites, however, differed significantly in their bird diversity and abundance depending on the vegetation in the plantation.

Even though oil palm plantations are often pure monocultures, especially in large estates (Foster et al., 2011), almost half of the sampled smallholder oil palm plantations had remnant or planted trees on them, and varying levels of ground vegetation. We found that the number of trees and the height of ground vegetation were important parameters in explaining variation in bird abundance and species richness. Structural complexity is in general known to positively affect avian community structure (Gordon et al., 2007; Stein et al., 2014; Tews et al., 2004; Van Bael et al., 2007). Azhar et al. (2011) showed that oil palm plantation estates and smallholdings supported similar bird assemblages, but the latter supported slightly more species due to higher complexity of vegetation structure compared to a typical mono-cultural plantation estate. However, our findings suggest that large-scale plantations could also create similar situa- 
tions like in smallholdings by planting trees for conservation outcomes. A positive effect of trees on bird diversity was also found in the studies by Abrahamczyk et al. (2008) and Clough et al. (2009), where cacao plantations in Sulawesi, Indonesia, with interspersed trees harboured more bird species than plantations without trees. On oil palm plantations in Thailand, Peninsular Malaysia and Guatemala bird species richness was enhanced by a well-developed understory vegetation (Aratrakorn et al., 2006; Azhar et al., 2011; Nájera and Simonetti, 2010). While we observed a considerable range in density of different fruit and timber trees (0-314.7 trees ha-1 (trees $>2 \mathrm{~m}$ )), the average number of tree species per hectare was low compared to traditional agroforestry crop plantations, such as coffee and cacao, where tree abundance and diversity can be much higher (8-128 trees $\mathrm{h}^{-1}$ (trees >10m); 12-104 tree species ha-1) (e.g., Clough et al., 2009). In our study, bird diversity and abundance showed a positive non-linear response to increasing numbers of remnant or planted trees. With increasing numbers of trees, however, there was a decreasing marginal effect of trees on predicted bird diversity and abundance.

In line with findings by Azhar et al. (2011), landscape-level attributes such as small secondary forest patches bordering the oil palm plantation, which we included as a landscape parameter, did not explain any variation in bird diversity and abundance in our study. This may be attributed to the low dependency of the majority of bird species (non-forest species) in oil palm plantations on forest habitats and resources as they find food within the plantations (Azhar et al., 2013), and the limited value of neighbouring small secondary forest patches as a source habitat for birds. The study region is characterized by highly isolated forest fragments in wide areas of homogenous oil palm monocultures. Harapan rainforest and the National Park Bukit Duabelas are the only two significant forest areas left in the study area and are not bordering the study sites.

While the number of trees benefited bird diversity and bird abundance, they negatively affected oil palm yields. Assuming that trees within or at the border of the oil palm plantation compete with oil palm for nutrients and light, we included the tree variable in the economic models as a negative input. Indeed, controlling for management practices, landscape, and habitat complexity, the results of the analyses showed that the oil palm yield (ton ha-1 $\mathrm{y}^{-1}$ ) decreased with increasing number of remnant or planted trees within or at the border of the oil palm plantation. Results indicated that the predicted yield conditional on the number of trees follow a non-linear pattern, with an increase of the 
marginal effect of trees on predicted yields with increasing numbers of trees. This is in accordance with findings by Corley and Tinker (2003) who stated that oil palm productivity is low when they are shaded by trees (also see Phalan et al., 2009). Oil palm, as a water-demanding plant with high light requirements would likely face intensive competition with intercropped trees for water, nutrients and light (Koh et al., 2009).

The use of a proxy measure for yields such as management intensity indices (e.g. number of trees) would not give the quantitative information on yields necessary to assess the trade-off between economic outcome and bird diversity (Phalan et al., 2011a; Steffan-Dewenter et al., 2007).

Since the economic outcome generated from the remnant or planted trees may compensate for the oil palm yield penalties, we considered the total revenue including the opportunity costs of fruit and timber products consumed by the household, even though this measure is affected by market fluctuations (Phalan et al., 2011a). The predicted total revenue also decreases with increasing number of trees within or at the border of the oil palm plantation (with increasing marginal loss in revenue).

\subsubsection{Implications for conservation}

The win-lose trade-off between the bird diversity and total revenue conditional on the number of remnant or planted trees within or at the border of the oil palm plantation implies that profit-maximizing farmers do not have, at least in economic terms, a private incentive to mitigate bird diversity loss by extensifying the oil palm cultivation. As in Europe, where land-sharing is encouraged by agri-environment payments for farmers (Kleijn et al. 2006), one could imagine that economic incentives could be implemented to foster the extensification of oil palm cultivation in terms of increasing the number of trees. The marginal loss in revenue with every unit increase in bird diversity conditional on the number of trees within or at the border of the oil palm plantation follows a positive non-linear pattern. Thus, with increasing extensification of the oil palm plantation in terms of the number of trees, the loss in revenue per additional bird species increases suggesting that conservation measures are relatively cheap at low abundances of trees within a plantation. While farmers of a rather intensively managed oil palm plantation (e.g. 10 trees per ha) lose $20 \%$ of their total revenue per additional bird species, farmers, who already harbour many trees (e.g. 50 trees per ha) on their oil palm plantation lose $67 \%$ of the total revenue per additional bird species. Similar results were found for 
bird abundance, but the loss in revenue per additional bird individual is in general lower than for an additional bird species. On an intensively managed oil palm plantation with 10 trees per ha the farmer experiences a loss in revenue of $11 \%$; farmers of extensively managed oil palm plantations with 50 trees per ha lose $39 \%$ of their revenue. Given a fixed conservation payment, farmers of highly intensified oil palm plantations with no or few trees therefore have a relatively strong incentive to expand the number of trees within the oil palm plot compared to farmers of already extensively managed oil palm plantations with many trees on the plot. In fact, the absolute number of bird individuals and bird species would still be lower in relatively intensive plantations with only a few trees compared to a more extensive plantation with more trees to start with. But even a slight increase in bird abundance on intensively managed plantations might already contribute to the system being more stable and resilient towards disturbance or pests due to increased ecosystem functioning and provision of ecosystem services such as pest control and soil fertility. Interestingly, such a gain in ecosystem functioning may exceed the associated increase in diversity (Barnes et al., 2014). Future studies need to address whether or not an increase in bird diversity also results in higher ecosystem functioning.

To compensate for a revenue loss associated with the increased abundance of trees within the oil palm plantation, both, the implementation of a premium price for ecofriendly certified palm oil products and relevant extension services financed through national or international environmental funds, are potential solutions. The rising public debate about the social and environmental impacts of oil palm cultivation prompted the establishment of the Round Table on Sustainable Palm Oil Production (RSPO, 2014a). The RSPO certification requirements cover a range of sustainability criteria, such as controlling of soil erosion, groundwater and chemical pollution. However, specific certification schemes requiring foliage cover, tree height and diversity, like in the SMBC (Smithsonian Migratory Bird Centre) bird friendly coffee certification scheme, do not exist for palm oil. In Europe, palm oil, as the "secret in the shopping basket" has often been hidden as generic vegetable oil in processed food (Paddison, 2014). In 2014, the EU launched the law on food information to consumers (FIC), determining that hiding ingredients under generic titles is no longer permitted. Whether the labelling of palm oil translates into a change in consumer preferences towards more eco-friendly produced palm oil products still remains to be seen (Smedley, 2014). 
Critics of wildlife-friendly interventions argue that they tend to reduce actual or potential farmland yields compared to conventional farming and thereby increase encroachment on natural habitat (Clough et al., 2011; Donald, 2004; Green et al., 2005; Phalan et al., 2011b; Tscharntke et al., 2012b). Indeed, in the majority of management intensity gradients ranging from no or minor management to high management intensity, biodiversity declines steeply in response to a slight increase in intensification (with a decreasing marginal rate of substitution), indicated by a concave function. It implies that the target species would benefit more from land-sparing associated with maximum attainable yield agriculture than from land-sharing (Baudron and Giller, 2014; Phalan et al., 2011a, 2011b). This shape holds for multiple taxa in Europe and the tropics (Gabriel et al., 2013; Hulme et al., 2013; Phalan et al., 2011b; Kleijn et al., 2009). Of course, also in our study region, large differences in bird diversity and abundance between forests and oil palm plantations suggest that when having to choose between diversification of oil palm and forest conservation (and assuming both are effective), the latter would be a more efficient way to maximise crop production and species conservation. The degree to which both the causal linkages (lower yields $\rightarrow$ encroachment on natural habitat) implicit in the models as well as the model assumptions hold, and whether the focus on two desired outcomes rather than a breadth of ecosystem services is relevant for resource management and policy, are issues severely debated elsewhere (Baudron and Giller, 2014; Tscharntke et al., 2012b; Phalan et al., 2011a; Koh et al., 2009). The debate suggests that oil palm diversification, such as the maintenance of trees in oil palm plantations, while not an alternative to conserving forests, should not be rejected a priori.

Interestingly, our results show that farmer choices are not governed purely by economic considerations: although yield and revenue were negatively affected by density of trees on the plantation, a significant part of the smallholders have either implicitly or explicitly chosen to keep and/or plant trees on their plantation, despite the likely perceived standard of oil palm management as a pure monoculture, which can be easily observed on nearby estate plantations. In this study, long-term resilience, as opposed to short-term yield maximization, was not considered as an economic objective, even though it might be pursued by risk-averse decision-makers. In our rather simplistic approach, other factors, such as cultural services (spiritual enrichment, recreation and aesthetic experiences), are also neglected (Kragt and Robertson, 2014). Further pro- 
gress on understanding farmer choices and value systems is critical to inform possible conservation actions.

Further research is needed to provide more specific recommendations on how to design potential oil palm plantations with high habitat complexity provided through the presence of trees and a well-developed ground layer vegetation. While this study investigated the effect of the presence of remnant or planted trees on bird diversity and abundance as well as on yields and revenue, we did not distinguish between remnant and planted trees, fruit trees and other trees nor was the size structure of trees considered. Other studies suggest that factors such as tree age, tree diversity, presence of specific functional groups of trees or tall trees, are decisive when it comes to associated animal diversity (Clough et al., 2011; Erskine et al., 2005; Kanowski et al., 2003). To test the effect of tree species diversity, size structure and composition on biodiversity and oil palm yields, a long term biodiversity enrichment experiment which systematically alters tree species richness and composition and the size of tree islands was established in the same region (Jambi Province, Sumatra, Indonesia). Monitoring the growth of trees, oil palm yield, bird and invertebrate diversity and abundance, this will allow us in the near future to address questions regarding the planting strategy under which biodiversity and ecosystem functions can be restored - which includes choosing the appropriate tree species for habitat enrichment - and how the economic functions of an oil palm plantation are affected by different types of enrichment plantings.

\subsection{Conclusion}

Our study confirmed that bird communities supported by oil palm plantations are extremely impoverished in comparison to natural forests. Nevertheless, the restoration of wildlife-friendly oil palm plantations associated with higher structural complexity can mitigate the loss of bird diversity with respect to edge-tolerant, open habitat and generalist species. Furthermore, we found a positive relationship between bird abundance and tree density. Thus, a slight increase in bird abundance on intensively managed plantations might already increase ecosystem functioning and provision of ecosystem services such as pest control and soil fertility. Studies, which investigate the ecological role of birds in oil palm plantations by identifying and analysing functional groups separately, are hence needed. The negative revenue - bird diversity and revenue - bird abun- 
dance relationship, respectively, suggests that profit-maximizing farmers do not have an incentive to establish or restore wildlife-friendly oil palm systems. However, since the relationship is non-linear, in a relatively extensively managed oil palm plantation (high number of trees, low oil palm yields), a further increase in the number of bird species and bird individuals leads to a relatively high loss in revenue, whereas in an intensively managed oil palm plantation the same increase in number of bird species and individuals results in a smaller loss in revenue. This indicates that there is room for tree-based enrichment of intensively managed oil palm plantations, where a relatively high increase in bird species richness and bird abundance could be achieved at relatively low cost. 


\title{
3 Frame-shifting and motivation crowding: A public good experiment on Payments for Environmental Services
}

\begin{abstract}
Itemizing the psychological mechanisms that underlie crowding effects is of essential relevance when it comes to the design of policy instruments. To get a better understanding of these mechanisms, this paper explores the effect of contextual manipulation-the framing of a monetary incentive as Payment for Environmental Services (PES) on conservation behaviour. The results of a public good experiment, conducted with farmers in Indonesia show that framing a monetary incentive as PES significantly crowds in conservation behaviour. This crowding in effect does not hold for the entire range of participants with different magnitudes of social preferences. The results from a zero-one inflated beta regression indicate that the behavior of participants with very weak preferences for conservation, as indicated by zero investment, is not affected by the framing. Controlling for perceived experimenter expectations, findings suggest that the overall crowding in effect is driven pro-social motives, such as the desire for social conformism or respect rather than by the activation of or changes in pro-nature motives.
\end{abstract}

Keywords: Motivation crowding, framing, Payments for Environmnetal Services, public good experiment, framed field experiment 


\subsection{Introduction}

In recent decades, payments for environmental services (PES) have been increasingly proposed as a market-based policy instrument for internalizing environmental externalities by creating an exchange value for ecosystem services (ES) (Alix-Garcia et al., 2008; Jack et al., 2008; Muradian et al., 2010; Pascual et al., 2010; Gómez-Baggethun et al., 2010; Wunder, 2014). However, critics have contested the effectiveness of PES in mitigating ecosystem degradation (McCauley, 2006; Child, 2009; Muradian et al., 2010). They argue that PES schemes reflect "commodity fetishisms" (Kosoy and Corbera, 2010, p.1229) that reduces all the functions of nature to a single exchange value, thereby denying the social embeddedness of ES provision (Muradian et al., 2013). In this context, one of the most frequent concerns is that PES may crowd out the intrinsic motivation to contribute to the public good. It hence leads to an outcome that is counterproductive or less efficient than predicted, assuming self-interested utility-maximizing behaviour (Frey and Jegen, 2001; Bowles, 2008). This seeming paradox may occur when monetary incentives ${ }^{6}$ not only alter economic reasoning but also affect preferences such as altruism, reciprocity, ethical commitment or other moral motives (Frey 1994, 1997; Frey and Oberholzer-Gee, 1997; Bowles, 2008; Bowles and Polanía-Reyes, 2012). To understand the mechanisms that underlie crowding effects is thus of essential relevance when it comes to the design of policy instruments (Rode et al., 2014). In this paper, we explore, to which extent the framing of an incentive as PES that aim to foster proenvironmental behaviour results in crowding effects.

Empirical evidence has identified a number of psychological mechanisms that may explain crowding effects in the provision of public goods induced by monetary incentives (e.g. Narloch et al., 2012; Rodriguez-Sickert et al., 2008; Cardenas et al., 2000; Vollan, 2008; D'Abba, 2011; for an overview see Rode et al., 2014). One line of thought assumes that incentives are part of how a situation is represented and that these contextual manipulations affect behaviour (Tversky and Kahnemann, 1981; Bowles, 2008; Dufwenberg and Gächter, 2011; Cookson, 2000). In the short run, PES may work as a frame shifting by changing the cognitive concept of the conservation logic towards economic reasoning, disregarding other-regarding motives (Bowles, 2008; Gómez-Baggethun et

\footnotetext{
${ }^{6}$ In the following incentives will refer only to monetary incentives and exclude non-monetary incentives such as social norms or non-monetary rewards (e.g. prestige).
} 
al., 2010; Vatn et al., 2010; García-Amado et al., 2013). Based on findings from a common pool resource game, Cardenas et al. (2000) show that, contrary to economic theory, in the absence of regulation individuals do not behave purely out of self-interest. Unexpectedly, with the introduction of fines for overexploitation, self-interested behaviour increased since other-regarding behaviour was crowded out.

In the long run, this frame shifting might induce long-term changes in motivation, such as the diminishing of environmental morale (Rode et al., 2014). Besides these forms of crowding out, frame shifting might also result in crowding in by either affecting prosocial or pro-nature motives to conserve. With respect to pro-social motives, frame shifting may work as a signal or prescriptive effect, highlighting the notion that conservation activities are socially esteemed and thus enforcing social norms (Bowles, 2008; Ellingsen et al., 2012). Furthermore, this framing may shape the expectations that peoples have about others' behaviour and thus affect the behavior of "conditional cooperators", who do not accept "free riders" (Narloch et al., 2012; Rodriguez-Sickert et al., 2008; Ellingsen et al., 2012). With respect to pro-nature motives, frame shifting may activate environmental considerations in the short run and strengthen endogenous preferences with respect to conservation in the long run (Sommerville et al., 2010).

This study uses a framed field experiment on public good contribution to explore crowding effects in the context of PES. Disentangling the psychological mechanisms behind motivation crowding, we investigate the extent to which the framing of an incentive as PES affect conservation behavior. Hence, we compare a non-framed treatment, where we introduce an increase in the relative profit without framing it as PES with a treatment in which we offer equal payments but explicitly framed as PES that aim to encourage pro-environmental behaviour. We not only measure the intrinsic motivation in the absence of incentives, we also investigate in how far participants with very weak or no intrinsic motivation (zero contribution to conservation) are affected by the framing. Using a zero-one inflated regression analysis, allows us not only to investigate the determinants of the entire range of relative contributions, but also to focus explicitly on the corner solutions (zero and full contribution to conservation). To interpret our results in terms of the motivational factors that may explain the framing effects, we consider survey measures of potential experimenter expectations. 
To increase the external validity of the study we conducted the experiments with farmers in Indonesia (island of Sumatra, province of Jambi). In Jambi Province, the rubber agroforestry area (conservation area) has been in a continuous decline due to the growing demand for oil palm. The practice of rubber agroforestry, while bringing lower private profit than oil palm, also generates positive externalities, such as higher biodiversity, water availability and soil fertility (Barnes et al., 2014). Therefore, PES to protect rubber agroforestry appear to be a promising tool for internalizing externalities (Villamor et al., 2011). To capture the dilemma that households face when deciding how to allocate their land between oil palm and rubber agroforestry, we applied a modified public good game with heterogeneous participants.

In recent years, a growing number of studies have assessed motivation crowding induced by PES-like schemes meant to encourage biodiversity conservation Narloch et al. (2012) link the effectiveness of collective vs. individual rewards to the motivation crowding theory by applying an experimental approach (see also Vollan, 2008; Travers et al., 2011). Others use case studies to examine the relation between PES and motivational factors (Fisher, 2012; García-Amado et al., 2013; Sommerville et al., 2010). The best of our knowledge, there are no studies investigating the extent to which the framing of an incentive as PES results in crowding effects. With this study, we aim to contribute to a better understanding of the psychological mechanisms that underlie crowding effects in the context of PES implementation.

The next section outlines the field context. Section 3.3 describes the conceptual framework. The experimental design and procedures are described in Section 3.4 and 3.5, and the econometric results are presented in Section 3.7 and 3.8.. The paper concludes with the main findings.

\subsection{Background on land use transformation}

In the last three decades, the global cultivation area of oil palm has tripled, making oil palm (Elaeis guineensis) the most rapidly expanding perennial crop in the tropics (Gilbert, 2012; Phalan et al., 2013). After Malaysia, Indonesia is the world's largest producer of palm oil, accounting for almost half the global production of crude palm oil (CPO). 
Between 2000 and 2010, Indonesia almost doubled its oil palm plantation area to approximately 8 million hectares (Obidzinski et al., 2012). This expansion triggered significant economic growth -alongside social conflicts (e.g. land disputes between oil palm companies and smallholders) and environmental implications (McCarthy et al., 2012; Colchester et al., 2006; Belcher and Schreckenberg, 2007). Oil palm expansion is one of the greatest causes of deforestation and intensification of traditional cultivation practices (Koh et al., 2011). Indonesia, naturally occupied by the most diverse terrestrial ecosystems on Earth, ranked second among the countries that faced a significant decline in forested area between 1990 and 2005 (World Trade Organization, 2010). This transformation process towards oil palm is having severe consequences for biodiversity and ecosystem functioning. As rainforest is converted into oil palm plantations, the functional diversity of almost all taxa significantly decreases, with negative implications for the provision of regulatory ecosystem services (e.g. water filtration, pest control) (Edwards et al., 2014; Azhar et al., 2013; Fitzherbert et al., 2008).

Jambi Province, the location of the study villages, is one of the provinces with the fastest and most complete transformation of lowland rainforest into monoculture plantations, leaving only small degraded forest fragments (Laumonier et al., 2010). Rubber agroforestry systems (hutan karet), where rubber stands are mixed with fruit and timber trees, are thus the most extensive forest-like vegetation type in Jambi Province (Ekadinata and Vincent, 2011; Gouyon et al., 1993). Rubber agroforestry systems incorporate high levels of bird and plant species richness. Also, regulatory ecosystem functions of the forest, such as water flow regulation and soil protection, can be preserved by rubber agroforestry systems (Feintrenie and Levang, 2009).

However, complex rubber agroforestry systems have either already been transformed into monoculture plantations or are threatened to be converted in the near future due to the higher direct profitability of oil palm or rubber monoculture, the lower labor requirements of homogeneous plantations, and the encouragement and support of the government and private oil palm companies. Feintrenie et al. (2010) estimate that the relative profit from agroforestry is between 61 and 69 percent of the profit from growing oil palm, depending on the relative prices. 
In order to counteract the threat of decreasing agro-biodiversity, the implementation of PES schemes has been proposed (Villamor et al., 2011). The World Agroforestry Centre (ICRAF) has launched the Rewarding Upland Poor for Environmental Services (RUPES) in Jambi Province (Bungo sub-district), which develops conservation agreements (CA ${ }^{7}$ to preserve rubber agroforestry. ICRAF expects that in the future, villagers will negotiate/specify their requirements for the fulfillment of market-based PES schemes, such as rubber latex eco-certifications ${ }^{8}$ and the reduction of emissions from deforestation and degradation (REDD) ${ }^{9}$ based on these CAs (ICRAF, 2014).

\subsection{Conceptual Framework}

\subsubsection{Pay-offs}

We used a partial equilibrium model in which participants decide how to allocate their land endowments $L$ between rubber agroforestry and oil palm cultivation. Since the private profit generated by rubber agroforestry is less than the profit generated by oil palm cultivation, each land unit allocated to oil palm $x$ yields a return of 1 , and each land unit allocated to rubber agroforestry yields a return $a$, where $a<1 .{ }^{10}$ Given that all land units should be cultivated, the number of land units allocated to rubber agroforestry equals $(L-X)$. Although it generates lower private profit, rubber agroforestry provides regulatory ecosystem functions. Thus, $b$ represents the positive externalities generated by each unit of land allocated to rubber agroforestry for $N$ community members.

This model can be extended by considering that producers have preferences for conservation. We thus assume that producers experience a moral cost of transforming the area into oil palm, $\mathrm{M}$, which is a function of an individual parameter $v_{i_{0}}$, capturing a set of preferences for conservation, and the individual area cultivated with oil palm, $x_{i_{0}}$. The moral cost of transformation is thus given by $M=v x_{i_{o}}^{2}$ implying that the cost increases at an increasing rate with an increase in the area cultivated with oil palm.

\footnotetext{
7 The conservation agreements incorporate aspects of (1) extension services, such as the provision of high-yield rubber seedlings, (2) the provision of ecosystem service, such as farmers' rubber agroforestry practices and (3) in-kind reward systems, such as the installation of micro-hydro power plants.

${ }^{8}$ Though there is no market yet for certified rubber (see Gouyon, 2003).

9 There is an on-going discussion as to whether rubber agroforestry through Hutan desa (village forest) should be included as a land use in the REDD+ scheme (see Pramova et al., 2013; Villamor et al., 2011). 10 The relative profit of rubber agroforestry is based on the findings of Feintrenie et al. (2010).
} 
The optimization problem for the individual producer is given by:

$$
\pi\left(i_{0}\right)=\max _{x_{i_{0}}}\left(x_{i_{0}}+a\left(L_{i_{0}}-x_{i_{o}}\right)+b \sum_{i=1}^{N}\left(L_{i}-x_{i}\right)-v_{i} x_{i_{o}}^{2}\right)
$$

Given that $a_{K}+b<1$, the first order condition implies that individual producers who have no social preferences for conservation would specialize and allocate all land units to oil palm cultivation. For producers who give a certain importance to conservation $\left(s \lambda_{0}>0\right)$ the optimal area cultivated with oil palm, $\mathrm{x}_{\mathrm{i}}^{*}$ is given by:

$x_{i_{0}}^{*}=\frac{1-a i_{i_{0}}-b}{2 v_{i_{0}}}$

We introduce a monetary incentive for practicing rubber agroforestry, resulting in an increase, $\delta$, in the relative profit of rubber agroforestry.

\subsubsection{Crowding effects}

We assume that the extent to which preferences for conservation enter into the decision problem is determined by the salience. Incentives are part of how a situation is represented and these contextual manipulations affect the salience. We assume that the framing of an incentive as PES affects the salience either through a prescriptive effect, indicating that pro-environmental behavior is socially desired (social image hypothesis) (see Rodriguez-Sickert et al., 2008, Van Hecken and Bastiaensen, 2010), or through a signaling effect, highlighting the salience of the environmental dimension of the problem and thereby activating pro-nature motives (Sommerville et al., 2010). In the case of crowding-out, the introduction of incentives diminishes the preferences to contribute to the public good, reducing the effectiveness of the policy intervention. Crowding in occurs if incentives and preferences instead function as complements. In the empirical environmental-related literature motivational crowding out is more frequently observed than crowding in. Rode et al. (2014) identify 13 studies that report crowding-out effects, of which two show statistically significant results applying a common pool resource experiment (either a total sample or a subsample) (Cardenas et al. 2000, Velez et al. 2010). Only four studies indicate crowding-in effects. Only Rodriguez-Sickert et al. (2008) show statistically significant crowding-in effects, using a common pool resource game. 
Based on real world examples, Frey and Stutzer (2006) conclude that while some environmental policy instruments, such as tradable emission rights and environmental taxes, crowd out the motivation to contribute to the public good, environmental-related appeals/ education campaigns and government subsidies tend instead to lead to motivational crowding in. We thus assume that given the framing of an incentive, the change in the salience is stronger than in the non-framed incentive.

Hypothesis 1 (H1): The increase in the proportion of land allocated to rubber agroforestry is larger under an incentive framed as PES- as opposed to a non-framed incentive-, indicating crowding-in.

Bowles and Polanía-Reyes (2012) show that the framing effect further depends on the baseline social preferences of the producers. It implies that if the baseline social perefernces of the producer are set to zero, we do not observe a crowding effect (Bohnet and Baytelmann, 2007; Carpenter and Myers, 2010). In other words, the likelihood of full specialization remains unaffected by the introduction of framing-as opposed to the non-framed incentive.

Hypothesis 2 (H2): The likelihood of full specialization in oil palm does not differ between the framed treatment group and the non-framed treatment group.

\subsection{Experimental Treatments}

To test the hypotheses, we conducted an artefactual field experiment. Participants were randomly matched in groups of three farmers. We consider producers heterogeneity in terms of available land size. In addition, we account for differences in the opportunity costs they face to conserve rubber agroforestry by varying the relative profit from rubber agroforestry. Two participants in each group received five experimental units of land $\left(L_{L}=5\right)$, whereas one participant received ten $\left(L_{H}=10\right)$. We assume that lowendowed participants would face higher opportunity costs of conservation, considering the survival constraints that poor users may face when making conservation efforts that involve real sacrifices (Baland and Platteau, 1999). Therefore, low-endowed participants $\left(a_{L}=0.3\right)$ faced a lower relative profit from rubber agroforestry than those with 
larger allotments $\left(a_{H}=0.4\right)\left(\mathrm{a}_{\mathrm{L}}<\mathrm{a}_{\mathrm{H}}\right)$. To capture the preferences associated with the alternative production systems, the endowment allocation decision was framed as a cultivation decision between oil palm and rubber agroforestry. When the cultivation systems were introduced to the participants, we explained once, irrespective of the treatment, that rubber agroforestry generates a number of ecosystem services, such as water, soil fertility and biodiversity, which would translate into higher payments for all group members. ${ }^{11}$ To exemplify this, we presented posters with photos of each cultivation system. To account for positive externalities generated from conservation, each land unit allocated by a group member to rubber agroforestry, increased the earnings of all group members by $b=0.2$.

Participants made five sequential decisions to capture preferences in the baseline decision, where no incentive was provided, and to test how changes in monetary incentives interact with pro-social and pro-nature motives. To investigate the extent to which prosocial and pro-nature preferences are affected by the framing effect in a hypothetical setting, we first introduced two hypothetical decisions. In the first scenario or decision, which served as a baseline, participants decided how to allocate their endowment given only hypothetical monetary pay-offs for cultivating oil palm and rubber. In the second hypothetical decision, the treatments were introduced. In order to avoid potential income and learning effects between decisions, participants did not receive feedback on their own earnings or group contributions. After the hypothetical decisions, the endowment status was again randomly assigned, indicating that the number of available land units might differ between the hypothetical and the incentivized decisions. Then, three incentivized decisions were played. While, in the first incentivized decision, participants allocated their endowment given only the oil palm and rubber agroforestry profits and the externality, in the following two decisions they encountered the treatment. We tested two treatments, applying a between-subject design:

- Non-Framed: The relative profit generated from rubber agroforestry was introduced .

"We would like to increase the relative profit generated from rubber agroforestry cultivation"

11 Instructions are available upon request. 
- Framed treatment: The monetary incentive for practicing rubber agroforestry was explicitly framed as PES intended to foster pro-environmental behavior. It was presented as follows:

“We would like to introduce Payments for Environmental Services (PES)-like a bonus for the practice of rubber agroforestry (you do not receive this bonus for the cultivation of oil palm). As we mentioned before, rubber agroforestry compared to oil palm has a positive impact on the environment: soil is healthier, more water is available and the number of birds and mammals increases. Therefore, we would like to foster pro-environmental behavior by paying extra amount of earning for rubber agroforestry."

Since we were interested in testing the effect of different levels of monetary incentive without creating a high cognitive load on participants we considered two payment sets of monetary incentive by applying a between-subject design. We also applied a withinsubject design, varying the payment levels of the monetary incentive. Thus, a participant faced different payment levels in the second and third incentivized decisions. The amount of the hypothetical incentive in the second hypothetical decision lay between the payment levels provided in the incentivized decisions and did not differ between participants. To account for order effects, we switched the order in which low and high payments were offered. Thus, half of the participants received a high payment in the second decision and a low payment in the third decision, whereas the other half received a low payment in the second decision and a high payment in the third. Table 3 presents the relative profit of rubber agroforestry by payment set. Given the parameters, a self-interested utility maximizer would fully specialize in oil palm, irrespective of the payment level.

Table 3: Relative profit of rubber agroforestry $(a+\delta)$ by payment set.

\begin{tabular}{lll}
\hline & Payment Set 1 & Payment Set 2 \\
\hline Hypothetical decision (NI) & & \\
No Payment (NI) & $\mathrm{a}$ & $\mathrm{A}$ \\
Payment (NI) & $\mathrm{a}+.2$ & $\mathrm{a}+.2$ \\
Incentivized decision (I) & & \\
No Payment (I) & $\mathrm{a}$ & $\mathrm{A}$ \\
Low Payment (I) & $\mathrm{a}+.05$ & $\mathrm{a}+.1$ \\
High Payment (I) & $\mathrm{a}+.25$ & $\mathrm{a}+.3$ \\
\hline
\end{tabular}


Decisions were made anonymously and, throughout the session, information on group membership or earnings were not provided to participants. Participants were not allowed to communicate with each other during the experiment. This was intended to minimize the threat of social sanctions and the consideration of pro-social motives with regard to group members.

\subsection{Experimental Procedure}

The workshops were carried out between November 2012 and March 2013. They were conducted in two autochthonous villages (Pulau Betung, Karmeo) and two transmigrant villages (Bukit Sari, Bukit Harapan) in Batanghari District, Jambi Province. Participants were household heads of oil palm and/or rubber cultivating families randomly selected from village census information. A total of 240 farmers participated in the experiment over 26 experimental sessions. Each session consisted of three groups of three participants, for a total of nine participants per session. Each experimental session lasted about two hours and had four stages. First, the instructions were read aloud to the participants and several examples were given. Next, two hypothetical decisions were played. In the third stage, participants made the three incentivized decisions. For those participants who had difficulty with reading/arithmetic, assistants were available during the decision-making process. Finally, participants completed a brief postexperimental questionnaire incorporating information related to the experiment. At the end of the session one decision was randomly drawn, and earnings from this decision were converted to local monetary units at a rate of 10 to 1 . All participants were paid privately using checks made payable for them in local shops. Typical earnings (mean = 86,347 IDR) were worth between one and two days of wage labour. Around two months later, the research team returned to the village to conduct a socioeconomic questionnaire with the workshop participants in which additional information on participants' demographics, farming activities and environmental-related perceptions was collected.

\subsection{Sample characteristics}

Table 4 provides a description of socioeconomic characteristics, such as information on age, gender, educational level, household size, living standard indicator, social capital, farming activities and environmental perceptions, both for the total sample and sepa- 
rated by treatment. To test the random assignments of participants to the treatments, we compared the socio-economic characteristics across treatments by using a Student's t-test.

Table 4: Descriptive results of socioeconomic indicators by treatment

\begin{tabular}{|c|c|c|c|c|}
\hline 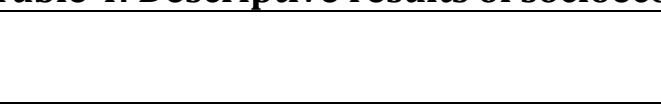 & Total & $\begin{array}{l}\text { Non- } \\
\text { Framed }\end{array}$ & Framed & $\begin{array}{l}\text { H0:NonFrame } \\
\text { d-Framed }\end{array}$ \\
\hline Age of participant (years) & $\begin{array}{l}43.254 \\
(11.121)\end{array}$ & $\begin{array}{l}43.084 \\
(12.197)\end{array}$ & $\begin{array}{l}43.391 \\
(10.201)\end{array}$ & 0.31 \\
\hline$=1$ if female & 0.075 & 0.093 & 0.060 & -0.03 \\
\hline Number of household members & $\begin{array}{c}4.179 \\
(1.474)\end{array}$ & $\begin{array}{c}4.065 \\
(1.468)\end{array}$ & $\begin{array}{c}4.271 \\
(1.478)\end{array}$ & 0.21 \\
\hline$=1$ if completion of primary education & 0.779 & 0.794 & 0.767 & -0.03 \\
\hline$=1$ if attained SMA degree (high school) & 0.183 & 0.178 & 0.188 & 0.01 \\
\hline$=1$ if migrant & 0.596 & 0.551 & 0.632 & 0.10 \\
\hline$=1$ if oil palm cultivated & 0.625 & 0.607 & 0.639 & 0.03 \\
\hline$=1$ if jungle rubber cultivated & 0.091 & 0.112 & 0.075 & -0.04 \\
\hline Asset Index & $\begin{array}{l}-0.000 \\
(1.571)\end{array}$ & $\begin{array}{l}-0.100 \\
(1.605)\end{array}$ & $\begin{array}{c}0.080 \\
(1.545)\end{array}$ & 0.18 \\
\hline Perceived poverty Index & $\begin{array}{l}-0.003 \\
(1.215)\end{array}$ & $\begin{array}{l}-0.065 \\
(1.183)\end{array}$ & $\begin{array}{c}0.046 \\
(1.242)\end{array}$ & 0.11 \\
\hline $\begin{array}{l}\text { Number of memberships in organiza- } \\
\text { tions }\end{array}$ & $\begin{array}{c}1.892 \\
(1.386)\end{array}$ & $\begin{array}{c}1.757 \\
(1.352)\end{array}$ & $\begin{array}{c}2.000 \\
(1.409)\end{array}$ & 0.24 \\
\hline Number of titles held by respondent & $\begin{array}{c}0.0354 \\
(0.711)\end{array}$ & $\begin{array}{c}0.318 \\
(0.638)\end{array}$ & $\begin{array}{c}0.383 \\
(0.766)\end{array}$ & 0.07 \\
\hline Emotional attachment to nature & $\begin{array}{c}5.986 \\
(1.433)\end{array}$ & $\begin{array}{c}6.093 \\
(1.378)\end{array}$ & $\begin{array}{c}5.902 \\
(1.476)\end{array}$ & -0.19 \\
\hline $\begin{array}{l}=1 \text { if agree that environmental shocks } \\
\text { will increase in future }\end{array}$ & 0.533 & 0.561 & 0.511 & -0.05 \\
\hline Observations & 240 & 107 & 103 & \\
\hline
\end{tabular}

Participants are mostly middle-aged (43 years) and male. Only 7.5\% of our participants are female. This is a result of the fact that we invited household heads to participate in the workshop, who are mostly male. In the study area, male household heads are usually responsible for most agricultural decisions, such as which perennial crops to cultivate. Regarding level of education, we differentiate between completion of primary school and completion of high school. While $77.9 \%$ of the participants have completed primary school, only $18.3 \%$ have attained a high school degree. Households comprising four to five members are common. Around $60 \%$ of the participants have migrated to study villages, either through the governmental trans-migrant program or spontaneously (mainly from other areas in Jambi Province). Reflecting the minor role of rubber agro- 
forestry (compared to oil palm), around 62.5\% of the participants cultivate oil palm, whereas only $9 \%$ practice rubber agroforestry.

To construct living standard indices, we conduct a principal component analysis (PCA). Besides variables on household ownership of durable assets and housing characteristics, the model also included questions related to perceived poverty. ${ }^{12} \mathrm{~A}$ description of the variables, the loading of the components and test statistics can be found in the appendices (see Table A2, A3, A4).

With respect to aspects of social capital, we consider the number of memberships in organizations and the numbers of official positions in organizations at the village level. The organizations depicted in the questionnaire comprise religious, social, political and agricultural-related groups, such as farmer organizations.

To measure the emotional connectedness of the self to nature, we use the inclusion of nature in the self (INS) measure developed by Davis et al. (2009) (see Appendix XI). The levels of connectedness ranges between 1 (no connection to nature) and 7 (complete connectedness of self and nature). The results show that on average the participants report that their connectedness with nature is quite close (mean $=5.98$ ). In terms of future perspectives, around half the participants believe that the number of environmental shocks will increase in the future. Turning to the test statistics, results indicate that participants were randomly assigned to the treatments.

\footnotetext{
121. Concerning your expenses for food, which of the following is true (reflects most accurately the situation of your household)? 2. Concerning expenses for your children's education, health care, clothing and housing, which of the following is true (reflects most accurately the situation of your household)? (1) your expenses are below the household's needs. (2) Your expenses are on the average comparable to your household's needs. (3) Your expenses exceed your household's needs.
} 


\subsection{Assessment of the framing effect}

\subsubsection{Descriptive analyses}

Figure 6 depicts the average share endowment contributed to rubber agroforestry by treatment and payment level for both hypothetical and incentivized decisions.

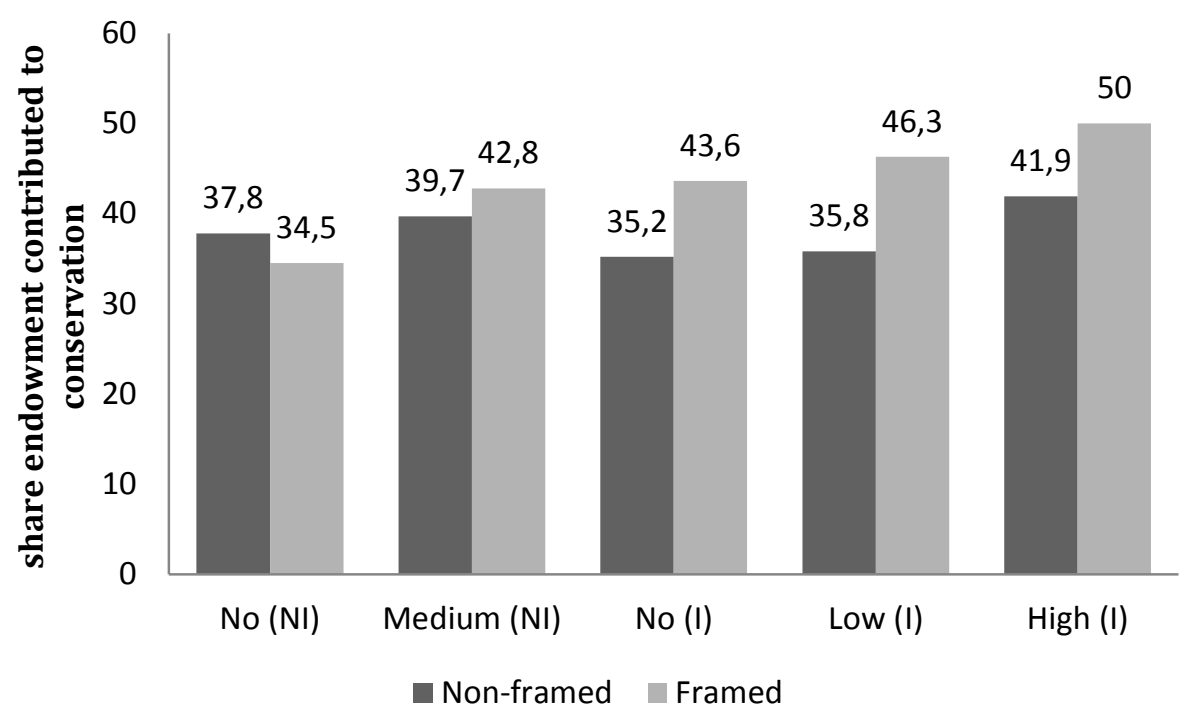

Figure 6: Average share endowment contributed to conservation by treatment and payment level (for both hypothetical and incentivized decisions).

In the first hypothetical decision, where participants did not receive a hypothetical incentive for the practice of rubber agroforestry, on average around one third of the endowment (non-framed 37.8, framed 34.5) is contributed to conservation. As expected, the average share endowment allocated to conservation in the first hypothetical decision does not significantly differ between the treatments (Wilcoxon rank sum test; pvalue 0.582 ). To investigate whether the framing even works in a hypothetical setting, in the second decision, we introduced a hypothetical incentive for the practice of rubber agroforestry. Indeed, in the framed treatment, the average share endowment assigned to conservation significantly increases by 0.082 compared to the first hypothetical decision (Wilcoxon signed-rank test; p-value 0.000). In the non-framed treatment, the average conservation behaviour (compared to the first hypothetical decision) increases only by 0.019 (Wilcoxon signed-rank test; p-value 0.000). Comparing the differences in the increase in conservation behaviour between non-framed and framed treatment reveals that the increase in conservation is significantly higher (Wilcoxon rank sum test; p- 
value 0.019) under the framed treatment than under the non-framed treatment. This indicates that the framing produces a crowding effect even in a hypothetical setting.

Turning to the incentivized decisions, we compare the first incentivized decision, where no monetary incentive for the cultivation of rubber was paid with the first hypothetical decision. Assuming a contingent restart effect or an effect due to the introduction of the non-hypothetical setting, we expect that differences in conservation behaviour between the decisions do not significantly differ between the treatments. In the non-framed treatment group, the average contribution to conservation does not significantly differ between the decisions (Wilcoxon signed-rank test; p-value 0.4945). However, in the framed treatment group the average contribution is significantly higher in the first incentivized decision than in the first hypothetical decision (Wilcoxon signed-rank test; pvalue 0.0024), suggesting that the framing effect induced by the hypothetical incentive persists even after its removal. Comparing the differences in conservation behaviour between the first decisions across treatments reveals that the difference is significantly higher under the framed treatment than under the non-framed treatment (Wilcoxon rank sum test; p-value 0.002).

To explore the effects resulting from the PES framing, we compare the average change in conservation behaviour in the second and third incentivized decisions (compared to the first hypothetical decision) across treatments. Since the first incentivized decision under the framed treatment is biased towards conservation due to the framing effect in the hypothetical setting, we use the first hypothetical decision as our baseline. We think that it is plausible to argue that potential restart effects and effects due to the change in the incentivized setting do not differ between the treatment group and hence do not target our main research question. Irrespective of the amount of the monetary incentive, in the non-framed treatment the average endowment share contributed to conservation does not significantly increase (Wilcoxon signed-rank test; p-value H0: NI-Low 0.6958, H0:NI-High 0.2256). In contrast, the introduction of an incentive explicitly framed as PES significantly increases the average endowment share contributed to rubber agroforestry for both low and high payment amounts (Wilcoxon signed-rank test $\mathrm{H0}$ :NI=low 0.0000; H0:NI=high 0.0000). To test H1-that the framing effect crowds in conservation behaviour-we investigate the differences in the change in conservation 
behaviour across treatments. Results confirm that the change in the average endowment share contributed to rubber agroforestry is significantly higher among participants in the framed treatment group than among those in the non-framed treatment group irrespective of the payment amount (Wilcoxon rank sum test; H0: Non framedframed for $\Delta$ NI-Low 0.0001; $\Delta$ NI-High 0.0008).

To address H2, which states that the crowding effect does not appear for participants with very weak or no preferences for the practice of rubber agroforestry, Table 5 depicts the share of participants with zero investment in rubber agroforestry by payment amount and treatment for hypothetical and incentivized decisions.

Table 5: Share participants with zero investment in rubber agroforestry by payment level and treatment for hypothetical and incentivized decisions

\begin{tabular}{lcccl}
\hline & Non-Framed & Framed & $\begin{array}{l}\text { H0: Non framed- } \\
\text { Framed }\end{array}$ \\
\hline No (NI) & $\%$ & 0.265 & 0.241 & 0.6810 \\
& & $(0.443)$ & $(0.429)$ & \\
No (I) & $\%$ & 0.292 & 0.167 & 0.0455 \\
& & $(0.457)$ & $(0.375)$ & \\
Low (I) & 0 & 0.283 & 0.153 & \\
& & $(0.453)$ & $0.361)$ & 0.0707 \\
SNo (NI)-Low & & -0.009 & -0.090 & \\
& $(0.323)$ & $0.359)$ & \\
High (I) & 0.230 & 0.153 & \\
$\Delta$ No (I)-High & & -0.062 & -0.090 & \\
& & $0.057)$ & $0.399)$ & \\
\hline H0: No (NI)-No (I) & 0.4469 & 0.0412 & \\
H0: No (I)-Low (I) & 0.5930 & 0.0047 & \\
H0: No (I)-high (I) & 0.3173 & 0.0105 & \\
Wilcoxon rank sum test for comparison across treatments; Wilcoxon signed-rank test for \\
comparison within treatment
\end{tabular}

In the first hypothetical decision around one fourth of all participants fully specialize in oil palm. Given a non-framed incentive, the proportion of participants that do zero investment in rubber agroforestry does not significantly change. In contrast, under the framed incentive, the proportion of participants that do zero investment significantly decreases. Given low payment levels, the change in the proportion is significantly different between the treatments. These findings do not support the notion (H2) that the conservation behaviour of participants with no preferences for rubber agroforestry is unaffected by the framing effect. 


\subsubsection{Econometric analyses}

\section{Methodology}

To test H1-that the framing of the incentive as PES crowds in conservation behaviour-and H2-that the likelihood of fully specializing in oil palm (zero investment in rubber agroforestry), reflecting the absence of preferences for conservation is not affected by framing-we estimate the elasticity of supply conditional on the treatment.

The dependent variable in our analysis is the share endowment contributed to rubber agroforestry, which can take values in the unit interval $[0,1]$. From a statistical point of view, the analysis of data in the form of fractions, rates or proportions is a challenging problem. Even though many studies use an ordinary least square (OLS) regression to analyse such data, this approach comes with a number of problems; it violates several conditions needed for the model to apply. Using OLS, the researcher implicitly assumes the underlying distribution to be normal. However, fractions are observed only over a closed interval, so that assuming them to be defined over the real numbers is a misspecification with respect to the conditional distribution, leading to biased estimators and hypothesis tests (Schmid et al., 2013). Moreover, in order to account for the bounded nature of the observations, the link function that models the conditional mean must be non-linear so that the conditional mean is mapped onto the interval $[0,1]$. OLS assumes the linear identity link for the mapping. Also, the variance must be heteroskedastic so that it is allowed to approach zero as the mean approaches the boundary points 0 and 1 (Kieschnick and McCullough, 2003). The last two issues, together with the fact that OLS assumes the data to be generated by a continuous distribution, while proportional data on $[0,1]$ follow a mixed discrete-continuous distribution, indicate that, in this situation, OLS is not the model of choice. Another model that is sometimes used for analysing proportional data is the Tobit model. However, as pointed out by Kieschnick and McCullough (2003), the Tobit model is not well suited for such an analysis. Firstly, it falsely assumes the values outside the $[0,1]$ interval to be censored, while they are just not defined outside this range, making the censoring assumption invalid for proportional data. Secondly, for the values within the interval $[0,1]$, the assumptions of the Tobit model are equivalent to OLS, so that the same objections apply to its use as with OLS (Kieschnick and McCullough, 2003). 
To overcome the problems associated with analysing proportional data, we follow the suggestion of Kieschnick and McCullough (2003), as well as Johnson et al. (1995) and Mittelhammer (1996), who report beta distribution to be a good distributional choice for proportional data. Beta distribution is very flexible since its density can assume a number of different shapes (e.g. left- or right-skewed) depending on the values of the distributional parameters, $\mu$, the mean and the precision parameter $\phi(0<\mu>0, \phi>0)$ (see Ferrari and Cribari-Neto, 2004 for further details on the beta regression). Our dependent variable, share endowment contributed to rubber agroforestry, contains the values 0 , reflecting the self-interested utility-maximizing behaviour of individuals without preferences for conservation (22.67\% of the total observations), and 1 (10.33\% of the total observations). To model these data sets, which are observed on the closed interval [0,1], Ospina and Ferrari (2010) propose a mixture of a continuous beta distribution on $(0,1)$ and the Bernoulli distribution, giving non-negative probabilities to 0 and 1 . This extension of the beta distribution is inflated, in the sense that the probability mass at 0 and 1 exceeds what is allowed by the beta distribution. In our case, the random outcome variable $y$, which lies in the closed interval $[0,1]$, is assumed to follow a zero-one inflated beta distribution (BEINF) with parameters $\mu$ (mean), $\sigma$ (variance), $\nu(Y=0)$ and $\tau$ $(\mathrm{Y}=1)$. The mean parameter $\mu$ thus refers to the range $0<\mathrm{y}>1$. The parameters $v(\mathrm{Y}=0)$ and $\tau(Y=1)$ are the mixture parameters allowing for 0 's and 1's. (see Ospina and Ferrari (2010) for further details on the zero-one inflated beta distribution). For each parameter, a possibly different set of covariates can be estimated. It allows us to test a different set of covariates for participants with and without (very weak) preferences. Also H3, which states that the likelihood of zero investment in conservation is not affected by framing effects can be tested.

We estimate the beta-inflated distribution (BEINF) model using the Bayesian structured additive distributional regression introduced by Klein et al (2013). In its original formulation, Bayesian structured additive distributional regression is a Bayesian formulation of generalized additive models for location, scale and shape (GAMLSS), which were originally introduced in a frequentist setting by Rigby and Stasinopoulos (2005). While in the generalized linear model (GLM) and generalized additive model (GAM) (Nelder and Wedderburn,1972; Hastie and Tibshirani, 1990) the dependent variable is assumed to follow a distribution within the exponential family, GAMLSS models relax this assump- 
tion and allow for a variety of continuous and mixed discrete-continuous distributions, where each distributional parameter is modelled as a function of covariates in a regression setting (see Klein et al., 2013 for an overview of the various distributions).

In Bayesian distributional regression, it is assumed that the conditional density function $f\left(y_{i} \mid \boldsymbol{\vartheta}_{i}\right), i=1, \ldots, n$ depends on $K$ distributional parameters $\boldsymbol{\vartheta}=\left(\vartheta_{1}, \ldots, \vartheta_{k}\right)$, where each distributional parameter $\vartheta_{k}$ is linked to a semi-parametric structured additive predictor $\eta^{\vartheta_{k}}$, which can be represented as follows:

$\eta_{i}^{\vartheta_{k}}=\boldsymbol{x}_{i}^{\vartheta_{k}} \boldsymbol{\beta}^{\vartheta_{k}}+\sum_{j=1}^{p_{k}} f_{j}^{\vartheta_{k}}\left(z_{i j}^{\vartheta_{k}}\right)$

where each of the distributional parameters $\vartheta_{k}$ is allowed to depend on a possibly different set of covariates. In order to ensure that the restrictions on the parameter space of $\vartheta_{k}$ are met, each parameter $\vartheta_{k}$ is linked to the predictor $\eta^{\vartheta_{k}}$ by a response function $h_{k}(\cdot)$ In the above equation, $\boldsymbol{x}_{i}^{\vartheta_{k}} \beta^{\vartheta_{k}}$ is the usual parametric part of categorical covariates including the overall intercept, and $\beta_{0}$ and $f_{j}^{\vartheta_{k}}$ are non-linear smooth effects of the continuous covariates, which can also be reformulated as random effect terms, which make it possible to account for the longitudinal nature of the data and to relax the assumption of independence between repeated observations within a cluster (Fahrmeir et al., 2009; Mayr et al., 2010).

\section{Model specification}

On the right side of the model, we include a dummy variable for the framed treatment and a continuous variable for the relative payment level offered for conservation, ranging between 0 and 1 . To test for framing effects, we consider an interaction term between framed treatment and relative payment level. Since we do not expect potential income and learning effects and since we controlled for order effects in the implementation of the experiment, we do not include decision fixed effects in the analysis. 
Except for the mean parameter $\mu$, we cannot derive-from theory-variables that may explain the parameters, $\sigma=$ variance, $v_{i}\left(y_{i}=0\right)$ and $\tau_{i i},\left(y_{i}=1\right)$. Therefore, the explanatory variables were chosen by forward selection. The variables that were considered in the full model are depicted in Table 6.

Table 6: Explanatory variables entering into full model

\begin{tabular}{ll}
\hline Variable name & Description \\
\hline Frame & $=1$ if framed treatment \\
Payment level & Relative payment amount offered for conservation \\
Framed*Payment level & $=1$ if framed treatment* Relative payment amount offered for con- \\
& servation \\
& $=1$ if 10 available land in incentivized decisions \\
& $=1$ if available endowment in hypothetical decisions equals en- \\
ha_10 & dowment in incentivized decisions \\
ha_same & Age of participant (years) \\
Age & $=1$ if female \\
Female & $=1$ if completed primary education \\
Primary & $=1$ if attained SMA degree (high school) \\
Sma & $=1$ if migrant \\
Migrant & $=1$ if oil palm cultivated \\
Oilpalm & $=1$ if rubber agroforestry cultivated \\
Ragroforestry & Asset index \\
Asset index & Perceived poverty index \\
Poverty Index & Number of memberships in organizations \\
No_memb & Number of titles hold by participant \\
No_title & Connectedness to nature \\
Nature & (1-7 [close]) \\
& $=1$ if Number of environmental shocks in future will increase \\
Env_future &
\end{tabular}

\section{Results}

Table 7 depicts the estimation results of the forward selection for the mean parameter $\mu .^{13}$

Table 7: Estimation results for mean parameter $\mu$.

\begin{tabular}{lll}
\hline Variable & Mean & Std. Dev. \\
\hline const & $-0.4089^{* *}$ & 0.1071 \\
Frame & 0.0092 & 0.1087 \\
Payment level & -0.0353 & 0.2650 \\
Frame* Payment level & $0.8262^{* *}$ & 0.3707 \\
Migrant & $0.2629^{* *}$ & 0.1111 \\
perceived Poverty Index & $0.0935^{*}$ & 0.0484
\end{tabular}

${ }^{* *}$ significance at $5 \%$ level, ${ }^{*}$ significance at $10 \%$ level

Since the effects have not yet been transformed to the y-axes, at this point, we can only interpret the sign of the effect and compare the effect sizes. The interpretation of the

13 The estimation of the model with GAMLSS yields comparable results, indicating the robustness of the Bayesian estimates (see Table A6-A9). 
estimation results for the mean parameter $\mu$ only refer to $0<y<1$. Focusing first on the baseline decision (the sign of the const. will change through a transformation), results reveal that as expected the endowment share contributed to rubber agroforestry does not significantly differ between the framed and the non-framed treatment. Furthermore, increasing the relative payment level introduced as a non-framed monetary incentive does not induce a significant change in the endowment share contributed to conservation. The significant and positive interaction term between payment amount and framed treatment indicates that the framing of the monetary incentive as PES significantly crowds in conservation behaviour, verifying $\mathrm{H} 1$.

In terms of socioeconomic explanatory variables, only the migration status and the perceived poverty index enter into the model. Both variables yield significant results. The higher the perceived poverty index, the higher the endowment share contributed to rubber agroforestry. This might be explained by the fact that in complex rubber agroforestry systems rubber stands are mixed with other tree species. These tree stands may provide forest products, such as fruits and timber. Studies have shown that households that perceive themselves as (or are) poor depend more strongly on non-marketed forest products (Leaky et al., 2005) and are therefore in favor of rubber agroforestry production. Migrants conserve a significantly higher endowment share than nonmigrants. This is unexpected since rubber agroforestry is actually practices by a significantly higher proportion of non-migrants than migrants. Additionally, a significantly higher proportion of non-migrants believe that environmental shocks will increase in future. Under the assumption that the awareness of negative consequences of environmentally harmful behavior translates into normative goals of pro-environmental behaviour, which outperform economic reasoning (Steg et al. 2014), we have expected to find a positive relationship between environmental awareness and conservation behavior and, therefore, that conservation efforts would stem primarily from non-migrants. However, values, partially mediated by beliefs about consequences reflect overarching goals in people's lives while normative goals reflect what motivates people in a given situation, depending not only on values but also on situational cues (Steg et al., 2014). It indicates that environmental awareness does not necessarily lead to greater conservation behavior. Furthermore, in reality, non-migrants face higher barriers to invest into oil palm cultivation, such as poor access to improved oil palm seedlings than migrants. 
This may explain why, in the experiment, where they did not face these barriers, they exhibit stronger preferences for oil palm cultivation.

To address $\mathrm{H} 2$ - that the likelihood of making zero investment (indicating very weak preferences for rubber agroforestry practices) is not affected by the framing-Table 8 shows the model estimates for the parameter $v$. The interaction term, which indicates the framing effect, does not enter into the model. This implies that accounting for the differences in the treatment, the framing effect, does not improve the explanatory power of the model, verifying H2. However, irrespective of the treatment, with an increase in the relative payment amount the likelihood of zero investment in rubber agroforestry significantly decreases. In accordance with our findings in Table 7 results show that migrants have a significantly lower likelihood of zero investment in rubber agroforestry.

Table 8: Estimation results for vi (yi=0)

\begin{tabular}{lll}
\hline Variable & Mean & Std. Dev. \\
\hline const & -0.8443 & 0.3690 \\
Payment level & $-2.1176^{*}$ & 1.1510 \\
Migrant & $-1.5465^{* *}$ & 0.4105 \\
ha_10 & -0.5474 & 0.4420 \\
\hline
\end{tabular}

${ }^{* *}$ significance at $5 \%$ level, ${ }^{*}$ significance at $10 \%$ level

Table 9 shows the estimates for the parameter $\tau_{i i,}$, which captures the full investment in rubber agroforestry. It implies that relatively strong preferences for rubber cultivation exist. The likelihood of full investment is influenced by a range of socio-economic variables. The interaction between PES treatment and payment amount does not enter into the model, again indicating that the explanatory power of the model is not improved by accounting for the framing effect.

Table 9: Estimation results for $\mathrm{\tau ii},(\mathrm{yi}=1)$.

\begin{tabular}{lll}
\hline Variable & Mean & Std. Dev. \\
\hline const & -5.9158 & 1.3196 \\
Payment level & $6.0455^{* *}$ & 1.3224 \\
SMA & $-1.1354^{*}$ & 0.6760 \\
Perceived poverty index & $0.5780^{* *}$ & 0.2087 \\
R_agroforestry & $1.3307^{*}$ & 0.7716 \\
Oil palm & $-0.9582^{*}$ & 0.4903 \\
Nature & 0.3031 & 0.1937 \\
Future_inc & $0.9220^{*}$ & 0.5065 \\
\hline
\end{tabular}

${ }^{* *}$ significance at $5 \%$ level, ${ }^{*}$ significance at $10 \%$ level 
Increase in payment amount significantly raises the likelihood of full specialization in rubber agroforestry, irrespective of the treatment. Moreover, educational level significantly affects the likelihood of full specialization. Participants with at least SMA degree (i.e. a high school degree) are significantly less likely to specialize in rubber agroforestry, perhaps due to greater awareness of economic processes and reasoning. In line with the estimation results in Table 7 and our argumentation, with increasing perceived poverty the likelihood of full specialization significantly increases. A number of experimental studies discuss the effect of actual resource management experience on experimental outcome (Castillo et al., 2011;Prediger et al., 2011; Janssen et al., 2012, Janssen et al. 2013). Our results reveal that participants who practice rubber agroforestry are significantly more likely to specialize completely in rubber agroforestry, whereas those who cultivate oil palm are significantly less likely to do so. Finally, environmentalrelated variables enter into the model, indicating that complete specialization induced by preferences is partly explainable by environmental-related concerns. Participants who believe that the number of environmental shocks will increase in the future are significantly more likely to invest completely in rubber agroforestry, indicating that awareness of environmental problems translates into behaviour at the corner solution.

The estimation results for the parameter sigma 2 can be found in the appendices (Table A5).

\subsection{Assessment of the motivational factors}

\subsubsection{Descriptive analyses}

Econometric results reveal that the framing of incentives as PES significantly crowds in conservation behaviour. So far, we cannot further specify the motivational factors that underlie this framing effect. As mentioned above, empirical evidence has shown that framing either has a prescriptive effect, highlighting society's normative vision of conservation (pro-social dimension), or induces a shift towards pro-nature motivation. To further investigate the mechanisms that can be abstracted from framing effects, Table 10 depicts the motives for rubber agroforestry and oil palm cultivation by treatment. These statements were presented in the post-experimental questionnaire using a Likert scale. 
Table 10: Motivational factors by treatment

\begin{tabular}{|c|c|c|c|}
\hline & $\begin{array}{l}\text { Non- } \\
\text { framed }\end{array}$ & Framed & $\begin{array}{l}\text { H0:Non_frame } \\
\text { d-Framed }\end{array}$ \\
\hline \multicolumn{4}{|l|}{ Decision to cultivate oil palm } \\
\hline $\begin{array}{l}=1 \text { if strongly agree because it generates the } \\
\text { highest earnings for me }\end{array}$ & $\begin{array}{l}0.449 \\
(0.499)\end{array}$ & $\begin{array}{l}0.459 \\
(0.500)\end{array}$ & -0.01 \\
\hline $\begin{array}{l}=1 \text { if strongly agree/agree because it gener- } \\
\text { ates the highest earnings for me }\end{array}$ & $\begin{array}{l}0.738 \\
(0.442)\end{array}$ & $\begin{array}{l}0.654 \\
(0.477)\end{array}$ & 0.08 \\
\hline $\begin{array}{l}=1 \text { if strongly agree because I did not want } \\
\text { my group members to benefit from my deci- } \\
\text { sion }\end{array}$ & $\begin{array}{l}0.084 \\
(0.279)\end{array}$ & $\begin{array}{l}0.128 \\
(0.355)\end{array}$ & -0.04 \\
\hline $\begin{array}{l}=1 \text { if strongly agree/agree because I did not } \\
\text { want my group members to benefit from my } \\
\text { decision }\end{array}$ & $\begin{array}{l}0.206 \\
(0.406)\end{array}$ & $\begin{array}{l}0.248 \\
(0.434)\end{array}$ & -0.04 \\
\hline \multicolumn{4}{|l|}{ Decision to practice rubber agroforestry } \\
\hline $\begin{array}{l}=1 \text { if strongly agree because I wanted to save } \\
\text { the environment }\end{array}$ & $\begin{array}{l}0.514 \\
(0.502)\end{array}$ & $\begin{array}{l}0.639 \\
(0.482)\end{array}$ & $-0.13^{*}$ \\
\hline $\begin{array}{l}=1 \text { if strongly agree/agree because I wanted } \\
\text { to save the environment }\end{array}$ & $\begin{array}{l}0.738 \\
(0.441)\end{array}$ & $\begin{array}{l}0.857 \\
(0.351)\end{array}$ & $-0.12^{* *}$ \\
\hline $\begin{array}{l}=1 \text { if strongly agree because I wanted my } \\
\text { group members to also profit from my deci- } \\
\text { sion }\end{array}$ & $\begin{array}{l}0.336 \\
(0.475)\end{array}$ & $\begin{array}{l}0.429 \\
(0.497)\end{array}$ & -0.09 \\
\hline $\begin{array}{l}=1 \text { if strongly agree/agree because I wanted } \\
\text { my group members to also profit from my } \\
\text { decision }\end{array}$ & $\begin{array}{l}0.598 \\
(0.493)\end{array}$ & $\begin{array}{l}0.662 \\
(0.475)\end{array}$ & -0.06 \\
\hline \multicolumn{4}{|l|}{ Social experimenter demand effects } \\
\hline $\begin{array}{l}\text { The researcher expected me to practice rub- } \\
\text { ber agroforestry. }\end{array}$ & $\begin{array}{l}0.439 \\
(0.499)\end{array}$ & $\begin{array}{l}0.534 \\
(0.500)\end{array}$ & -0.09 \\
\hline $\begin{array}{l}\text { The researcher expected me to cultivate oil } \\
\text { palm. }\end{array}$ & $\begin{array}{l}0.243 \\
(0.432)\end{array}$ & $\begin{array}{l}0.256 \\
(0.438)\end{array}$ & -0.01 \\
\hline The researcher did not have any expectations. & $\begin{array}{l}0.308 \\
(0.465)\end{array}$ & $\begin{array}{l}0.211 \\
(0.409)\end{array}$ & $0.10^{*}$ \\
\hline $\begin{array}{l}=1 \text { if strongly agree/agree that these expecta- } \\
\text { tions influenced your decision }\end{array}$ & $\begin{array}{l}0.594 \\
(0.493)\end{array}$ & $\begin{array}{l}0.684 \\
(0.467)\end{array}$ & -0.10 \\
\hline $\begin{array}{l}=1 \text { if strongly agree /agree that these expecta- } \\
\text { tions influenced your decision to practice } \\
\text { rubber agroforestry }\end{array}$ & $\begin{array}{l}0.374 \\
(0.486)\end{array}$ & $\begin{array}{l}0.451 \\
(0.499)\end{array}$ & -0.08 \\
\hline $\begin{array}{l}=1 \text { strongly agree /agree that these expecta- } \\
\text { tions influenced your decision to practice } \\
\text { agroforestry }\end{array}$ & $\begin{array}{l}0.215 \\
(0.413)\end{array}$ & $\begin{array}{l}0.233 \\
(0.424)\end{array}$ & -0.02 \\
\hline Observations & 240 & & \\
\hline
\end{tabular}

Means are depicted.

According to the results, between $60 \%$ and $70 \%$ of the participants who chose to cultivate oil palm agree that economic considerations influenced their decision process. This consideration is unaffected by the framing of the incentive as PES. Nevertheless, the share of participants who take environmental motives into account is significantly high- 
er when the incentive is framed as PES. We cannot preclude that answers were influenced by the desire to be respected by the experimenter or by social conformism. However, this finding underpins our assumption that framing works as a signal, highlighting the environmental dimension of the cultivation decision and hence reinforces pronature motives.

We turn next to the pro-social dimensions that might explain the crowding effect of the framing. Participants made their decisions anonymously, and group membership was unknown in order to minimize the effect of social norms with regard to other group members. Aspects of the externality seem to be of less relevance for participants in their decision-making progress (compared to economic reasons and environmental-related motives) and remain unaffected by the introduction of the framing.

Related to the social image hypothesis, experimenter demand effects (EDE) induce behavioural changes through cues as to what constitutes appropriate behaviour (Zizzo, 2010). Zizzo (2010) differentiates between purely cognitive and social EDE. While in social EDE, participants perceive social pressure, such as feelings of social conformism or the desire for respect (Ellingsen and Johannesson, 2008), in the case of cognitive EDE, participants identify appropriate behaviour for the task. The results of the postexperimental questionnaire reveal that around half of the participants perceived experimenter expectations that they would either practice rubber agroforestry or cultivate oil palm. Furthermore, around one third of those who perceived expectations also stated that these expectations influenced their behaviour. While the share of participants that perceived expectations with regard to rubber agroforestry or oil palm cultivation remains unaffected, the share of participants that did not perceive expectations significantly decreases in response to the framing of incentives as PES.

\subsubsection{Econometric analyses}

To discern the motivational factors behind the crowding effect, we estimate a zero-one inflated beta regression, in which we considered a dummy variable for perceived experimenter expectations that participants conserve rubber agroforestry (shown in Table 10). Since we are interested in the extent of the framing effect conditional on social experimenter demand effects, we include a threefold interaction between the framed 
treatment, the payment level and the dummy variable for perceived expectations. The threefold interaction is inserted for the mean parameters $\mu$; the variables selected to describe the other parameters are kept the same as above. The estimation results are shown in Table 11. Figure 7 depicts the predicted share of endowment allocated to rubber agroforestry, conditional on perceived expectations and treatment.

Table 11: GAMLSS estimation results for mean parameter $\mu$.

\begin{tabular}{lll}
\hline Variable & Estimate & Std. Error \\
\hline Const & $-0.7423^{* *}$ & 0.0485 \\
Expectation to conserve & $0.7562^{* *}$ & 0.0624 \\
Frame & $0.2523^{* *}$ & 0.0625 \\
Expectation to conserve *Frame & $-0.5434^{* *}$ & 0.0869 \\
Payment level & 0.4201 & 0.2638 \\
Expectation to conserve *payment level & $-0.8807^{* *}$ & 0.3826 \\
Payment level *Frame & 0.0819 & 0.3925 \\
Expectation to conserve *payment level *Frame & $1.3114^{* *}$ & 0.5361 \\
Migrant & $0.2253^{* *}$ & 0.0351 \\
Perceived Poverty Index & $0.0929^{* *}$ & 0.0150 \\
\hline
\end{tabular}

${ }^{* *}$ significance at $5 \%$ level, ${ }^{*}$ significance at $10 \%$ level 


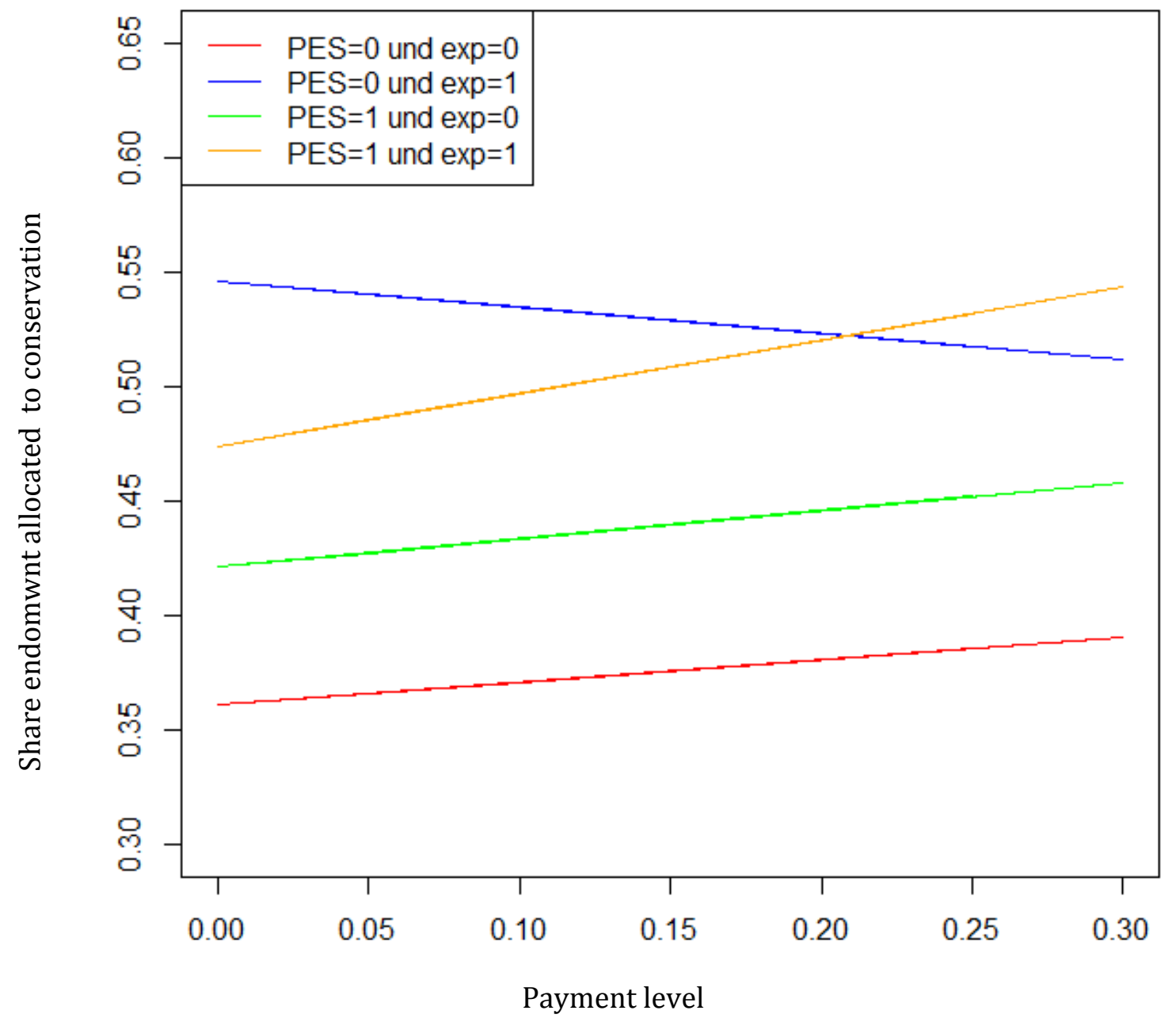

Figure 7: Predicted share of endowment allocated to rubber agroforestry (sh_jrn) due to an increase in payment level (sh_pes_n) conditional on perceived expectations and treatment (PES=framed treatment).

Regarding the baseline decisions, the results illustrated in Figure 7, show that, irrespective of the treatment, participants who report perceived expectations to practice rubber agroforestry, conserve a significantly higher share of their endowment than participants who do not perceive expectations. There are two possible explanations for this: The expectations were either formed before incentives were introduced or they did not. If the expectations occured prior to the implementation of the incentives, conservation behaviour had already been influenced by demand effects at the time the first decision was made. If this was the case, the desire for social conformism or respect would have led to higher land allocation to conservation by those participants who perceived such expectations. The second possibility is that the formation of the demand effects did not take place before the introduction of the incentives-whether framed as PES and not. This would imply that individuals with stronger preferences to practice rubber agroforestry 
in the absence of incentives, indicated by allocating a higher share of their endowment to conservation, were more likely to perceive expectations in the course of the game.

Focusing on the treatment decisions, results indicate that the effect of introducing an incentive is conditional on the perceived expectations. Given the non-framed treatment, the change in the conservation behaviour of participants who report experimenter expectations is significantly lower (even negative) than of those without expectations. The framing of the incentive does not significantly affect the conservation behaviour of participants who did not perceive experimenter expectations. This indicates that framing does not significantly crowd in motivational factors other than pro-social motives. In contrast, framing as PES results in a significantly higher increase in the conservation behaviour of participants with perceived expectations than in the non-framed treatment. Thus, it can be inferred that the overall positive crowding effect observed in Table 7 is primarily driven by social EDE. Results also indicate that pro-social motives rather than pro-nature motives are crowded in by the framing.

\subsection{Conclusion}

In this paper, we explore the extent of the crowding effect induced by the introduction of PES. In order to get a better understanding of the psychological mechanisms that underlie crowding effects, we investigate the effect of contextual manipulation-the framing of a monetary incentive as Payment for Environmental Services (PES) on conservation behaviour. The data from a field experiment in Indonesia indicate that it cannot be generally assumed that the same level of compensation under different policy schemes increases conservation efforts to the same extent. The results of the public good experiment show that framing a monetary incentive significantly crowds in conservation efforts. Furthermore, results suggest that this crowding-in effect does not hold for the entire range of participants with different social preferences. The use of a zero-one inflated beta regression allowed us to discriminate participants with zero-investment in rubber agroforestry (no preferences for rubber agroforestry) and full investment into rubber agroforestry (strong preferences for rubber agroforestry) from the range of participants that lie between these two corner solutions. While crowding-in effect is observable for the range of participants with "moderate" preferences for rubber agrofor- 
estry, the conservation efforts of participants with very weak or very strong preferences is not affected by the framing. These findings highlight the importance for policymakers to take into consideration the contextual manipulations associated with the implementation of a policy design and to carefully assess the heterogeneity in the existing preferences for the desired conservation activity. The descriptive results of the hypothetical decisions show that the framing effect works even in a hypothetical setting and persists even after the removal of the hypothetical incentives as well as when the setting changes to a non-hypothetical one. This might suggest the potential of environmental campaigns that are conducted prior to the implementation of monetary incentives to highlight the decision problem without being linked to an economic incentive to foster proenvironmental behavior.

To assess the social legitimacy of policy instruments ex ante, it is essential to understand the mechanism behind the observable framing effect. The design of the experiment (anonymous decisions, no information on membership) allowed us to minimize the effect of pro-social motives related to group members. Regarding the social image hypothesis, we investigate the framing effect conditional on the perceived experimenter expectations captured in a post-experimental survey. Results indicate that, while we observe a significant and positive framing effect for participants who perceived expectations, this effect disappears when only those participants who did not perceive expectations are taken into account. These findings show that the overall significant crowdingin effect is driven by pro-social motives rather than by pro-nature motives. This demand effect is also a common phenomenon in reality, where stakeholders, implementing incentive schemes signal social expectations about socially desirable behavior. The participation in an environmental-related program is then driven by feelings of social conformism or the desire for respect (Ellingsen and Johannesson, 2008) rather than by the activation of pro-nature motives in the short run or even change in environmental morale in the long run. As a result, it may endanger the long-term success of the program.

The extent to which frame shifting induce changes in environmental behavior in the long run remains unclear since participants made decisions in only three sequential sessions, each with a different setting. Cardenas et al. (2000), who conducted a number of sequential decisions, describes how participants initially respond to the introduction 
of a governmental intervention by restricting the withdrawal of a common pool resource. However, after two periods participants tend to behave self-interestedly and in the last three rounds behave almost entirely out of self-interest. This indicates that, while the framing effect, more precisely the social experimenter demand effect might enhance conservation behavior in the short run, it does not necessarily hold in the long run. Further research could investigate the conditions under which short term crowding effects due to frame shifting induce changes in conservation behavior in the long run. Moreover, further empirical studies that do not only provide suggestive comments regarding the motivational factors behind crowding effects are needed. 


\title{
4 Conservation vs. Equity: Can Payments for Environmental Services achieve both?
}

\begin{abstract}
This paper explores the trade-off between conservation and equity considerations in the use of payments for environmental services (PES). We conducted a framed field experiment in Jambi province (Indonesia), where rubber agroforestry area has continuously declined due to the growing demand for oil palm area in the last two decades. In particular, we investigate the impact of two alternative PES schemes, which are implicitly associated with different fairness principles, on conservation and distributional outcomes under endowment and productivity heterogeneity. We test an equal PES scheme, where a fixed flat rate per conserved hectare is paid, and a discriminatory PES scheme, where low-endowed participants receive a higher payment per conserved hectare than high-endowed participants. The main findings indicate that the introduction of a discriminatory PES scheme can function as a multi-purpose instrument that realigns the income distribution in favor of low-endowed farmers and reduces inequality among group members. Importantly, our results show that the introduction of a discriminatory PES scheme does not necessarily need to be compromised by lower environmental additionality at the group level.
\end{abstract}

Keywords: Payments for Environmental Services, efficiency equity trade-off, public good experiment, endowment heterogeneity, productivity heterogenity 


\subsection{Introduction}

Payments for environmental services (PES) aim to create, conserve and restore natural resources by creating a market for environmental services or at least by covering the opportunity costs associated with the provision of the well-defined service (Alix-Garcia et al., 2008; Jack et al., 2008; Muradian et al., 2010; Engel et al., 2008; Pascual et al., 2010). Although PES are increasingly proposed as an efficient instrument to promote conservation $^{14}$, critics argue that PES are regressive as they privilege few large-scale farmers, who are often the least-cost suppliers of environmental services (Pascual et al., 2010; Narloch et al., 2013; Muradian et al., 2010). ${ }^{15}$ Hence, practitioners (e.g. NGOs, government agencies) have proposed that PES shall function as a win-win mechanism for both environmental protection and poverty alleviation to secure the political and social legitimacy of the intervention (Landell-Mills and Porras, 2002; Pagiola et al., 2005; Grieg-Gran et al., 2005; Corbera et al., 2007; Muradian et al., 2010; Corbera and Pascual, 2012; Narloch et al., 2013; Muradian et al., 2013). This paper investigates the potential of using PES as a multi-purpose instrument to promote conservation and enhance equity. In particular, we study if the use of PES as a redistributive instrument compromises conservation goals, measured as environmental additionality. Following Brown and Corbera (2003), the distributional implications of PES can be assessed according to three criteria: equity in access, equity in decision making and equity in outcome (Konow, 2003; Corbera et al., 2007; Pascual et al., 2010; Muradian et al., 2010)16. In this paper, we focus on on the latter by investigating the changes in the distribution of income among group members induced by PES, since the transfer of payments itself

\footnotetext{
${ }^{14}$ Compared to traditional command-and-control mechanisms (e.g. integrated conservation and development goals (ICDPs)) (Pagiola et al., 2005).

${ }^{15}$ Evidence shows that in the majority of PES schemes poor landholders tend to be excluded from participation or lack adequate benefits generated through a program participation (Landell-Mills, 2002; Zbinden and Lee, 2005; Grieg-Gran et al., 2005; Corbera et al., 2007; Sommerville et al., 2010). Yet, examples of successful pro-poor targeting are provided by Pagiola et al. (2008) in Nicaragua, where the program explicitly includes a social objective and hence poor landholders benefit.

${ }^{16}$ While it is often assumed that equity is a matter of distribution based on universal principles, some scholars point out the manifold nature of equity, stressing that the definition of equity varies across societies, contexts and time (Corbera et al., 2007; Konow, 2003; Pascual et al., 2010).
} 
has been identified as a major contributor to poverty reduction in PES programs (Pagiola et al., 2005) ${ }^{17}$.

Formal institutions such as PES are embedded in complex social systems and thus interact with social norms (Cardenas et al., 2000; Cardenas and Carpenter, 2008; Vollan, 2008; Narloch et al., 2012). Pascual et al. (2010) identify a number of PES design principles which considerably differ in their implicit fairness criterion or rather in their relative weights given to equity and efficiency concerns. Such intangible factors associated with the policy design criteria may affect the intrinsic motivation of landholders to conserve (Kosoy et al., 2007; Rodriguez-Sickert et al., 2008; Sommerville et al., 2010; Narloch et al., 2013). In practice, manifold fairness criteria exist, and what is perceived as fair or equitable is time and context dependent and varies within heterogeneous groups. Consequently, individuals participating in a program may differ on the supported fairness criteria, and as a result the implicit fairness criterion adopted in a PES scheme will have implications for environmental additionality and equity considerations (Pascual et al., 2010). Former studies using micro simulation modelling cannot capture embedded norms of fairness and attitudes towards conservation due to the chosen methodology (Alix- Garcia et al., 2008; Börner et al., 2010). We thus use a experimental approach, which allows to measure in a controlled and incentive compatible environment the behavioral response to alternative PES schemes that implicitly incorporate two different fairness criteria.

To increase external validity, we conducted a framed field experiments in Indonesia (island of Sumatra, Jambi province) with farmers, who face the decision to exploit rubber agroforestry, a traditional complex cultivation system, in their daily life. In Jambi province rubber agroforestry area has continuously declined due to the growing demand for oil palm area. The cultivation of rubber agroforestry, while generating lower private profit than oil palm, is associated with positive externalities in oil-palm dominated landscapes, such as biodiversity and water purification (Barnes et al., 2014). Therefore, PES to protect rubber agroforestry has been identified as a promising tool to internalize externalities and foster sustainable land use (Villamor et al., 2011). Pagiola

${ }^{17}$ The concept of poverty goes beyond economic dimensions, capturing socio-cultural aspects (e.g. dignity) and political dimensions (e.g. empowerment) (Pascual et al., 2010). The consideration of these aspects goes beyond the scope of this paper. 
et al. (2005) show that the desire of the poor to participate in a PES scheme, in our experiment equivalent to the ability to participate and actual participation ${ }^{18}$, is often restricted by significantly higher relative opportunity costs to allocate scarce resources to conservation, when limited endowments need to be used for income generation (Baland and Platteau, 1999; Narloch et al., 2013). This is reflected in our experimental design, where participants with lower endowments have higher opportunity costs of conservation.

To capture the dilemma that households face when deciding how to allocate their land between oil palm and rubber agroforestry, we apply a modified public good game with heterogeneous participants. Participants, who differ in terms of the endowment - land experimental units - and opportunity costs of conservation, decide how to allocate their endowment to the alternative cultivation systems. We compare two alternative PES schemes: an equal PES scheme and a discriminatory PES scheme. In the equal PES scheme ${ }^{19}$ the conservation fund is equally distributed among the participants (fixed flat rate per conserved land unit), irrespective of the cost and level of environmental service provision. In the discriminatory PES scheme, unlike other pro-poor schemes that focus on accessibility, we explicitly consider redistribution as a strategic objective. Hence, in this scheme the payment is conditional on the level of endowment. Keeping the conservation fund constant, the total payment is redistributed by offering higher payments per conserved land unit to small landholders and lower payments per conserved land unit to larger landholders (see Pascual et al., 2010). These alternative PES schemes implicitly incorporate different fairness principles. While the equal PES scheme is in accordance with the egalitarian principle, the discriminatory PES scheme corresponds with the "max-min" principle, where those resource users with the highest needs receive a higher payment (Pascual et al., 2010).

To the best of our knowledge only a very limited number of studies investigate PES schemes using framed field experiments in a developing country context. Narloch et al.

\footnotetext{
18 In our study, we neglect insecure property rights, the ability to meet investments costs, and technical constraints which may explain, according to Pagiola et al. (2005) the discrepancy between the desire to participate and actual participation.

19 This scheme is widely adopted in practice, e.g. the nation-wide forest conservation program (FONAFIFO) in Costa Rica.
} 
(2013) implement an agro-biodiversity conservation auction in Bolivia and Peru to investigate the distributional outcomes of three alternative payment rules ${ }^{20}$ that differ in terms of how they allocate payments to the ranked bid offers and implicitly incorporate different fairness criteria. The paper shows that both conservation and distributional outcomes are highly sensitive to the PES scheme (see also Jindal et al., 2013). Several authors have used framed field experiments, either applying a public good or commom pool experiment, to investigate the role of PES-like schemes on cooperation between homogenous resource users (Vollan, 2008; Rodriguez-Sickert et al., 2008; Travers et al., 2011; Kerr et al., 2012; Narloch et al., 2012).

However, both the social preferences associated with the provision of a public good (e.g. Cardenas et al., 2002; Janssen et al., 2012; Janssen et al., 2013) as well as the valuation of intangible factors associated with the PES scheme (Schilizzi, 2011; Sommerville et al., 2010) depend on the relative position of a participant within a group. Hence, the consideration of heterogeneity is an essential extension in the public good literature. To the best of our knowledge only the paper of Narloch et al. (2012) applied a public good game with heterogeneous groups in the context of PES. In these groups, game participants only differ in terms of endowment status, ignoring differences in opportunity costs of conservation (productivity heterogeneity). They investigate to which extent alternative reward systems (individual vs. collective) interact with social norms. Results indicate that the impact of alternative rewards schemes on cooperation is not conditional on the endowment status. To best of our knowledge, studies that investigate the distributional outcome of alternative PES schemes using a public good experiment with heterogenous particpants have not yet been conducted.

The vast majority of experimental literature on public good games considers only one type of heterogeneity, either e.g. endowment heterogeneity (see Cherry et al., 2005; Narloch et al., 2012; Reuben and Riedl, 2013) or productivity heterogeneity (see Cardenas et al., 2002; Reuben and Riedl, 2013). Only Chan and Mesterlman (1999) introduce inequality by varying both the endowment and the value of the public good. They found that under a perfect information and non-communication scenario, adding a sin-

${ }^{20}$ They tested (a) a discriminatory rule, where the level of payment is selected according to the conservation costs; (b) a uniform rule, where each selected group receives the same payment per hectare and (c) a conditional rule, where each group was paid the payment level requested per hectare. 
gle type of inequality (endowment or value) does not change the public contribution, while introducing both types of inequality simultaneously significantly increases contribution to the group account. We extend the existing literature by introducing both endowment and productivity heterogeneity in a public good experiment to study the conservation and distributional outcomes of two alternative PES schemes that implicitly incorporate different fairness principles.

The next section briefly outlines the field context in which the framed field experiment was carried out. Sections 4.3. and 4.4. develop the conceptual framework and describe the experimental design and procedures used in the implementation. Descriptive and econometric results are presented in Section 4.5. We start with the analysis of the alternative PES schemes on conservation behavior both at group level and separated by endowment status, allowing us to draw conclusions on environmental additionality. In the second part, we focus on equity implications by investigating the distribution of income among group members and the gini index. The results are discussed in Section 4.7. The paper concludes with the main findings and implications.

\subsection{Background}

During the last decade oil palm cultivation increased rapidly in Indonesia. Between 2000 and 2010, the oil palm area almost doubled from 4.2 million hectares to around 8 million hectares, accounting for $46 \%$ of the world's crude palm oil production (Obidzinski et al., 2012). This expansion mostly took place on the islands of Sumatra and Kalimantan, which concentrate $66 \%$ and $30 \%$ of the national oil palm area, respectively (PWC, 2012). For future oil palm expansion 18 million hectares have been earmarked by local governments (The Jakarta Post, 2009), mainly located on the islands of Kalimantan, Sulawesi and Papua. For many rural households the increasing oil palm sector offers an attractive pathway out of poverty (in 2010, 38\% of the total oil palm area was managed by smallholder farmers (PWC, 2012)) (McCarthy et al., 2012) ${ }^{21}$. At the same time, oil palm expansion in Indonesia has been associated with significant negative environmental impacts and social conflicts (Colchester et al., 2006; Belcher and Schreckenberg, 2007; McCarthy et al., 2012).

\footnotetext{
${ }^{21}$ In 2000, private enterprises manage $58 \%$ of the total oil palm area and dropped to $54 \%$ in 2010 . Meanwhile the share of smallholder plantation increase by $10 \%$, from $28 \%$ to $38 \%$ in the same period (PWC, 2012).
} 
The establishment of oil palm plantations has been linked to significant losses in rainforest area, where the majority of endemic species are located (Fitzherbert et al., 2008; UNEP, 2011). Estimates suggest that between 1990 and 2005 around 57\% of the oil palm expansion occurred at the expense of tropical rainforest (Koh and Wilcove, 2008). Among the countries which faced significant losses in forest land between 1990 and 2005, Indonesia ranks second with regard to the absolute decline in forest area $\left(280,000 \mathrm{~km}^{2}\right)($ WTO, 2010). Jambi Province is one of the provinces with the fastest and most complete transformation of tropical lowland rainforest into rubber and oil palm plantations worldwide (Laumonier et al., 2010). Lowland rainforest area was massively cut by concession logging, leaving only few remaining rainforest spots in national parks (National Park Bukit Duabelas, Harapan rainforest). This transformation process was mainly driven by the trans-migrant program, which was launched by the Indonesian government in the early 1980's. It aimed at moving households from the over-populated island of Java to the less populous islands of Sumatra and Kalimantan (Feintrenie and Levang 2009; Feintrenie et al., 2010). Trans-migrant villages were established in Nucleus Estate and Smallholder schemes (NES), where a company-owned refinery and estate is surrounded by smallholder-owned plantations (Fearnside, 1997; Elmhirst, 1999). Each trans-migrant household received two hectares of oil palm plantation within the NES scheme (McCarthy et al., 2012). In Jambi province, NES schemes exist for both rubber monoculture as well as oil palm.

The transformation of complex land use systems into oil palm plantations has been identified as a major factor in the significant loss in biodiversity (Danielsen et al., 2009; Wilcove and Koh, 2010) and ecosystem functioning (Barnes et al., 2014). Since primary lowland rainforest has been almost completely converted into more intensive land uses, currently rubber agroforestry systems are the most extensive, forest-like vegetation type in Jambi province. Rubber agroforestry, which is cultivated since the early $20^{\text {th }}$ century in Jambi province, is a smallholder cultivation system that combines the cultivation of a perennial crop (i.e. rubber) with other plants, such as timber and fruit trees, building/handicraft and medical plants. From a biodiversity viewpoint, rubber agroforests mimic secondary forest, since they incorporate the components of spontaneous second- 
ary vegetation (pioneer, post-pioneer and late-phase species ${ }^{22}$ ) (Beukema et al., 2007; Feintrenie and Levang, 2009; Feintrenie et al., 2010). In rubber agroforestry systems fertilizer and pesticide applications are rarely reported. Weeding is limited to paths, which allow the tapping of the rubber trees. Beukema et al. (2007) show that rubber agroforestry systems incorporate high levels of bird and plant species richness and are more similar to neighboring forest than to oil palm monocultures. Ecological functions of the forest such as water flow regulation and soil protection can be preserved in rubber agroforestry systems (Feintrenie and Levang, 2009). Despite the environmental benefits of rubber agroforestry, oil palm and rubber monocultures are often preferred by farmers due to their higher direct profitability. For the case of Jambi, Feintrenie et al. (2010) estimate that the relative profit of agroforestry represents approximately $61 \%$ to $69 \%$ of the profit of oil palm, depending on relative prices ${ }^{23}$. Furthermore, technical characteristics, in particular lower labor requirements, and the encouragement and support by the government and private oil palm companies may explain farmers' preference for oil palm compared to rubber agroforestry. Hence, the remaining rubber agroforestry area in Jambi province is threatened by conversion into monocultures, in particular oil palm plantations.

To counteract the threat of rapidly decreasing agro-biodiversity in Jambi province, the implementation of payments for environmental services has been proposed (Villamor et al., 2011). In 2002, the World Agroforestry Centre (ICRAF) launched the Rewarding Upland Poor for Environmental Services (RUPES) program in upland Jambi Province (Bungo district) (ICRAF, 2014). Due to the climatic conditions, the upland of Jambi is not affected by oil palm expansion, but rubber agroforest gives way to more intensively managed rubber monoculture plantations. The RUPES program implemented conservation agreements with local communities, providing them with extension services and in-kind

\footnotetext{
${ }^{22}$ In the pioneer stage, the first stage after slash and burn, heliophilous crops (such as rice and vegetables) function as pioneers, inhibiting weed. This stage creates a favorable microclimate for tree species (such as rubber, fruit and timber trees). Post- pioneers are fast growing species, such as coffee or pepper maintaining a favorable biophysical environment for the main perennial crops (such as rubber). After 1520 years rubber agroforestry systems simulate complex secondary forests, reaching maximum canopy height of 20-40 meters (Feintrenie and Levang, 2009).

${ }^{23}$ To the best to our knowledge, only the study of Feintrenie et al. (2010) compares the profitability of oil palm monoculture, rubber monoculture and rubber agroforestry in Jambi Province. Considering relatively high rubber and palm oil prices (July 2008), they estimate an average return to land based on a full plantation cycle of 2,100 Euro/ha for oil palm, 2,600 Euro/ha for rubber plantation and 1,300 Euro/ha for rubber agroforestry. With low rubber and palm oil prices (November 2008), average returns to land decrease to 990 Euro/ha for oil palm, 1,300 Euro/ha for rubber and 690 Euro/ha for rubber agroforestry.
} 
rewards (such as the installation of micro-hydro power plants) in exchange for the preservation of rubber agroforestry. Based on these experiences, the aim is to strengthen the communities' negotiating power and support the development of market-based incentive schemes, such as rubber latex eco-certifications ${ }^{24}$ and Reduced Emissions from Deforestation and Degradation (REDD) ${ }^{25}$ schemes, offering monetary incentives to conserve agro-biodiversity.

\subsection{Conceptual framework}

\section{The producer problem}

We consider a partial equilibrium model in which farmers decide how to allocate their land, L, between rubber agroforestry and oil palm cultivation. The private profit of rubber agroforestry is lower than the profit generated from oil palm cultivation. Hence each land unit allocated to oil palm, $\mathrm{x}$, yields a return of 1 , while each land unit allocated to rubber agroforestry gives a return $a$, where $a<126$. Assuming that all land units need to be distributed, the number of land units allocated to rubber agroforestry equals (L-X). Rubber agroforestry generates positive environmental effects, such as improved water quality, increased soil fertility and higher biodiversity. Let $b$ be the positive externalities for $\mathrm{N}$ community members, generated by each unit of land allocated to rubber agroforestry. We consider that the marginal incentive to cultivate oil palm is positive, so $a+b<1$. Furthermore, we take into account that producers are heterogeneous in terms of the size of available land and the opportunity cost that they face to conserve rubber agroforestry. Type 1 producers have low land endowments $L_{L}$ and high opportunity cost of conservation, whereas Type 2 producers have high land endowments $L_{H}$ and low opportunity cost of conservation. In order to represent this difference in the opportunity cost of conservation, we allow the relative profit of rubber agroforestry to differ between Type 1 and Type 2 producers. Thus, the relative profit of rubber agroforestry of low-endowed producers $\left(a_{L}\right)$ is lower than that generated by high-endowed participants $\left(a_{H}\right)\left(\mathrm{a}_{\mathrm{L}}<\mathrm{a}_{\mathrm{H}}\right)$.

\footnotetext{
${ }^{24}$ Though there is no market yet for certified rubber (see Gouyon, 2003).

25 There is an on-going discussion whether to allow rubber agroforestry through Hutan desa (village forest) to be included as a land use in the REDD+ scheme (see Pramova et al., 2013; Villamor et al., 2011). ${ }^{26}$ The relative profit of rubber agroforestry is based on the findings of Feintrenie et al. (2010).
} 
This model can be extended by considering that producers have an intrinsic motivation to conserve. We thus assume that producers experience a moral cost of transforming the area into oil palm, M, which is a function of an individual parameter $c_{i}$, capturing the importance that the individual gives to conservation, and the individual area cultivated with oil palm, $x_{i}$. The moral cost of transformation is given by $M=c_{i} x_{i}^{2}$, implying that the cost increases at a increasing rate with an increase in the area cultivated with oil palm. The optimization problem for the individual producer is given by:

$$
\pi\left(i_{0}\right)=\max _{x_{i_{0}}}\left(x_{i_{0}}+a_{K}\left(L_{k_{i_{0}}}-x_{i_{o}}\right)+b \sum_{i=1}^{N}\left(L_{i}-x_{i}\right)-c_{i} x_{i_{o}}^{2}\right) \quad \text { For } K=L, H
$$

where the subindex $\mathrm{K}$ denotes producer type $\mathrm{L}$ or $\mathrm{H}$. Given that $a_{K}+b<1$, the first order condition implies that individual producers who derive no intrinsic utility from conservation $\left(c_{i}=0\right)$ would specialize and allocate all land units to oil palm cultivation. For producers who give a certain importance to conservation $\left(c_{i}>0\right)$, the optimal area cultivated with oil palm, $\mathrm{x}_{\mathrm{i}}{ }^{*}$ is given by:

$$
x_{i_{0}}^{*}=\frac{1-a_{K_{i_{0}}}-b}{2 c_{i_{0}}}
$$

Since $\mathrm{a}_{\mathrm{L}}<\mathrm{a}_{\mathrm{H}}$, producer Type 1 has a higher incentive to cultivate oil palm than producer Type 2. Hence, our first hypothesis is:

\section{Hypothesis 1-H1}

In the absence of payments for environmental services, Type 1 producers with low endowments of land and high opportunity cost of conservation allocate a smaller fraction of land to rubber agroforestry than Type 2 producers with high endowments of land and low opportunity cost of conservation.

Proof 1: The proportion of land endowment allocated to rubber agroforestry, $R_{R E L}$, is:

$$
R_{R E L}=\frac{L-x}{L}=1-\frac{1-a-b}{2 c_{i} L} \text {; with } \frac{d R_{R E L}}{d a}=\frac{1}{2 c_{i} L}>0 ; \quad \frac{d R_{R E L}}{d L}=\frac{\frac{1-a-b}{2 c_{i}}}{L^{2}}>0 \text {; hence } R_{L}<R_{H} .
$$




\section{The social planner problem}

The problem for the social planner is to maximize welfare selecting the optimal amount of land to be transformed into oil palm. For a society that is composed of $N$ individuals, the social welfare function $W$ is given by maximizing the sum of the individual pay-off functions:

$$
W=\max _{x=\left(x_{i}, \ldots, x_{N}\right)}\left(\sum_{i=1}^{N}\left(x_{i}+a_{K_{i}}\left(L_{K_{i}}-x_{i}\right)+b \sum_{j=1}^{N}\left(L_{K_{j}}-x_{j}\right)-c_{i} x_{i}^{2}\right)\right)
$$

The optimal social allocation of land to oil palm is given by $x_{s}{ }^{*}=\frac{1-a_{K_{i}}-N b}{2 c_{i}}$. If the social benefit of rubber agroforestry conservation $(\mathrm{Nb})$ is larger than the private net benefit 1$a_{K_{i}}\left(1-a_{K_{i}}<\mathrm{Nb}\right)$, the optimal amount of land allocated to oil palm is zero. Otherwise, the optimal amount of land allocated to oil palm is positive, but from the social point of view it is always smaller than the optimal amount of land that is allocated to oil palm privately. In order to induce producers to consider the positive externalities associated with conservation, the social planer could offer monetary incentives, such as payments for environmental services (PES), such that $x_{s}{ }^{*}=\sum_{i=1}^{N} x^{*}$.

\section{Payments for Environmental Services (PES)}

Modeling PES as an increase in the relative profit of rubber agroforestry, $a_{K_{i}}+$ PES, it is straight-forward to show that keeping everything else constant, the proportion of land allocated to rubber agroforestry increases with the introduction of PES. Yet, the effect of the introduction of an equal PES scheme on the proportion of land endowment contributed to conservation would be different for producers Type 1 and Type 2. This leads to our second hypothesis:

\section{Hypothesis 2-H2}

The implementation of an equal PES scheme will result in a larger increase in the proportion of land conserved for producers Type 1 with lower endowments and high opportunity costs of conservation than for producers Type 2 who are high-endowed and have low opportunity costs of conservation. 
Proof 2: As shown in Proof 1, the proportion of land that is conserved increases linearlywith an increase in the relative profit of rubber agroforestry, a.The change in the proportion of land that is conserved is a negative function of the land size

$\frac{d^{2} R}{d a d L}=-\left(\frac{1}{2 c_{i} L^{2}}\right)<0$. Hence, the increase in the proportion of land conserved of Type 2 producers with higher relative profit of rubber agroforestry, $a_{H}$, and higher land endowments, $\mathrm{L}_{\mathrm{H}}$ is lower than the increase in the proportion of land of Type 1 producers.

Since the introduction of an equal PES scheme induces Type 1 producers more strongly to increase their proportion of land allocated to rubber agroforestry than Type 2 producers and the PES does not fully compensate for the forgone benefits, the implementation of the PES scheme might result in an increase in income inequality among Type1 and Type 2 producers.

\section{Hypothesis 3-H3}

Assuming that the individual preferences for rubber agroforestry $c_{i}, c_{j}$ are equal in absolute values, i.e. $c_{i}=c_{j}=c$, an equal PES scheme might increase income inequality by generating a larger reduction in the income of Type 1 producers relative to Type 2 producers.

Proof: Based on equation (2) it is possible to show that the optimal amount of land allocated to oil palm cultivation of producer Type 1 is $x_{L}=x_{H}+\frac{a_{H}-a_{L}}{2 c}$. The difference in the income between Type 1 and Type 2 producers is hence given by:

$$
I\left(a_{H}, a_{L}\right)=\pi_{H}-\pi_{L}=\frac{a_{L}-a_{H}}{2 c}\left(1-\frac{a_{L}-a_{H}}{2}\right)+a_{H} L_{H}-a_{L} L_{L}
$$

The larger the differences in the amount of available land endowments and in the relative profit of rubber agroforestry, the larger the inequality, I, among Type 1 and Type 2 producers. Next, we want to know how I changes if we add a fixed amount of $\delta$ to both returns $a_{H}, a_{L}$. Defining a new function $G\left(\delta, a_{H}, a_{L}\right):=\mathrm{I}\left(a_{H}+\delta, a_{L}+\delta\right)$

$$
G\left(\delta ; a_{H}, a_{L}\right)=I\left(a_{H}, a_{L}\right)+\delta\left(L_{H}-L_{L}-\frac{a_{L}-a_{H}}{2 c}\right)
$$

In particular, differentiating yields 


$$
\frac{d G\left(\delta ; a_{H}, a_{L}\right)}{d \delta}=L_{H}-L_{L}+\frac{a_{H}-a_{L}}{2 c}>0
$$

A social planner that takes into account the distributional outcome might consider using PES not only to increase conservation, but also to reduce inequality. Hence, this social planner might offer a higher PES to producer Type 1 and a lower PES to producer Type 2 to compensate the differences in the opportunity costs of conservation.

\section{Hypothesis 4-H4}

A discriminatory payment scheme that reallocates payments toward the low-endowed participants and hence results in a higher (lower) payments for low-endowed (highendowed) participants, decreases income inequality (compared to the equal PES scheme).

Proof: Defining a new function $D\left(\delta, \gamma, a_{H}, a_{L}\right):=\mathrm{I}\left(a_{H}+\delta-\gamma, a_{L}+\delta+\gamma\right)$, where $\gamma$ is the fraction of payment that is taken from the high-endowed participant and redistributed to the low-endowed participant. It can be shown that:

$D\left(\delta, \gamma, a_{H}, a_{L}\right):=\mathrm{I}\left(a_{H}, a_{L}\right)+\delta\left(L_{H}-L_{L}-\frac{a_{L}-a_{H}}{2 c}\right)+\frac{\gamma}{c}\left(1-\frac{a_{L}+a_{H}}{2}-\delta-c L_{H}-c L_{L}\right)$

The effect on an increase in the relative profit of rubber agroforestry on income inequality is given by :

$$
\frac{d D}{d \delta}=L_{H}-L_{L}+\frac{a_{H}-a_{L}}{2 c}-\frac{\gamma}{c}<\frac{d G\left(\delta ; a_{H}, a_{L}\right)}{d \delta}
$$

Therefore, the use of a discriminatory payment reduces the income inequality increasing effect of an increase in the relative profit of rubber agroforestry compared to an equal PES scheme. Moreover, the effect of an increase in the amount of payment that is redistributed in favor of low-endowed particpants , $\gamma$, on income inequality is:

$$
\frac{d D}{d \gamma}=\frac{1}{c}\left(1-\frac{a_{L}+a_{H}}{2}-\delta-c L_{H}-c L_{L}\right)
$$

with $\frac{1}{c}\left(1-\frac{a_{L}+a_{H}}{2}-\delta\right)<L_{H}+L_{L} ; \frac{d D}{d \gamma}<0$.

Hence, the income inequality decreases, the larger the amount of payment redistribution. 


\section{Hypothesis 5-H5}

The discriminatory PES scheme does not lead to a reduction in the increase in the conservation area at community level compared to an equal PES scheme.

Proof: Since the change in the proportion of land that is conserved is a negative function of the land size $\frac{d^{2} R}{d a d L}=-\left(\frac{1}{2 c_{i} L^{2}}\right)<0$, we can assume that the relative increase (compared to the equal PES scheme) in land endowments that is allocated to conservation by Type 1 producers is higher than the respective decrease of conservation by Type 2 producers.

\subsection{Experimental Design and Procedures}

To test the above-depicted hypotheses, we applied a modified public good game. Participants were randomly matched into groups of three farmers. Two participants in the group were endowed with five experimental units of land $\left(L_{L}=5\right)$, whereas one participant received ten experimental units of land $\left(L_{H}=10\right)$. To reflect differences in the opportunity cost of conservation, the relative profit of rubber agroforestry of lowendowed participants, L was lower than that generated by high-endowed participants $\left(\mathrm{a}_{\mathrm{L}}<\mathrm{a}_{\mathrm{H}}\right)$. We consider that for low-endowed participants the relative profit of rubber agroforestry to oil palm is 0.3 whereas for the high-endowed participant, the profit is 0.4 .

To capture perceptions and preferences associated with the two cultivation systems, the endowment allocation decision was framed as a cultivation decision between oil palm and rubber agroforestry. We explained participants that rubber agroforestry has positive environmental effects that translate into higher payments for all group members. To illustrate this we presented posters with photos of each cultivation system. Each land unit allocated to rubber agroforestry by a group member increased the income of each group member by $b=0.2$.

\section{Experimental treatments}

Our experiment uses a within-between subject design. The within-subject design was used to capture individual preferences for conservation and test how changes in con- 
servation incentives interact with these preferences. Hence, each participant played three scenarios that were presented as sequential decisions. In each scenario, we varied the monetary incentives for conservation. In the first scenario or decision, participants decided how to allocate their endowment without any PES. This first decision allows us to capture individual heterogeneity in preferences for conservation. Moreover, this decision allows us to build a baseline against which to compare the effect of PES on the additional units of experimental land conserved. In decisions 2 and 3, monetary incentives for the practice of rubber agroforestry were introduced. Each unit of endowment allocated to rubber agroforestry hence generated a relative profit of $(a+\delta)$. The monetary incentives were framed as PES that aim to foster environmentally friendly behavior through the practice of rubber agroforestry. Each participant was confronted with a low and a high payment level. To account for order effects we randomly switched the order in which payments were offered. Hence, half of the participants received a high payment in the second decision and a low payment in the third decision, whereas the other half received a low payment in the second decision and a high payment subsequently. Since we were interested in testing the effect of different payment levels without creating a high cognitive load for participants, we used two payment sets that were randomly allocated to participants. The first payment set offered relatively lower payments compared with the second payment set. Decisions 2 and 3 allow us to generate the elasticity of supply of PES. In order to avoid potential income and learning effects, participants did not receive feedback on their own earnings or group contributions between decisions.

The between-subject design allows us to compare the conservation and distributional outcomes of two alternative PES schemes. Hence, each participant took part in only one of the schemes. In the equal PES scheme high and low-endowed participants received a unitary payment for each unit of land conserved $\left(\delta_{L}=\delta_{H}\right)$. Thus, under this scheme the difference in the relative profit of agroforestry between high and low-endowed participants remains, $a_{L}+\delta_{L}<a_{H}+\delta_{H}$, implying higher opportunity costs of conservation for low-endowed participants. In addition, we tested a discriminatory PES scheme in which low-endowed participants received a higher payment than high-endowed participants $\left(\delta_{L}>\delta_{H}\right)$. This scheme allowed to completely compensate the differences in the opportunity costs of conservation between high and low-endowed participants, $a_{L}+\delta_{L}=a_{H}+$ $\delta_{H}$ 
Table 12 depicts the relative profit of rubber agroforestry $(\mathrm{a}+\delta)$ by payment level (no, low, high), PES scheme (equal, discriminatory), payment set $(1,2)$ and endowment status (L, H). In the baseline decision (decision 1) no PES are offered. Under the equal PES scheme, payment set 1 offered a payment of 0.05 (low level) and 0.25 (high level) experimental units for each unit of land invested in rubber agroforestry, whereas payment set 2 offered a payment of 0.1 (low level) and 0.3 (high level) for each unit of land conserved. The discriminatory PES scheme provided different payments to low and highendowed participants. Compared to the equal PES scheme, the payments for lowendowed participants increased by 0.05 , whereas the payments for high-endowed participants decreased by 0.05 experimental units. Hence under the low payment scheme low-endowed participants received either 0.1 or 0.15 in payment set 1 and 2 , respectively. On the other hand, high-endowed participant received either zero or 0.05 in each of the payment sets. To compare the two alternative PES schemes, the average payment per unit conserved (av.PES) was kept constant across the two alternative PES schemes.

Table 12: Relative profit of rubber agroforestry $(a+\delta)$ by PES scheme, payment set, payment level, and endowment status

\begin{tabular}{|c|c|c|c|c|c|}
\hline & & \multicolumn{4}{|c|}{ PES schemes } \\
\hline \multirow[b]{2}{*}{ Payment Set 1} & & \multicolumn{2}{|c|}{ Equal PES scheme } & \multicolumn{2}{|c|}{ Discriminatory scheme } \\
\hline & & $\mathrm{L}(\mathrm{e}=5)$ & $\mathrm{H}(\mathrm{e}=10)$ & $\mathrm{L}(\mathrm{e}=5)$ & $\mathrm{H}(\mathrm{e}=10)$ \\
\hline No Payment & & $\mathrm{a}_{\mathrm{L}}=0.30$ & $\mathrm{a}_{\mathrm{H}}=0.40$ & $\mathrm{a}_{\mathrm{L}}=0.30$ & $\mathrm{a}_{\mathrm{H}}=0.40$ \\
\hline Low Payment & av.PES=0.05 & $\mathrm{a}_{\mathrm{L}}+0.05$ & $\mathrm{a}_{\mathrm{H}}+0.05$ & $\mathrm{a}_{\mathrm{L}}+0.1$ & $\mathrm{a}_{\mathrm{H}}$ \\
\hline High Payment & av.PES=0.25 & $\mathrm{a}_{\mathrm{L}}+0.25$ & $\mathrm{a}_{\mathrm{H}}+0.25$ & $a_{L}+0.3$ & $\mathrm{a}_{\mathrm{H}}+0.2$ \\
\hline \multicolumn{6}{|l|}{ Payment Set 2} \\
\hline No Payment & & $\mathrm{a}_{\mathrm{L}}=0.30$ & $\mathrm{a}_{\mathrm{H}}=0.40$ & $\mathrm{a}_{\mathrm{L}}=0.30$ & $\mathrm{a}_{\mathrm{H}}=0.40$ \\
\hline Low Payment & av.PES=0.1 & $\mathrm{a}_{\mathrm{L}}+0.1$ & $\mathrm{a}_{\mathrm{H}}+0.1$ & $\mathrm{a}_{\mathrm{L}}+0.15$ & $\mathrm{a}_{\mathrm{H}}+0.05$ \\
\hline High Payment & av.PES=0.3 & $\mathrm{a}_{\mathrm{L}}+0.3$ & $\mathrm{a}_{\mathrm{H}}+0.3$ & $\mathrm{a}_{\mathrm{L}}+0.35$ & $\mathrm{a}_{\mathrm{H}}+0.25$ \\
\hline
\end{tabular}




\section{Procedures}

The experiment was conducted in four villages in Batanghari district (Jambi province); two autochthonous villages (Pulau Betung, Karmeo), which were not targeted by the governmental trans-migration program and two trans-migrant villages (Bukit Harapan, Bukit Sari). In total, 32 experimental sessions were carried out between November 2012 and March 2013. Participants were randomly selected among household heads of oil palm and/or rubber cultivating families using village census information. A total number of 260 farmers took part in the experiment. All decisions were made anonymously and information on group membership or identity was not revealed to participants. Thus, the composition of their group was unknown to the participants. Each experimental session consisted of four different stages. First the instructions of the game were read aloud to the participants, followed by several examples. In a second step, two hypothetical decisions without feedback were played to improve and confirm the understanding of the game. In the third stage, participants were presented the different scenarios and made their decisions. Assistants were available for those participants who had difficulties with reading or arithmetic. Once participants had completed the three decisions, one was randomly drawn and paid out to them. Earnings in the game were transferred to local currency units at a rate of 10 experimental units of payment to 1 IDR. All participants were paid privately using checks made payable for them in their local shops. Typical earnings (Mean 86347 IDR) were worth between one and two days of wage labor. At the end of the game a brief post-experimental questionnaire was completed, incorporating questions related to the experiment, participants' demographics and farming activities. 


\subsection{Results}

\subsubsection{Socioeconomic characteristics of the sample}

Based on the post-experimental questionnaire, Table 2 provides a description of socioeconomic characteristics of the participants, such as information on age, gender, educational level, household size and farming activities. In their real lives, $61 \%$ of the participants cultivate oil palm, $48 \%$ practice rubber monoculture and $12.7 \%$ practice rubber agroforestry. While $17.3 \%$ of the participants combine the cultivation of oil palm and rubber monoculture, only $4.2 \%$ of the participants cultivate both oil palm and rubber agroforestry. Overall, these numbers reflect the declining role of rubber agroforestry in the research area.

Table 13: Socio-economic characteristics of participants.

\begin{tabular}{|c|c|c|c|}
\hline Variables & Definition & Mean & Std. Dev. \\
\hline Age & Age of participant in years & 43.37 & 10.501 \\
\hline Female & $=1$ if female participant & 0.085 & 0.279 \\
\hline Secondary & $\begin{array}{l}=1 \text { if completion of secondary educa- } \\
\text { tion }\end{array}$ & 0.415 & 0.494 \\
\hline HH_size & Number of hh members & 4.204 & 1.494 \\
\hline Transmigrant* & $\begin{array}{l}=1 \text { if hh has migrated to Jambi within } \\
\text { trans-migrant program }\end{array}$ & 0.300 & 0.459 \\
\hline Oil palm & $=1$ if hh cultivates oil palm & 0.608 & 0.489 \\
\hline Oil palm_ha & $\begin{array}{l}\text { Total individually cultivated oil palm } \\
\text { area (ha) }\end{array}$ & 3.419 & 2.793 \\
\hline Rubber monoculture & $=1$ if hh cultivates rubber monoculture & 0.478 & 0.500 \\
\hline Rubber monoculture_ha & $\begin{array}{l}\text { Total individually cultivated rubber } \\
\text { monoculture area (ha) }\end{array}$ & 1.550 & 1.185 \\
\hline Rubber agroforestry & $=1$ if hh cultivates rubber agroforestry & 0.127 & 0.334 \\
\hline Rubber agroforestry_ha & $\begin{array}{l}\text { Total individually cultivated rubber } \\
\text { agroforestry area (ha) }\end{array}$ & 2.766 & 4.104 \\
\hline $\begin{array}{l}\text { Oil palm_rubber mono- } \\
\text { culture }\end{array}$ & $\begin{array}{l}=1 \text { if hh cultivates rubber monoculture } \\
\text { and oil palm }\end{array}$ & 0.173 & 0.379 \\
\hline $\begin{array}{l}\text { Oil palm_rubber agrofo- } \\
\text { restry }\end{array}$ & $\begin{array}{l}=1 \text { if hh cultivates rubber agroforestry } \\
\text { and oil palm }\end{array}$ & 0.042 & 0.202 \\
\hline Size of owned land (ha) & Area of owned land (ha) & 4.160 & 4.919 \\
\hline
\end{tabular}

Total number of observations: 260 
${ }^{*}$ The remaining $70 \%$ of the participants include second-generation trans-migrants (following family members who migrated within the trans-migrant program), other migrants, and autochthonous population.

To test the random assignment of participants to the respective PES scheme and endowment status in our experiment, we estimate a set of seemingly unrelated regressions with the socio-economic characteristics and session characteristics as dependent variables (see Table A10) ${ }^{27}$. We find no significant differences across treatments.

\subsubsection{Experimental results}

\section{Descriptive results}

In the descriptive analysis of our experimental results, we pool the data from payment sets 1 and 2, resulting in two payment levels (low and high). Figure 8 depicts the average share of land units allocated to conservation by PES scheme, payment level, and endowment status.

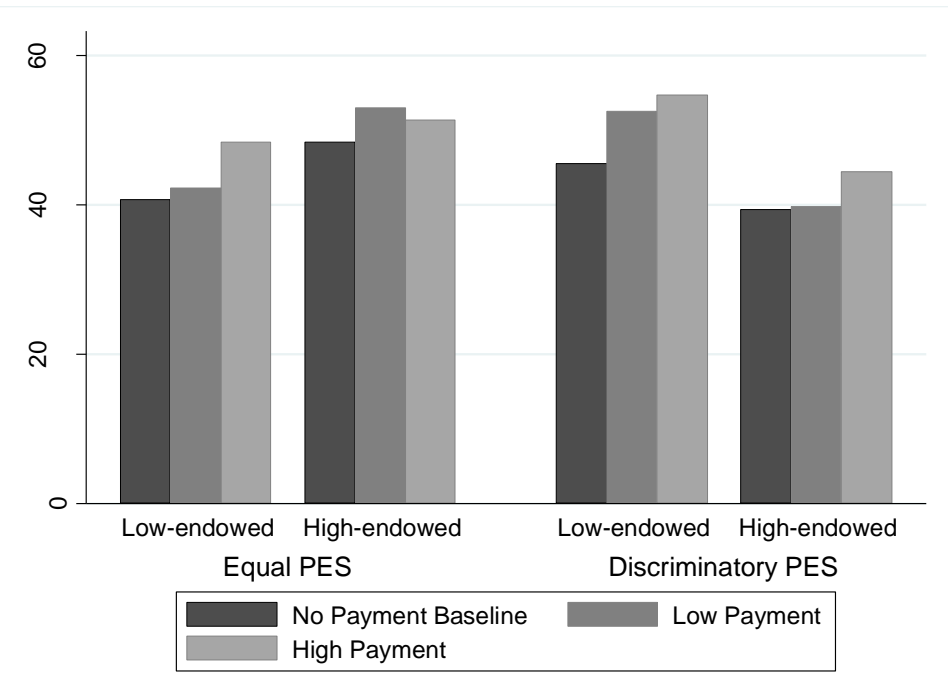

Figure 8: Average share of endowment contributed to rubber agroforestry by PES scheme, endowment status and payment level.

We find that in the baseline decision participants conserve on average between 39 and 47 percent of their endowment, which is in line with the vast majority of experimental

\footnotetext{
${ }^{27}$ Session characteristics include the following variables: share of participants known by name in session and share of family members in session.
} 
literature showing that participants of heterogeneous groups in public good experiments do not play purely self-interested strategies (e.g., Cardenas et al., 2002; Ostrom, 2000). This is consistent with our conceptual framework, which considers that economic decisions are not solely driven by economic incentives, but are also shaped by normative factors (see Equation 2). In the baseline decision of the equal (discriminatory) PES treatment low-endowed participants allocate on average 40.68 percent (45.53 percent) of their land endowment to conservation, whereas high-endowed participants conserve on average 48.41 percent (39.36 percent). For both types of producers, the difference in the baseline contribution to conservation across the two alternative PES treatments is not statistically significant.

We find that when no incentives for conservation are offered- pooling the data from both treatments- low-endowed participants conserve a slightly smaller share of their endowment than high-endowed participants, although this difference is not statistically significant (Wilcoxon rank-sum test 0.6461). These results are in line with other experimental studies showing that in relative terms low-endowed participants conserve as much as their better endowed counterparts (Cardenas et al., 2002; Narloch et al., $2012)^{28}$.

Figure 8 further shows that with the introduction of PES the average share of endowment contributed to conservation tends to increase. In the case of low-endowed participants, the introduction of an equal PES scheme leads to significant increases in conservation only if high payment levels are offered (Low Payment: Wilcoxon sign-rank test 0.2973; High Payment: Wilcoxon sign-rank test 0.0033), whereas the introduction of a discriminatory PES scheme leads to significant increases in the share of land allocated to conservation irrespective of the payment level (Low Payment: Wilcoxon sign-rank test 0.0005; High Payment: Wilcoxon sign-rank test 0.0010). Figure 8 also suggests that for low-endowed participants we can observe a standard price effect, indicating that with increasing relative payment levels the average conservation behavior increases (see Frey and Jegen, 2000). In contrast, for high-endowed participants, the introduction

\footnotetext{
${ }^{28}$ Cardenas et al. (2002) e.g. introduce heterogeneity by varying the private returns in an experiment and find that low-wage participants contribute less in absolute terms, but are willing to bear a higher burden in relative terms showing significantly more restraint to their pure Nash equilibrium compared to high-wage participants.
} 
of an equal PES scheme does not induce significant increases in conservation behavior (Low Payment: Wilcoxon sign-rank test 0.1383; High Payment: Wilcoxon sign-rank test 0.4032). We only observe a significant increase in the share of land allocated to conservation by high-endowed participants when high payment levels are offered under the discriminatory PES scheme (Low payment: Wilcoxon sign-rank test 0.6327; High payment: Wilcoxon sign-rank test 0.0723).

Regarding the distributional outcome of the alternative PES schemes, Figure 9 depicts the average share of total earnings held by individual by PES scheme, payment level, and endowment status.

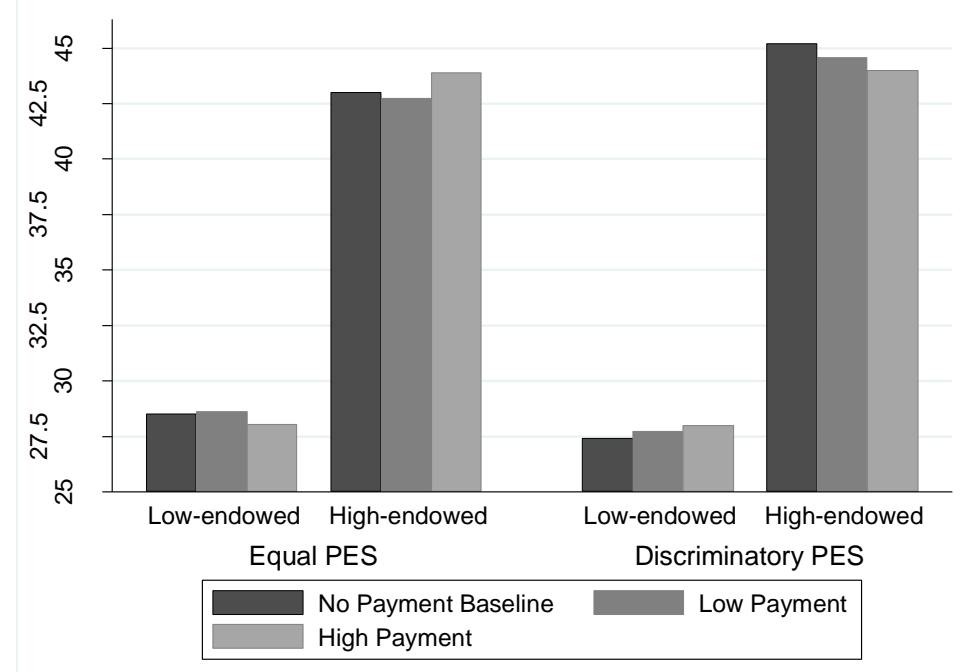

Figure 9: Average share of total group earnings held by individual by PES scheme, payment level, and endowment status.

In the baseline, low-endowed participants earn around 28 percent and high-endowed participants around 44 percent of the total group earnings. Under the equal PES scheme, low payment levels do not significantly shift the income distribution (Lowendowed: Wilcoxon sign-rank test 0.5190; High-endowed: Wilcoxon sign-rank test 0.9907). Yet, when high payment levels are offered, low-endowed participants earn significantly smaller shares and high-endowed participants significantly larger shares of the total group earnings, compared to the baseline distribution. (Low-endowed: Wilcoxon sign-rank test 0.0896; High-endowed: Wilcoxon sign-rank test 0.0400). Thus, the 
introduction of an equal PES tends to exacerbate inequalities in the prevailing income distribution.

The introduction of a discriminatory PES scheme tends to redistribute the income in favor of the low-endowed participants, as expected. In particular, we can observe that the share of total group earnings held by high-endowed participants significantly decreases irrespective of the offered payment level (Low Payment: Wilcoxon sign-rank test 0.0966; High payment: Wilcoxon sign-rank test 0.0277). Yet, the observed increase in the share of total group earnings held by low-endowed participants is not statistically significant (Low Payment: Wilcoxon sign-rank test 0.3024; High Payment: Wilcoxon sign-rank test 0.1439 ).

\section{Econometric results}

To test the hypotheses derived in the conceptual framework, we estimate a series of econometric models. Econometric estimation allows us to obtain the effect of a variable of interest (e.g. the payment scheme) while holding other variables constant (e.g. the payment level). Based on the within-subject design of the experiment, we are able to analyze individual behavioral dynamics over time.

\section{Impact of endowment status on conservation behavior}

In the following, we address the first two hypotheses, which posit that both the conservation behavior in the baseline and the change in conservation behavior induced by the introduction of PES are conditional on the endowment status. In Model 1 and Model 2, we analyze the share of individual land endowment allocated to conservation, $\mathrm{R}$, by individual $i$ in decision $t$, under the equal and discriminatory PES scheme, respectively. Taking into account that individuals took repeated decisions and that the share of endowment allocated to conservation is censored at zero and one, we estimate the following Random Effects Tobit model:

$$
R_{i t}=\beta_{0}+\beta_{1} \text { Ha10 }_{i t}+\beta_{2} \text { PesLevel }_{i t}+\beta_{3} \text { HA10 }_{i t} * \text { PesLevel }_{i t}+\vartheta_{i}+\mu_{i t}
$$

where Ha10 is a dummy variable for high endowment $(\mathrm{e}=10)$ and PesLevel is a continuous variable on the payment level offered for conservation $(\delta=[0.05,0.10,0.20,0.25$, 
$0.30,0.35,0.40])$. The estimated parameter $\beta_{0}$ indicates the area conserved by lowendowed participants when no payments are offered. The estimated coefficient $\beta_{1}$ reflects the difference in the area conserved by high-endowed participants compared to low-endowed participants, when payments equal zero (no payment = baseline) ${ }^{29}$. The estimated coefficient $\beta_{2}$ reflects the elasticity of supply of conservation to PES by lowendowed participants. The estimated coefficient $\beta_{3}$ tests whether the estimated elasticity of supply is different between low and high-endowed participants. The parameter $\vartheta_{\mathrm{i}}$ captures individual time-invariant unobserved heterogeneity that is assumed to be uncorrelated with the other covariates. The parameter $\mu_{\mathrm{it}}$ is the individual time-variant unobserved heterogeneity. Estimation results are presented in Table $14^{30}$.

Table 14: Random effects Tobit model on the share of endowment conserved under equal and discriminatory PES schemes

Model (1) Model (2)

Equal PES scheme

Discriminatory PES scheme

\begin{tabular}{lrr}
\hline Dummy Ha_10 & $0.1424^{*}$ & -0.1506 \\
& $(0.0760)$ & $(0.1098)$ \\
PESLevel & $0.3679^{* * *}$ & $0.4079 \quad * * *$ \\
& $(0.1289)$ & $(0.1322)$ \\
Dummy Ha_10* & -0.2575 & -0.0870 \\
PESLevel & & \\
& $(0.2202)$ & $(0.2630)$ \\
Constant & 0.3648 & $0.4791 \quad * * *$ \\
& $(0.0441)$ & $(0.0650)$ \\
\hline No. of observations & 396 & 423 \\
No. of groups & 132 & 141 \\
Waldchi2 & 10.98 & 14.1 \\
Prob>chi2 & 0.0118 & 0.0024 \\
\hline
\end{tabular}

${ }^{*} \mathrm{p}<0.10,{ }^{* *} \mathrm{p}<0.05,{ }^{* * *} \mathrm{p}<0.01$.

H1 posits that the share of endowment allocated to conservation is larger for highendowed participants; thus we expect $\beta_{1}$ to be positive and significant. Results of Model

\footnotetext{
${ }^{29}$ Given that under the discriminatory PES scheme and payment set one, high-endowed participants do not receive any payment when the low payment level is introduced (see Table 12), this decision is also reflected in the ha10 dummy.

${ }^{30}$ Since potential income and learning effects as well as order effects were minimized in the implementation phase of the experiment (no feedback on earnings was provided during decisions, order of payment levels was randomly varied), we do not include decision (scenario) fixed effects in the models.
} 
1 indicate that low-endowed participants conserve on average 36 percent of their endowment in the baseline decision (i.e., when no payments are offered). Compared to low-endowed participants, the share of endowment contributed to conservation in the baseline by high-endowed participants is significantly higher. This is consistent with H1 suggesting that Type 1 producers with low endowment and high opportunity costs of conservation tend to conserve less in the absence of PES. Under the discriminatory PES scheme, however, the share of endowment allocated to conservation by high and lowendowed participants does not differ significantly. We thus do not find strong and unambiguous support for $\mathrm{H} 1$.

The second hypothesis predicts a stronger supply elasticity among low-endowed participants when payments are introduced under an equal PES scheme. Hence, we expect $\beta_{3}$ to be negative. Model 1 reveals that when payment levels increase by one percentage point, low-endowed participants significantly increase the share of land allocated to conservation by 0.37 percent. The coefficient of the interaction term, while having a negative sign as expected, is not statistically significant. Thus, we do not find evidence for significant differences in supply response between low and high-endowed participants and accordingly reject $\mathrm{H} 2$.

Under the discriminatory PES scheme the supply response looks similar. Low-endowed participants increase the share of their land conserved by 0.41 percent in response to a one-percentage point increase in payment levels. The elasticity of supply of lowendowed participants does not differ significantly between the two alternative PES schemes (see Table A11). As under the equal PES scheme, the supply response of highendowed participants does not significantly deviate from that of low-endowed participants. Despite this finding, it should be noted that on the average high-endowed participants display a very low supply elasticity with respect to changes in the offered payment for conservation. In fact, our experimental evidence suggests that their propensity to conserve remains unaffected by the introduction of the economic incentives (Table A11). 


\section{Impact of alternative PES schemes on distributional outcome}

In this section we address the impact of the two alternative PES schemes on distributional outcomes. In particular, we test whether the introduction of an equal PES scheme increases inequality among group members, as proposed in H3, and whether the discriminatory PES scheme can function as a redistributive instrument decreasing inequality among group members, as proposed in H4. For this purpose, we estimate two Random Effects Tobit models for low and high-endowed participants, respectively:

$$
I_{i t}=\theta_{0}+\theta_{1} \text { Disc }_{i t}+\theta_{2} \text { PesLevel }_{i t}+\theta_{3} \text { Disc }_{i t} * \text { PesLevel }_{i t}+\vartheta_{i}+\mu_{i t}
$$

where the dependent variable I captures the distributional outcome and is measured as the share of total group earnings held by individual. The variable Disc is a dummy variable that takes the value of one for the discriminatory PES scheme. The $\theta^{\prime}$ s are parameters to be estimated: $\theta_{0}$ captures the degree of inequality under the equal PES scheme treatment in the baseline (PesLevel $=0) ; \theta_{1}$ captures differences in distributional outcome between the baseline decisions of the two alternative PES schemes ${ }^{31} ; \theta_{2}$ measures the change in distributional outcome associated with a change in payment level under the equal PES scheme; and $\theta_{3}$ tests for potential differences in the payment level effects between the two alternative PES schemes.

Last but not least, we estimate a Random Effects Tobit model at the group level (indexed by subscript $g$ ):

$$
G I_{g t}=\theta_{0}+\theta_{1} \text { Disc }_{g t}+\theta_{2} \text { PesLevel }_{g t}+\theta_{3} \text { Disc }_{g t} * \text { PesLevel }_{g t}+\eta_{g}+\varepsilon_{g t}
$$

where the dependent variable GI is measured as the Gini index capturing distributional outcome at the group level. The Gini coefficient is calculated based on the income distribution within groups and varies between 0 , reflecting complete equality, and 1 , reflecting complete inequality. The parameters $\eta_{\mathrm{g}}$ and $\varepsilon_{\mathrm{gt}}$ capture time-invariant and timevariant group-level heterogeneity and the time-invariant heterogeneity is assumed to

31 Given that under the discriminatory PES scheme and payment set one, high-endowed participants do not receive any payment when the low payment level is introduced (see Table 10), this decision is also reflected in the discriminatory PES dummy. 
be uncorrelated with the other covariates. Table 15 presents the estimation results. Model 1 and Model 2 provide the results on the earnings share held by low-endowed and high-endowed participants, respectively. Model 3 provides the results on the grouplevel Gini index.

Table 15: Random effects Tobit model on the share of total group earnings and the Gini index

\begin{tabular}{lccc}
\hline & $\begin{array}{c}\text { Model (1) } \\
\text { Earnings share }\end{array}$ & $\begin{array}{c}\text { Model (2) } \\
\text { Earnings share }\end{array}$ & $\begin{array}{c}\text { Model (3) } \\
\text { Gini index }\end{array}$ \\
\hline Dummy Disc & $-0.0118^{* *}$ & $0.0218^{* *}$ & $0.0297^{* * *}$ \\
& $(0.0051)$ & $(0.0094)$ & $(0.0103)$ \\
PESLevel & -0.0184 & $0.0369^{*}$ & 0.0185 \\
& $(0.0113)$ & $(0.0219)$ & $(0.0216)$ \\
Dummy Disc * PESLevel & $0.0367^{* *}$ & $-0.0812^{* *}$ & $-0.0959^{* * *}$ \\
& $(0.0148)$ & $(0.0315)$ & $(0.0295)$ \\
Constant & $0.2861^{* * *}$ & $0.4278^{* * *}$ & $0.1088^{* * *}$ \\
& $(0.0036)$ & $(0.0068)$ & $(0.0074)$ \\
\hline No. of observations & 546 & 273 & 273 \\
No. of groups & 182 & 91 & 91 \\
Wald chi2 & 8.51 & 9.04 & 19.05 \\
Prob>chi2 & 0.0366 & 0.0288 & .0003 \\
\hline
\end{tabular}

${ }^{*} \mathrm{p}<0.10,{ }^{* *} \mathrm{p}<0.05,{ }^{* * *} \mathrm{p}<0.01 ;$

Results presented in Table 15 allow us to address H3 hypothesizing that the introduction of an equal PES scheme increases inequality. The signs of the coefficients on PesLevel, indeed indicate that the introduction of payments under an equal PES scheme decrease the earnings share held by low-endowed participants and increase the earnings share held by high-endowed participants. In line with these distributional changes the Gini index increases in response to the introduction of equal payments. Yet, these effects are only significant in the case of high-endowed participants implying that the evidence for an inequality-increasing effect of the equal PES scheme is weak.

In contrast, we find significant evidence in favor of $\mathrm{H} 4$ stating that the introduction of a discriminatory PES scheme reduces inequality. The estimated coefficient on the interaction term indicates that under the discriminatory PES scheme the effect of one- 
percentage point increase in payment levels leads to an increase of 0.04 percent in the share of group earnings of low-endowed participants compared with the equal PES scheme and to a decrease of 0.08 percent in the share of group earnings of highendowed participants. These changes in distributional outcome are also reflected in the group level analysis. Model 3 shows that a one-percentage point increase in payment levels under the discriminatory PES scheme decreases the Gini coefficient by 0.1 index points. The results hence imply that the introduction of a discriminatory PES scheme, under the assumptions made, can have an inequality-decreasing effect influencing the income distribution in favor of producers with lower endowments.

\section{Impact of alternative PES schemes on environmental additionality at group level}

Finally, we investigate whether the introduction of a discriminatory PES scheme that offers higher payments to low-endowed participants comes at the cost of lower environmental additionality at group level. To test for this effect, and considering the panel structure of our experimental data, we estimate the following Random Effects Tobit model at group level:

$$
R_{g t}=\theta_{0}+\theta_{1} \text { Disc }_{g t}+\theta_{2} \text { PesLevel }_{g t}+\theta_{3} \text { Disc } * \text { PesLevel }_{g t}+\eta_{g}+\varepsilon_{g t}
$$

where $R$ measures the share of total endowment contributed to rubber agroforestry by group $g$ in decision $t$. Table 16 presents the results. 
Table 16: Random effects Tobit model on the share of endowment conserved at group level

\begin{tabular}{ll}
\hline & Model \\
\hline Dummy Disc & -0.0211 \\
PESLevel & $(0.0388)$ \\
& $0.1812^{* *}$ \\
Dummy Disc* PES level & $(0.0835)$ \\
& 0.0485 \\
Constant & $(0.1137)$ \\
& $0.4526^{* * *}$ \\
\hline No. of observations & $(0.0278)$ \\
No. of groups & 273 \\
Wald chi2 & 91 \\
Prob $>$ chi2 & 13.67 \\
\hline
\end{tabular}

${ }^{*} \mathrm{p}<0.10,{ }^{* *} \mathrm{p}<0.05,{ }^{* * *} \mathrm{p}<0.01$

According to the results reported in Table 16, the elasticity of aggregate supply of conservation is positive and significant, indicating that a one-percentage point increase in payment levels offered under the equal PES scheme increases the share of land conserved at group level by 0.18 percent. Furthermore, we find no significant difference in the supply response between the equal and the discriminatory PES scheme. These findings support hypothesis H5 that the introduction of a discriminatory PES scheme (compared to an equal PES scheme) does not necessarily need to be compromised by lower conservation outcomes at the aggregate level.

\subsection{Conclusion}

While payments for environmental services are increasingly proposed as an efficient instrument to promote conservation, concerns have been raised that they privilege large landowners and perpetuate or even aggravate existing inequalities in resource distribution. Against this background, it has been claimed that besides environmental goals PES should also address equity considerations to secure the social and political legitimacy of program interventions. In this paper, we contribute to this discussion by providing experimental results on the effects of two alternative PES schemes on conser- 
vation decisions and distributional equity. Our results show that the introduction of a discriminatory PES scheme realigns income in favor of low-endowed participants, while providing environmental additionality similar to an equal PES scheme. This implies that payment schemes can be designed in such a way that they function as multi-purpose instruments suitable for policy-makers wishing to reconcile equity and conservation goals.

Our findings further suggest that while low-endowed participants conserve significantly more with increasing payment levels, the conservation behavior of high-endowed participants remains largely unaffected by the introduction of incentive payments. We can thus conclude that the increase in conservation area at the group level in response to the introduction of PES mainly stems from low-endowed participants. This supports the common criticism that large-scale farmers may cash-in on PES for conservation activities that they would have carried out anyway. It also suggests that under the conditions explored here, targeting large landowners does not necessarily make conservation policy interventions more effective in achieving environmental additionality.

When assessing policy implications, it is crucial to consider the external validity of the experiment. Evidence has shown that the necessary simplifications in experimental settings can affect the external validity of experimental results (Castillo et al., 2011; Rustagi et al., 2010; Gurven and Winking, 2008; Travers et al., 2011). A central assumption in our experimental design is that low-endowed participants have higher opportunity costs of conservation. To what extent this applies to small-scale farmers is debated in the literature. Some scholars point out that poor households tend to own marginal land of low soil fertility, which results in lower opportunity costs of conservation. Here, we assume that poor households face survival constraints when making conservation efforts that endure present sacrifices (Baland and Plateau, 1999) and thus have high opportunity costs of conservation. In a situation, where small-scale farmers indeed face lower opportunity costs of conservation, their initial conservation levels in the absence of incentive payments is likely to be higher, and consequently, their response to the introduction of payments will be lower. Thus, the aggregate conservation outcome at the group level is unclear, in particular, because under the current setting the increase in group-level conservation mostly resulted from the conservation decision of low- 
endowed participants. Regarding the distributional implications of the PES scheme, we would still expect the discriminatory scheme to have an (even stronger) inequalitydecreasing effect. But even the equal PES scheme may contribute to decreasing inequality in such a scenario: equation (5) shows that the inequality-increasing effect of the equal PES scheme is conditional on the opportunity costs of conservation. If the opportunity costs of low-endowed participants are substantially lower than those of highendowed participants, the introduction of an equal PES scheme may indeed decrease inequality.

From a policy perspective, it is important to note that the focus of our analysis is on environmental additionality and hence disregards the cost-effectiveness of the alternative PES schemes. To evaluate cost-effectiveness, the implementation costs of alternative schemes need to be taken into account, which besides the direct costs of compensation, also comprise the transaction costs associated with the delivery of payments. Since these costs depend to a large extent on the amount of information required, it can be argued that a discriminatory PES scheme would imply higher transaction costs than an equal PES scheme relying on a flat-rate payment (Pascual et al., 2010). On the other hand, if the equity principle underlying the discriminatory PES scheme increases acceptance of the scheme in the community, this is likely to facilitate program implementation, induce community cooperation, and effectively reduce transaction costs.

In our study, we investigated the behavioral responses of Indonesian farmers to the introduction of alternative payment schemes reflecting different implicit equity principles. It should be kept in mind that several institutional factors potentially affecting the conservation decision of farmers could not be considered in the experimental design. In practice, the establishment of oil palm plantations is associated with high upfront investments that only yield a return once the palms start producing. Effectively, for creditconstrained farmers this is likely to be a barrier to oil palm adoption. Thus, in comparison to the experimental land use decisions, in reality we may observe less land allocated to oil palm cultivation, due to existing capital constraints.

On the other hand, land use decisions are likely to be influenced by insecure land tenure, overlapping claims and lacking information on private tenure (Engel and Palmer, 
2008; Muradian et al., 2010; Börner et al., 2010). This is of special relevance in our study region. While oil palm farmers who obtained their land through nucleus estate smallholder schemes - in our sample, the trans-migrant villages-and who participate in the rural microfinance program often hold formal land titles, other rural households receive private land through "informal" land markets based on customary land tenure arrangements (McCarthy et al., 2012; Hauser-Schäublin and Steinebach, 2014). In the case of customary land, overlapping claims from the community and state are common, posing a threat to land tenure security. Given that rubber agroforestry is traditionally practiced on customary land, farmers may be reluctant to convert oil palm into rubber agroforestry, as this may jeopardize land security.

In summary, our study provides behavioral evidence on the implications of different payment scheme designs for environmental and social outcomes. In order to inform policy-makers, further research is needed testing alternative PES designs and capturing additional institutional drivers and constraints of land use transformation. 


\section{General Conclusion}

\subsection{Summary of findings}

Ecosystems have undergone rapid and extensive changes, such as the transformation of semi-natural or natural habitats into monocultural annual or perennial cropping. While these changes have led to substantial gains in human well-being, they also entail the depletion of regulating and supporting ecosystem services to a greater extent than would be socially optimal. To address this externality problem, PES are increasingly proposed as efficient, market-based policy instruments.

Previous studies on PES have primarily been based on the Coasean approach. However, practitioners can rarely find or establish the conditions that underlie the Coasean approach, such as clear property rights, perfect information and competition. Critics thus postulate a new conceptualization of PES that accounts for the complexities that characterize the real-world implementation of PES. In particular, participants face uncertainties associated with the heterogeneity in the environmental, socio-economic and sociocultural background (contextual factors), as well as strategic decisions regarding the trade-offs in the PES outcomes, in which measures of efficiency are not the sole concerns. Therefore, the aim of this study was to contribute to a better understanding of the relationships among PES outcomes, PES policy designs and contextual factors. Specifically, three research objectives have been addressed. First, we have assessed the relationship between ecological (bird diversity, bird abundance) and economic outcomes (yields, revenue) of remnant or planted trees in smallholder oil palm plantations along a management intensity gradient. Second, we have investigated the crowding effect induced by the framing of incentives, as PES. Third, we have analyzed the conservation and distributional outcomes of two alternative PES schemes that employed different implicit fairness criteria.

In Chapter II, we have combined economic and ecological data of 120 smallholder oil palm plots in Jambi province, Sumatra, Indonesia to investigate the ecological-economic 
trade-off from remnant or planted tree stands. We have contributed to the extant literature in two broad ways. First, we have assessed the costs of conserving the diversity (abundance) of bird species through wildlife-friendly strategies in oil-palm-dominated landscapes. Second, we have accounted for the non-linearity of environmental additionality by collecting data along a management intensity gradient. Our study have confirmed that oil palm plantations are poor habitats for bird communities relative to natural forests. However, the restoration of wildlife-friendly oil palm plantations containing mixed tree stands can mitigate the loss of bird diversity and abundance of edge-tolerant, open-habitat and generalist species with low conservation status. The results have shown that this gain in bird diversity and abundance, which was conditional on increases in tree stands, entails a loss in revenue, implying a "win-lose" relationship between ecological and economic outcomes. Because both the marginal gain in bird species (abundance) and the marginal loss in revenue conditional on the number of trees are non-linear, the marginal shadow price of bird species richness (abundance) changes depending on the initial level of management intensity. In a relatively extensively managed oil palm plantation (with an initial number of trees equal to 50), environmental additionality in terms of bird species richness can be achieved at the expense of relatively high revenue penalties (67\% decline in total revenue), whereas in relatively intensively managed oil palm plantations (with an initial number of trees equal to 10), the same increase in bird species richness can be achieved with a considerably smaller loss in revenue ( $20 \%$ loss of total revenue). Furthermore, our results have suggested that conservation decisions are not purely governed by economic reasoning. Although we have observed a trade-off, farmers explicitly or implicitly decided to maintain/plant trees on their oil palm plantations. This leads us to Chapter III and IV, where data from framed field experiments have been used to capture preferences associated with conservation activities.

In Chapter III, we have investigated the extent to which contextual manipulations of a policy invention affect conservation behavior. We have contributed to the existing literature by providing the first estimates of the crowding effect induced by explicitly framing incentives as PES. Furthermore, we have added to the extant literature by applying a zero-one inflated beta regression that allows us to explicitly focus on the corner solution (e.g., zero investment in conservation activity) and thereby to further investigate 
the heterogeneity in the framing effects. The results have shown that framing a monetary incentive as PES significantly crowds in conservation behavior. However, this crowding-in effect is not observable across the full range of participants, who differ in the level of their preferences for conservation. The behavior of participants with very weak preferences for conservation, as indicated by zero investment, is not affected by the framing. Moreover, descriptive results from a hypothetical setting have shown that the framing effect is operative even in a hypothetical setting, albeit with the caveat that the deviation from self-regarding behavior is costless. This framing effect persists after the removal of the hypothetical incentive and when a non-hypothetical setting is considered. Regarding the identification of the motivational factors underlying the framing effect, we have investigated the framing effect conditional on the social experimenter demand effect captured in a post-experimental survey. Results have indicated that the overall crowding-in effect is driven by pro-social motives, such as social conformism or the desire for respect rather than by pro-nature motives.

In Chapter IV, we have explored the trade-off between conservation and equity outcome in the use of PES. Specifically, we have investigated the conservation and distributional outcome of two alternative PES schemes, which implicitly incorporate different fairness criteria. We have extended the existing literature by for the first time introducing both endowment and productivity heterogeneity in a public good experiment to study the conservation and distributional outcomes of alternative PES schemes that implicitly incorporate different fairness principles. We have tested two alternative PES schemes; in the equal PES scheme the conservation fund is equally distributed among the participants (fixed flat rate per conserved land unit), which is in accordance with an egalitarian fairness principle. Keeping the conservation fund constant, in the discriminatory PES scheme, the total payment is redistributed by offering higher payments per conserved land unit to small landholders and lower payments per conserved land unit to larger landholders. The latter scheme corresponds with the "max-min" fairness principle, where those resource users with the highest needs receive a higher payment. Results have indicated that with the introduction of PES the conservation behavior at group level significantly increases, indicating that environmental additionality in terms of conservation area can be achieved. While the conservation behavior of low-endowed participants significantly increases with the introduction of an equal PES scheme, the con- 
servation behavior of high-endowed subjects remains unaffected by the introduction of PES. Findings have thus suggested that an increase in conservation area at the group level that can be observed in response to the introduction of an equal PES scheme mainly stems from low-endowed participants. The analyses of the distributional implications have shown that the introduction of an equal PES scheme does not signficnatly enhance inequality among group members. Compared to the baseline (and the equal PES scheme). the discriminatory PES scheme realigns the income distribution in favor of low-endowed participants and reduces inequality among group members (as measured by the gini index). Furthermore, the introduction of a discriminatory PES scheme (compared to an equal PES scheme) does not necessarily need to be compromised by lower conservation area at the group level.

This thesis has illustrated empirically that the context in which a PES scheme is implemented affects the effectiveness of the intervention. In this context, the findings of all chapters have confirmed that the decisions of resource users to conserve are not merely driven by economic reasoning, but rather by social preferences associated with provision. Furthermore, the results have confirmed that by interacting with contextual factors the policy design significantly alters the PES outcome.

\subsection{Policy recommendations}

The results presented above allow us to provide a number of recommendations relevant for policy makers attempting to design PES, particularly in the context of wildlifefriendly strategies for oil-palm-dominated landscapes.

Our analyses have confirmed the high sensitivity of many bird species, particularly forest and edge-intolerant species, to anthropogenic disturbances, such as the transformation of natural habitats into monoculture oil palm plantations. To conserve those species it is crucial to protect natural habitats though land-sparing approaches. However, our results have shown that wildlife-friendly oil palm plantations that restore a certain degree of habitat complexity (mixed tree stands, ground layer vegetation) provide a valuable habitat for edge-tolerant, open-habitat and generalist species. It suggest that 
wildlife-friendly strategies in oil-palm-dominated landscapes while not replacing natural habitats should not rejected a priori by policy makers.

Furthermore, we have shown that the implementation of wildlife-friendly strategies comes at the cost of lower revenues, indicating that self-interested, profit-maximizing farmers do not have an incentive to extensify their oil palm cultivation. Assuming that policy makers or other stakeholders are interested in encouraging wildlife-friendly strategies, governmental and private institutions should place greater emphasis on the development and implementation of market-based policy instruments, such as certification schemes or PES. We have exhibited that the marginal shadow price of bird species varies conditional on the initial management intensity gradient. It suggests that a deviation from a "flat" PES scheme might be feasible to increase economic efficiency (under certain conditions discussed below). Flat payments are not differentiated according to the costs of providing environmental services. Payment schemes other than a flat scheme include a "compensation" scheme, whereby land users that can provide environmental services at the least cost are targeted and only compensated for their costs of provision (Narloch et al., 2011; Pascual et al., 2010).

The results of both experimental studies have confirmed that the introduction of PES induces environmental additionality in terms of conservation area, albeit not markedly. Considering that almost half of the group endowment has already been assigned to conservation in the baseline, which would be compensated for in the PES scheme, the costs per additional hectare conserved are considerably higher for the policy maker than the average payments received by resource users. It implies that although the PES intervention might be recommendable under the consideration of environmental effectiveness, this might change when considering the efficiency of the intervention.

Since the levels of payment do not fully compensate for the forgone benefits associated with the conservation, results have indicated that intangible factors associated with the PES policy design or the desired activity affect conservation behavior. It implies that policy makers should understand PES not only as an instrument that alter economic reasoning, but also as an institutional mechanism that interacts with moral and social incentives in complex ways. In this context, our results have confirmed that incentives 
are part of how a situation is represented. Policy makers should consider these contextual manipulations associated with the policy intervention. Specifically, the results have shown that conservation behavior is significantly crowded in when framing a policy intervention as an environmental intervention (such as PES), which signals the environmental dimension of the decisions. However, this framing effect is not observed for participants with very weak or no preferences for conservation. Results presented in Chapter II indicate that farmers of relatively intensively managed oil palm plantations are the lowest-cost suppliers of bird diversity (abundance). Assuming that this level of management intensity also reflects their very weak preferences for conservation findings have suggested that although these farmers should be targeted from a neoclassical perspective, the consideration of crowding effects might reverse this finding. This highlights the importance for policymakers to carefully assess the heterogeneity in the existing preferences for the desired conservation activity and potential interaction effects of incentives with preferences.

The further specification of the motivational factors that underlie the observed framing effect, has confirmed a common phenomenon in practice, where participation in an environmental-related program is driven by pro-social motives induced by stakeholders, such as the desire for social conformism rather than by an activation of or change in environmental-related preferences.

Moreover, the results from the hypothetical setting have suggested that environmental campaigns prior to the PES implementation might play an important role in encouraging pro-environmental behavior.

Considering heterogeneity in land size and productivity, we have found that environmental additionality at the group level that can be observed in response to the introduction of an equal PES scheme mainly stems from low-endowed participants. This suggests that under the conditions explored here, conservation policy interventions are not necessarily more effective in terms of environmental additionality if targeting large landowners. Furthemore, results have indicated that the distribution of the incomes (direct income from activities) among landholders is not affected by the introduction of an equal PES scheme. 
Practicioners might explicitly consider redistribution as strategiy objective in the implementation of PES. Results have confirmed that the introduction of a discriminatory PES scheme, indeed, raligns income in favor of the poor and decrease inequality among group members (compared to the baseline decision and the equal PES scheme). At the same time, it does not necessarily need to be compromised by environmental additionality at community level. It implies that discriminatory PES scheme, might function as a multipurpose instrument that promote conservation and enhance equity. These hold only under certain conditions discussed further below.

\subsection{Limitations and further research}

This study contributes to a better understanding of the relationships among PES outcomes, PES policy design and contextual factors. Nevertheless, the results have to be critically assessed with respect to both theoretical assumptions made and methods applied in this study.

We have estimated the environmental additionality conditional on an increase in the number of mixed tree stands using the richness (abundance) of bird species. The results have shown that given a fixed conservation budget, farmers operating highly intensified oil palm plantations have a relatively stronger incentive to expand the number of trees within their oil palm plantations relative to farmers operating extensively managed oil palm plantations. However, the absolute number of bird species (abundance) would still be lower in intensified plantations with increasing number of trees compared to extensively cultivated plantations. In our study, the observable measure of bird species richness (abundance) has been used a proxy for a range of ecosystem services provided by birds, such as pest control, seed dispersal and pollination. However, the marginal benefits in ecosystem services due to marginal changes in bird species richness (abundance) might be conditional on the initial number of bird species. Further studies are needed to address whether non-linearity of the relationship between bird diversity (abundance) and ecosystem service provision would fundamentally oppose our findings.

Furthermore, our analysis is limited to the analysis of quantitative changes in tree numbers. Other studies suggest that qualitative factors, such as tree age, tree diversity or the presence of specific functional groups of trees, are crucial to the design of wildlife- 
friendly strategies (Clough et al., 2011, Erskesine et al., 2005, Kanowski et al., 2003). This represents an avenue for further research.

The results, depicted in Chapter II have suggested that farmers' decisions to retain/plant trees on their oil palm plantations is not solely determined by short-term yield maximization considerations. However, in this part of the dissertation we have not incorporated other economic objectives, such as the long-term resilience of the ecosystem and further intangible values derived from ecosystems, such as cultural services (e.g., spiritual enrichment, recreation and aesthetic experiences). Therefore, the application of "stated preferences" methods, such as the Contingent Valuation Method (CVM), could be a useful extension to specify the "willingness to accept compensation."

The analyses of the experimental data have shown that the framing of a monetary incentive scheme, as PES crowds in conservation behavior. However, the extent to which frame shifting induce changes in environmental behavior in the long run remains unclear since participants made decisions in only three sequential sessions, each with a different setting. Although we observed crowding-in effects in the first decisions, this effect may disappear or even be reversed in subsequent decisions through durable learning effects (see Cardenas et al. 2000). Further research that investigate the conditions under which short term crowding effects due to frame shifting induce changes in the values in the long run is needed.

The consideration of social experimenter demand effects in the analysis of the framing effect, presented in Chapter III, is a first step in identifying the psychological mechanisms that underlie framing effects. However, using aggregated survey measures, we have provided suggestive comments rather than figuring out what general principles (theory of framing) can be abstracted from framing effects (see Ellingsen et al., 2012)

Our results have suggested that environmental campaigns prior to the PES implementation might be effective in enhancing conservation behavior. This issue must be further examined, for example, in framed field experiments in which informational material on the environmental context is explicitly given to the participants prior to the introduction of PES. 
The experimental setting is based on a number of assumptions that determine the predicted outcome of the experiment, as shown in the conceptual framework in Chapter IV. For example, in the experiment low-endowed participants face higher opportunity costs of conservation than high-endowed participants, assuming that poor households face survival constraints when making conservation efforts that endure present sacrifices. In contrast, other scholars suppose that poor households tend to own marginal land (i.e. lower soil fertility), which results in lower opportunity costs to leave the land in more natural ecosystems. Following the second argumentation, the predicted outcome of the experiment would have changed. Likewise the number of available land units, the difference in the land units between low and high-endowed participants and the group size has implications on the predicted outcomes.

Although we implicitly consider interactions between the fairness criteria of the PES scheme and social preferences, we do not explicitly incorporate this aspect in the conceptual framework. Hence the development of an conceptual framework which integrates social-welfare preferences with implicit fairness criteria of incentives might be useful in providing progress in conceptualizing observations in experiments (see Charness and Rabin, 2002).

In Chapter IV, we have drawn conclusions only with respect to the environmental additionality, neglecting the efficiency of the alternative PES schemes. The discriminatory PES scheme does not come at the costs of environmental additionality as opposed to the equal PES scheme. Considering the implementation costs of the alternative PES scheme may reverse the findings. The implementation costs do not only comprise the direct costs of compensation, but also all types of transaction costs. Since these costs largely depend on the amount of quality of information that need to be gathered, it can be assumed that a discriminatory PES would imply higher transaction costs than a flat PES scheme. Further research on the efficiency of different PES scheme designs should therefore put particular emphasis on transaction costs.

When assessing the policy implications it is crucial to consider the external validity of the experiment. Evidence has shown that the necessary abstractions in experimental 
settings and even in field experiments increase internal validity at the costs of the external validity of experimental results. The applied experimental design does not cover a wide range of institutional factors that are likely to affect the PES adoption of farmers and especially of the poor in reality. In this context further research, that focuses among other factors on transaction costs, insecure land tenure, investment costs, alternative cultivation systems and non-material dimensions of poverty (e.g., status, dignity, and political empowerment) is highly needed to complement the presented experimental findings. 


\section{Declaration on the proportion of own work performed}

I, hereby, declare the proportion of own work performed in the scientific paper, which are included in this Ph. D. dissertation

In the first paper titled "How much is a bird? Trade-off between bird diversity and abundance, yields and revenue in smallholder oil palm plantations" in which I share the first authorship with Miriam Teuscher and which is co-authored by Prof. Dr. Meike Wollni, Prof. Dr. Ulrich Brose, Dr. Yeni Mulyani and Prof. Dr. Yann Clough, the following parts have been performed by me: conceptualization and design of the study together with Miriam Teuscher and in close cooperation with Prof. Dr. Meike Wollni, Prof. Dr. Ulrich Brose and Prof. Dr. Yann Clough, collection of household survey data in together with Miriam Teuscher, analysis and interpretation of the research results together with Miriam Teuscher and in cooperation with Prof. Dr. Meike Wollni, Prof. Dr. Ulrich Brose and Prof. Dr. Yann Clough, preparation of a first draft together with Miriam Teuscher, revision in close cooperation with Miriam Teuscher, Prof. Dr. Meike Wollni, Prof. Dr. Ulrich Brose, Dr. Yeni Mulyani and Prof. Dr. Yann Clough.

In the second paper titled "Frame-shifting and motivation crowding: A public good experiment of Payments for Environmental services", which is co-authored by Prof. Dr. Marcela Ibañez, Prof. Dr. Meike Wollni and Alexander März, the following parts have been performed by me: conceptualization and design of the experiment and household survey in close cooperation with Prof. Dr. Marcela Ibañez and Prof. Dr. Meike Wollni, implementation of the experiment and household survey, analyses in close cooperation with Alexander März, interpretation of the research results in cooperation with Prof. Dr. Marcela Ibañez, Prof. Dr. Meike Wollni and Alexander März, preparation of a first draft in cooperation with Alexander März, revision in cooperation with Prof. Dr. Marcela Ibañez and Prof. Dr. Meike Wollni. 
In the third paper titled “Conservation vs. Equity: Can Payments for Environmental Services achieve both?", which is co-authored by Prof. Dr. Meike Wollni and Prof. Dr. Marcela Ibañez, the following parts have been performed by me: conceptualization and design of the experiment in close cooperation with Prof. Dr. Meike Wollni and Prof. Dr. Marcela Ibañez, implementation of the experiment, analysis in cooperation with Prof. Dr. Marcela Ibañez, interpretation of the research results in close cooperation with Prof. Dr. Meike Wollni and Prof. Dr. Marcela Ibañez, preparation of first draft, revision in close cooperation with Prof. Dr. Meike Wollni and Prof. Dr. Marcela Ibañez. 


\section{Declarations}

1. I, hereby, declare that this Ph.D. dissertation has not been presented to any other examining body either in its present or a similar form.

Furthermore, I also affirm that I have not applied for a Ph.D. at any other higher schoolof education.

Göttingen,

(Signature)

(Name in block capitals)

2. I, hereby, solemnly declare that this dissertation was undertaken independently and without any unauthorized aid.

Göttingen,

(Signature)

(Name in block capitals) 


\section{Bibliography}

Abrahamczyk, S., Kessler, M., Dwi Putra, D., Waltert, M., \& Tscharntke, T. (2008). The value of differently managed cacao plantations for forest bird conservation in Sulawesi, Indonesia. Bird Conservation International, 18, 349-362.

Alix-Garcia, J., De Janvry, A., \& Sadoulet, E. (2008). The role of deforestation risk and calibrated compensation in designing payments for environmental services. Environment and Development Economics, 13, 375-394.

Anand, M.O., Krishnaswamy, J., \& Das, A. (2008). Proximity to forests drives bird conservation value of coffee plantations: implications for certification. Ecological Applications, 18, 1754-63.

Aratrakorn, S., Thunhikorn, S., \& Donald, P.F. (2006). Changes in bird communities following conversion of lowland forest to oil palm and rubber plantations in southern Thailand. Bird Conservation International, 16, 71-82.

Atkinson, P.W., Fuller, R.J., Vickery, J. A., Conway, G.J., Tallowin, J.R.B., Smith, R.E.N., Haysom, K. A., Ings, T.C., Asteraki, E.J., \& Brown, V.K. (2005). Influence of agricultural management, sward structure and food resources on grassland field use by birds in lowland England. Journal of Applied Ecology, 42, 932-942.

Azhar, B., Lindenmayer, D.B., Wood, J., Fischer, J., Manning, A., McElhinny, C., \& Zakaria, M. (2013). The influence of agricultural system, stand structural complexity and landscape context on foraging birds in oil palm landscapes. Ibis, 155, 297-312.

Azhar, B., Lindenmayer, D.B., Wood, J., Fischer, J., Manning, A., McElhinny, C., \& Zakaria, M. (2011). The conservation value of oil palm plantation estates, smallholdings and logged peat swamp forest for birds. Forest Ecology and Management, 262, 2306-2315.

Baland, J.M., \& Platteau, J.P. (1999). The ambiguous impact of inequality on local resource management. World Development, 27, 773-778.

Barnes, A.D., Jochum, M., Mumme, S., Farikhah Haneda, N., Farajallah, A., Widarto, T.H. \& Brose, U. (2014). Consequences of tropical land use for multitrophic biodiversity and ecosystem functioning, Nature Communication, 5, 1-7

Baudron, F., \& Giller, K.E. (2014). Agriculture and nature: Trouble and strife? Biological Conservation, 170, 232-245.

Belcher, B., \& Schreckenberg, K. (2007). Commercialization of Non-timer Forest Products: A Reality Check. Development Policy Review, 25, 355-377.

Benton, T.G., Vickery, J.A., \& Wilson, J.D. (2003). Farmland biodiversity: is habitat heterogeneity the key? Trends in Ecology and Evolution, 18, 182-187.

Beukema, H., Danielsen, F., Vincent, G., Hardiwinoto, S., \& van Andel, J. (2007). Plant and bird diversity in rubber agroforestry in the lowlands of Sumatra, Indonesia. Agroforestry Systems, 70, 217-242.

Bhagwat, S. A., \& Willis, K.J. (2008). Agroforestry as a solution to the oil-palm debate. Conservation Biology, 22, 1368-9. 
Bhagwat, S. A., Willis, K.J., Birks, H.J.B., \& Whittaker, R.J. (2008). Agroforestry: a refuge for tropical biodiversity? Trends in Ecology \& Evolution, 23, 261-267.

Bohnet, I., \& Baytelman, Y. (2007). Institutions and trust: Implications for preferences, beliefs and behavior. Rationality and Society, 19, 99-135.

Börner, J., Wunder, S., Wertz-Kanounnikoff, S., Rügnitz Tito, M., Pereira, L., \& Nascimento, N. (2010). Direct conservation payments in the Brazilian Amazon: Scope and equity implications. Ecological Economics, 69, 1272-1282.

Bowles, S. \& Polanía-Reyes, S. (2012). Economic incentives and social preferences: Substitutes or complements? Journal of Economic Literature, 50, 368-425.

Bowles, S. (2008). Policies designed for self-interested citizens may undermine "the moral sentiments": Evidence from economic experiments. Science, 320, 1605-1609.

Brown. K. \& Corbera, E. (2003). Exploring equity and sustainable development in the new carbon economy. Climate Policy, 3, S41-S56

Budidarsono, S. (2012). Socio-economic impact assessment of palm oil production. World Agrofor. Centre. - ICRAF. Technial Brief No.27

Cardenas, J.C., \& Carpenter, J. (2008). Behavioral development Economic: Lessons from field Labs in the Developing World. Journal of Development Studies, 44, 311-338

Cardenas, J.C., Stranlund, J., \& Willis, C. (2000). Local Environmental Control and Institutional Crowding-Out. World Development, 28, 1719-1733

Cardenas, J.C., Stranlund, J., \& Willis, C. (2002). Economic inequality and burden-sharing in the provision of local environmental quality. Ecological Economics, 40, 379-395

Cardinale, B.J., Duffy, J.E., Gonzalez, A., Hooper, D.U., Perrings, C., Venail, P., Narwani, A., Mace, G.M., Tilman, D., Wardle, D. a, Kinzig, A.P., Daily, G.C., Loreau, M., Grace, J.B., Larigauderie, A., Srivastava, D.S., \& Naeem, S. (2012). Biodiversity loss and its impact on humanity. Nature, 486, 59-67.

Carpenter, J., \& Myers, C.K. (2010). Why volunteer? Evidence on the role of altruism, image, and incentives. Journal of Public Economics, 94, 911-920.

Castillo, D., Bousquet, F., Janssen, M., Worrapimphong, K., \& Cardenas, J.C. (2011). Context matters to explain field experiments: results from Colombian and Thai fishing villages. Ecological Economics, 70, 1609-1620.

Chan, K. S., \& Mesterlman, S. (1999). Heterogeneity and the Voluntary provision of Public Goods, Experimental Economics, 2, 5-30

Charness, G., \& Rabin, M. (2002). Understanding Social preferences with Simple Tests. The Quartely Journal of Economics, 117, 817-869

Chazdon, R.L. (2008). Beyond deforestation: restoring forests and ecosystem services on degraded lands. Science, 320, 1458-60.

Cherry, T.L., Kroll, S., \& Shrogren, J.F. (2005). The impact of endowment heterogeneity and origin on public good contributions: evidence from the lab. Journal of Economic Behavior \&Organization, 57, 357-365

Child, M.F. (2009). The Thoreau ideal as unifying thread in the conservation movement. Conservation Biology, 23, 241-243. 
Clough, Y., Barkmann, J., Juhrbandt, J., Kessler, M., Wanger, T.C., Anshary, A., Buchori, D., Cicuzza, D., Darras, K., Putra, D.D., Erasmi, S., Pitopang, R., Schmidt, C., Schulze, C.H., Seidel, D., Steffan-Dewenter, I., Stenchly, K., Vidal, S., Weist, M., Wielgoss, A.C., \& Tscharntke, T. (2011). Combining high biodiversity with high yields in tropical agroforests. PNAS, 108, 8311-6.

Clough, Y., Dwi Putra, D., Pitopang, R., \& Tscharntke, T. (2009). Local and landscape factors determine functional bird diversity in Indonesian cacao agroforestry. Biological Conservation ,142, 1032-1041.

Clough, Y., Kruess, A., \& Tscharntke, T. (2006). Local and landscape factors in differently managed arable fields affect the insect herbivore community of a non-crop plant species. Journal of Applied Ecology, 44, 22-28.

Colchester, M., Jiwan, N., Andiko, Sirait, M., Firdaus, A.Y., Surambo, A., \& Pane, H. (2006). Promised land: Palm oil and land acquisition in Indonesia: Implications for local communities and indigenous peoples. Bogor, Indonesia: Forest Peoples Programme, Sawit Watch, ICRAF.

Cole, R.J., Holl, K.D., \& Zahawi, R. A. (2010). Seed rain under tree islands planted to restore degraded lands in a tropical agricultural landscape. Ecological Applications, 20, 1255-69.

Cookson, R. (2000). Framing effects in public goods experiments, Experimental Economics, 3, 55-79.

Corbera, E., \& Pascual, U. (2012). Ecosystem services: head social goals. Science, 335, 655-656

Corbera, E., Brown, K., \& Adger, W.N. (2007). The equity and legitimacy of markets for ecosystem services. Development and Change, 17, 365-380

Corley, R.H.V. (2009). How much palm oil do we need? Environmental Science \& Policy, 12, 134139.

Corley, R.H.V., \& Tinker, P.B. (2003). The oil palm, 4th edition. ed. Wiley-Blackwell.

D'Abba, G. (2011). Motivation crowding in environmental protection: Evidence from an artefactual field experiment. Ecological Economics, 70, 2083-2097.

Danielsen, F., Beukema, H., Burgess, N.D., Parish, F., Brühl, C.A. Donald, P.F. Murdiyarso, D., Phalan, B., Reijnders, L., Struebig, M., \& Fitzherbert, E.B. (2009). Biofuel plantations on forested lands: Double jeopardy for biodiversity and climate. Conservation Biology, 23, 348-358

Davis, J.L., Green, J.D., \& Reed, A. (2009). Interdependence with the environment: Commitment, interconnectedness, and environmental behavior. Journal of Environmental Psychology, 29, 173-180.

Dercon, S. (2009). Rural poverty: Old challenges in new contexts. The World Bank Research, 24, $1-28$

DIE (2012). Sustainability Standards and Certification-Towards Sustainable Palm Oil in Indonesia. Briefing Paper 9, Bonn, Germany, DIE (German Development Institue)

Donald, P.F. (2004). Biodiversity Impacts of Some Agricultural Commodity Production Systems. Conservation Biology, 18, 17-37.

Dufwenberg, M., Gächter, S., \& Hennig-Schmidt, H. (2011). The framing of games and the psychology of play. Games and Economic Behavior, 73, 459-478.

Edwards, D.P., Hodgson, J.A., Hamer, K.C., Mitchell, S.L., Ahmad, S.H., Cornell, S.J. \& Wilcove, D.S. (2010). Wildlife-friendly oil palm plantations fail to protect biodiversity effectively. Conservation Letters, 3, 236-242 
Edwards, F.A., Edwards, D.P., Hamer, K.C., \& Davies, R.G. (2013). Impacts of logging and conversion of rainforest to oil palm on the functional diversity of birds in Sundaland. Ibis, $155,313-326$.

Edwards, F.A., Edwards, D.P., Larsen, T.H., Hsu, W.W., Benedick, S., Chung, A.,Vun Khen, C., Wilcove, D.S., Hamer, K.C. (2014). Does logging and forest conversion to oil palm agriculture alter functional diversity in a biodiversity hotspot? Animal Conservation, 17, 163-173.

Ekadinata, A., \& Vincent, G. (2011). Rubber Agroforests in a Changing Landscape: Analysis of Land Use/Cover Trajectories in Bungo District, Indonesia. Forests, Trees and Livelihoods, 20, 3-14.

Ellingsen, T., \& Johannesson, M. (2008). Pride and prejudice: The human side of incentive theory. American Economic Review, 98, 990-1008.

Ellingsen,T., Johannesson, M., Mollerstrom, J., \& Munkhammar, S. (2012). Social framing effects: Preferences or belief? Game and Economic Behavior, 76, 117-130.

Elmhirst, R. (1999). Space, identity politics and resource control in Indonesia's transmigration programme. Political Geography, 18, 813-835

Engel, S., \& Palmer, C. (2011). Complexities of Decentralization in a Globalizing World. Environmental Resource Economics, 50, 157-174

Engel, S., Pagiola, S., \& Wunder, S. (2008). Designing payments for environmental services in theory and practice: An overview of the issues. Ecological Economic, 65, 663-674

Erskine, P.D., Lamb, D., \& Bristow, M. (2005). Reforestation in the Tropics and Subtropics of Australia, 05/087 ed, Rural Industries Research and Development Corporation. Canberra.

Fahrmeir, L., Kneib, T., \& Land, S. (2009). Regression: Modelle, Methoden und Anwendungen. Berlin, Germany, Springer Verlag.

FAO (2014a). FAOSTAT. Rome, Italy, FAO (Food and Agriculture Organization of the United Nations) http://faostat.fao.org/site/567/DesktopDefault.aspx?PageID=567\#ancor

FAO (2014b). The State of Food Insecurity in the World. Rome, Italy, FAO (Food and Agriculture Organization of the United Nations)

FAO (2015). The food systems of the future need to be smarter, more efficient. Rome, Italy, FAO (Food and Agriculture Organization of the United Nations)

http://www.fao.org/news/story/en/item/275009/icode/

Fayle, T.M., Turner, E.C., Snaddon, J.L., Chey, V.K., Chung, A.Y.C., Eggleton, P., \& Foster, W.A. (2010). Oil palm expansion into rain forest greatly reduces ant biodiversity in canopy, epiphytes and leaf-litter. Basic and Applied Ecology, 11, 337-345.

Fearnside, P.M. (1997). Transmigration in Indonesia: Lessons from Its Environmental and Social Impacts. Environmental Management, 21, 553-570

Feintrenie, L., \& Levang, P. (2009). Sumatra's Rubber Agroforestrys: Advent, Rise and Fall of s Sustainable Cropping System, Small-scale Forestry, 8, 323-335.

Feintrenie, L., Chong, W.K. \& Levang, P. (2010). Why do Farmers Prefer Oil Palm? Lessons Learnt from Bungo District, Indonesia, Small-scale Forestry, 9, 379-396

Ferrari, S.L., \& Cribari-Neto, F. (2004). Beta regression for modelling rates and proportions, Journal of Applied Statistics, 31, 799-815.

Field, C.B., Campbell, J.E., \& Lobell, D.B. (2008). Biomass energy: the scale of the potential resource. Trends in Ecology \& Evolution, 23, 65-72. 
Fischer, J., Stott, J., \& Law, B.S. (2010). The disproportionate value of scattered trees. Biological Conservation, 143, 1564-1567.

Fisher, J. (2012). No pay, no care? A case study exploring motivations for participation in payments for ecosystem services in Uganda. Oryx, 46(1), 45-54.

Fitzherbert, E. B., Struebig, M.J., Morel, A., Danielsen, F., Brühl, C.A., Donald, P.F. \& Phalan, B. (2008). How will oil palm expansion affect biodiversity?. Trends in Ecology and Evolution, $23,539-545$

Foster, W. a, Snaddon, J.L., Turner, E.C., Fayle, T.M., Cockerill, T.D., Ellwood, M.D.F., Broad, G.R., Chung, A.Y.C., Eggleton, P., Khen, C.V., \& Yusah, K.M. (2011). Establishing the evidence base for maintaining biodiversity and ecosystem function in the oil palm landscapes of South East Asia. Philosophical transactions of the Royal Society of London. Series B, Biological sciences, 366, 3277-91.

Frey, B.S. (1994). How intrinsic motivation crowded out or in. Rationality and Society, 6, 334352.

Frey, B.S. (1997). A constitution for knaves crowds out civic virtues. The Economic Journal, 107, 1043-1053.

Frey, B.S., \& Jegen, R. (2001). Motivation crowding theory. Journal of Economic Surveys, 15, 589611.

Frey, B.S., \& Oberholzer-Gee, F. (1997). The cost of price incentives: An empirical analysis of motivation crowding-out. The American Economic Review, 87, 746-755.

Frey, B.S., \& Stutzer, A. (2006). Environmental morale and motivation (CREMA, No. 2006-17). Basel, Switzerland: Center for Research in Economics, Management and the Arts.

Gabriel, D., Sait, S.M., Kunin W.E., \& Benton, T.G. (2013). Food production vs. biodiversity:comapring organic and conventional agriculture, Applied Ecology, 50, 355364.

García-Amado, L.R., Pérez, M. R., \& García, S.B. (2013). Motivation for conservation: Assessing integrated conservation and development projects and payments for environmental services in La Sepultura Biosphere Reserve, Chiapas, Mexico. Ecological Economics, 89, $92-$ 100.

Gilbert, N. (2012). Palm-oil boom raises conservation concerns. Nature, 487, 14-15.

Godfray, C., Beddinton, J., Crute, I., Haddad, l., Lawrence, D., Muir, J., Pretty, J., Robinson, S., Thomas, S.M., Toulmin, C. (2010). Food security: the challenge of feeding 9 billion people. Science, 327, 812-818

Gómez-Baggethun, E., De Groot, R., Lomas, P.L., \& Montes, C. (2010). The history of ecosystem services in economic theory and practice: From early notions to markets and payment schemes. Ecological Economics, 69, 1209-1218.

Gordon, C., Manson, R., Sundberg, J., \& Cruz-Angón, A. (2007). Biodiversity, profitability, and vegetation structure in a Mexican coffee agroecosystem. Agriculture, Ecosystems \& Environment, 118, 256-266.

Gouyon, A. (2003). Eco-certification as an incentive to conserve biodiversity in rubber smallholder agroforestry systems: A preliminary study, ICRAF Southeast Asia Working Paper No 2003_1 Bogor, Indonesia. ICRAF (World Agroforestry Centre).

Gouyon, A., Foresta, H., \& Levang, P. (1993). Does "jungle rubber" deserve its name? An analysis of rubber agroforestry systems in southeast Sumatra. Agroforestry Systems, 22, 181-206.

Green, R.E., Cornell, S.J., Scharlemann, J.P.W., \& Balmford, A. (2005). Farming and the fate of wild nature. Science, 307, 550-5. 
Grieg-Gran, M., Porras, I., \& Wunder, S. (2005). How Can Market Mechanisms for Forest Environmental Services Help the Poor? Preliminary Lessons from Latin America. World Development, 33, 1511-1527

Gurven, M., \& Winking, J. (2008). Collective action in action: prosocial behavior in and out of the laboratory. American Anthropologist, 110, 179-190.

Hastie, T.J., \& Tibshirani, R.J. (1999). Generalized additive models (Chapman \& Hall/CRC Monographs on Statistics \& Applied Probability 43). Boca Raton, FL: CRC Press. (Original work published 1990)

Hauser-Schäublin, B., Steinebach, S. (2014). Harapan: A “No Man's Land" Turned into a Contested Agro-Industrial Zone. EFForTS Discussion Paper Series No. 4. Göttingen, Germany.

Hulme, M.F., Vickery, J.A., Green, R.E., Phalan, B., Chamberlain, D.E., Pomeroy, D.E., Nalwanga, D., Mushabe, D., Katebaka, R, Bolwig, S., \& Atkinson, P.W. (2013). Conserving the Birds of Uganda's Banana-Coffe Arc: Land Sparing and Land Sharing compared. PLOSOne, 8.

ICRAF (2014). Rewarding upland poor for environmental services, Kenya, Nairobi, ICRAF (World Agroforestry Centre). http://worldagroforestrycentre.net/regions/southeast_asia/Indonesia/projects/profile/ RUPES\%20I

IFAD (2010). Rural Poverty Report 2011. Rome, Italy, IFAD (International Fund for Agricultural Development)

Immerzeel, D.J., Verweij, P. A., van der Hilst, F., Faaij, A.P.C. (2014). Biodiversity impacts of bioenergy crop production: a state-of-the-art review. GCB Bioenergy, 6, 183-209.

IUCN (2014). Red List of threatened species, IUCN (International Union for Conservation of Nature) www.iucnredlist.org

Jack, B.K., Kousky, C., \& Sims, K.R.E., (2008). Designing payment for ecosystem services: lessons from previous experience with incentive-based mechanisms. PNAS, 105, 9465-9470

Janssen, M.A., Bousquet, F., Cardena J.C., Castillo, D. \& Worrapimphong, K. (2012). Field experiments of irrigation dilemmas. Agricultural Systems, 109, 65-75

Janssen, M.A., Bousquet, F., Cardenas, J.C., Castillo, D. \& Worrapimphong, K. (2013). Breaking the elected rules in a field experiment on forestry resources. Ecological Economics, 90, 132139

Jindal, R., Kerr, J.M., Ferraro, P.J., \& Swallow, B.M. (2013). Social dimensions of procurement auctions for environmental contracts: evaluating tradeoffs cost-effectiveness and participation by the poor in rural Tanzania. Land Use Policy, 31, 71-80

Johnson, N.L., Kotz, S., \& Balakrishnan, N. (1995). Continuous univariate distributions (Vols. 1-2, 2nd ed.). New York, NY: John Wiley \&Sons, Inc.

Kanowski, J., Catterall, C.., Wardell-Johnson, G.., Proctor, H., \& Reis, T. (2003). Development of forest structure on cleared rainforest land in eastern Australia under different styles of reforestation. Forest Ecology and Management, 183, 265-280.

Karp, D.S., Mendenhall, C.D., Sandí, R.F., Chaumont, N., Ehrlich, P.R., Hadly, E. A., \& Daily, G.C. (2013). Forest bolsters bird abundance, pest control and coffee yield. Ecology letters, 16, 1339-47.

Kerr, J., Vardhan, M., \& Jindal, R. (2012). Prosocial behavior and incentives: Evidence from field experiments in rural Mexico and Tanzania. Ecological Economics, 73, 220-227

Kieschnick, R., \& McCullough, B.D. (2003). Regression analysis of variates observed on $(0,1)$ : Percentages, proportions and fractions. Statistical Modelling, 3, 193-213. 
Klaver, R. (2013). REDD+ in Indonesia-Is Indonesia Ready? In, UN-REDD Programme Newletter, 35 http://www.unredd.org/Newsletter35/REDD_in_Indonesia/tabid/105799/Default.aspx

Kleijn, D., Baquero, R.A., Clough, Y., Diaz, M., De Esteban, J., Fernandez, F., Gabriel, D., Herzog, F., Holzschuh, A., Jöhl, R., Knop, E., Marshall, E.J.P., Kruess, A., Tscharntke, T., Verhulst, J., West, T.M. \& Yela, J.L. (2006). Mixed biodiversity benefits of agri-environment schemes in five European countries. Ecology Letters, 9, 243-254.

Klein, N., Kneib, T., \& Lang, S. (2013). Bayesian structured additive distributional sion ,Working Papers in Economics and Statistics 2013-2, University of Innsbruck.Innsbruck, Austria.

Koh, L.P. \& Wilcove, D.S. (2008). Is oil palm agriculture really destroying tropical biodiversity? Conservation Letters, 1, 60-64

Koh, L.P., \& Ghazoul, J. (2008). Biofuels, biodiversity, and people: Understanding the conflicts and finding opportunities. Biological Conservation, 141, 2450-2460.

Koh, L.P., \& Ghazoul, J. (2010). Spatially explicit scenario analysis for reconciling agricultural expansion, forest protection, and carbon conservation in Indonesia. PNAS, 107, 11140-4.

Koh, L.P., \& Wilcove, D.S. (2007). Cashing in palm oil for conservation. Nature, 448, 993-4.

Koh, L.P., \& Wilcove, D.S. (2008). Is oil palm agriculture really destroying tropical biodiversity? Conservation Letters, 1, 60-64.

Koh, L.P., Levang, P., \& Ghazoul, J. (2009). Designer landscapes for sustainable biofuels. Trends in ecology \& evolution, 24, 431-8.

Koh, L.P., Miettinen, J., Liew, S.C., \& Ghazoul, J. (2011). Remotely sensed evidence of tropical peatland conversion to oil palm. PNAS, 108, 5127-5132.

Koh, L.P.L. (2008). Can oil palm plantations be made more hospitable for forest butterflies and birds? Journal of Applied Ecology, 45, 1002-1009.

Konow, J. (2003). Which is the fairest one of all? A positive analysis of justice theories. Journal of Economic Literature, 41, 1186-1237

Kosoy, N., \& Corbera, E. (2010). Payments for ecosystem services as commodity fetishism. Ecological Economics, 69, 1228-1236.

Kosoy, N., Martinez-Tuna, M., Muradian, R., \& Martinez-Alier, J. (2007). Payments for environmental services in watershed: Insights from a comparative study of three cases in Central America. Ecological Economic, 61, 446-455

Kragt, M.E., \& Robertson, M.J. (2014). Quantifying ecosystem services trade-offs from agricultural practices. Ecological Economics, 102, 147-157.

Landell-Mills, N. \& Porras, I. (2002). Silver bullet or foods gold? A global review of markets for forest environmental services and their impacts on the poor. Instruments for Sustainable Private Sector Forestry Series. International Institute for Environment and Development, London

Landell-Mills, N. (2002). Developing markets for forest environmental services: an opportunity for promoting equity for while securing efficiency. Philosophical Transactions of the Royal Society, 360, 1817-1825

Laumonier, Y., Uryu, Y., Stüwe, M., Budiman, A., Setiabudi, B., \& Hadian, O. (2010). Eco-floristic and deforestation threats in Sumatra: Identifying new conservation area network priorities for ecosystem-base land use planning. Biodiversity and Conservation, 19, 1153-1174 
Leaky, R.R.B., Tchoundjeu, Z., Schreckenberg, K., Shackleton, S.E., \& Shackleton, C.M. (2005). Agroforestry tree products (AFTPs): Targeting poverty reduction and enhanced livelihoods. International Journal of Agricultural Sustainability, 3, 1-23.

Lee, J.S.H., Ghazoul, J., Obidzinski, K., \& Koh, L.P. (2013). Oil palm smallholder yields and incomes constrained by harvesting practices and type of smallholder management in Indonesia. Agronomy for Sustainable Development, 34, 501-513.

MA (2005). Ecosystems and Human Well Being, Synthesis, A Report of the Millenium Ecosystem Assessment, USA, Washington D.C., MA (Millenium Ecosystem Assessment)

Maas, B., Clough, Y., \& Tscharntke, T. (2013). Bats and birds increase crop yield in tropical agroforestry landscapes. Ecology letters, 1480-1487.

MacKinnon, J., Phillipps, K., \& Andrew, P. (1993). A Field Guide to Birds of Borneo, Sumatra and Bali: The Greater Sunda Islands. Oxford University Press.

Manning, A.D., Fischer, J., \& Lindenmayer, D.B. (2006). Scattered trees are keystone structures Implications for conservation. Biological Conservation, 132, 311-321.

Mayr, A., Fenske, N., Hofner, B., Kneib, T., \& Schmid, M. (2010). GAMLSS for high-dimensional data: A flexible approach based on boosting, Technical Report Number 098, Ludwig Maximilians University Munich, Department of Statistics. Munich, Germany.

McCarthy, J.F., Gillespie, P., \& Zen, Z. (2012). Swimming Upstream: Local Indonesian Production Networks in "Globalized" Palm Oil Production. World Development, 40, 555-569.

McCauley, D.J. (2006). Selling out on nature. Nature, 443, 27-28.

Miccolis, A., Vasconcelos, S., Castellani, D., Carvalho, V., Kato, O., \& Silva, A. (2014). Oil palm and Agroforestry Systems: coupling yields with environmental services, an experiment in the Brazilian Amazon [WWW Document]. ICRAF Brazil. URL

http://de.slideshare.net/agroforestry/session-66-oil-palm-agroforestry-systemsbrazilian-amazon

Minang, P.A., Duguma, L.A., Bernard, F., Mertz, O, \& Van Noordwijk, M. (2014). Prospects for agroforestry in REDD+ landscapes in Africa. Current Opinion ienEnvironmnetal Sustainability, 6, 78-82

Mittelhammer, R.C. (1996). Mathematical statistics for economics and business. New York, NY: Springer Verlag.

Muradian, R., Arsel, M., Pellefrini, L., Adaman, F., Aguilar, B., Agarwal, B., Corbera, E., Ezzine de Blas, D., Farley, J., Froger, G., Garcia-Frapolli, E., Gomez-Baggethun, E., Gowdy, J., Kosoy, N., Le Coq, J.F., Leroy, P., May, P., Meral, P., Mibielli, P., Norgaard, R., Ozkaynak, B., Pascual, U., Pengue, W., Perez, M., Pesche, D., Pirard, R., Ramos-Martin, J., Rival, L., Saenz, F., Van Hecken, G., Vatn, A., Vira, B. \& Urama, K. (2013). Payments for ecosystem services and the fatal attraction of win-win solutions. Conservation letters, 6, 1-6

Muradian, R., Corbera, E., Pascual, U., Kosoy, N., \& May, P.H. (2010). Reconciling theory and practice: An alternative conceptual framework for understanding payments for environmental services. Ecological Economics, 69, 1202-1208.

Nájera, A., \& Simonetti, J. A. (2010). Can oil palm plantations become bird friendly? Agroforestry Systems,. 80, 203-209.

Narloch, U., Pascual, U. \& Drucker, A.G. (2012). Collective Action Dynamics under external Rewards: Experimental Insights from Andean Farming Communities. World Development, 40, 2096-2107 
Narloch, U., Pascual, U., \& Drucker, A.G. (2013). How to achieve fairness in payments for ecosystem services? Insights from agrobiodiversity conservation auctions. Land use Policy, 35, 107-118

Nelder, J.A., \& Wedderburn, R.W.M. (1972) . Generalized linear models. Journal of the Royal Statistical Society, 135, 370-384.

Obidzinski, K., Andriani, R., Komarudin, H., \& Andrianto, A. (2012). Environmental and Social Impacts of Oil Palm Plantations and their Implications for Biofuel Production In Indonesia. Ecology and Society, 17, 25

Ospina, R., \& Ferrari, S.L.P. (2010). Inflated beta distributions. Statistical Papers, 51, 111-126.

Ostrom, E. (2000). Collective action and evolution of social norms. Journal of Economic Perspectives, 14, 137-158.

Paddison, L. (2014). Palm oil: the secret in your shopping basket - have your say. The Guardian.

Pagiola, S., (2008). Payments for Environmental services in Costa Rica. Ecological Economics, 65, 712-724

Pagiola, S., Arcenas, A., \& Platais, G. (2005). Can Payments for environmental Services Help reduce Poverty? An Exploration of the Issue and the Evidence to Date from Latin America. World Development, 33, 237-253

Pagiola, S., Ramírez, E., Gobbi, J., de Haan, C., Ibrahim, M., Murgueitio, E., \& Ruíz, J.P. (2008). Paying for the environmental services of silvopastoral practices in Nicaragua. Ecological Economics, 64, 374-385

Pascual, U., Muradian, R., Rodriguez, L.C., \& Duraiappah, A. (2010). Exploring the links between equity and efficiency in payments for environmental services: A conceptual approach. Ecological Economics, 69, 1237-1244.

Peh, K.S.-H., Sodhi, N.S., de Jong, J., Sekercioglu, C.H., Yap, C. A.-M., \& Lim, S.L.-H. (2006). Conservation value of degraded habitats for forest birds in southern Peninsular Malaysia. Diversity and Distributions, 12, 572-581.

Perfecto, I., Vandermeer, J., Mas, A., \& Pinto, L.S. (2005). Biodiversity, yield, and shade coffee certification. Ecological Economics, 54, 435-446.

Petheram, L., \& Campbell, B.M. (2010). Listening to locals on payments for environmental services. Jorunal of Environmental Management, 91, 1139-1149

Phalan, B., Balmford, A., Green, R.E., \& Scharlemann, J.P.W. (2011a). Minimising the harm to biodiversity of producing more food globally. Food Policy, 36, S62-S71.

Phalan, B., Bertzky, M., Butchart, S. H. M., Donald, P. F., Scharlemann, J., P. W. Stattersfield, A. J., \& Bamfold, A. (2013). Crop expansion and Conservation Priorities in Tropical Countries, PLOSOne, 8, 1-13

Phalan, B., Fitzherbert, E.B., Rafflegeau, S., Struebig, M.J., \& Verwilghen, A. (2009). Conservation in oil-palm landscapes. Conservation Biology, 23, 244-5.

Phalan, B., Onial, M., Balmford, A., \& Green, R.E. (2011b). Reconciling food production and biodiversity conservation: land sharing and land sparing compared. Science, 333, 128991.

Pramova, E., Locatelli, B., Mench, A., Marbyanto, E., Kartika, K. \& Prihatmaja, H. (2013). Integrating adaptation into REDD+: Potential impacts and social return on investment in Setulang, Malinau District, Indonesia (CIFOR Working Paper No. 112). Bogor, Indonesia: Center for International Forestry Research. 
Prediger, S., Vollan, B., \& Frölich, M. (2011). The impact of culture and ecology on cooperation in a common-pool resource experiment. Ecological Economics, 70, 1599-1608.

PWC (2012). Palm Oil Plantation. Industry landscape, regulatory and financial overview. http://www.pwc.com/id/en/publications/assets/palm-oil-plantation-2012.pdf

R Core Team (2014). R: A language and environment for statistical computing. R Foundation for Statistical Computing, Vienna, Austria. URL http://www.R-project.org/.

Raudsepp-Hearne, C., Peterson, G.D., Tengö, M., Bennett, E.M., Holland, T., Benessaiah, K., MacDonald, G.K., \& Pfeifer, L. (2010). Untangling the Environmentalist's Paradox: Why Is Human Well-being Increasing as Ecosystem Services Degrade? Bioscience, 60, 576-589.

Reuben, E., \& Riedl, A. (2013). Enforcement of contribution norms in public good games with heterogenous populations. Games and Economic Behavior, 77, 122-137

Rianto, B., Mochtar, H., \& Sasmito, A. (2012). Palm Oil Plantation. Industry landscape, regulatory and financial overview. Jakarta.

Rigby, R.A., \& Stasinopoulos, D.M. (2005). Generalized additive models for location, scale and shape. Applied Statistics, 54, 507-554.

Rist, L., Feintrenie, L., \& Levang, P. (2010). The livelihood impacts of oil palm: smallholders in Indonesia. Biodiverversity Conservation,19, 1009-1024.

Rode, J., Gómez-Baggethun, E. \& Krause, T. (2014). Motivation crowding by economic incentives in conservation policy: A review of the empirical evidence. Ecological Economics. Advance online publication.

Rodriguez-Sickert, C., Guzmán, R.A. \& Cardenas, J.C. (2008). Institutions influence preferences: Evidence from a common pool resource experiment. Journal of Economic Behavior \& Organization, 67, 215-227

Rotenberg, J., \& Stouffer, P. (2007). Ecological role of a tree (Gmelina arborea) plantation in Guatemala: an assessment of an alternative land use for tropical avian conservation. The Auk, 124, 316-330.

RSPO (2014a). How RSPO certification works. Kuala Lumpur, Malaysia, RSPO (Roundtable on Sustainable Palm Oil), http://www.rspo.org/certification/how-rspo-certification-works.

RSPO (2014b). RSPO Trademark. Kuala Lumpur, Malaysia, RSPO (Roundtable on Sustainable Palm Oil). http://www.rspo.org/trademark.

Rustagi, D., Engel, S., \& Kosfeld, M. (2010). Conditional cooperation and costly monitoring explain success in forest commons management. Science, 330, 961-965.

Sala, O.E. (2000). Global Biodiversity Scenarios for the Year 2100. Science, 287, 1770-1774.

Schielzeth, H. (2010). Simple means to improve the interpretability of regression coefficients. Methods in Ecology and Evolution, 1, 103-113.

Schilizzi, S. (2011). Equity judgements and context dependence: Knowledge, efficiency and incentives. Working Paper 1106. School of Agricultural and Resource Economics, The University of Western Australia.

Schmid, M., Wickler, F., Maloney, K.O., Mitchell, R., Fenske, N., \& Mayr, A. (2013). Boosted beta regression. PLOS One, 8, e61623.

Sekercioğlu, C.H., Daily, G.C., \& Ehrlich, P.R. (2004). Ecosystem consequences of bird declines. PNAS, 101, 18042-7.

Sekercioğlu, C.H., Ehrlich, P.R., Daily, G.C., Aygen, D., Goehring, D., \& Sandi, R.F. (2002). Disappearance of insectivorous birds from tropical forest fragments. PNAS, 99, 263-7. 
Smedley, T. (2014). EU labelling changes force industry action on palm oil. The Guardian.

Sodhi, N.S., Koh, L.P., Brook, B.W., \& Ng, P.K.L., (2004). Southeast Asian biodiversity: an impending disaster. Trends in Ecology\& Evolution, 19, 654-60.

Sommerville, M., Jones, J.P. G., Rahajaharison, M., \& Mildner-Gulland, E.J. (2010). The role of fairness and benefit distribution in community-based Payment for Environmental Services interventions: A case study from Menabe, Madagascar. Ecological Economics, 69, 12621271

Steffan-Dewenter, I., Kessler, M., Barkmann, J., Bos, M.M., Buchori, D., Erasmi, S., Faust, H., Gerold, G., Glenk, K., Gradstein, S.R., Guhardja, E., Harteveld, M., Hertel, D., Höhn, P., Kappas, M., Köhler, S., Leuschner, C., Maertens, M., Marggraf, R., Migge-Kleian, S., Mogea, J., Pitopang, R., Schaefer, M., Schwarze, S., Sporn, S.G., Steingrebe, A., Tjitrosoedirdjo, S.S., Tjitrosoemito, S., Twele, A., Weber, R., Woltmann, L., Zeller, M., \& Tscharntke, T. (2007). Tradeoffs between income, biodiversity, and ecosystem functioning during tropical rainforest conversion and agroforestry intensification. PNAS, 104, 4973-8.

Steg,L., Bolderdijk, J.W., Keizer, K., \& Perlaviciute, G. (2014). An integrated framework for encouraging pro-environmental behaviour: The role of values, situational factors and goals. Journal of Environmental Psychology, 38, 104-115.

Stein, A., Gerstner, K.,\& Kreft, H. (2014). Environmental heterogeneity as a universal driver of species richness across taxa, biomes and spatial scales. Ecology letters, 866-880.

Tacconi, L. (2012). Redefining payments for environmental services. Ecological Economics, 73, 29-36

Tews, J., Brose, U., Grimm, V., Tielborger, K., Wichmann, M., Schwager, M., \& Jeltsch, F. (2004). Animal species diversity driven by habitat heterogeneity/diversity: the importance of keystone structures. Journal of Biogeography, 31, 79-92.

The Jakarta Post, (2009). Indonesia allocates 18 million hectares of land for palm oil. Jakarta Post. http://www.thejakartapost.com/news/2009/12/02/indonesia-allocates-18million-hectares-land-palm-oil.html

The World Bank, (2011). The World Bank Group Framework and IFC Strategy for Engagement in the Palm Oil Sector. USA, Washington D.C..

Tilman, D., Cassman, K.G., Matson, P. a, Naylor, R., \& Polasky, S. (2002). Agricultural sustainability and intensive production practices. Nature, 418, 671-7.

Travers, H., Clements, T., Keane, A., \& Mildner-Gulland, E.J. (2011). Incentives for cooperation: The effects of institutional controls on common pool resource extraction in Cambodia. Ecological Economics, 71, 151-161.

Tscharntke, T., Clough, Y., Wanger, T.C., Jackson, L., Motzke, I., Perfecto, I., Vandermeer, J., \& Whitbread, A. (2012a). Global food security, biodiversity conservation and the future of agricultural intensification. Biological Conservation, 151, 53-59.

Tscharntke, T., Tylianakis, J.M., Rand, T. a, Didham, R.K., Fahrig, L., Batáry, P., Bengtsson, J., Clough, Y., Crist, T.O., Dormann, C.F., Ewers, R.M., Fründ, J., Holt, R.D., Holzschuh, A., Klein, A.M., Kleijn, D., Kremen, C., Landis, D. a, Laurance, W., Lindenmayer, D., Scherber, C., Sodhi, N., Steffan-Dewenter, I., Thies, C., van der Putten, W.H., \& Westphal, C. (2012b). Landscape moderation of biodiversity patterns and processes - eight hypotheses. Biological Reviews, 87, 661-85.

Tversky, A., \& Kahneman, D. (1981). The framing of decisions and the psychology of choice. Science, 211, 453-458.

UNCTAD (2014). Infocomm commofity profile palm oil, UNCTAD (United Nations conference on Trade and Development), http://www.unctad.info/en/Infocomm/AACP-Products/Palm- 
oil/

UNEP (2007). Global Environment Outlook 4: Environment for Development, Nairobi, Kenya, UNEP (United Nations Environment Programme)

UNEP (2011). Oil palm plantations: threats and opportunities for tropical ecosystems, UNEP Global Environmental Alert Services (GEAS), Nairobi, Kenya: UNEP (United Nations Environment Programme)

Van Bael, S. A., Bichier, P., Ochoa, I., \& Greenberg, R. (2007). Bird diversity in cacao farms and forest fragments of western Panama. Biodiversity and Conservation, 16, 2245-2256.

Van Bael, S.A., Philpott, S.M., Greenberg, R., Bichier, P., Barber, N.A., Mooney, K.A., \& Gruner, D.S. (2008). Birds as predators in tropical agroforestry systems. Ecology, 89, 928-34.

Van Hecken, G., \& Bastiaensen, J. (2010). Payments for ecosystem services in Nicaragua: Do market-based approaches work? Development and Change, 41, 421-444.

Vatn, A. (2010). An institutional analysis of payments for environmental services. Ecological Economics, 69, 1245-1252.

Velez, M.A., Murphy, J.J., \& Stranlund, J.K. (2010). Centralized and decentralized management of local common pool resources in the developing world: Experimental evidence from fishing communities in Colombia. Economic Inquiry, 48, 254-265.

Villamor, G.B., Le, Q.B., Vlek, P.L.G., \& Van Noordwijk, M. (2011). Payments for agro-biodiversity: An analysis of participation in Jambi's conservation agreements for rubber agroforests, (Sumatra) Indonesia. Paper presented at the 13th Annual BIOECON Conference on Resource Economics, Biodiversity Conservation and Development, Geneva, Switzerland.

Vollan, B. (2008). Socio-ecological explanations for crowding-out effects from economic field experiments in southern Africa. Ecological Economics, 67, 560-573.

Wilcove, D.S., \& Koh, L.P. (2010). Addressing the threats to biodiversity from oil-palm agriculture. Biodiversity and Conservation, 19, 999-1007.

Wilcove, D.S., Giam, X., Edwards, D.P., Fisher, B., \& Koh, L.P. (2013). Navjot's nightmare revisited: logging, agriculture, and biodiversity in Southeast Asia. Trends in Ecology \&. Evolution, 28, 531-40.

World Bank (2010). World development report 2010: development and climate change. Washington DC, http://data.worldbank.org/indicator/SI.POV.GINI?order=wbapi_data_value_2011\%20wb api_data_value\&sort=asc

World Trade Organization. (2010). World trade report 2010: Trade in natural resources. Switzerland, Geneva

Wunder, S. (2014). Revisiting the concept of payments for environmental services. Ecological Economics. Advance online publication.

Zahawi, R. A.,\& Augspurger, C.K. (2006). Tropical forest restoration: tree islands as recruitment foci in degraded lands of Honduras. Ecological Applications, 16, 464-78.

Zbinden, S., \& Lee, D.R. (2005). Paying for Environmental Services: An Analysis Of Participation in Costa Rica's PSA Program. World Development, 33, 255-272

Zizzo, D.J. (2010). Experimenter demand effects in economic experiments. Experimental Economics, 13, 75-98. 


\section{Appendices}

\section{Appendix I: Recorded bird species}

Table A1: List of bird species recorded within a $25 \mathrm{~m}$ radius around the centre of oil palm plantations

\begin{tabular}{|c|c|c|c|c|}
\hline Species name & Family & Common name & ahabitat & bIUCN status \\
\hline Aegithina viridissima & Aegithinidae & Green Iora & gene & NT \\
\hline Aegithina tiphia & Aegithinidae & Common Iora & gene & $\mathrm{LC}$ \\
\hline Aethopyga siparaja & Nectariniidae & Crimson Sunbird & gene & $\mathrm{LC}$ \\
\hline $\begin{array}{l}\text { Amaurornis phoeni- } \\
\text { curus }\end{array}$ & Rallidae & $\begin{array}{l}\text { White-breasted Water- } \\
\text { hen }\end{array}$ & gene & $\mathrm{LC}$ \\
\hline $\begin{array}{l}\text { Anthreptes malacen- } \\
\text { sis }\end{array}$ & Nectariniidae & Plain-throated Sunbird & openco & $\mathrm{LC}$ \\
\hline $\begin{array}{l}\text { Artamus leu- } \\
\text { corhynchus }\end{array}$ & Artamidae & $\begin{array}{l}\text { White-breasted } \\
\text { Woodswallow }\end{array}$ & openco & $\mathrm{LC}$ \\
\hline Celeus brachyurus & Picidae & Rufous Woodpecker & edgetol & LC \\
\hline $\begin{array}{l}\text { Centropus bengalen- } \\
\text { sis }\end{array}$ & Cuculidae & Lesser Coucal & openco & $\mathrm{LC}$ \\
\hline Centropus sinensis & Cuculidae & Greater Coucal & openco & $\mathrm{LC}$ \\
\hline Chalcophaps indica & Columbidae & Emerald Dove & edgetol & $\mathrm{LC}$ \\
\hline $\begin{array}{l}\text { Chrysocolaptes luci- } \\
\text { dus }\end{array}$ & Picidae & Greater Flameback & edgespec & $\mathrm{LC}$ \\
\hline Cisticola exilis & Cisticolidae & Golden-headed Cisticola & openco & LC \\
\hline Dicaeum cruentatum & Dicaeidae & $\begin{array}{l}\text { Scarlet-backed Flower- } \\
\text { pecker }\end{array}$ & edgetol & $\mathrm{LC}$ \\
\hline $\begin{array}{l}\text { Dicaeum trigonos- } \\
\text { tigma }\end{array}$ & Dicaeidae & $\begin{array}{l}\text { Orange-bellied Flower- } \\
\text { pecker }\end{array}$ & edgetol & $\mathrm{LC}$ \\
\hline Gallus gallus & Phasianidae & Red junglefowl & openco & $\mathrm{LC}$ \\
\hline Halcyon chloris & Alcedinidae & Collared Kingfisher & openco & $\mathrm{LC}$ \\
\hline Halcyon smyrnensis & Alcedinidae & $\begin{array}{l}\text { White-throated King- } \\
\text { fisher }\end{array}$ & openco & $\mathrm{LC}$ \\
\hline Hirundo rustica & Hirundinidae & Barn Swallow & openco & LC \\
\hline $\begin{array}{l}\text { Lonchura leuco- } \\
\text { gastra }\end{array}$ & Estrildidae & White-bellied Munia & openco & $\mathrm{LC}$ \\
\hline Lonchura molucca & Estrildidae & Black-faced Munia & openco & LC \\
\hline Lonchura punctulata & Estrildidae & Nutmeg Mannikin & openco & $\mathrm{LC}$ \\
\hline Loriculus galgulus & Psittacidae & $\begin{array}{l}\text { Blue-crowned Hanging- } \\
\text { parrot }\end{array}$ & edgetol & $\mathrm{LC}$ \\
\hline $\begin{array}{l}\text { Megalaima hae- } \\
\text { macephala }\end{array}$ & Ramphastidae & Coppersmith Barbet & openco & $\mathrm{LC}$ \\
\hline $\begin{array}{l}\text { Orthotomus } \\
\text { atrogularis }\end{array}$ & Sylviidae & Dark-necked Tailorbird & edgespe & $\mathrm{LC}$ \\
\hline Orthotomus ruficeps & Sylviidae & Ashy Tailorbird & edgespe & $\mathrm{LC}$ \\
\hline Orthotomus sericeus & Sylviidae & Rufous-tailed Tailorbird & edgespe & LC \\
\hline
\end{tabular}




\begin{tabular}{lllll}
\hline Species name & Family & Common name & ahabitat & bIUCN status \\
\hline Prinia familiaris & Cisticolidae & Bar-winged Prinia & openco & LC \\
$\begin{array}{l}\text { Prinia flaviventris } \\
\text { Pycnonotus aurigas- }\end{array}$ & Cisticolidae & Yellow-bellied Prinia & openco & LC \\
ter & Pycnonotidae & Sooty-headed Bulbul & edgespec & LC \\
$\begin{array}{l}\text { Pycnonotus goiavier } \\
\text { Pycnonotus plumosus }\end{array}$ & Pycnonotidae & Pellow-vented Bulbul & gene & LC \\
$\begin{array}{l}\text { Rhipidura javanica } \\
\text { Streptopelia chinen- } \\
\text { sis }\end{array}$ & Rhipiduridae & Olive-winged Bulbul & edgespec & LC \\
\hline
\end{tabular}

a Habitat affinities of birds as classified by Rotenberg and Stouffer (2007): forspec = forest specialist, edgetol $=$ edge-tolerant forest species, edgespec $=$ edge specialist, openco $=$ opensemiopen species, gene=generalist bIUCN status (IUCN, 2014): LC = least concern, NT = near threatened

\section{Appendix II: Principal Component Analysis (PCA)}

Table A2: Variables entering Principal Component Analysis (PCA)

\begin{tabular}{lll}
\hline & Mean & SD \\
\hline $\begin{array}{l}=1 \text { if perceived poverty in terms of food } \\
=1 \text { if perceived poverty in terms of }\end{array}$ & .1625 & .3696798 \\
health/education/clothing & .2458333 & .4314801 \\
Number of rooms & & \\
$=1$ if hh owns motorcycle & 5.170833 & 1.472191 \\
$=1$ if hh owns TV & .8958333 & .306115 \\
$=1$ if hh owns fridge & .8666667 & .3406451 \\
$=1$ if hh owns washing maschine & .5333333 & .4999303 \\
$=1$ if hh owns car & .2458333 & .4314801 \\
$=1$ if hh owns sound system /DVD player & .0791667 & .270563 \\
$=1$ if hh owns water pump & .65 & .4779664 \\
$=1$ if house owned by hh & .6625 & .4738452 \\
\hline
\end{tabular}

Table A3: Loadings of rotated components (varimax)

\begin{tabular}{lccll}
\hline Variable & Comp1 & Comp2 & Comp3 & Unexplained \\
\hline Food_poor & & & 0.6526 & 0.3269 \\
Other_poor & & & 0.6415 & 0.3467 \\
Nb_rooms & & & 0.4184 \\
Motor & 0.3480 & & & 0.7427 \\
TV & 0.4384 & & & 0.534 \\
Fridge & 0.3423 & & & 0.4421 \\
Washing machine & & 0.4103 & & 0.534 \\
Car/Trcuk & & 0.6020 & & 0.4258 \\
CD/DVD player & 0.5413 & -0.3057 & & 0.3781 \\
Water pump & 0.4391 & & & 0.3928 \\
House_ownership & & & & 0.6536 \\
\hline
\end{tabular}

blanks are abs (loading) $<0.3$ 
Component loadings inform us about the interpretation of the components. The majority of asset variables load on component 1, whereas the variables related to perceived poverty load on component 3 . Hence predicted values of component 1 were used as an asset index and those of component 3 were interpreted as a perceived poverty index.

Table A4: Kaiser-Meyer-0lkin measure of sampling adequacy.

\begin{tabular}{ll}
\hline Variable & KMO \\
\hline Food_poor & 0.5899 \\
Other_poor & 0.5925 \\
Nb_rooms & 0.7785 \\
Motor & 0.7423 \\
TV & 0.8047 \\
Fridge & 0.8110 \\
Washing machine & 0.7802 \\
Car/Trcuk & 0.6354 \\
CD/DVD player & 0.7324 \\
Water pump & 0.7743 \\
House_ownership & 0.8002 \\
\hline Overall & 0.7426
\end{tabular}

The Kaiser-Meyer-Olkin measure compares the values of correlations between variables with the values of the partial correlations and thus gives us the sampling adequancy. The KMO takes values between 0 and 1 . With a KMO $=0.7426$, the degree of common variance in our dataset is "middling". Lying above the critical value of 0.6 , the application of the PCA approach is appropriate.

\section{Appendix III: BayesX estimation results (framing effects)}

Table A5: Estimation results for parameter $\sigma^{2}=$ variance

\begin{tabular}{lll}
\hline Variable & Mean & Std. Dev. \\
\hline const & $-2.8613^{* *}$ & 0.4186 \\
PES & $0.3187^{*}$ & 0.1616 \\
Ha_same & $0.3182^{*}$ & 0.1730 \\
SMA & 0.3387 & 0.2102 \\
Female & 0.3310 & 0.3080 \\
Asset Index & $0.1514^{* *}$ & 0.0509 \\
Oil palm & $-0.3491^{* *}$ & 0.1760 \\
Nb_title & $-0.3387^{* *}$ & 0.2102 \\
nature & -0.0478 & 0.0583 \\
\hline
\end{tabular}

\footnotetext{
${ }^{* *}$ significance at $5 \%$ level, * significance at $10 \%$ level
} 


\section{Appendix IV: GAMLSS estimation results (framing effects)}

Table A6: GAMLSS estimation results for mean parameter $\mu$.

\begin{tabular}{lll}
\hline Variable & Estimate & Std. Error \\
\hline const & $-0.4176^{* *}$ & 0.0405 \\
PES & 0.0156 & 0.0436 \\
Payment level & 0.0096 & 0.1936 \\
PES* Payment level & $0.7544^{* *}$ & 0.2674 \\
migrant & $0.2612^{* *}$ & 0.0351 \\
Perceived Poverty Index & $0.0929^{* *}$ & 0.0150 \\
\hline
\end{tabular}

${ }^{* *}$ significance at $5 \%$ level, ${ }^{*}$ significance at $10 \%$ level

Table A7: GAMLSS Estimation results for parameter $\sigma^{2}=$ variance

\begin{tabular}{lll}
\hline Variable & Mean & Std. Dev. \\
\hline const & $-1.4085^{* *}$ & 0.1950 \\
PES & $0.2190^{* *}$ & 0.0758 \\
Ha_same & $0.2481^{* *}$ & 0.0764 \\
SMA & $0.2423^{* *}$ & 0.0986 \\
Female & 0.1752 & 0.1553 \\
Asset Index & $0.0997^{* *}$ & 0.0236 \\
Oil palm & $-0.2278^{* *}$ & 0.0852 \\
Nb_title & $-0.1901^{* *}$ & 0.0529 \\
nature & -0.0448 & 0.0272 \\
\hline
\end{tabular}

${ }^{* *}$ significance at $5 \%$ level, ${ }^{*}$ significance at $10 \%$ level

Table A8: GAMLSS estimation results for parameter vi (yi=0).

\begin{tabular}{lll}
\hline Variable & Estimate & Std. Error \\
\hline const & -0.3837 & 0.3079 \\
Payment level & $-3.7557^{* *}$ & 1.4714 \\
Migrant & $-1.6290^{* *}$ & 0.3358 \\
ha_10 & -0.5755 & 0.3596 \\
\hline
\end{tabular}

${ }^{* *}$ significance at $5 \%$ level, ${ }^{*}$ significance at $10 \%$ level

Table A9: GAMLSS estimation results for parameter $\tau \mathrm{ii},(\mathrm{yi}=1)$,

\begin{tabular}{lll}
\hline Variable & Estimate & Std. Error \\
\hline const & $-5.0916^{* *}$ & 1.2335 \\
Payment level & $8.0113^{* *}$ & 1.5534 \\
SMA & $-1.0431^{* *}$ & 0.5302 \\
Perceived poverty index & $0.5327^{* *}$ & 0.1736 \\
R_agroforestry & $1.2881^{* *}$ & 0.5428 \\
Oil palm & $-0.9472^{* *}$ & 0.3783 \\
nature & 0.2635 & 0.1768 \\
Future_inc & $0.8044^{*}$ & 0.4144 \\
\hline
\end{tabular}

${ }^{* *}$ significance at $5 \%$ level, * significance at $10 \%$ level 
Appendix V: Q-Q plots

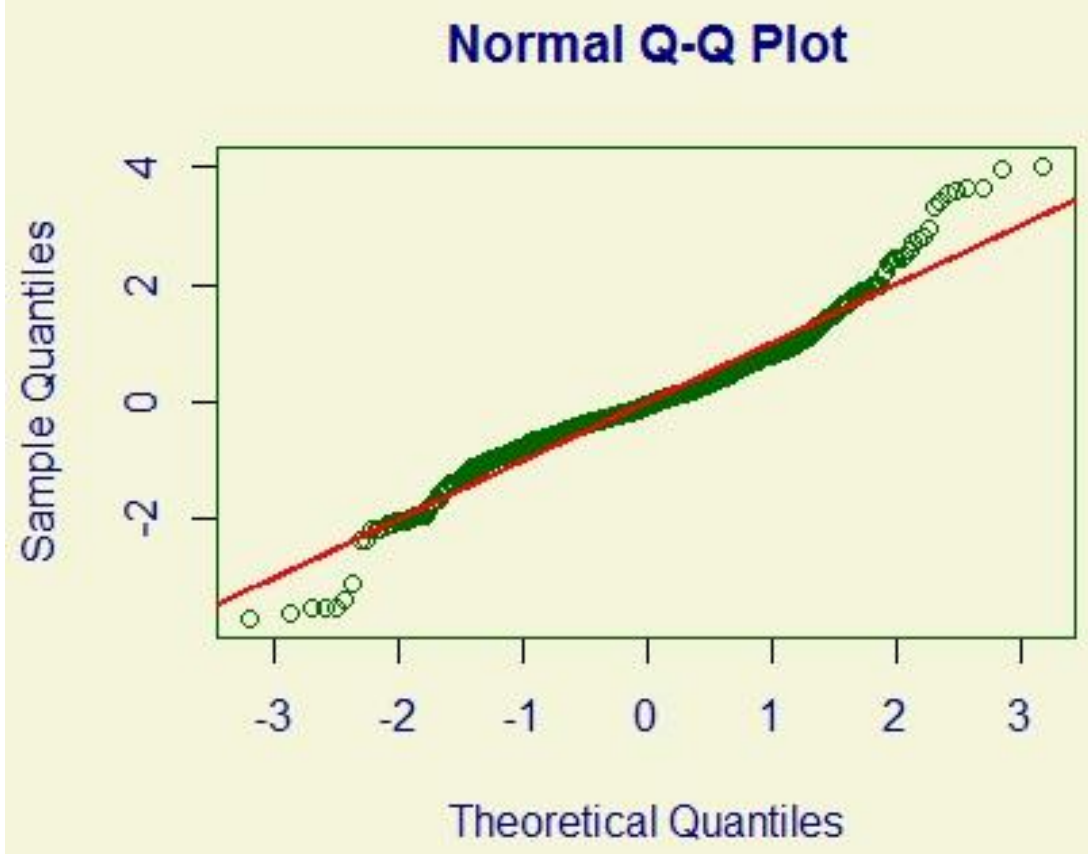

Figure A1: Q-Q Plot of the residuen from a mixed model estimation with random effect (Assumption of normal distribution)

\section{Normal Q-Q Plot}

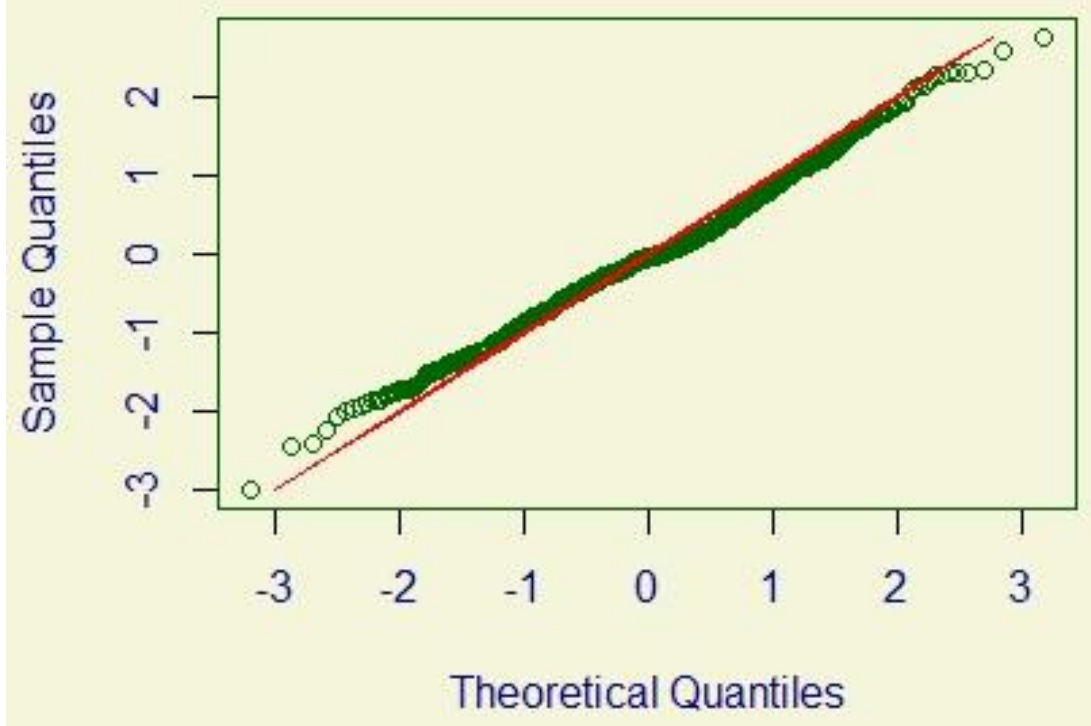

Figure A1: Q-Q Plot of the residuen from the BEINF model (GAMLSS estimation) 
The Q-Q plots allow us to graphically check the validity of the distributional assumptions of the data set. If the data follow the assumed distribution, the points on the $q-q$ plot fall approximately on the straight line. A comparison of Figure A1 and A2 shows that the distributional assumption made in the BEINF model fits better the data than the assumption of normal distribution in a mixed model with random effect.

\section{Appendix VI: Random assignment test}

Table A10 : Results of the seemingly unrelated regressions with socio-economic and session characteristics as the dependent variables.

\begin{tabular}{|c|c|c|c|c|}
\hline & \multicolumn{2}{|l|}{ Equal PES } & \multicolumn{2}{|c|}{ Discriminatory PES } \\
\hline & $\begin{array}{l}\mathrm{e}=5 \text { (Con- } \\
\text { stant) }\end{array}$ & $e=10$ & $\mathrm{e}=5$ & $\mathrm{e}=10$ \\
\hline Age (\# years) & $\begin{array}{l}44.01 \\
(1.14)\end{array}$ & $\begin{array}{l}-0.79 \\
(1.97)\end{array}$ & $\begin{array}{l}-2.02 \\
(1.58)\end{array}$ & $\begin{array}{l}3.99 \\
(2.77)\end{array}$ \\
\hline Female $(0 / 1)$ & $\begin{array}{l}0.059 \\
(0.029)\end{array}$ & $\begin{array}{l}0.045 \\
(0.072)\end{array}$ & $\begin{array}{l}0.050 \\
(0.041)\end{array}$ & $\begin{array}{l}.056 \\
(0.051)\end{array}$ \\
\hline Secondary $(0 / 1)$ & $\begin{array}{l}0.476 \\
(0.053)\end{array}$ & $\begin{array}{l}0.036 \\
(0.130)\end{array}$ & $\begin{array}{l}-0.036 \\
(0.074)\end{array}$ & $\begin{array}{l}-0.143 \\
(0.092)\end{array}$ \\
\hline HH_size & $\begin{array}{l}4.29 \\
(0.163)\end{array}$ & $\begin{array}{l}0.225 \\
(0.396)\end{array}$ & $\begin{array}{l}-0.154 \\
(0.226)\end{array}$ & $\begin{array}{l}-0.119 \\
(0.282)\end{array}$ \\
\hline Transmigrant $(0 / 1)$ & $\begin{array}{l}0.333 \\
(0.049)\end{array}$ & $\begin{array}{l}0.013 \\
(0.122)\end{array}$ & $\begin{array}{l}-0.037 \\
(0.069)\end{array}$ & $\begin{array}{l}-0.047 \\
(0.087)\end{array}$ \\
\hline Oil palm $(0 / 1)$ & $\begin{array}{l}0.642 \\
(0.053)\end{array}$ & $\begin{array}{l}-0.059 \\
(0.122)\end{array}$ & $\begin{array}{l}-0.060 \\
(0.073)\end{array}$ & $\begin{array}{l}0.024 \\
(0.092)\end{array}$ \\
\hline Oil palm_ha (ha) & $\begin{array}{l}1.92 \\
(0.299)\end{array}$ & $\begin{array}{l}-0.530 \\
(0.727)\end{array}$ & $\begin{array}{l}0.342 \\
(0.414)\end{array}$ & $\begin{array}{l}0.608 \\
(0.517)\end{array}$ \\
\hline Rubber monoculture $(0 / 1)$ & $\begin{array}{l}0.476 \\
(0.054)\end{array}$ & $\begin{array}{l}-0.009 \\
(0.133)\end{array}$ & $\begin{array}{l}-0.015 \\
(0.076)\end{array}$ & $\begin{array}{l}0.024 \\
(0.094)\end{array}$ \\
\hline $\begin{array}{l}\text { Rubber monoculture_ha } \\
\text { (ha) }\end{array}$ & $\begin{array}{l}0.708 \\
(0.122)\end{array}$ & $\begin{array}{l}-0.151 \\
(0.298)\end{array}$ & $\begin{array}{l}-0.044 \\
(0.169)\end{array}$ & $\begin{array}{l}0.238 \\
(0.212)\end{array}$ \\
\hline Rubber agroforestry $(0 / 1)$ & $\begin{array}{l}0.095 \\
(0.036)\end{array}$ & $\begin{array}{l}0.039 \\
(0.088)\end{array}$ & $\begin{array}{l}0.081 \\
(0.050)\end{array}$ & $\begin{array}{l}-0.048 \\
(0.062)\end{array}$ \\
\hline $\begin{array}{l}\text { Rubber agroforestry_ha } \\
\text { (ha) }\end{array}$ & $\begin{array}{l}0.440 \\
(0.186)\end{array}$ & $\begin{array}{l}0.484 \\
(0.453)\end{array}$ & $\begin{array}{l}-0.091 \\
(0.253)\end{array}$ & $\begin{array}{l}-0.369 \\
(0.323)\end{array}$ \\
\hline $\begin{array}{l}\text { Oil palm_rubber monocul- } \\
\text { ture }(0 / 1) \\
\text { Oil palm_rubber agrofor- } \\
\text { estry }(0 / 1)\end{array}$ & $\begin{array}{l}0.178 \\
(0.041) \\
0.024 \\
(0.020)\end{array}$ & $\begin{array}{l}-0.036 \\
(0.100) \\
0.029 \\
(0.053)\end{array}$ & $\begin{array}{l}-0.036 \\
(0.057) \\
0.042 \\
(0.030)\end{array}$ & $\begin{array}{l}0.059 \\
(0.071) \\
-0.024 \\
(0.038)\end{array}$ \\
\hline Session characteristics & & & & \\
\hline Share_known_names & $\begin{array}{l}0.840 \\
(0.019)\end{array}$ & $\begin{array}{l}-0.007 \\
(0.047)\end{array}$ & $\begin{array}{l}-0.038 \\
(0.027)\end{array}$ & $\begin{array}{l}0.029 \\
(0.033)\end{array}$ \\
\hline Share_family_members & $\begin{array}{l}0.132 \\
(0.022)\end{array}$ & $\begin{array}{l}0.017 \\
(0.052)\end{array}$ & $\begin{array}{l}-0.013 \\
(0.030)\end{array}$ & $\begin{array}{l}-0.019 \\
(0.037)\end{array}$ \\
\hline
\end{tabular}

Depicted are coefficients and standard errors in parentheses. ${ }^{*} \mathrm{p}<0.10,{ }^{* *} \mathrm{p}<0.05,{ }^{* * *} \mathrm{p}<0.01$ 


\section{Appendix VII: Random effects Tobit model}

Table A11: Random effects Tobit model on the share of endowment allocated to conservation

\begin{tabular}{lll}
\hline & Model (1) & $\begin{array}{l}\text { Model (2) } \\
\mathbf{e = 1 0}\end{array}$ \\
\hline Dummy Dicsriminatory & $\mathbf{e = 5}$ & $-0.1570^{*}$ \\
PESLevel & $(0.0850)$ & $(0.0846)$ \\
& $0.3901^{* * *}$ & 0.1080 \\
Discriminatory * PESLevel & $(0.1449)$ & $(0.1688)$ \\
& 0.0108 & 0.1967 \\
Constant & $(0.1956)$ & $0.2550)$ \\
& $0.3492^{* * *}$ & $0.5070^{* * *}$ \\
\hline No. of observations & $(0.0602)$ & $(0.0610)$ \\
No. of groups & 546 & 273 \\
Wald chi2 & 182 & 91 \\
Prob>chi2 & 19.52 & 6.11 \\
\hline p & 0.0002 & 0.1063 \\
\hline
\end{tabular}

${ }^{*} \mathrm{p}<0.10,{ }^{* *} \mathrm{p}<0.05,{ }^{* * *} \mathrm{p}<0.01 ;$ 


\section{Appendix VIII: Questionnaire "tree enrichment"}

We are students from Gottingen University-Germany, Universitas Jambi and IPB, Bogor, who are studying the impact of intercropping fruit and timber trees in oil-palm plantations on bird biodiversity. Your participation in answering these questions is very much appreciated. Your responses will be COMPLETELY CONFIDENTIAL and will only be used for research purpose. Your responses will be added to those of 120 other households and analyzed together. If you indicate your voluntary consent by participating in this interview, may we begin?

\section{Household Identification}

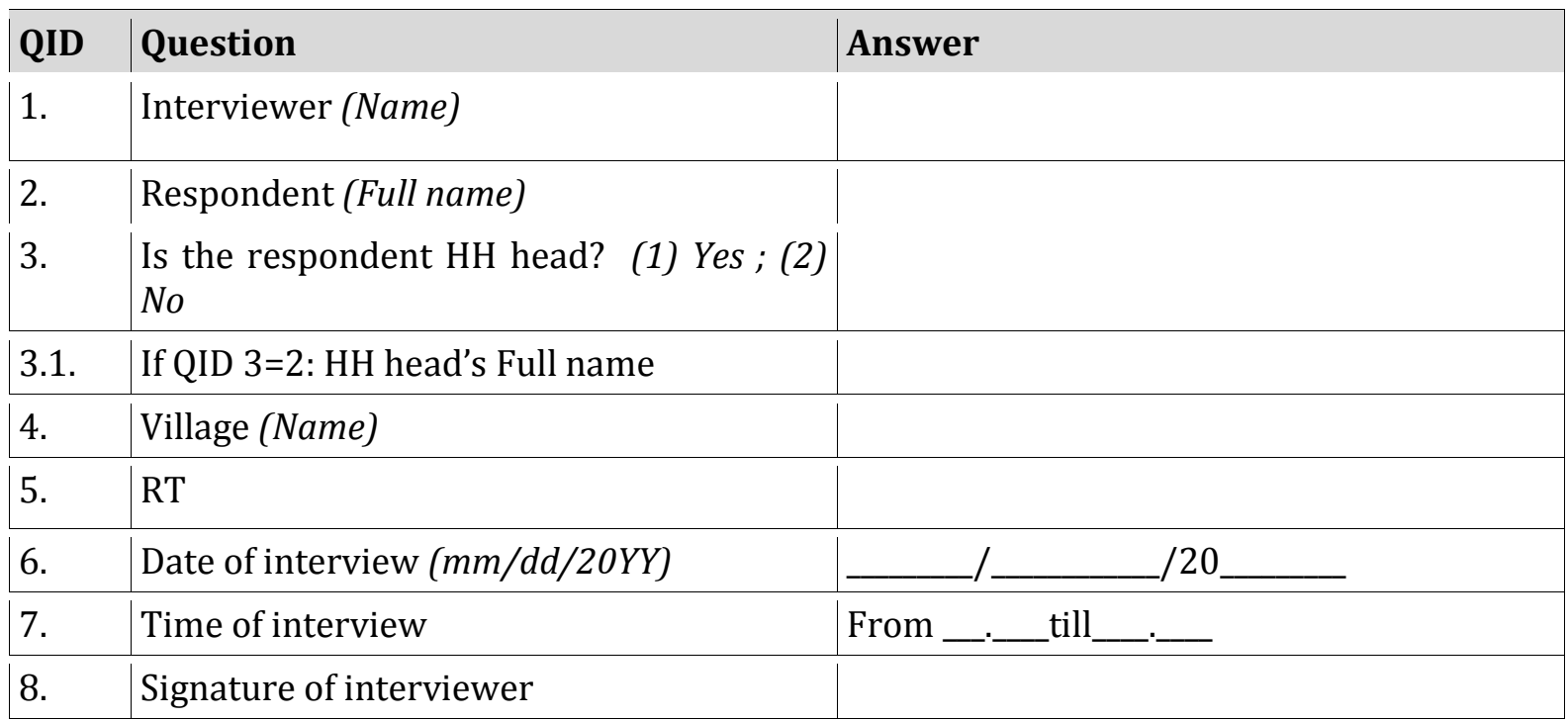




\section{General Plot Information (Oil Palm Farmer)}

[A plot is defined as a piece of land under one crop, which is not segmented spatially and where the managerial practices are common and palms/trees are of approximately the same age.]

1. How many oil palm plots do you have?

\begin{tabular}{|c|c|c|c|c|c|c|}
\hline QID & & Plot 1 & Plot 2 & Plot 3 & Plot 4 & Plot 5 \\
\hline 2. & Area of plot (ha) & & & & & \\
\hline 3. & Number of oil palms in the plot (\#) & & & & & \\
\hline 4. & Year of planting $(Y Y Y Y)$ & & & & & \\
\hline 5. & Year of first harvest ever $(Y Y Y Y)$ & & & & & \\
\hline 6. & $\begin{array}{l}\text { Year of last replanting in the plot } \\
(Y Y Y Y)\end{array}$ & & & & & \\
\hline 7. & $\begin{array}{l}\text { If replanted, year of first harvest } \\
\text { after replanting }(Y Y Y Y)\end{array}$ & & & & & \\
\hline
\end{tabular}

Selection criteria for the "specific plot": biggest (ha), one of all the plots and the plot must be already productive.

Plot number:

7. Who is currently managing the plot?

(1) household; (2) entrusted to company; (3) entrusted to farmer cooperative; (4) others, specify:

8. Is the plot managed by sharecropping? (1) Yes; (2) No

If QID 8=1, change plot.

\section{Specific Plot Information}

\subsection{Ownership}

The following questions refer to the specific plot. Now we would like to ask you some questions about your biggest plot, the one you mentioned that has ha.

\begin{tabular}{|l|l|l|}
\hline QID & Question & Answer \\
\hline 1. & Ownership of land. (1) leased-in; (2) owned & \\
\hline 2. & If QID1=1: Amount of rent paid in last 12 months ('000 Rp). & \\
\hline
\end{tabular}




\subsection{Oil-Palms on the Specific Plot}

\begin{tabular}{|l|l|l|}
\hline QID & Question & Answer \\
\hline 3. & Number of different oil palm varieties. (\#) & \\
\hline 4. & Name of Variety 1 (Number of oil palms per variety1 (\#) ) & \\
\hline 5. & Name of Variety 2 (Number of oil palms per variety2 (\#)) & \\
\hline 6. & Number of oil palms which are not productive in the plot. (\#) & \\
\hline 7. & Number of oil palms which are affected by diseases or pests & \\
\hline 8. & $\begin{array}{l}\text { What kind of pest or disease do you experience on your oil palm } \\
\text { plot? (1) rats (2) pigs (3) pest insects (4) others, specify }\end{array}$ & \\
\hline (Multiple answers possible) & Distance between oil palm. (__meters*_meters) & \\
\hline 9. & Number of oil palm rows. (\#) & \\
\hline 11. & Number of oil palm trees per row. (\#) & \\
\hline 12. & Have you ever used fire for clearing the land? (1) Yes; (2) No & \\
\hline 13. & If QID12=1, Year of last clearing using fire. (YYYY) & \\
\hline 14. & $\begin{array}{l}\text { In the last 12 months, did you keep the cut-off plants and crop } \\
\text { residues on the plot? (1) Yes; (2) No }\end{array}$ & \\
\hline
\end{tabular}

\subsection{Distance from the plot to other structures}

Distance from the plot to (only if not more than 500 m away from the plot; if it is within the plot, please write $0 \mathrm{~m}$ ).

\begin{tabular}{|l|l|l|}
\hline QID & Distance from the plot to: & Answer \\
\hline 1. & Nearest road. (meters) & \\
2. & Nearest secondary forest. (meters) & \\
\hline 3. & Nearest production forest. (meters) & \\
\hline 4. & Nearest jungle rubber. (meters) & \\
\hline 5. & Nearest rubber plantation. (meters) & \\
\hline 6. & $\begin{array}{l}\text { Nearest fallow land/cleared land/revitalization (oil palm). (me- } \\
\text { ters) }\end{array}$ & \\
\hline 7. & Nearest paddy field. (meters) & \\
\hline 8. & Nearest home/kitchen garden. (meters) & \\
\hline 9. & Nearest river or lake. (meters) & \\
\hline
\end{tabular}




\section{Input Use on this Specific Plot in the Last 12 Months}

The following questions refer to the specific plot.

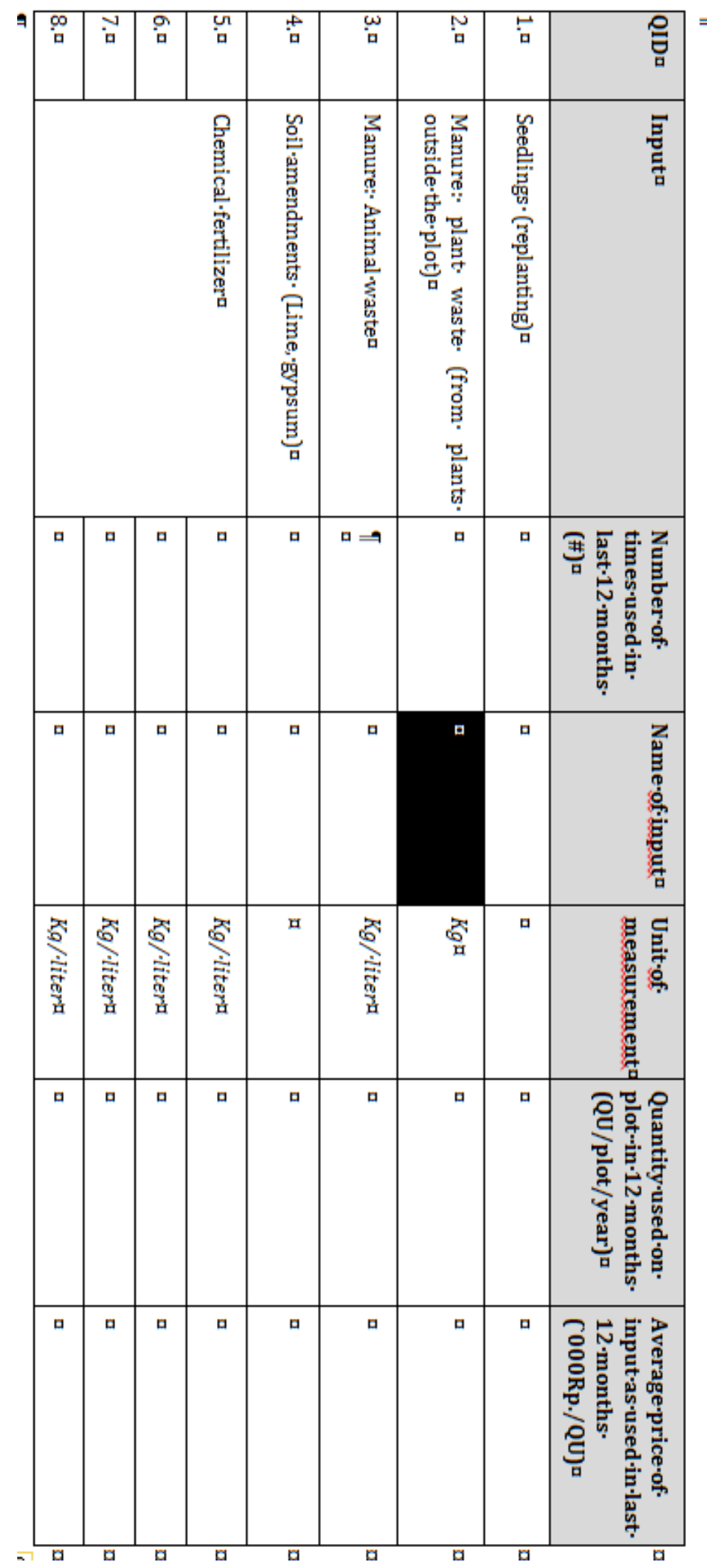




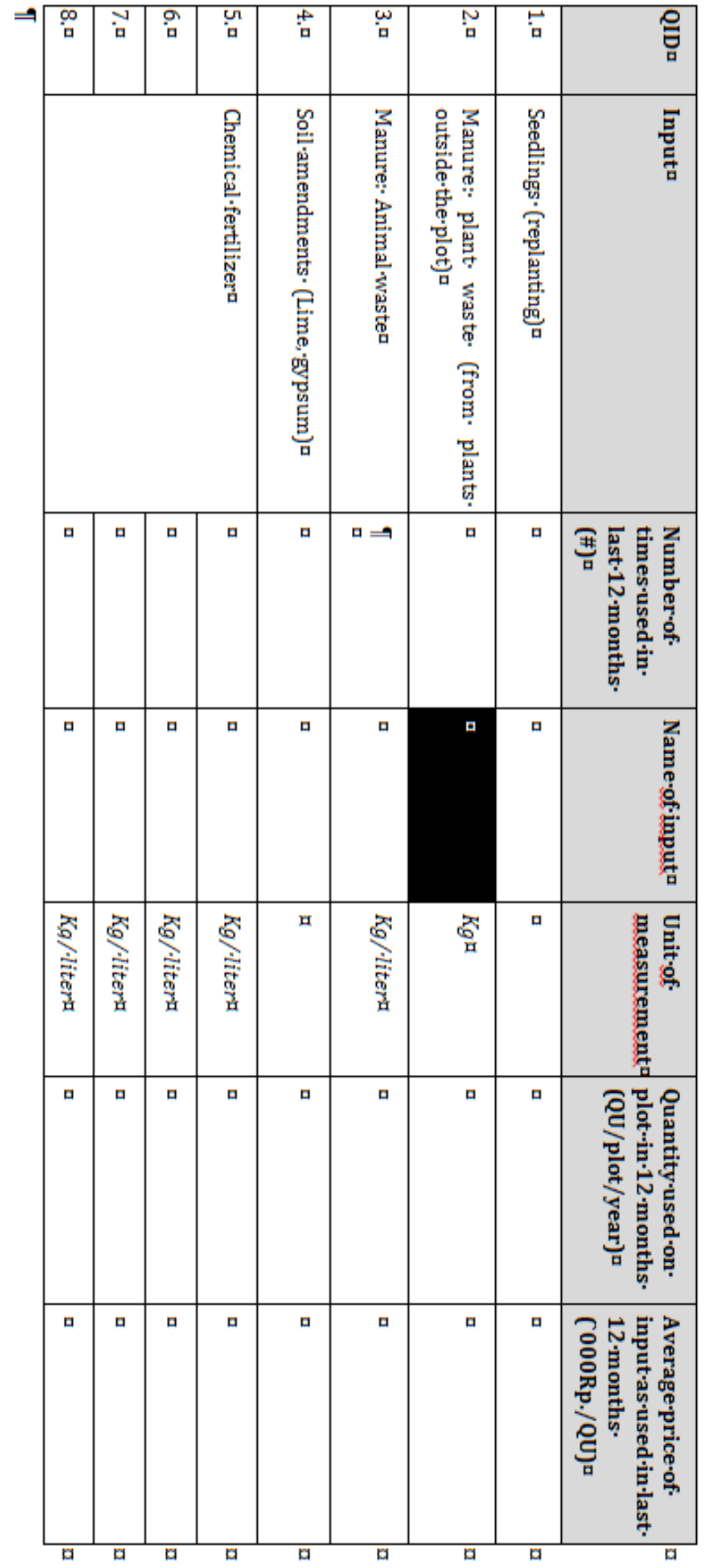




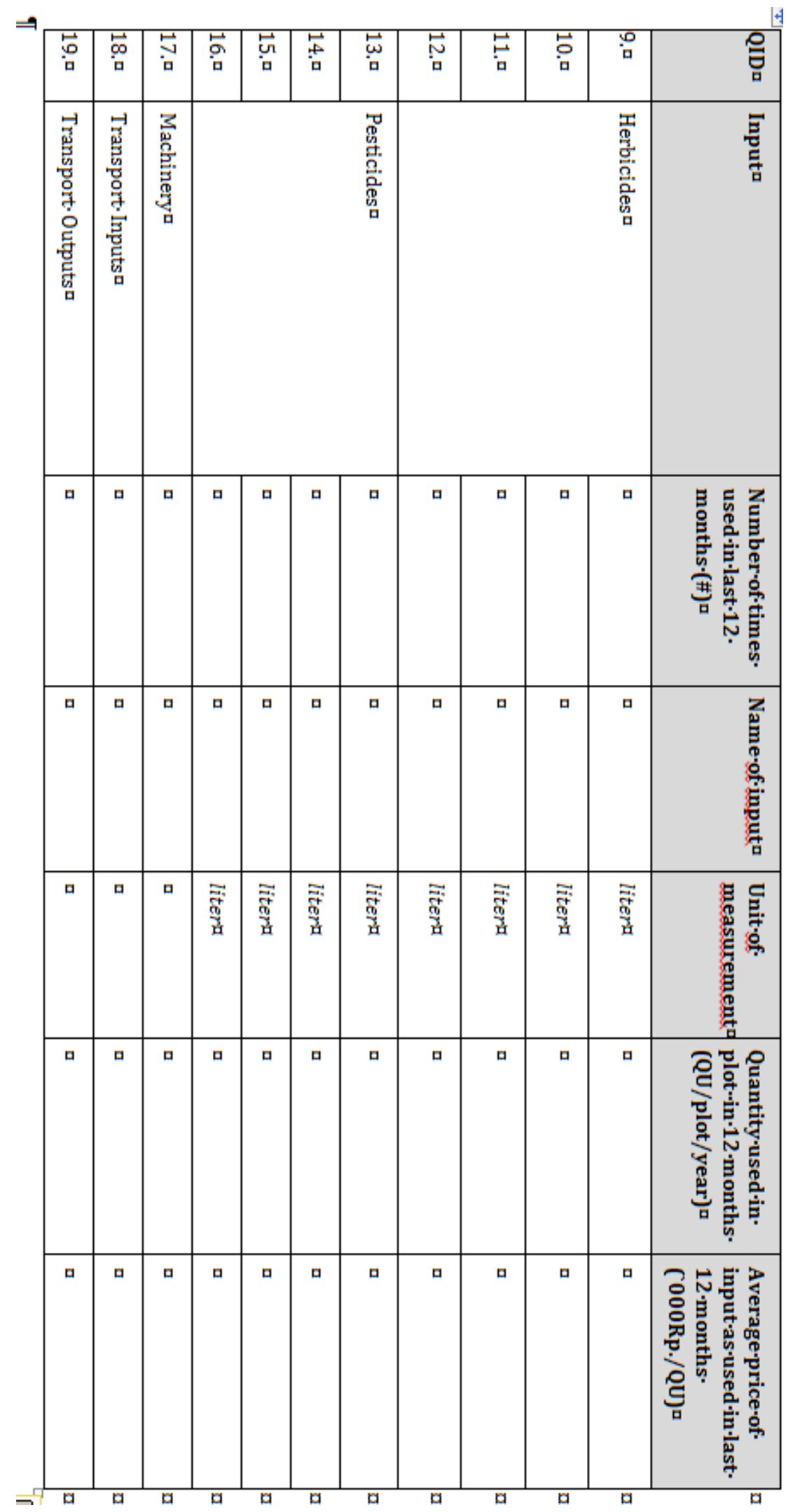




\section{Labor Input in Last 12 Months (Specific Plot)}

The following questions refer to the specific plot.

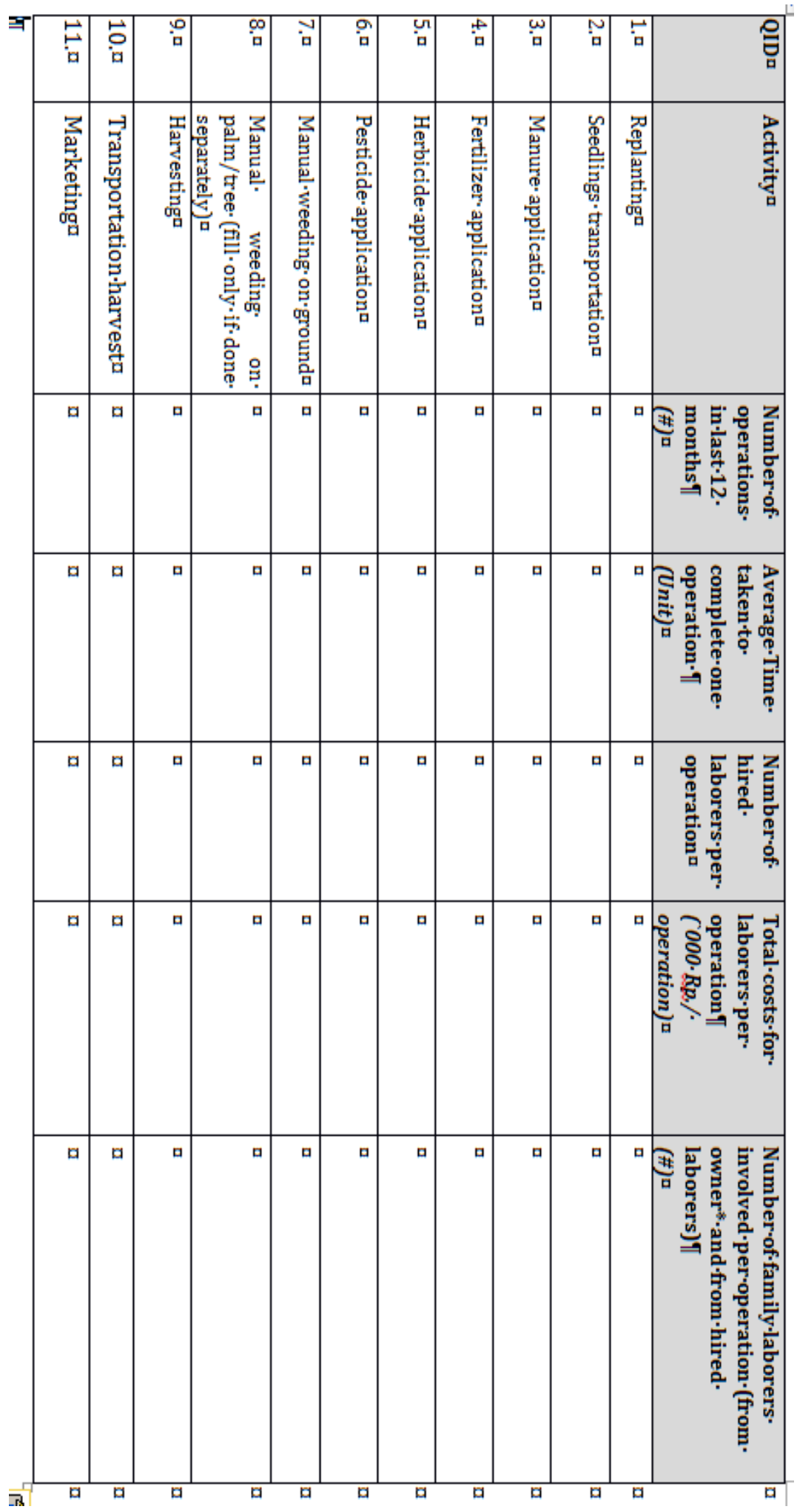




\section{Outputs Oil Palm from the Specific Plot}

The following questions refer to the specific plot.

\subsection{Last three Sales from this Specific Plot.}

\begin{tabular}{|l|l|l|l|l|}
\hline QID & $\begin{array}{l}\text { Sale ID (1= } \\
\text { most recent } \\
\text { sale) }\end{array}$ & $\begin{array}{l}\text { Date of sale } \\
\text { (mm/dd/20YY) }\end{array}$ & $\begin{array}{l}\text { Total quantity sold } \\
\text { (kg) }\end{array}$ & $\begin{array}{l}\text { Average price ob- } \\
\text { tained for output } \\
\text { ('000 Rp/kg) }\end{array}$ \\
\hline 1. & 1 & & & \\
\hline 2. & 2 & & & \\
\hline 3. & 3 & & & \\
\hline
\end{tabular}

\subsection{Harvest in the Last 12 Months}

\begin{tabular}{|l|l|l|}
\hline QID & $\begin{array}{l}\text { Total harvest in last 12 months from } \\
\text { this specific plot (ton) }\end{array}$ & Total quantity sold (kg) \\
\hline $1 . / 2$. & & \\
\hline
\end{tabular}

\subsection{Change of Harvest last 12 Months}

Please indicate how the harvest changed throughout the last 12 months. Please distinguish between dry and rainy season.

\begin{tabular}{|l|l|l|l|l|l|}
\hline QID & $\begin{array}{l}\text { Frequency of } \\
\text { harvest (once in } \\
\text { how many days) } \\
\text { on this specific } \\
\text { plot }\end{array}$ & $\begin{array}{l}\text { Quantity of har- } \\
\text { vest per month } \\
\text { (kg/month) from } \\
\text { this specific plot } \\
\text { shocks? } \\
\text { Code A }\end{array}$ & $\begin{array}{l}\text { Were } \\
\text { there any } \\
\text { obtained for } \\
\text { output in this } \\
\text { season ('000Rp } \\
\text { /kg) }\end{array}$ \\
\hline 1 & $\begin{array}{l}\text { Dry season } \\
\text { (April- } \\
\text { October) }\end{array}$ & & & \\
\hline 2 & $\begin{array}{l}\text { Rain season } \\
\text { (November- } \\
\text { March) }\end{array}$ & & & \\
\hline Code A: (1) None; (2) drought; (3) fire; (3) flood; (4) theft; (5) pest; (6) other, specify:
\end{tabular}




\section{Intercropping with Fruit and Timber Trees (Perennial Crops)}

Questions refer to the specific plot.

1. Do you have fruit or timber trees on your oil palm plot (surrounded by oil palm trees; and not at the edge of oil palm plantation)? (1) Yes, (2) No

If $\mathbf{Q I D 1}=\mathbf{2}$, continue with section 9.

If QID1=1, please specify in the table below:

\begin{tabular}{|c|c|c|c|c|c|c|c|c|}
\hline \multirow[t]{2}{*}{ QID } & \multirow{2}{*}{$\begin{array}{l}\text { Name } \\
\text { of tree } \\
\text { species } \\
\text { (\#) }\end{array}$} & \multirow{2}{*}{$\begin{array}{l}\text { Number } \\
\text { of trees } \\
(\#)\end{array}$} & \multirow{2}{*}{$\begin{array}{l}\text { Number of } \\
\text { already } \\
\text { productive } \\
\text { trees } \\
\text { (\#) }\end{array}$} & \multirow{2}{*}{$\begin{array}{l}\text { Are the } \\
\text { trees } \\
(1) \\
\text { planted } \\
\text { (ever) } \\
\text { or (2) } \\
\text { left- } \\
\text { overs? }\end{array}$} & \multicolumn{4}{|c|}{$\begin{array}{l}\text { Did you maintain these trees at least in } \\
\text { the last } 12 \text { months? (1) Yes, (2) No }\end{array}$} \\
\hline & & & & & Weeding & Fertilizer & Herbicides & Pesticides \\
\hline \multicolumn{9}{|l|}{2.} \\
\hline \multicolumn{9}{|l|}{3.} \\
\hline \multicolumn{9}{|l|}{4.} \\
\hline \multicolumn{9}{|l|}{5.} \\
\hline \multicolumn{9}{|l|}{6.} \\
\hline \multicolumn{9}{|l|}{7.} \\
\hline \multicolumn{9}{|l|}{8.} \\
\hline \multicolumn{9}{|l|}{9.} \\
\hline 10. & & & & & & & & \\
\hline
\end{tabular}




\subsection{Input Use Intercropped Trees in last 12 Months}

If the respondent maintained the trees by weeding, fertilizer, herbicide or pesticide application, in the last 12 months please continue with the following table.

Please sum it up for all trees. It just refers to trees in the oil palm plot.

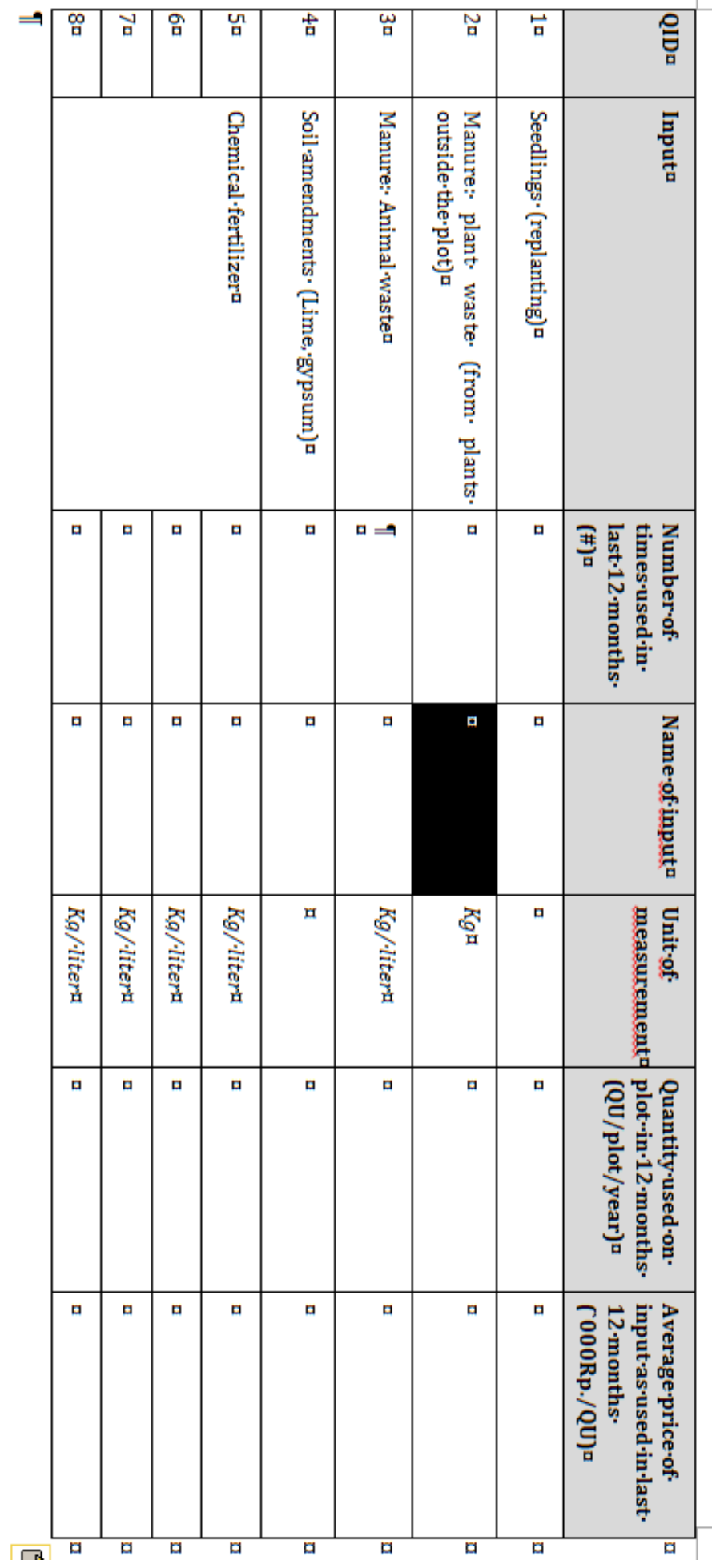




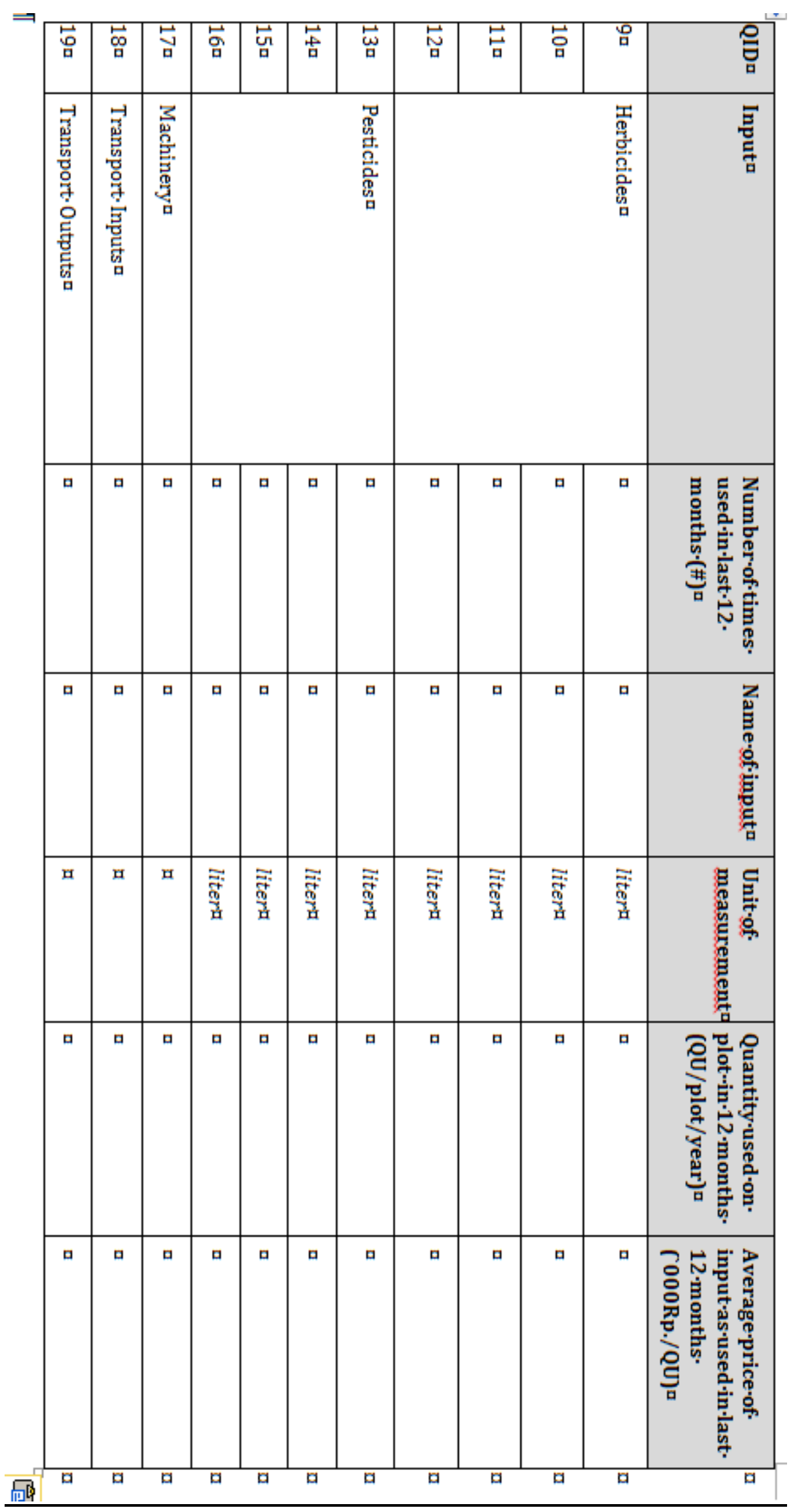




\subsection{Labor Input intercropped trees last 12 months}

If the respondent maintained the trees by weeding, fertilizer, herbicide or pesticide application, in the last 12 months please continue with the following table.

Please sum it up for all trees. It just refers to trees in the oil palm plot.

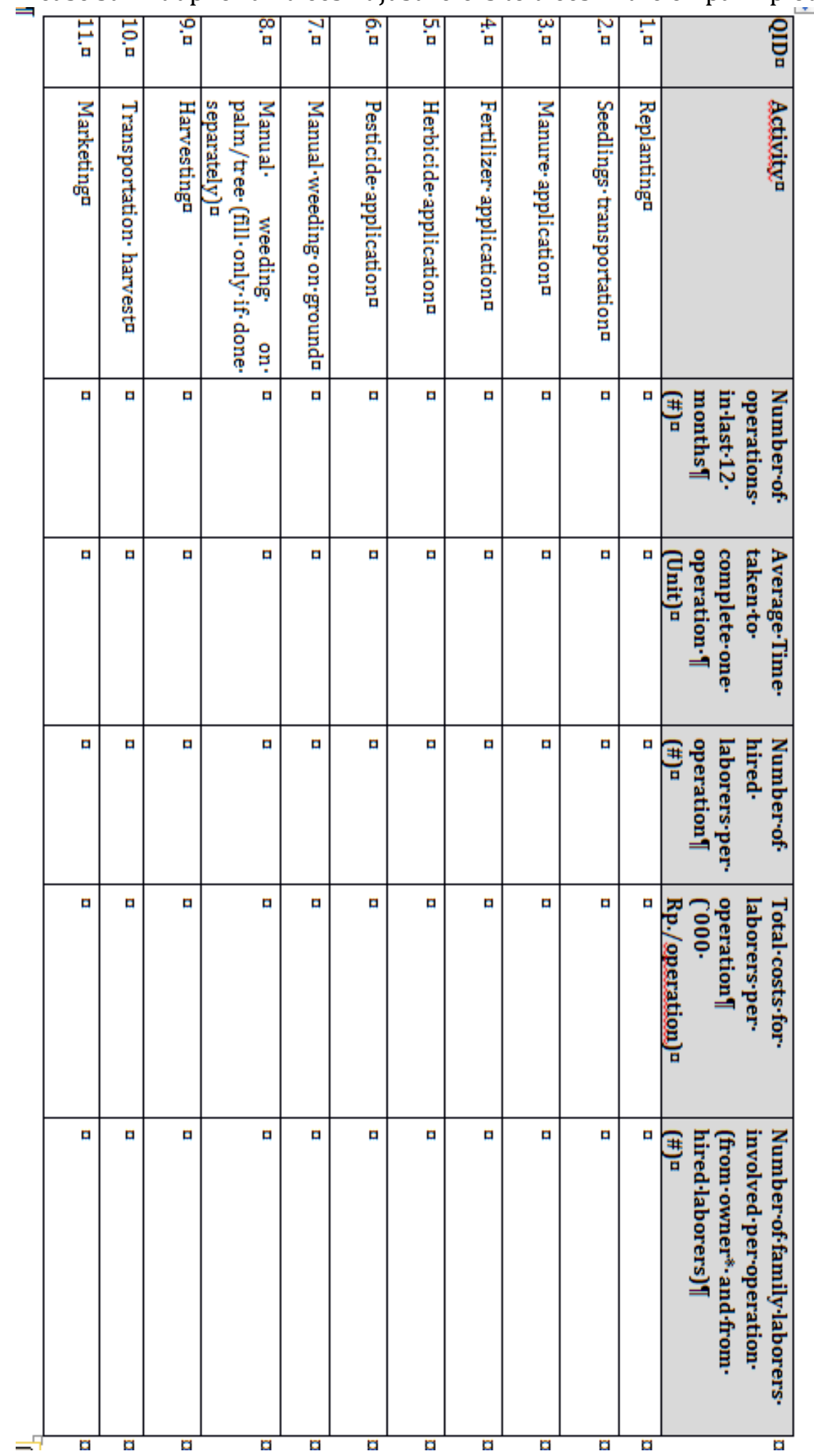




\section{Tree By-Products}

Please do not include rubber here, separate table for rubber.

\begin{tabular}{|l|l|l|l|l|l|l|}
\hline QID & $\begin{array}{l}\text { Name of } \\
\text { tree spe- } \\
\text { cies }\end{array}$ & $\begin{array}{l}\text { By- } \\
\text { product } \\
\text { type } \\
\text { (Code A) }\end{array}$ & $\begin{array}{l}\text { Unit of meas- } \\
\text { urement } \\
\text { (QU, name) }\end{array}$ & $\begin{array}{l}\text { Production } \\
\text { in the last 12 } \\
\text { months (QU) }\end{array}$ & $\begin{array}{l}\text { Quantity } \\
\text { (QU) mar- } \\
\text { keted in } \\
\text { the last 12 } \\
\text { months }\end{array}$ & $\begin{array}{l}\text { Average } \\
\text { Price ob- } \\
\text { tained in } \\
\text { the last 12 } \\
\text { months } \\
\text { ('000 } \\
\text { Rp/QU) }\end{array}$ \\
\hline 1. & & & & & \\
\hline 2. & & & & & \\
\hline 3. & & & & & \\
\hline 4. & & & & & \\
\hline 5. & & & & \\
\hline 6. &
\end{tabular}

\subsection{Labor Input (for Harvesting/ Marketing)}

Please sum it up for all trees. It just refers to trees in the oil palm plot. Include rubber here.

\begin{tabular}{|c|c|c|c|c|c|c|}
\hline QID & & $\begin{array}{l}\text { Number of } \\
\text { operations } \\
\text { in the last } \\
12 \text { months } \\
\text { (\#) }\end{array}$ & $\begin{array}{l}\text { Time } \\
\text { taken to } \\
\text { complete } \\
\text { one op- } \\
\text { eration } \\
\text { (hours) }\end{array}$ & $\begin{array}{l}\text { Number } \\
\text { of hired } \\
\text { laborers } \\
\text { per oper- } \\
\text { ation } \\
\text { (\#) }\end{array}$ & $\begin{array}{l}\text { Total costs for } \\
\text { laborers per } \\
\text { operation in } \\
\text { the last } 12 \\
\text { months ( } 000 \\
\text { Rp./operation) }\end{array}$ & $\begin{array}{l}\text { Number of } \\
\text { family } \\
\text { laborers } \\
\text { involved } \\
\text { per opera- } \\
\text { tion (from } \\
\text { owner* } \\
\text { and from } \\
\text { hired la- } \\
\text { borers) } \\
\text { (\#) }\end{array}$ \\
\hline 1. & Harvesting & & & & & \\
\hline 2. & $\begin{array}{l}\text { Transport } \\
\text { output }\end{array}$ & & & & & \\
\hline 3. & Marketing & & & & & \\
\hline
\end{tabular}




\subsection{Harvest Rubber Intercropped in Oil Palm}

If the oil palm plot is intercropped with rubber, please continue with this table. Otherwise switch to section 8.

\begin{tabular}{|l|l|l|l|l|}
\hline QID & $\begin{array}{l}\text { Sale ID (1= } \\
\text { most recent } \\
\text { sale) }\end{array}$ & $\begin{array}{l}\text { Date of sale } \\
(\mathrm{mm} / \mathrm{dd} / \mathbf{2 0 Y Y})\end{array}$ & $\begin{array}{l}\text { Total quantity } \\
\text { sold }(\mathrm{kg})\end{array}$ & $\begin{array}{l}\text { Average price obtained } \\
\text { for output ('000 } \mathrm{Rp} / \mathrm{kg})\end{array}$ \\
\hline 1. & 1 & & & \\
\hline 2. & 2 & & & \\
\hline 3. & 3 & & & \\
\hline
\end{tabular}

7.3. Harvest Rubber Intercropped in Oil Palm in the last 12 Months

\begin{tabular}{|l|l|l|}
\hline QID & $\begin{array}{l}\text { Total harvest in the last } 12 \text { months from this } \\
\text { specific plot (ton) }\end{array}$ & Total quantity sold (kg) \\
\hline $1 . / 2$. & & \\
\hline
\end{tabular}

\subsection{Change of Harvest Rubber Intercropped in Oil Palm}

Please indicate how the harvest changed throughout the last 12 months. Please distinguish between dry and rainy season.

\begin{tabular}{|l|l|l|l|l|l|}
\hline QID & & $\begin{array}{l}\text { Frequency of } \\
\text { harvest (once } \\
\text { in how many } \\
\text { days) }\end{array}$ & $\begin{array}{l}\text { Quantity of } \\
\text { harvest per } \\
\text { month } \\
\text { (kg/month) }\end{array}$ & $\begin{array}{l}\text { Were } \\
\text { there } \\
\text { any } \\
\text { shocks? } \\
\text { Code A }\end{array}$ & $\begin{array}{l}\text { Average price } \\
\text { obtained for out- } \\
\text { put in this season } \\
\text { ('000Rp /kg) }\end{array}$ \\
\hline 1. & $\begin{array}{l}\text { Dry season } \\
\text { (April-October) }\end{array}$ & & & & \\
\hline 2. & $\begin{array}{l}\text { Rain season } \\
\text { (November- } \\
\text { March) }\end{array}$ & & & & \\
\hline $\begin{array}{l}\text { Code A: (1) None; (2) drought; (3) fire; (3) flood; (4) theft; (5) pest; (6) other, speci- } \\
\text { fy: }\end{array}$
\end{tabular}




\section{Arrangement of Fruit and Timber Trees}

Please show the pictures.

1. Could you please describe to us the arrangement of fruit and timber trees on the specific oil palm plot? Number:

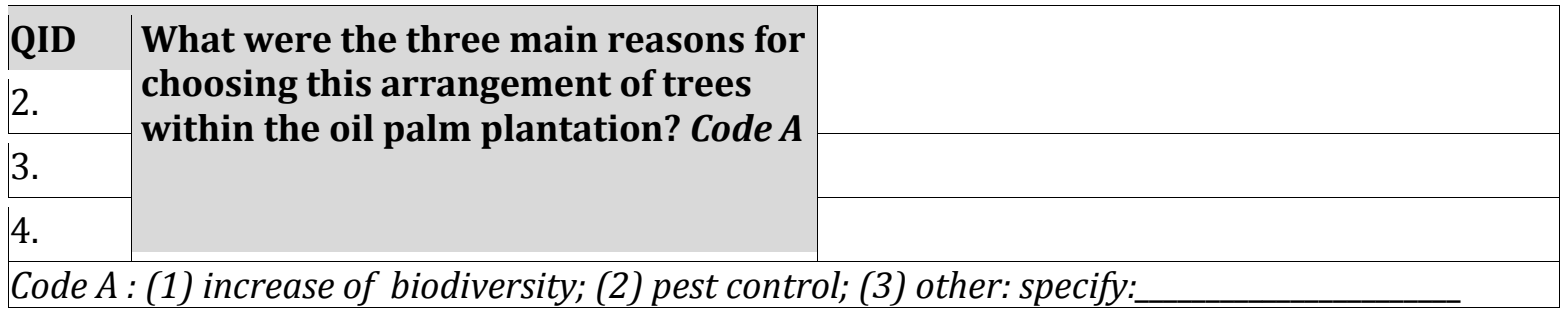

\section{Cut-Off of Fruit and Timber Trees on the Specific Plot}

\begin{tabular}{|l|l|l|}
\hline QID & $\begin{array}{l}\text { Answer } \\
\text { 1. }\end{array}$ & $\begin{array}{l}\text { Have you ever cut any productive tree in the oil palm } \\
\text { plantation (surrounded by oil palm) in the last 5 years? }\end{array}$ \\
\hline 2. & If QID1=1, number of cut productive trees (\#) & \\
\hline 3. & $\begin{array}{l}\text { If QID1=1, please name the main rea- } \\
\text { Son: }\end{array}$ \\
\hline
\end{tabular}

\begin{tabular}{|c|c|}
\hline QID & What are the three main reasons for you \\
\hline 4. & for planting the above trees or not re- \\
\hline 5. & palm plantation? Code $A$ \\
\hline 6. & \\
\hline
\end{tabular}

Code A: (1) to maintain soil fertility; (2) to reduce likelihood for soil erosion; (3) to increase rainfall absorption; (4) to preserve groundwater; (5) to fulfill food/housing needs; (6) for other economic activities; (7) pest management; (8) weed management; (9) to make border with border to neighboring plots ; (10) others, specify:

\begin{tabular}{|l|l|l|}
\hline QID & $\begin{array}{l}\text { From your perspective, what are the } \\
\text { three main problems associated with } \\
\text { planting trees within the oil palm plan- }\end{array}$ & \\
7. & tation? ( general question) Code $\boldsymbol{A}$ & \\
\hline 8. & & \\
\hline 9. & & \\
\hline $\begin{array}{l}\text { Code A: (1) no problems (2) competition for water (3) competition for nutrients (4) others, speci- } \\
\text { fy: }\end{array}$
\end{tabular}




\section{Perception About Functions of Fruit and Timber Trees within Oil Palm Planta-} tions

Now, we would like to know your perception on fruit or timber trees in oil palm plantations. We will read some statements. Please answer whether you (1) strongly disagree; (2) disagree; (3) agree; (4) strongly agree; (5) don't know

\begin{tabular}{|c|c|c|c|c|c|c|}
\hline QID & $\begin{array}{l}\text { Fruit and Timber trees within } \\
\text { oil palm plantations........ }\end{array}$ & $\begin{array}{l}\text { Strongly } \\
\text { Disagree }\end{array}$ & Disagree & Agree & $\begin{array}{l}\text { Strongly } \\
\text { Agree }\end{array}$ & $\begin{array}{l}\text { Don't } \\
\text { know }\end{array}$ \\
\hline 1. & Increase soil fertility & & & & & \\
\hline 2. & Decrease soil erosion & & & & & \\
\hline 3. & Decrease water availability & & & & & \\
\hline 4. & Increase bird diversity & & & & & \\
\hline 5. & $\begin{array}{l}\text { Increase number of individuals } \\
\text { per bird species }\end{array}$ & & & & & \\
\hline 6. & Increase insect diversity & & & & & \\
\hline 7. & $\begin{array}{l}\text { Increase number of individuals } \\
\text { per insect species }\end{array}$ & & & & & \\
\hline 8. & $\begin{array}{l}\text { Decrease likelihood of pest and } \\
\text { disease in oil palm plantations }\end{array}$ & & & & & \\
\hline 9. & Increase the oil palm yield & & & & & \\
\hline 10. & Decrease oil palm yield & & & & & \\
\hline 11. & $\begin{array}{l}\text { Compete with oil palm trees for } \\
\text { nutrients }\end{array}$ & & & & & \\
\hline
\end{tabular}




\section{Cultivation of Fruit and Timber Trees Outside Oil-Palm Plots}

Now we would like to know, if you cultivate any of the below mentioned fruit and timber trees outside oil palm plantations. If the respondent does not cultivate the following systems, please indicate this by N.A.

Please tick $(\sqrt{ })$ the related blank box, which shows the name of the trees and the type of the field where it is cultivated!

\begin{tabular}{|c|c|c|c|c|c|c|}
\hline \multirow[t]{2}{*}{ QID } & \multirow[t]{2}{*}{ Type of fields } & \multicolumn{5}{|c|}{ Type of tree } \\
\hline & & Jengkol & Durian & Petai & Jelutung & Sungkai \\
\hline 1. & Home garden & & & & & \\
\hline 2. & Rubber Plantation & & & & & \\
\hline 3. & $\begin{array}{l}\text { Individual owned production } \\
\text { forest }\end{array}$ & & & & & \\
\hline 4. & Other, specify: & & & & & \\
\hline
\end{tabular}

\section{Bird Diversity, Abundance and Distribution in Oil Palm Plantation}

The following questions refer to the specific plot.

1. Have you ever observed any birds on your oil palm plot?

If QID1=1:

2. How many different bird species have you observed on the plot? (1) Yes, (2) No

If you know the names of the birds observed on the plots, please write them down below:

\begin{tabular}{|l|l|}
\hline QID & Name of birds \\
\hline 3. & \\
\hline 4. & \\
\hline 5. & \\
\hline 6. & \\
\hline
\end{tabular}

7. Have you observed birds feeding on the oil palm fruits? (1) Yes, (2) No

If QID7=1:

If you know the names of the birds feeding on oil palms, please write down below:

\begin{tabular}{|l|l|}
\hline QID & Name of birds \\
\hline 8. & \\
\hline 9. & \\
\hline 10. & \\
\hline 11. & \\
\hline
\end{tabular}


12. According to your observation, is the number of bird species and/or the number of individuals per bird species in non-oil palm structures (fruit and timber tress, river, lake) larger, the same or smaller than in oil palm plantations?

smaller, (3) the same

(1) larger, (2)

13. Do you think that birds have a positive, negative, or no effect on the yield of oil palm? (1) Positive effect, (2) Negative effect, (3) No effect

14. Please specify why you think that birds have a (see answer QID: 13) effect:

15. Do you currently own rubber or jungle rubber plantations?

(1)Yes, (2) No

\section{If QID15=1:}

16. Have you observed more, less or the same number of birds on the rubber/jungle rubber plots compared to oil palm plots?

(1) More, (2) the same (3) less

\section{Birds Caught at the Specific Oil-Palm Plot}

1. Have you caught any birds in the last 12 months? If QID1=1, please fill out the table: (1) Yes, (2) No

\begin{tabular}{|l|l|l|l|l|}
\hline QID & $\begin{array}{l}\text { Total number of birds } \\
\text { caught in the last 12 } \\
\text { months (\#) }\end{array}$ & \multicolumn{3}{|l|}{ Number of birds caught per location (\#) } \\
\cline { 3 - 5 } & & On specific plot & $\begin{array}{l}\text { Within 1 km around } \\
\text { plot }\end{array}$ & $\begin{array}{l}\text { Other loca- } \\
\text { tion }\end{array}$ \\
\hline 2. & & & & \\
\hline
\end{tabular}

3. Do you know the species name of at least one caught bird? If QID3=1, please fill out table: (1) Yes, (2) No

\begin{tabular}{|l|l|l|l|l|}
\hline QID & Bird species & $\begin{array}{l}\text { Number of caught } \\
\text { birds per bird species } \\
\text { (if known) in last 12 } \\
\text { months (\#) }\end{array}$ & $\begin{array}{l}\text { Number of sold } \\
\text { birds per bird } \\
\text { species } \\
\text { (\#) }\end{array}$ & $\begin{array}{l}\text { Average price } \\
\text { per bird spe- } \\
\text { cies } \\
\text { ('000 Rp) }\end{array}$ \\
\hline 4. & & & & \\
\hline 5. & & & & \\
\hline 6. & & & & \\
\hline 7. & & & & \\
\hline
\end{tabular}


We will read out three categories of bird sizes. Please, name the number of birds caught per category of bird size (not wingspan).

\begin{tabular}{|l|l|l|l|l|}
\hline QID & Bird size & $\begin{array}{l}\text { Number of caught } \\
\text { birds per bird size cat- } \\
\text { egory (if known) in } \\
\text { last 12 months (\#) }\end{array}$ & $\begin{array}{l}\text { Number of sold } \\
\text { birds per bird } \\
\text { size category } \\
\text { (\#) }\end{array}$ & $\begin{array}{l}\text { Average price } \\
\text { per bird per } \\
\text { bird size cate- } \\
\text { gory } \\
\text { ('000 Rp) }\end{array}$ \\
\hline 8. & $<15 \mathrm{~cm}$ & & & \\
\hline 9. & $15 \mathrm{~cm}-25 \mathrm{~cm}$ & & & \\
\hline 10. & $>25 \mathrm{~cm}$ & & & \\
\hline
\end{tabular}

Which characteristics/features of birds increase the selling price? Order features according to importance.

\begin{tabular}{|l|l|}
\hline QID & Characteristics \\
\hline 11. & \\
\hline 12. & \\
\hline 13. & \\
\hline
\end{tabular}

Which method(s) do you use to catch the birds?

\begin{tabular}{|l|l|}
\hline QID & Method \\
\hline 14. & \\
\hline 15. & \\
\hline 16. & \\
\hline
\end{tabular}

17. Number of birds that you keep as pet in your household: (\#)

Thanks for your participation! 


\section{Appendix IX: “Warm-up” questions}

\section{Question 1:}

A farmer owns 5 hectares of land. He decides to cultivate oil palm on 3 hectares of land. How many hectares of land are still available for cultivation? Please record your answer.

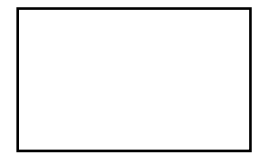

\section{Question 2:}

How many bottles of coca cola are stacked on these two pallets (assuming that no bottle is missing)? Please record your answer.
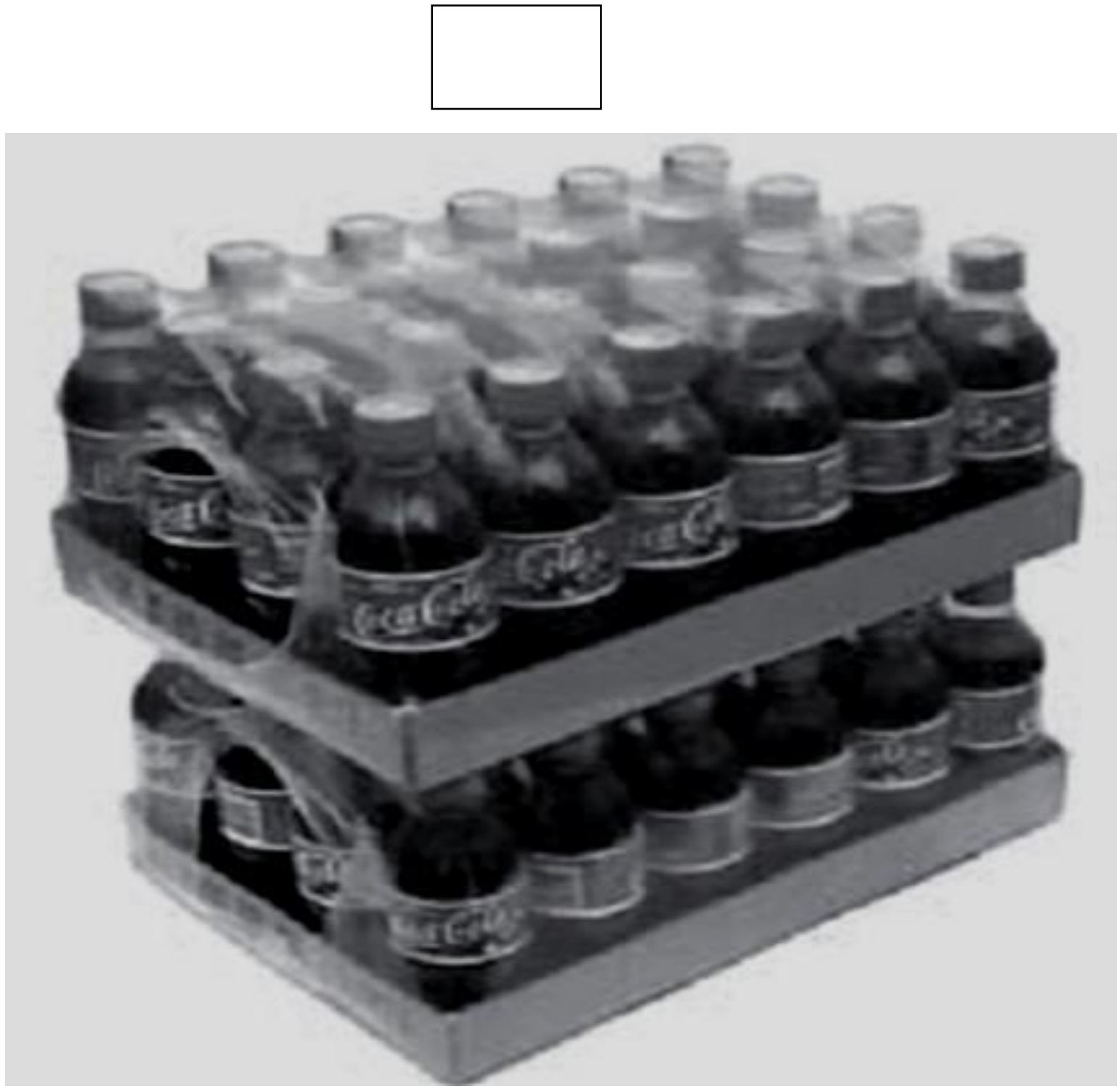


\section{Question 3:}

\begin{tabular}{|l|l|}
\hline & Profit \\
\hline Crop A & 100,000 IDR/ha \\
\hline Crop B & 50,000 IDR/ha \\
\hline
\end{tabular}

This table depicts the profit per hectare of crop A and B, respectively. One hectare cultivated with crop A generates a profit of 100,000 IDR. One hectare cultivated with crop B gives a profit of 50,000 IDR. Which crop yields the higher profit per hectare? Please tick the respective box.

\section{Crop A}

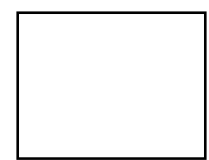

Crop B

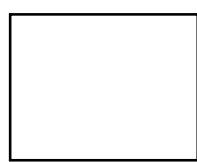

\section{Question 4:}

\begin{tabular}{|l|l|l|}
\hline & Profit & Bonus \\
\hline Crop A & 100,000 IDR $/ \mathrm{ha}$ & -- \\
\hline Crop B & 50,000 IDR/ha & 10,000 IDR $/ \mathrm{ha}$ \\
\hline
\end{tabular}

This table depicts the profit per hectare of crop A and B, respectively. One hectare cultivated with crop A generates a profit of 100,000 IDR. One hectare cultivated with crop B gives a profit of 50,000 IDR. In addition, a bonus of 10,000 IDR per hectare cultivated with crop B is paid. Which crop yields the higher overall profit (incl. bonus) per hectare? Please tick the respective box.

\section{Crop A}

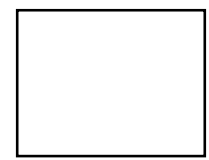

\section{Crop B}

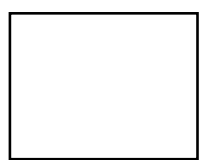




\section{Question 5:}

\begin{tabular}{|l|l|l|}
\hline & Profit & Bonus \\
\hline Crop A & 100,000 IDR $/ \mathrm{ha}$ & -- \\
\hline Crop B & 50,000 IDR/ha & 30,000 IDR /ha \\
\hline
\end{tabular}

This table depicts the profit per hectare of crop A and B, respectively. One hectare cultivated with crop A generates a profit of 100,000 IDR. One hectare cultivated with crop B gives a profit of 50,000 IDR. In addition, a bonus of 30,000 IDR per hectare cultivated with crop B is paid. Which crop yields the higher overall profit (incl. bonus) per hectare? Please tick the respective box.

Crop A

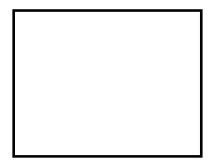

Crop B

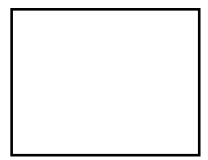




\section{Appendix X: Instructions Public good game}

The workshop comprises:

1. Sign-in (location and arrival)

2. Introduction and agenda (an introduction of the experimenter, enumerators and the project)

3. Warm-up Quiz

4. Instructions and examples

5. Hypothetical and non-hypothetical decisions

6. Post-experimental survey

7. Payment (voucher)

\section{Sign-in (location and arrival)}

- Each participant is signed in by stating his/her name and showing the invitation letter. An enumerator accompanies the participant to a randomly assigned seat, which is the participant's location throughout the session.

- The experiment is conducted in session of 9 participants in classrooms in local schools or kindergartens.

- The typical layout of the room is as follows:

Front of the room (experimenter, and white board)

\begin{tabular}{|l|l|l|}
\hline Seat 1 & Seat4 & Seat7 \\
\hline Seat2 & Seat5 & Seat8 \\
\hline Seat3 & Seat6 & Seat9 \\
\hline Back of the room (Enumerators) & \\
\hline
\end{tabular}

Notes:

- Text in italics is not part of the instructions.

- The instructions are explained orally by the experimenter in the local language (Bahasa Indonesia). 


\section{Introduction and agenda}

Good afternoon and welcome to this workshop. Before we start we would like to thank you for your assistance. The experimenter introduces himself, the enumerators and the project, typically as follows:This workshop is organized by the EFFORTS project that aims to understand the decisions that farmers make associated to the four transformation systems: forest, rubber agroforestry, rubber and oil palm monoculture. The project is affiliated to the University of Göttingen, Germany, University of Jambi and IPB University of Bogor. The results will used for academic purpose only. We have been holding workshops with farmers in three other villages, e.g. , in Batanghari district.

In this workshop you can earn some money, which will be given to you as a voucher for the shop in your village. Your earnings in this workshop depend on your decisions and the decisions of your group members. In other words, you can influence the amount of money the group members earn and your earnings will be influenced by your group members. Today's workshop includes the following steps. First, we explain the instructions of the different tasks on decision making. Then you will do two hypothetical runs by yourself, before we will start with the actual decision rounds. At the end of the workshop you receive the earnings you have generated in this workshop, as a food voucher, which can be made payable in the local shop in your village. The workshops will take approximately two hours.

\section{Some general comments:}

- Please don't use your mobile phone throughout the workshop.

- The workshop in which you participate now is most likely different from the ones your neighbors in this village have already participated. Hence comments you might have heard in the last days, do not apply necessarily for your session.

- All decisions you make or answers you give during the workshop will remain private, confidential and anonymous. Only the number tags that you will receive in a moment will help us to distinguish your answers. So neither the other session members no the experimenter team are able to assign you as a person to a specific decision or earning.

- Since all your decisions are private, don't talk to each other anymore. Please do not discuss with your neighbor. 
- Please follow these instructions carefully, so that everbidy can make sure that you understood the explanation. If you have any questions, please raise your hands. A member of the research team will come to you and answer your questions.

Do you have any questions so far?

\section{Warm-up Quiz}

We will start today's workshop with a short warm-up exercise. The experimenter hands out the questionnaires to the participants. Three enumerators assist the participants in filling out the questionnaire. The exercise contains four different questions. It is not at test; so you don't need to worry if they seem difficult. Please fill out the questions by yourself and do not discuss it with your neighbors. When you have finished, please turn round the sheets. Questions are asked with regard to subtraction and addition of numbers. This basically enables the participants to start thinking about the material and decisions they will be presented with during the workshop. After all participants have finished the sheets were collected by enumerators.

\section{Instructions}

Posters are displayed on a large white board in front of the room to explain the basics of the experiment. In addition, the experimental material, such as envelopes, decision cards and stickers are used by the experimenter to explain the decision making progress.

\section{- General}

\section{What you need to do during the workshop?}

In this workshop you will play in groups of 3 people. It means that two other people in this session will be in your group. You don't know and will never know who is in your group. The groups remain the same throughout the whole workshop.

In this session you can own either 5 or 10 ha of land. Each of you will choose one of these brown closed envelopes at the beginning of the session. In the envelope you find these green stickers. One sticker represents one ha. So you will find in your chosen envelope either 5 or 10 stickers in a row, indicating 5 or 10 ha. Whether you receive 5 or 10 ha depend on the envelope you choose at the beginning of the session. It indicates it is completely random how many ha you receive and cannot be influenced by you or 
others in the group. Experimenter shows both the brown envelope, one sticker and the row of 5 and 10 stickers respectively.

Then you have to decide what you want to plant on your land. You can choose between two production systems: Oil palm and Jungle rubber. You can decide how many ha you plant with oil palm and how many ha you plant with jungle rubber. Experimenter shows a picture of oil palm monoculture plantation and jungle rubber system, respectively. Even though, I guess you are familiar with these two production systems, I would like to briefly introduce them to you. Here you can see a picture of an oil palm plantation, where the oil palms are planted in rows and fertilizer and herbicides are applied. This is a picture of a jungle rubber plot. In jungle rubber, you can find besides rubber trees also other trees like Rambutan, Durian, Meranti and fertilizer and herbicides are seldom used. Compared to oil palm, jungle rubber is good for the environment: soil is healthier, more water is available and the number of birds and mammals is higher. As in real life the earnings in this session depend on what you plant on your ha. The earnings from oil palm and jungle rubber differ. Oil palm generates a higher profit per ha than jungle rubber.

So far any questions? To wrap up, you receive either 5 or 10 ha and you have to decide how many you plant with oil palm plantation and jungle rubber, respectively. While jungle rubber is better for the environment, oil palm generated higher earnings.

\section{How much can you earn in this game?}

The experimenter displays a large earning table on the white board.

Here you can see an earning table. The earning table of one decision round remains here until you have made your decision that you can look up the earnings again during your decision making process. We will go slowly through it.

As I already mentioned, the amount on the voucher that you can earn in this workshop, depends on the decision on how many hectares you cultivate oil palm and jungle rubber respectively.

The earnings that you receive per ha oil palm and jungle rubber depend on the amount of land that you own. Participants with 5 ha look their earnings up here; participants with 10 ha look their earnings up here. Experimenter points at the respective columns.

Suppose that you own 5 ha: One ha planted with oil palm gives you 100,000 IDR; one ha with jungle rubber gives you 50,000 IDR. Experimenter points at respective cells. 
Which production system gives the higher earnings per ha? The earnings from one ha planted with oil palm are higher than the earnings generated from one ha cultivated with jungle rubber.

Suppose that you own 10 ha: One ha planted with oil palm gives you 100,000 IDR. One ha planted with jungle rubber gives you 60,000 IDR.

Which production system generates the higher earning per ha? Like for the 5 ha farmers, the earnings from one ha planted with oil palm are higher than the earnings generated from one ha cultivated with jungle rubber.

Now, let us compare the earnings for farmers with 5 ha with the earnings of farmers with 10 ha: For oil palm, both farmers with 5 and 10 ha receive 100,000 IDR. Are the earnings per ha oil palm the same for 5 and 10 ha farmers? Yes! Are they also the same for jungle rubber? Let's take a look. Farmers with 5 ha receive 50,000 IDR from one ha planted with jungle rubber. Farmers with 10 ha receive 60,000 IDR from one ha planted with jungle rubber. So farmers with 5 ha receive less from one ha planted with jungle rubber than farmers with 10 ha. Experimenter points at respective cells.

As I have already mentioned, your earnings do not only depend on your decision on how many ha you plant with oil palm and jungle rubber respectively, it also depends on the decision of your group members (the other two participants in your group). These earnings are depicted in this column. Experimenter point at respective column. One ha that you plant with jungle rubber, gives your two group members 20,000 IDR. And the other way around, one ha planted by your group members gives you 20,000 IDR. Let's make an example: Suppose we (Experimenter randomly selects two others) are in one group. Of course, in the experiment you won't know the other two group members. Let's assume I plant one ha of jungle rubber, he/she receives 20,000 IDR each. It indicates that I can influence the earnings of my two group members. And the other way around, let's assume, he /she plants one ha jungle rubber I receive 20,000 IDR. It means that my earnings are affected by the decision of my group members.

If you have any questions, please ask.

We will play together a number of decisions. In each decision we will change the earnings. In each decision, you decide how many ha you want to plant with oil palm and how many ha you want to plant with jungle rubber. Due to the fact that the numbers change from decision to decision, please make your decision very carefully. 


\section{How to make decisions?}

As I mentioned before, in this brown envelope you can find stickers, the number of ha that you own in this workshop. For each decision you will receive a new envelope with the same amount of stickers as in the previous decision. In addition you will find this decision card, with a picture of an oil palm plantation and jungle rubber plot. Experimenter show small decision card. A large decision card is displayed on the white board. On this decision card you make your decisions on how many ha you want to plant with oil palm and how many ha you want to plant with jungle rubber.

Let's make an example (1). The example is done on the white board with green dots, representing the stickers. Suppose that you receive a brown envelope with 5 ha, (represented by 5 stickers) Experimenter holds up the green dots and you decide to plant 3 ha with oil palm. You stick 3 stickers here, where you can see the picture of an oil palm plantation. Experimenter sticks the green dots on the white board. Now, you have planted 3 ha with oil palm plantation. In this example you intend to plant 2 ha with jungle rubber. Therefore you stick the stickers here, where you can see the picture of a jungle rubber plot. Experimenter sticks the green dots on the white board. What have you planted? Experimenter counts the green dots. Now you have planted 3 ha oil palm plantation and 2 ha jungle rubber plot. All ha (stickers) have to be used in one decision round. Experimenter shows two alternative combinations of oil palm and jungle rubber by switching the green dots on the white board (1 oil palm/4 jungle rubber, 4 oil palm/1 jungle rubber). All possible combination should be considered in your decision process (Also $5 / 0 ; 0 / 5$ ).

Let's make a second example (2): Again, the experimenter does the example on a white board (decision card for 10 ha farmers). Suppose that you receive a brown envelope with 10 ha, indicating that you own 10 ha in each decision round. Assuming that you decide to plant 4 ha with oil palm plantation, you stick 4 stickers here where you can see the picture of oil palm plantation. Experimenter sticks the stickers on the white board. Now you have planted 4 ha with oil palm plantation. On the remaining 6 ha you decide to cultivate jungle rubber. You stick 6 stickers, where you can see the picture of a jungle rubber plot. Experimenter sticks the stickers on the white board. Experimenter shows two alternative combinations of oil palm and jungle rubber by switching the green dots on the white board $(8 / 2 ; 2 / 8)$. All possible combination should be considered in your decision process (Also 10/0;0/10).

\section{What would have you earned in these two examples?}


Example 1: Experimenter has both the earning table and the decision cards from the previous examples on the white board. The calculation is written on a large blank paper on the white board. In the first example, you had 5 ha of land. You planted 3 ha with oil palm and 2 ha with jungle rubber. Experimenter shows on white board. Where do you have to look up the earnings for 5 ha farmers? This row. Experimenter points at respective row. One ha planted with oil palm gives you 100,000 IDR. Experimenter shows respective cell. Since you decided in this example to plant 3 ha with oil palm, the earnings from oil palm are $3 * 100,000$ IDR $=300,000$ IDR. In addition, we assumed that you decided to plant 2 ha with jungle rubber. One ha gives you 50,000 IDR. You earned from jungle rubber $2 * 50,000$ IDR $=100,000$ IDR. The calculation is written on white board. Are we already done with the whole calculation of your earning? No, the earnings generated due to the cultivation of jungle rubber by the group members have to be calculated. In addition, each ha that your two group members plant with jungle rubber, gives you 20,000 IDR. Experimenter shows on white board. Let's suppose that your group members planted together 6 ha of jungle rubber. You earned $6 * 20,000$ IDR=120,00 IDR. In this example you earned in total 520,000 IDR. Amounts are summed up by experimenter. At the end of the session one decision is randomly drawn, $10 \%$ of the earnings are given to you in a closed envelope. Since the envelopes are closed, none of the other workshop members receive information on how much the others have earned in this workshop. $10 \%$ of 520,000 IDR are 52,000 IDR. Experimenter writes down the calculation on white board. Experimenter shows a voucher, containing the information on the amount of earnings $(52,000 I D R)$.

Example 2: In this example you own 10 ha. You decided to plant 4 ha with oil palm and 6 ha with jungle rubber. Experimenter shows on white board. Since you owned 10 ha, we have to look the earnings up here. Experimenter points at respective cell. What have you earned in this decision round? How much do you earn from one ha cultivated with oil palm? Calculation is written on white board by experimenter. One ha planted with oil palm gives you 100,000 IDR. In this example, you plant 4 ha with oil palm plantation. The earnings from oil palm are 4*100,000 IDR=400,000 IDR. You planted 6 ha with jungle rubber. How much do you earn from one ha cultivated with jungle rubber? One ha planted with jungle rubber gives you 60,000 IDR. You earned from jungle rubber 6*60,000 IDR=360,000 IDR. Are we already done with the calculation of the earnings? No! In addition, each ha that your group members plant with jungle rubber gives you 
20,000 IDR. Let's suppose that your other two group members planted in total 6 ha with jungle rubber. You earned $6 * 20,000$ IDR=120,000 IDR. In this example, you earned in total $880,000 \mathrm{IDR} * 10 \%=88,000 \mathrm{IDR}$.

You do not need to worry that you have to calculate your earnings by yourself. The earnings will be calculated by the team of enumerators. Nevertheless, for your decision making process it is quite important that you listen carefully to the explanations of the earning tables.

Do you have any questions so far?

Then, it is time that you make your decision by yourself. Before we start with the actual decisions, we play two decisions. The earnings of those two decisions won't be paid out to you. It more that you get used to the whole procedure. The earnings we state here are for the next two decisions only hypothetical, afterwards we will play the actual decisions, where you can earn money. The enumerators assist you.

\section{Hypothetical decisions}

Communication of any kind is not allowed. Please make your private decisions.

Now, each of you choose one of these brown envelopes and keep it closed in front of you. Participant choose brown envelope. Please open your envelope. Please fix this ID card on your cloth. Experimenter shows how to fix ID card. Enumerators assist participants. In the envelope you can find either 5 or 10 stickers, indicating the number of ha you own in each decision and the decision card.

Before you make your decision, I will explain the earning table to you.

\section{- Decision 1 (base scenario, no PES):}

Experimenter uses the earning table displayed on white board to explain the earnings.

Suppose that you own 5 ha: One ha planted with oil palm gives you 100,000 IDR, one ha with jungle rubber gives you 50,000 IDR. Experimenter points at respective cells.

Suppose that you own 10 ha: One ha planted with oil palm gives you 100,000 IDR. One ha planted with jungle rubber gives you 60,000 IDR. Which production system generates higher earnings per ha? The earnings from one ha planted with oil palm are higher than the earnings generated from one ha cultivated with jungle rubber.

Now, let us compare the earnings for farmers with 5 ha with the earnings of farmers with 10 ha: For oil palm, both farmers with 5 and 10 ha receive 100,000 IDR. Are the earnings per ha jungle rubber the same for 5 and 10 ha farmers? No! Farmers with 5 ha 
receive 50,000 IDR from one ha planted with jungle rubber. Farmers with 10 ha receive 60,000 IDR from one ha planted with jungle rubber. Hence, farmers with 5 ha receive less from one ha planted with jungle rubber than farmers with 10 ha. Experimenter points at respective cells. Are we already done with the explanation of the earning table? No! One ha that you plant with jungle rubber gives your two group members 20,000 IDR. And the other way around, one ha planted by your group members gives you 20,000 IDR. Remember, now we play only hypothetically, so this money is not paid out to you.

Please make you decision on how many ha you plant with oil palm and jungle rubber, respectively by sticking our stickers on the respective areas of the decision card. The enumerators assist you.

When you have done your decisions and no stickers are left, please put your decision card back into the brown envelope.

Now we play a second decision round. You will receive a white envelope, where you can find the same amount of stickers, as in the previous decision round and again the decision card. Since some numbers in the earning table will change, we will go again through the earning table. Please listen carefully. After the explanation, you are allowed to make your decision. Enumerators distribute white envelopes.

- Decision with monetary incentive for jungle rubber From here on, the explanations differ according to the treatments. Treatments:

1. Equal PES scheme, where incentive is explicitly framed as Payments for Environmental Services.

2. Discriminatory PES scheme, where incentive is explicitly framed as Payments for Environmental Services.

3. Non-framed incentive, where incentive is not framed as Payments for Environmental Services.

\section{Equal PES treatment:}

What is different in this decision round? We would like to introduce Payments for Environmental Services (PES)-like a bonus for the cultivation of jungle rubber (you do not receive this bonus for the cultivation of oil palm). As we mentioned before, jungle rub- 
ber cultivation compared to oil palm has a positive impact on the environment: soil is healthier, more water is available and the number of birds and mammals increases. Therefore, we would like to foster pro-environmental behavior by paying extra amount of earning for the cultivation of jungle rubber. Experimenter changes the earning table by sticking an additional row for the Payments for environmental services on the white board.

Let's go through the earning table together: Suppose that you own 5 ha. One ha planted with oil palm gives you 100,000 IDR, one ha with jungle rubber gives you 50,000 IDR. Here, you can see the bonus for the cultivation of jungle rubber. For each ha cultivated with jungle rubber, we give you a PES of 20,000 IDR, since jungle rubber cultivation is positive for the environment. In total, you earn per ha cultivated with jungle rubber 70,000 IDR. Experimenter points at respective cells. Which production system generates higher earning per ha? The earnings from one ha planted with oil palm are higher than the earnings generated from one ha cultivated with jungle rubber. Suppose that you own 10 ha. One ha planted with oil palm gives you 100,000 IDR. One ha planted with jungle rubber gives you 60,000 IDR. Here you can see the bonus for the cultivation of jungle rubber. For each ha cultivated with jungle rubber, we give you a PES of 20,000 IDR, since jungle rubber cultivation is positive for the environment. In total, you earn per ha cultivated with jungle rubber 80,000 IDR. Which production system generates higher earnings per ha? The earnings from one ha planted with oil palm are higher than the earnings generated from one ha cultivated with jungle rubber.

Let's compare the bonus of 5 and 10 ha farmers. Both 5 and 10 ha farmers receive the same amount of bonus per ha jungle rubber. It indicates that, even with bonus, 10 ha farmers earn more (80,000 IDR) per ha than 5 ha farmers. They earn only 70,000 IDR per ha jungle rubber. In addition, one ha that you plant with jungle rubber gives your two group members 20,000 IDR. And the other way around, one ha planted by your group members gives you 20,000 IDR. Remember this only a hypothetical decisions, so the money you earn in this round in not paid out to you.

Please make you decision on how many ha you plant with oil palm and jungle rubber, respectively by sticking our stickers on the respective areas of the decision card. The enumerators assist you. When you have done your decisions and no stickers are left, please put your decision card back into the white envelope. 
We have played decisions. As you have recognized, we change the earnings between the decision rounds. Therefore it is quite essential that you make your decision very carefully. All combinations of oil palm /jungle rubber are possible and reasonable.

Now, we going to make the actual decisions. Now, it is not hypothetically any more. Your decisions in the upcoming decisions determine the amount that you gain in this workshop.

\section{Discriminatory PES treatment}

What is different in this decision round? We would like to introduce Payments for Environmental Services (PES)-like a bonus for the cultivation of jungle rubber (you do not receive this bonus for the cultivation of oil palm). As we mentioned before, jungle rubber cultivation compared to oil palm has a positive impact on the environment: soil is healthier, more water is available and the number of birds and mammals increases. Therefore, we would like to foster pro-environmental behavior by paying extra amount of earning for the cultivation of jungle rubber. Experimenter changes the earning table by sticking an additional row for the Payments for environmental services on the white board.

But this bonus is not the same for 5 and 10 ha farmers. 5 ha farmers receive a bonus for the cultivation of jungle rubber than 10ha farmers. Let's compare the bonus of 5 and 10 ha farmers. 5 ha farmers receive a bonus of 25,000 IDR, while 10 ha farmers receive only a bonus of 15,000 IDR. So, if you have 5 ha you receive more than the farmers with 10 ha. We decided to give 5 ha farmers a higher bonus than 10 ha farmers because 5 ha farmers receive without bonus less for jungle rubber than 10 ha farmers $(50,000$ vs. 60,000). Experimenter points at respective cell. Let's go through the earning table together: Suppose that you own 5 ha. One ha planted with oil palm gives you 100,000 IDR, one ha with jungle rubber gives you 50,000 IDR. Here, you can see the bonus for the cultivation of jungle rubber. For each ha cultivated with jungle rubber, we give you a PES of 25,000 IDR, since jungle rubber cultivation is positive for the environment. In total, you earn per ha cultivated with jungle rubber 75,000 IDR. Experimenter points at respective cells. Which production system generates higher earning per ha? The earnings from one ha planted with oil palm are higher than the earnings generated from one ha cultivated with jungle rubber. Suppose that you own 10 ha. One ha planted with oil 
palm gives you 100,000 IDR. One ha planted with jungle rubber gives you 60,000 IDR. Here you can see the bonus for the cultivation of jungle rubber. For each ha cultivated with jungle rubber, we give you a PES of 15,000 IDR, since jungle rubber cultivation is positive for the environment. In total, you earn per ha cultivated with jungle rubber 75,000 IDR. Which production system generates higher earnings per ha? The earnings from one ha planted with oil palm are higher than the earnings generated from one ha cultivated with jungle rubber. In addition, one ha that you plant with jungle rubber gives your two group members 20,000 IDR. And the other way around, one ha planted by your group members gives you 20,000 IDR. Remember this only a hypothetical decisions, so the money you earn in this round in not paid out to you.

Remember, the PES is different for 5 and 10 ha farmers. We decided to give 5 ha farmers a higher bonus than 10 ha farmers because 5 ha farmers receive without bonus less for jungle rubber than 10 ha farmers $(50,000$ vs. 60,000). After the introduction of this unequal PES both type of farmers receive 75,000 IDR per ha jungle rubber. So before the introduction of PES 5 and 10ha were unequal, now they are equal in terms of earnings from jungle rubber.

Please make you decision on how many ha you plant with oil palm and jungle rubber, respectively by sticking our stickers on the respective areas of the decision card. The enumerators assist you. When you have done your decisions and no stickers are left, please put your decision card back into the white envelope.

We have played decisions. As you have recognized, we change the earnings between the decision rounds. Therefore it is quite essential that you make your decision very carefully. All combinations of oil palm /jungle rubber are possible and reasonable.

Now, we going to make the actual decisions. Now, it is not hypothetically any more. Your decisions in the upcoming decisions determine the amount that you gain in this workshop.

\section{Non-framed treatment}

What is different in this decision round? We would like to increase the profit generated from rubber agroforestry. Experimenter changes the earning table by sticking an additional row for the Payments for environmental services on the white board. 
Let's go through the earning table together: Suppose that you own 5 ha. One ha planted with oil palm gives you 100,000 IDR, one ha with jungle rubber gives you 50,000 IDR. Here, you can see the increase in the profit for the cultivation of jungle rubber. For each ha cultivated with jungle rubber, you receive in addition 20,000 IDR.. In total, you earn per ha cultivated with jungle rubber 70,000 IDR. Experimenter points at respective cells. Which production system generates higher earning per ha? The earnings from one ha planted with oil palm are higher than the earnings generated from one ha cultivated with jungle rubber. Suppose that you own 10 ha. One ha planted with oil palm gives you 100,000 IDR. One ha planted with jungle rubber gives you 60,000 IDR. For each ha cultivated with jungle rubber, you receive in addition 20,000 IDR. In total, you earn per ha cultivated with jungle rubber 80,000 IDR. Which production system generates higher earnings per ha? The earnings from one ha planted with oil palm are higher than the earnings generated from one ha cultivated with jungle rubber.

Let's compare the bonus of 5 and 10 ha farmers. Both 5 and 10 ha farmers receive the same amount of bonus per ha jungle rubber. It indicates that, even with bonus, 10 ha farmers earn more (80,000 IDR) per ha than 5 ha farmers. They earn only 70,000 IDR per ha jungle rubber. In addition, one ha that you plant with jungle rubber gives your two group members 20,000 IDR. And the other way around, one ha planted by your group members gives you 20,000 IDR. Remember this only a hypothetical decisions, so the money you earn in this round in not paid out to you.

Please make you decision on how many ha you plant with oil palm and jungle rubber, respectively by sticking our stickers on the respective areas of the decision card. The enumerators assist you. When you have done your decisions and no stickers are left, please put your decision card back into the white envelope.

We have played decisions. As you have recognized, we change the earnings between the decision rounds. Therefore it is quite essential that you make your decision very carefully. All combinations of oil palm /jungle rubber are possible and reasonable.

Now, we going to make the actual decisions. So, it is not hypothetically anymore. Your decisions in the upcoming decisions determine the amount that you gain in this workshop.

\section{Non-hypothetical setting}


Communication of any kind is still not allowed. Please make your private decisions.

Now, each of you choose one of these brown envelopes and keep it closed in front of you. Participant choose brown envelope. Please open your envelope. Please fix this ID card on your cloth. Experimenter shows how to fix ID card. Enumerators assist participants. In the envelope you can find either 5 or 10 stickers, indicating the number of ha you own in each decision and the decision card. Before you make your decision, I will go again through the earning table. It is very essential that you listen very carefully.

- Decision 1 (base scenario, no PES):

Experimenter uses the earning table displayed on white board to explain the earnings.

Suppose that you own 5 ha: One ha planted with oil palm gives you 100,000 IDR, one ha with jungle rubber gives you 50,000 IDR. Experimenter points at respective cells.

Suppose that you own 10 ha: One ha planted with oil palm gives you 100,000 IDR. One ha planted with jungle rubber gives you 60,000 IDR. Again, the earning for jungle rubber is lower than for oil palm. Are the earnings per ha jungle rubber the same for 5 and 10 ha farmers? No! Farmers with 5 ha receive less from one ha planted with jungle rubber than farmers with 10 ha. Experimenter points at respective cells. Please consider, furthermore that one ha that you plant with jungle rubber gives your two group members 20,000 IDR. And the other way around, one ha planted by your group members gives you 20,000 IDR. Please make you decision on how many ha you plant with oil palm and jungle rubber, respectively by sticking our stickers on the respective areas of the decision card. The enumerators assist you. When you have done your decisions and no stickers are left, please put your decision card back into the brown envelope.

Now we play a second decision round. You will receive a white envelope, where you can find the same amount of stickers, as in the previous decision round and again the decision card. Since some numbers in the earning table will change, we will go again through the earning table. Please listen carefully. After the explanation, you are allowed to make your decision. Enumerators distribute white envelopes.

- 1. Decision with monetary incentive for jungle rubber

From here on, the explanations differ according to the treatments.

Treatments:

1. Equal PES scheme, where incentive is explicitly framed as Payments for Environmental Services. 


\section{Discriminatory PES scheme, where incentive is explicitly framed as Payments for Environmental Services.}

\section{Non-framed incentive, where incentive is not framed as Payments for Environ- mental Services.}

Please consider that you have to listen very carefully, since the earnings of these decisions will be paid out to you. Please make your decision carefully.

\section{Equal PES treatment:}

What is different in this decision round? We would like to introduce Payments for Environmental Services (PES)-like a bonus for the cultivation of jungle rubber (you do not receive this bonus for the cultivation of oil palm). As we mentioned before, jungle rubber cultivation compared to oil palm has a positive impact on the environment: soil is healthier, more water is available and the number of birds and mammals increases. Therefore, we would like to foster pro-environmental behavior by paying extra amount of earning for the cultivation of jungle rubber. Experimenter changes the earning table by sticking an additional row for the Payments for environmental services on the white board.

Let's go through the earning table together: Suppose that you own 5 ha. One ha planted with oil palm gives you 100,000 IDR, one ha with jungle rubber gives you 50,000 IDR. Here, you can see the bonus for the cultivation of jungle rubber. For each ha cultivated with jungle rubber, we give you a PES of X IDR, since jungle rubber cultivation is positive for the environment. In total, you earn per ha cultivated with jungle rubber X IDR. Experimenter points at respective cells. Which production system generates higher earning per ha? The earnings from one ha planted with oil palm are higher than the earnings generated from one ha cultivated with jungle rubber. Suppose that you own 10 ha. One ha planted with oil palm gives you 100,000 IDR. One ha planted with jungle rubber gives you 60,000 IDR. Here you can see the bonus for the cultivation of jungle rubber. For each ha cultivated with jungle rubber, we give you a PES of X IDR, since jungle rubber cultivation is positive for the environment. In total, you earn per ha cultivated with jungle rubber X IDR. Which production system generates higher earnings per ha? The earnings from one ha planted with oil palm are higher than the earnings generated from one ha cultivated with jungle rubber. 
Let's compare the bonus of 5 and 10 ha farmers. Both 5 and 10 ha farmers receive the same amount of bonus per ha jungle rubber. It indicates that, even with bonus, 10 ha farmers earn more per ha than 5 ha farmers. They earn only X IDR per ha jungle rubber. In addition, as always one ha that you plant with jungle rubber gives your two group members 20,000 IDR. And the other way around, one ha planted by your group members gives you 20,000 IDR.

Please make you decision on how many ha you plant with oil palm and jungle rubber, respectively by sticking our stickers on the respective areas of the decision card. The enumerators assist you. When you have done your decisions and no stickers are left, please put your decision card back into the white envelope.

\section{Discriminatory PES treatment}

What is different in this decision round? We would like to introduce Payments for Environmental Services (PES)-like a bonus for the cultivation of jungle rubber (you do not receive this bonus for the cultivation of oil palm). As we mentioned before, jungle rubber cultivation compared to oil palm has a positive impact on the environment: soil is healthier, more water is available and the number of birds and mammals increases. Therefore, we would like to foster pro-environmental behavior by paying extra amount of earning for the cultivation of jungle rubber. Experimenter changes the earning table by sticking an additional row for the Payments for environmental services on the white board.

But this bonus is not the same for 5 and 10 ha farmers. 5 ha farmers receive a bonus for the cultivation of jungle rubber than 10ha farmers. Let's compare the bonus of 5 and 10 ha farmers. 5 ha farmers receive a bonus of X IDR, while 10 ha farmers receive only a bonus of X IDR. So, if you have 5 ha you receive more than the farmers with 10 ha. We decided to give 5 ha farmers a higher bonus than 10 ha farmers because 5 ha farmers receive without bonus less for jungle rubber than 10 ha farmers $(50,000$ vs. 60,000$)$. Experimenter points at respective cell. Let's go through the earning table together: Suppose that you own 5 ha. One ha planted with oil palm gives you 100,000 IDR, one ha with jungle rubber gives you 50,000 IDR. In addition, for each ha cultivated with jungle rubber, we give you a PES of X IDR, since jungle rubber cultivation is positive for the environment. In total, you earn per ha cultivated with jungle rubber X IDR. Experimenter 
points at respective cells. Suppose that you own 10 ha. One ha planted with oil palm gives you 100,000 IDR. One ha planted with jungle rubber gives you 60,000 IDR. Here you can see the bonus for the cultivation of jungle rubber. For each ha cultivated with jungle rubber, we give you a PES of X IDR, since jungle rubber cultivation is positive for the environment. In total, you earn per ha cultivated with jungle rubber X IDR. Which production system generates higher earnings per ha? For both farmers, the earnings from one ha planted with oil palm are higher than the earnings generated from one ha cultivated with jungle rubber. In addition, as always one ha that you plant with jungle rubber gives your two group members 20,000 IDR. And the other way around, one ha planted by your group members gives you 20,000 IDR.

Remember, the PES is different for 5 and 10 ha farmers. We decided to give 5 ha farmers a higher bonus than 10 ha farmers because 5 ha farmers receive without bonus less for jungle rubber than 10 ha farmers $(50,000$ vs. 60,000). After the introduction of this unequal PES both type of farmers receive X IDR per ha jungle rubber. So before the introduction of PES 5 and 10ha were unequal, now they are equal in terms of earnings from jungle rubber.

Please make you decision on how many ha you plant with oil palm and jungle rubber, respectively by sticking our stickers on the respective areas of the decision card. The enumerators assist you. When you have done your decisions and no stickers are left, please put your decision card back into the white envelope.

\section{Non-framed treatment}

What is different in this decision round? We increase the profit generated from jungle rubber. Experimenter changes the earning table by sticking an additional row for the Payments for environmental services on the white board.

Let's go through the earning table together: Suppose that you own 5 ha. One ha planted with oil palm gives you 100,000 IDR, one ha with jungle rubber gives you 50,000 IDR. The profit of jungle rubber increases by X IDR.. In total, you earn per ha cultivated with jungle rubber X IDR. Experimenter points at respective cells. Suppose that you own 10 ha. One ha planted with oil palm gives you 100,000 IDR. One ha planted with jungle rubber gives you 60,000 IDR. In addition the profit increase by X IDR. In total, you earn per ha cultivated with jungle rubber X IDR. Which production system generates higher earn- 
ings per ha? For both farmers, the earnings from one ha planted with oil palm are higher than the earnings generated from one ha cultivated with jungle rubber.

Let's compare the bonus of 5 and 10 ha farmers. For both 5 and 10 ha the jungle rubber profit increase by the same amount. It indicates that, even with an higher profit, 10 ha farmers earn more (X IDR) per ha than 5 ha farmers. They earn only X IDR per ha jungle rubber. As always, one ha that you plant with jungle rubber gives your two group members 20,000 IDR. And the other way around, one ha planted by your group members gives you 20,000 IDR.

Please make you decision on how many ha you plant with oil palm and jungle rubber, respectively by sticking our stickers on the respective areas of the decision card. The enumerators assist you. When you have done your decisions and no stickers are left, please put your decision card back into the white envelope.

\section{- 2. Decision with monetary incentive}

\section{Equal PES treatment:}

What is different in this decision round? While in the last decision you received X IDR, we would like to increase /decrease the amount of Payments for environmental services. As we mentioned before, jungle rubber cultivation compared to oil palm has a positive impact on the environment: soil is healthier, more water is available and the number of birds and mammals increases. Therefore, we would like to foster proenvironmental behavior by paying extra amount of earning for the cultivation of jungle rubber. Experimenter changes the earning table by sticking an additional row for the Payments for environmental services on the white board.

Let's go through the earning table together: Suppose that you own 5 ha. The earning per ha oil palm and jungle rubber remain the same, 100,000 IDR and 50,000 IDR. Here, again the bonus for the cultivation of jungle rubber. For each ha cultivated with jungle rubber, we give you a PES of X IDR, since jungle rubber cultivation is positive for the environment. In total, you earn per ha cultivated with jungle rubber X IDR. Experimenter points at respective cells. Suppose that you own 10 ha. The earning per ha oil palm and jungle rubber remain the same, 100,000 IDR and 50,000 IDR. Here again the bonus for the cultivation of jungle rubber. For each ha cultivated with jungle rubber, we give you a 
PES of X IDR, since jungle rubber cultivation is positive for the environment. In total, you earn per ha cultivated with jungle rubber X IDR. Which production system generates higher earnings per ha? The earnings from one ha planted with oil palm are higher than the earnings generated from one ha cultivated with jungle rubber, irrespective of the farmer type you are.

As in the decision before, both 5 and 10 ha farmers receive the same amount of bonus per ha jungle rubber. It indicates that, even with bonus, 10 ha farmers earn more per ha than 5 ha farmers. They earn only X IDR per ha jungle rubber. In addition, as always one ha that you plant with jungle rubber gives your two group members 20,000 IDR. And the other way around, one ha planted by your group members gives you 20,000 IDR. Please make you decision on how many ha you plant with oil palm and jungle rubber, respectively by sticking our stickers on the respective areas of the decision card. The enumerators assist you. When you have done your decisions and no stickers are left, please put your decision card back into the white envelope.

\section{Discriminatory PES treatment}

What is different in this decision round? While in the last decision 5 ha farmers received $X$ IDR and 10 ha farmers X IDR, we would like to increase /decrease the amount of Payments for environmental services. As we mentioned before, jungle rubber cultivation compared to oil palm has a positive impact on the environment: soil is healthier, more water is available and the number of birds and mammals increases. Therefore, we would like to foster pro-environmental behavior by paying extra amount of earning for the cultivation of jungle rubber. Experimenter changes the earning table by sticking an additional row for the Payments for environmental services on the white board.

As before this bonus is not the same for 5 and 10 ha farmers. 5 ha farmers receive a higher bonus for the cultivation of jungle rubber than 10 ha farmers. 5 ha farmers receive a bonus of X IDR, while 10 ha farmers receive only a bonus of XIDR. So, if you have 5 ha you receive more than the farmers with 10 ha. We decided to give 5 ha farmers a higher bonus than 10 ha farmers because 5 ha farmers receive without bonus less for jungle rubber than 10 ha farmers $(50,000$ vs. 60,000). Experimenter points at respective cell. Let's go through the earning table together: Suppose that you own 5 ha. The earning per ha oil palm and jungle rubber remain the same, 100,000 IDR and 50,000 IDR. Here, 
again the bonus for the cultivation of jungle rubber. For each ha cultivated with jungle rubber, we give you a PES of X IDR, since jungle rubber cultivation is positive for the environment. In total, you earn per ha cultivated with jungle rubber X IDR. Experimenter points at respective cells. Suppose that you own 10 ha. The earning per ha oil palm and jungle rubber remain the same, 100,000 IDR and 50,000 IDR. Here again the bonus for the cultivation of jungle rubber. For each ha cultivated with jungle rubber, we give you a PES of X IDR, since jungle rubber cultivation is positive for the environment. In total, you earn per ha cultivated with jungle rubber X IDR. Which production system generates higher earnings per ha? The earnings from one ha planted with oil palm are higher than the earnings generated from one ha cultivated with jungle rubber, irrespective of the farmer type you are.

Remember, the PES is different for 5 and 10 ha farmers. We decided to give 5 ha farmers a higher bonus than 10 ha farmers because 5 ha farmers receive without bonus less for jungle rubber than 10 ha farmers $(50,000$ vs. 60,000). After the introduction of this unequal PES both type of farmers receive X IDR per ha jungle rubber. So before the introduction of PES 5 and 10ha were unequal, now they are equal in terms of earnings from jungle rubber.

Please make you decision on how many ha you plant with oil palm and jungle rubber, respectively by sticking our stickers on the respective areas of the decision card. The enumerators assist you. When you have done your decisions and no stickers are left, please put your decision card back into the white envelope.

\section{Non-framed treatment}

What is different in this decision round? While in the last decision you received X IDR, the profit of jungle rubber increases /decreases Experimenter changes the earning table by sticking an additional row for the Payments for environmental services on the white board.

Let's go through the earning table together: Suppose that you own 5 ha. The earning per ha oil palm and jungle rubber remain the same, 100,000 IDR and 50,000 IDR. For each ha cultivated with jungle rubber, we give you now X IDR. Experimenter points at respective cells. Suppose that you own 10 ha. The earning per ha oil palm and jungle rubber remain the same, 100,000 IDR and 50,000 IDR. For each ha cultivated with jungle rub- 
ber, we give you now X IDR. Which production system generates higher earnings per ha? The earnings from one ha planted with oil palm are higher than the earnings generated from one ha cultivated with jungle rubber, irrespective of the farmer type you are. In addition, as always one ha that you plant with jungle rubber gives your two group members 20,000 IDR. And the other way around, one ha planted by your group members gives you 20,000 IDR.

Please make you decision on how many ha you plant with oil palm and jungle rubber, respectively by sticking our stickers on the respective areas of the decision card. The enumerators assist you. When you have done your decisions and no stickers are left, please put your decision card back into the white envelope.

Thank you very much for your participation. Now we would like to continue with a short post experimental survey. The interviews will be done individually. Since we cannot conduct all questionnaire parallel, we ask some of you to wait until they are picked up by the enumerators. Please help yourself with the refreshers. Now you are also allowed to communicate, but we kindly ask you not to talk with your neighbors about the game until the workshop is over. In the meantime your earning that you gained in this workshop will be calculated. 


\section{Appendix: XI: Questionnaire “ Post-Experimental Survey”}

Q1. ID:

Q3. Treatment No.:

Q4. Date of workshop: Q2.Workshop ID:

Q5. Full name of Respondent:

Q6. Interviewer:

Q7. Interviewer's signature:

We kindly ask you to answer some questions regarding the decisions you have recently made. Please tick the appropriate answer.

Q8. In this workshop you earned some money. The amount of money that you earned in this workshop depends:

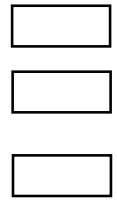

Only on your production decision in this workshop

On your production decision and the production decision of your group members

Neither on your production decision, nor on the production decision of your group members. It was not possible for you or your group members to influence the amount of money earned.

Q 9. In the decisions, all participants had the same amount of available land.

Yes

No

Q 10. The earnings from oil palm (per hectare) were higher than the earnings from rubber agroforestry (per hectare).

$$
\text { Yes }
$$

Q 11. The earnings per hectare rubber agroforestry were different for participants with 5 hectare and those with 10 ha.
$\square$ Yes
No

Q 12. The introduction of Payments for Environmental Services aimed to foster rubber agroforestry cultivation.
$\square$ Yes
No

Q 13. The amount of Payments for Environmental services per hectare rubber agroforestry was different for participants with 5 hectare and those with 10 hectare.

\begin{tabular}{|l|}
$\square$ Yes \\
\hline Q 14. What do you think was the objective of this workshop? \\
\hline
\end{tabular}




\begin{tabular}{|l|l|l|l|l|}
\hline \multicolumn{2}{|c|}{ Do you strongly agree, agree, disagree or strongly disagree with following statements? } \\
\hline & $\begin{array}{l}\text { Strongly } \\
\text { Agree }\end{array}$ & Agree & Disagree & $\begin{array}{l}\text { Strongly } \\
\text { Disagree }\end{array}$ \\
\hline $\begin{array}{l}\text { Q 15. I feel satisfied with the earnings I re- } \\
\text { ceived in this workshop. }\end{array}$ & & & & \\
\hline $\begin{array}{l}\text { Q 16. I had the feeling that I could influence } \\
\text { the amount of the earnings that I received in } \\
\text { this workshop. }\end{array}$ & & & & \\
\hline $\begin{array}{l}\text { Q 17. I had the feeling that the amount of the } \\
\text { earnings was just a matter of luck. }\end{array}$ & & & & \\
\hline $\begin{array}{l}\text { Q 18. I had the feeling that the other group } \\
\text { members mainly behaved fair in this game. }\end{array}$ & & & & \\
\hline
\end{tabular}

In the workshop you decided how many hectares you plant with oil palm and how many hectares you plant with rubber agroforestry. Please indicate below your main reasons for your personal decision. Please indicate how strongly you feel about each reason. If the respective reason does not hold for you, please tick irrelevant.

Q 19. Did you cultivate any oil palm in this workshop?

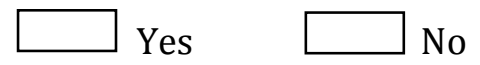

If the respondent did not cultivate oil palm, please continue with Q24.

\begin{tabular}{|l|l|l|l|l|}
\hline $\begin{array}{l}\text { In this workshop, I } \\
\text { planted oil palm }\end{array}$ & Very strongly & Strongly & Moderate & Irrelevant \\
\hline $\begin{array}{l}\text { Q } 20 . . . \text { because it gener- } \\
\text { ates the highest earnings } \\
\text { for me. }\end{array}$ & & & \\
\hline $\begin{array}{l}\text { Q } 21 . . . \text { because I did not } \\
\text { want that my group } \\
\text { members benefit from my } \\
\text { decision and receive the } \\
\text { externality. }\end{array}$ & & & \\
\hline $\begin{array}{l}\text { Q } 22 . . . \text { because I did not } \\
\text { want that my group } \\
\text { member with 10 hectare } \\
\text { benefits from my decision } \\
\text { and receive the externali- } \\
\text { ty. }\end{array}$ & & & \\
\hline $\begin{array}{l}\text { Q } 23 . \text { Was there any other reason for you to plant oil palm in this workshop? } \\
\text { 1.- }\end{array}$ & & \\
$\mathbf{2 . -}$ & & \\
$\mathbf{3}$
\end{tabular}


If respondent owned 10 ha, go to Q37. You owned 5 ha in each decision round. Now, we present some feelings you might have had in this workshop with respect to the fact that you had 5ha. Please indicate how strong you feel about each aspect.

\begin{tabular}{|l|l|l|l|l|}
\hline & $\begin{array}{l}\text { Very } \\
\text { strong }\end{array}$ & Strong & Moderate & $\begin{array}{l}\text { Not at } \\
\text { all }\end{array}$ \\
\hline $\begin{array}{l}\text { Q 29. I had the feeling that it was absolutely } \\
\text { random, that I had 5 hectares in this work- } \\
\text { shop. }\end{array}$ & & & \\
\hline $\begin{array}{l}\text { Q 30. I had the feeling of injustice that I had 5 } \\
\text { hectares in this workshop. }\end{array}$ & & & \\
\hline $\begin{array}{l}\text { Q 31. I think participants with 10 hectares had } \\
\text { feelings of injustice. }\end{array}$ & & & \\
\hline $\begin{array}{l}\text { Q 32. I had the feeling that I had the same pos- } \\
\text { sibilities in this workshop as participants with } \\
10 \text { ha. }\end{array}$ & & & \\
\hline $\begin{array}{l}\text { Q 33. I had the feeling that I had to make more } \\
\text { efforts to earn same money as participants } \\
\text { with 10 hectares. }\end{array}$ & & & \\
\hline $\begin{array}{l}\text { Q 34. I had the feeling that participants with } \\
10 \text { ha earned more money than I. }\end{array}$ & & & \\
\hline $\begin{array}{l}\text { Q 35. I had the feeling that I earned more } \\
\text { money than other participants with 5 hec- } \\
\text { tares. }\end{array}$ & & & & \\
\hline $\begin{array}{l}\text { Q 36. If Q30 != not at all. My feeling of treated } \\
\text { unjustly decreased throughout the workshop. }\end{array}$ & & & & \\
\hline
\end{tabular}

If respondent owned 5 ha, go to Q46. You owned 10 ha in each decision round. Now, we would like to present some feelings you might have had in this workshop with respect to the fact that you had 10ha. Please indicate how strong you feel about each aspect.

Q 37. I had the feeling that it was absolutely random that I had 10 hectares in this workshop.

Q 38. I had the feeling of injustice that I had 10 hectares in this workshop.

Q 39. I think participants with 5 hectares had feelings of injustice.

Q 40. I had the feeling that I had more possibilities in this workshop than participants with 5ha.

Q 41. I had the feeling that I could influence the feeling of injustice of participants with 5 ha by my decisions.

Q 42. I had the feelings that I had to make fewer efforts than participants with 5 ha.

Q 43. I had the feeling that participants with 5 hectares earned less money than I.

$\mathrm{Q}$ 44. I had the impression that I earned more money than other participants with 10 hectares.

Q 45. If Q38 != not at all. My feeling of treated unjustly decreased throughout the workshop. 


\begin{tabular}{|c|c|c|c|c|}
\hline \multicolumn{5}{|c|}{$\begin{array}{l}\text { I decision } 2 \text { and } 3 \text { (non-hypothetical game) we introduced Payment for Environmental } \\
\text { Services for the cultivation of rubber agroforestry. Now we would like to introduce } \\
\text { some feelings you might have had with respect to the bonus. Please indicate how } \\
\text { strong you feel about each aspect. }\end{array}$} \\
\hline & \begin{tabular}{|l|l|l} 
Very \\
strong
\end{tabular} & Strong & Moderate & $\begin{array}{l}\text { Not at } \\
\text { all }\end{array}$ \\
\hline \multicolumn{5}{|l|}{$\begin{array}{l}\text { Q 46. I had the feeling that the bonus for the } \\
\text { planting of rubber agroforestry privileged } \\
\text { participants with } 5 \text { hectares. }\end{array}$} \\
\hline \multicolumn{5}{|l|}{$\begin{array}{l}\text { Q 47. I had the feeling that the bonus for plant- } \\
\text { ing rubber agroforestry privileged partici- } \\
\text { pants with } 10 \text { hectares. }\end{array}$} \\
\hline \multicolumn{5}{|l|}{$\begin{array}{l}\text { Q 48. I had the feeling that the bonus im- } \\
\text { proved my situation in this workshop. }\end{array}$} \\
\hline \multicolumn{5}{|l|}{$\begin{array}{l}\text { Q 49. I had the feeling that the bonus was un- } \\
\text { fair. }\end{array}$} \\
\hline \multicolumn{5}{|c|}{$\begin{array}{l}\text { When you look back at your life, which statements apply to your experience in life and } \\
\text { your person? Please indicate how strong you agree or disagree with the statement. }\end{array}$} \\
\hline & $\begin{array}{l}\text { Strongly } \\
\text { agree }\end{array}$ & Agree & Disagree & $\begin{array}{l}\text { Strong } \\
\text { ly dis- } \\
\text { agree }\end{array}$ \\
\hline \multicolumn{5}{|l|}{ Q 50. I have often experienced injustice. } \\
\hline \multicolumn{5}{|l|}{$\begin{array}{l}\text { Q 51. My family has often experienced injus- } \\
\text { tice. }\end{array}$} \\
\hline \multicolumn{5}{|l|}{ Q 52. I have often observed injustice. } \\
\hline \multicolumn{5}{|l|}{$\begin{array}{l}\text { Q 53. When I meet other people, I am con- } \\
\text { cerned about their expectations about me. }\end{array}$} \\
\hline \multicolumn{5}{|l|}{$\begin{array}{l}\text { Q 54. I try to act like others to be consistent } \\
\text { with social norms. }\end{array}$} \\
\hline \multicolumn{5}{|l|}{$\begin{array}{l}\text { Q 55. I would not complain publicly even } \\
\text { when I have been treated unfair. }\end{array}$} \\
\hline \multicolumn{5}{|l|}{$\begin{array}{l}\text { Q 56. When I have been treated unfair, I will } \\
\text { try to punish others' behavior. }\end{array}$} \\
\hline $\begin{array}{l}\text { Q 57. When I have been treated unfair, I will } \\
\text { try to punish others' behavior even if I lose } \\
\text { money. }\end{array}$ & & & & \\
\hline
\end{tabular}




\begin{tabular}{|l|l|l|l|l|}
\hline & $\begin{array}{l}\text { Very inte- } \\
\text { resting }\end{array}$ & Interesting & Uninteresting & $\begin{array}{l}\text { Very unin- } \\
\text { teresting }\end{array}$ \\
\hline $\begin{array}{l}\text { Q 58. How interesting did you find } \\
\text { this workshop? }\end{array}$ & & & & \\
\hline & $\begin{array}{l}\text { Strongly } \\
\text { Agree }\end{array}$ & Agree & Disagree & $\begin{array}{l}\text { Strongly } \\
\text { disagree }\end{array}$ \\
\hline $\begin{array}{l}\text { Q 59. I received sufficient infor- } \\
\text { mation on the procedure of this } \\
\text { workshop. }\end{array}$ & & & & \\
\hline
\end{tabular}

Q 60. What is fairness for you?

Q 61. How many workshop participants are members of your extended family? (\#)

Q 62. How many workshop participants do you know by name? (\#)

Q 63. To how many workshop participants do you speak at least once

per month? (\#)

Q 64. Nick name

Q 65. Name of your father

Q 66. Name of your firstborn

Q 66. Mobile phone number

Thanks for your participation. 


\section{Appendix XII: Questionnaire “General Household Survey”}

We are researchers from the EFFORT project. It is a collaboration of the University of Goettingen, Germany, the Universitas Pertanian Bogor and the Universitas Jambi. We would like to better understand the decision farmers make in Jambi Province.

If you agree to participate in this study you will be asked to answer some questions. You will be asked some questions about yourself and your family members, your farming activities and your housing and assets. The interview will take about 1 hour.

You are free to ask at any time. All information collected in this study is confidential and will be used strictly for research purpose. In the last workshop you received an ID number, which will also be used in the analysis of this study. Hence your name will not be used.

\section{Respondent Identification}

\begin{tabular}{|l|l|l|}
\hline QID & Question & Answer \\
\hline 1 & Interviewer (Name) & \\
\hline 2 & Respondent (Full name) & \\
\hline 3. & $\begin{array}{l}\text { Is the respondent HH head? } \\
\text { (1) Yes ; (2) No }\end{array}$ & \\
\hline 3.1 & If QID 1.3=2 HH head's full name & \\
\hline 4 & Village (Name) & \\
\hline 5 & RT (Number) & From__t___ \\
\hline 6 & Date of interview (mm/dd/20YY) \\
\hline 7 & Time of interview & \\
\hline 8 & Signature of interviewer & \\
\hline
\end{tabular}

\section{Household Identification and Socio-Demographic Characteristics}

\begin{tabular}{|l|l|l|}
\hline QID & Question & Answer \\
\hline 1. & Total number of members staying in the house in the last 12 months (\#) & \\
\hline 2. & Total number of household members younger than 18 years (\#) & \\
\hline 2.1. & If Q2.2.>0: Number of children visiting regularly school (\#) & \\
\hline 3. & $\begin{array}{l}\text { Total number children (younger than 18 years) staying outside of village } \\
(\#)\end{array}$ & \\
\hline
\end{tabular}


Please fill in the following Table for the RESPONDENT:

\begin{tabular}{|c|c|c|c|c|c|c|}
\hline \multirow[t]{3}{*}{ QID } & 4. & 5. & 6. & 7. & 8. & \\
\hline & \multirow[t]{2}{*}{$\begin{array}{l}\text { Age } \\
\text { (Years) }\end{array}$} & \multirow[t]{2}{*}{$\begin{array}{l}\text { Marital } \\
\text { status } \\
\text { (Code A) }\end{array}$} & \multirow{2}{*}{$\begin{array}{l}\text { Duration } \\
\text { school or } \\
\text { college } \\
\text { (Years) }\end{array}$} & \multirow[t]{2}{*}{$\begin{array}{l}\text { Last gradu- } \\
\text { ation } \\
\text { (Code B) }\end{array}$} & \multicolumn{2}{|c|}{$\begin{array}{l}\text { Main occupation of re- } \\
\text { spondent (in the last } 12 \\
\text { months)? (Code C) }\end{array}$} \\
\hline & & & & & Primary & $\begin{array}{l}\text { Se- } \\
\text { condary }\end{array}$ \\
\hline \multicolumn{7}{|c|}{$\begin{array}{l}\text { Respon- } \\
\text { dent }\end{array}$} \\
\hline \multicolumn{7}{|c|}{ Code A: (1) single; (2) married; (3) widow/widower (4) divorced } \\
\hline \multicolumn{7}{|c|}{$\begin{array}{l}\text { Code B:(1) no graduation; (2) SD (primary); (3) completed SMP (Middle); (4) completed SMA } \\
\text { (High School); (5) D3 or S1 (Associates Degree or University level first stage); (6) student at } \\
\text { present;(7) other, specify: }\end{array}$} \\
\hline \multicolumn{7}{|c|}{$\begin{array}{l}\text { Code C: (1) self-employed agriculture; (2) self-employed non-farm activity; (3) government } \\
\text { employee; (4) daily labourer agriculture; (5) daily labourer outside agriculture; (6) Salaried } \\
\text { employee agriculture; (7) Salaried employee outside agriculture; (8) Student; (9) village em } \\
\text { ployee; (10) unemployed, but looking for job (11) unemployed, unwilling to work (12) retired, } \\
\text { (13) handicapped; (14) housewife (15) other, specify: }\end{array}$} \\
\hline
\end{tabular}

If QID 2.8. = (4) or (6), please continue here:

\begin{tabular}{|l|l|l|l|}
\hline QID & Question & Answer & Code \\
\hline 9. & $\begin{array}{l}\text { On what kind of plantation have you mainly (in } \\
\text { terms of income) worked in the last 12 months? }\end{array}$ & & $\begin{array}{l}\text { (1) Rubber; (2) Oil palm; } \\
\text { (3) Other: speci- } \\
\text { fy: }\end{array}$ \\
\hline
\end{tabular}

\section{Land Ownership}

\begin{tabular}{|c|c|c|c|}
\hline QID & Question & Answer & \\
\hline \multirow[t]{2}{*}{1.} & \multirow[t]{2}{*}{$\begin{array}{l}\text { Land owned by the household at the time of } \\
\text { interview. (1) Yes; (2) No }\end{array}$} & & $\begin{array}{l}\text { If QID 3.1.=1 Size of land in } \\
\text { village: } \quad \text { ha }\end{array}$ \\
\hline & & & $\begin{array}{l}\text { If QID 3.1.=1 Size of land } \\
\text { outside village: }\end{array}$ \\
\hline \multirow[t]{2}{*}{2.} & \multirow[t]{2}{*}{$\begin{array}{l}\text { Land rented by the household at the time of } \\
\text { interview. (1) Yes; (2) No }\end{array}$} & & $\begin{array}{l}\text { If QID 3.2. =1 Size of land } \\
\text { in village: }=\text { ha }\end{array}$ \\
\hline & & & $\begin{array}{l}\text { If QID 3.2.=1 Size of land } \\
\text { outside village: __ ha }\end{array}$ \\
\hline 3. & $\begin{array}{l}\text { Total land cultivated by your household } \\
\text { (individually) at the time of interview. }\end{array}$ & & Size of land: ___ ha \\
\hline 4. & $\begin{array}{l}\text { Do you cultivate any land, owned by others, } \\
\text { at the time of the interview? (1) Yes; (2) No }\end{array}$ & & $\begin{array}{l}\text { If QID 3.4.=1 Size of } \\
\text { land:__ha }\end{array}$ \\
\hline 5. & $\begin{array}{l}\text { Total land cultivated jointly (with inputs } \\
\text { and/or output shared) with other farmers } \\
\text { at the time of interview: } \\
\text { (1) Yes; (2) No }\end{array}$ & & $\begin{array}{l}\text { If QID 3.5.=1 Size of land: } \\
\text { ha } \\
\text { If for more than one } \\
\text { group: Size of land: }\end{array}$ \\
\hline
\end{tabular}




\section{Cultivation (perennial crops)/fallow land}

4.1.What kind of perennial crops are you currently cultivating?

\begin{tabular}{|l|l|l|l|l|}
\hline QID & Question & Oil palm & Rubber plantation & $\begin{array}{l}\text { Jungle rub- } \\
\text { ber }\end{array}$ \\
\hline 1. & Cultivated area of land (ha) & & & \\
\hline 2. & $\begin{array}{l}\text { Cultivated are of land (under } \\
\text { contract) (ha) }\end{array}$ & & & \\
\hline
\end{tabular}

\begin{tabular}{|l|l|l|}
\hline QID & Question & Answer \\
\hline 3. & $\begin{array}{l}\text { Area of land of Fallow land ( land not cultivated } \\
\text { for the last 12 months). (ha) }\end{array}$ & \\
\hline
\end{tabular}

\subsection{History of Cultivation}

\subsubsection{Oil Palm}

1. Have you ever cultivated oil palm? (1) Yes; (2) No

If QID4.2.1.1. =2, go to 4.2.2.

\begin{tabular}{|c|c|c|}
\hline QID & Question & Answer \\
\hline 2. & With how many hectares did you start cultivation? & \\
\hline 3. & Year & \\
\hline 4. & How did this start happen? Code $A$ & \\
\hline 5. & $\begin{array}{l}\text { If QID 4.2.1.4 =1, 3, } 8 \text { or 9: What kind of crop was on this area be- } \\
\text { fore? Code B }\end{array}$ & \\
\hline \multicolumn{3}{|c|}{$\begin{array}{l}\text { Code A: (: (1) purchasing; (2) selling; (3) converted from/to other crops ; (4) conversion of for- } \\
\text { est ; (5) obtained as part of a government programme (e.g. "transmigransi"); (6) established } \\
\text { plantation obtained from company; } \\
\text { (7) inherited; (8) received as gift ; (9) others: specify: }\end{array}$} \\
\hline \multicolumn{3}{|c|}{$\begin{array}{l}\text { Code B: (1) oil palm; (2) plantation rubber ; (3) jungle rubber ; (4) other plantation ; (5) annu- } \\
\text { al crops, specify:_; (6) grassland; (7) forest; (8) bush; } \\
\text { (9) others, specify: }\end{array}$} \\
\hline
\end{tabular}

\begin{tabular}{|l|l|l|l|}
\hline QID & Question & Answer & Code \\
\hline 6. & $\begin{array}{l}\text { Have you ever extended the cultivat- } \\
\text { ed oil palm area? }\end{array}$ & $\begin{array}{l}\text { (1)Yes; (2) No } \\
\text { If QID4.2.1.6=1: Have you ever con- } \\
\text { verted forest to oil palm? }\end{array}$ & $\begin{array}{l}\text { (1)Yes;(2) No } \\
\text { If QID4.2.1.7 =1: Total area of } \\
\text { land:_ha }\end{array}$ \\
\hline 7. & $\begin{array}{l}\text { If QID 4.2.1.6=1: Have you ever con- } \\
\text { verted rubber to oil palm? }\end{array}$ & $\begin{array}{l}\text { (1)Yes; (2) No } \\
\text { If QID4.2.1.8=1: Total area of } \\
\text { land:_ha }\end{array}$ \\
\hline 8. & $\begin{array}{l}\text { Have you ever reduced the cultivated } \\
\text { oil palm area? }\end{array}$ & (1)Yes; (2) No \\
\hline 9.
\end{tabular}




\subsubsection{Rubber plantation}

1. Have you ever cultivated rubber monoculture? (1) Yes; (2) No

If QID 4.2.2.1.=2, go to 4.2.3.

\begin{tabular}{|l|l|l|}
\hline QID & Question & Answer \\
\hline 2. & With how many hectares did you start cultivation? & \\
\hline 3. & Year & \\
\hline 4. & How did this start happen? Code $A$ & \\
\hline 5. & $\begin{array}{l}\text { If QID } \mathbf{4 . 2 . 2 . 4}=\mathbf{1}, \mathbf{3}, \mathbf{8} \text { or 9: What kind of crop was on this area } \\
\text { before? Code } B\end{array}$ & \\
\hline
\end{tabular}

Code A: (1) purchasing; (2) selling; (3) converted from/to other crops ; (4) conversion from forest ; (5) obtained as part of a government programme (e.g. "transmigransi"); (6) established plantation obtained from company;(7) inherited ; (8) received as gift ; (9) others: specify:

Code B: (1) oil palm; (2) plantation rubber ; (3) jungle rubber ; (4) other plantation ; (5) annual crops, specify: ; (6) grassland; (7) forest; (8) bush; (9) others, speci-

fy:

\begin{tabular}{|l|l|l|l|}
\hline QID & Question & Answer & Code \\
\hline 6. & $\begin{array}{l}\text { Have you ever extended the culti- } \\
\text { vated rubber plantation area? }\end{array}$ & (1)Yes; (2) No \\
\hline 7. & $\begin{array}{l}\text { If QID4.2.2.6=1: Have you ever } \\
\text { converted forest to rubber planta- } \\
\text { tion? }\end{array}$ & $\begin{array}{l}\text { (1)Yes;(2) No } \\
\text { If QID4.2.2.7 =1: Total area of } \\
\text { land: } \text { ha }\end{array}$ \\
\hline 8. & $\begin{array}{l}\text { If QID4.2.2.6=1: Have you ever } \\
\text { converted oil palm to rubber planta- } \\
\text { tion? }\end{array}$ & $\begin{array}{l}\text { (1)Yes; (2) No } \\
\text { If QID4.2.2.8=1: Total area of } \\
\text { land:_ha }\end{array}$ \\
\hline 9. & $\begin{array}{l}\text { Have you ever reduced the cultivat- } \\
\text { ed rubber plantation area? }\end{array}$ & (1)Yes; (2) No \\
\hline
\end{tabular}

\subsubsection{Jungle rubber}

1. Have you ever cultivated jungle rubber? (1) Yes; (2) No

If QID4.2.3.1., go to 5.

\begin{tabular}{|c|c|c|}
\hline QID & Question & Answer \\
\hline 2. & With how many hectares did you start cultivation? (ha) & \\
\hline 3. & Year (YYYY) & \\
\hline 4. & How did this start happen? Code $A$ & \\
\hline 5. & $\begin{array}{l}\text { If QID 4.2.3.4 =1, 3, } 8 \text { or 9: What kind of crop was on this area be- } \\
\text { fore? Code } B\end{array}$ & \\
\hline \multicolumn{3}{|c|}{$\begin{array}{l}\text { Code A: (1) purchasing; (2) selling; (3) converted from/to other crops ; (4) conversion from } \\
\text { forest ; (5) obtained as part of a government programme (e.g."transmigransi"); (6) established } \\
\text { plantation obtained from company;(7) inherited ; (8) received as gift ; (9) others: speci- } \\
\text { fy: }\end{array}$} \\
\hline $\begin{array}{l}\text { Code } \\
\text { nual } \\
\text { fy: }\end{array}$ & $\begin{array}{l}\text { 1) oil palm; (2) plantation rubber; (3) jungle rubber ; (4) other plc } \\
\text { S, specify:_(6) grassland; (7) forest; (8) bush; (9) }\end{array}$ & $\begin{array}{l}\text { ition; (5) an- } \\
\text { ers, speci- }\end{array}$ \\
\hline
\end{tabular}




\begin{tabular}{|l|l|l|l|}
\hline QID & Question & Answer & Code \\
\hline 6. & $\begin{array}{l}\text { Have you ever extended the cultivat- } \\
\text { ed jungle rubber area? }\end{array}$ & $\begin{array}{l}\text { (1)Yes; (2) No } \\
\text { verted forest to jungle rubber? }\end{array}$ & $\begin{array}{l}\text { (1)Yes;(2) No } \\
\text { If QID4.2.3.7 =1: Total area of } \\
\text { land:__ha }\end{array}$ \\
\hline 7. & $\begin{array}{l}\text { If QID4.2.6=1: Have you ever con- } \\
\text { If QID4.2.3.6=1: Have you ever con- } \\
\text { verted oil palm to jungle rubber? }\end{array}$ & $\begin{array}{l}\text { (1)Yes; (2) No } \\
\text { If QID4.2.3.8=1: Total area of } \\
\text { land:_ha }\end{array}$ \\
\hline 8. & $\begin{array}{l}\text { Have you ever reduced the cultivated } \\
\text { jungle rubber area? }\end{array}$ & (1)Yes; (2) No \\
\hline 9
\end{tabular}

\section{Plantation}

\begin{tabular}{|l|l|c|}
\hline QID & Question & Answer \\
\hline 1. & $\begin{array}{l}\text { How many hours have you spent in the plantations (oil palm, rubber or } \\
\text { jungle rubber) in the last 7 days? (\#) }\end{array}$ & \\
\hline
\end{tabular}

\section{Consumption}

1. On how many days has your hour household consumed following good during the past 7 days?

\begin{tabular}{|l|l|l|}
\hline QID & Goods & $\begin{array}{l}\text { \# days in } \\
\text { last } \\
\text { days }\end{array}$ \\
\hline 1. & Fruits collected by one of your household members & \\
\hline 2. & Fruits (bought/gift) & \\
\hline 3. & Vegetable cultivated/collected by one of your household members & \\
\hline 4. & Vegetable (bought/gift) & \\
\hline 5. & Fire wood collected by one of your household members & \\
\hline 6. & Fire wood (bought/gift) & \\
\hline
\end{tabular}

\section{Perceived Welfare}

\begin{tabular}{|l|l|l|}
\hline QID & Question & Answer \\
\hline 1. & $\begin{array}{l}\text { Concerning your expenses for food, which of the following is true (re- } \\
\text { flects most accurately the situation of your household)? Code A }\end{array}$ & \\
\hline 2. & $\begin{array}{l}\text { Concerning your expenses for children's' education, health care, clothing, } \\
\text { housing, which of the following is true (reflects most accurately the situ- } \\
\text { ation of your household)? Code A }\end{array}$ & \\
\hline 3. & $\begin{array}{l}\text { How much does your household need (not spent!) per month for food (in } \\
\text { order to meet all basic needs adequately)? ('000 Rp) }\end{array}$ & \\
\hline 4. & $\begin{array}{l}\text { How much does your household need (not spent!) per month for chil- } \\
\text { dren's education, health care, clothing, housing (in order to meet all basic } \\
\text { needs adequately)? ('000 Rp) }\end{array}$ & \\
\hline $\begin{array}{l}\text { Code A: (1) your expenses are below the household's needs; (2) Your expenses are on the aver- } \\
\text { age comparable to your household's needs; (3) Your expenses exceed your household's needs }\end{array}$ \\
\hline
\end{tabular}




\section{Assets}

1. At present how many/much of the following does this household own that are in usable/repairable condition?

\begin{tabular}{|c|c|c|c|}
\hline QID & 1 & \multirow{2}{*}{$\begin{array}{l}2 \\
\text { Price (purchasing) Rp. ('000 } \\
\text { Rp) }\end{array}$} & 3. \\
\hline $\begin{array}{l}\text { Asset } \\
\text { (usable/repairable } \\
\text { condition) }\end{array}$ & (\#) & & $\begin{array}{l}\text { Year (purchasing) (if } \\
\text { HH owns more than } \\
\text { one, ask for year } \\
\text { (purchasing) of old- } \\
\text { est) }\end{array}$ \\
\hline \multicolumn{4}{|l|}{ Television (colour) } \\
\hline \multicolumn{4}{|l|}{ Satellite dish } \\
\hline \multicolumn{4}{|l|}{$\begin{array}{l}\text { Television and satellite } \\
\text { dish }\end{array}$} \\
\hline \multicolumn{4}{|l|}{ Motor cycle } \\
\hline \multicolumn{4}{|l|}{ Car } \\
\hline \multicolumn{4}{|l|}{ Jeep/Truck/Angkot } \\
\hline \multicolumn{4}{|l|}{ Fridge } \\
\hline \multicolumn{4}{|l|}{ Washing machine } \\
\hline \multicolumn{4}{|l|}{$\begin{array}{l}\text { DVD player/sound } \\
\text { system }\end{array}$} \\
\hline Water pump & & & \\
\hline
\end{tabular}

\section{Housing}

\begin{tabular}{|c|c|c|c|}
\hline QID & Question & Answer & Code \\
\hline 1. & $\begin{array}{l}\text { How would you describe the dwelling } \\
\text { in which your family currently resides? }\end{array}$ & & $\begin{array}{l}\text { (1) wooden house; (2) stone } \\
\text { house; (3) other; specify: }\end{array}$ \\
\hline 2. & $\begin{array}{l}\text { Some people fully own their dwelling, } \\
\text { some still pay them off, or rent them or } \\
\text { simply live in a dwelling they do not } \\
\text { pay for. What characterize you situati- } \\
\text { on? }\end{array}$ & & $\begin{array}{l}\text { (1)own ; (2)own, with credit; } \\
\text { (3)rent; (4) live without paying } \\
\text { anything; (5) other: specify: }\end{array}$ \\
\hline 3. & $\begin{array}{l}\text { How many rooms does your dwelling } \\
\text { have (total number of rooms on com- } \\
\text { pound if same household)? Please } \\
\text { exclude toilet/bathroom. }\end{array}$ & & Number of rooms \\
\hline 4. & What is the material of the roof? & & $\begin{array}{l}\text { (1) iron sheet; (2)wood; } \\
\text { (3)tiles; (4) other, speci- } \\
\text { fy: }\end{array}$ \\
\hline 5. & On what do the HH members sleep? & & Code $A$ \\
\hline \multicolumn{4}{|c|}{$\begin{array}{l}\text { Code A: (1)mat (natural material) on the floor; (2) mat (natural material) above ground; } \\
\text { 3)plastic mat on the floor; (4) plastic mat above ground; (5) mattress on the floor; (6) mat- } \\
\text { tress above the ground; (7) foam mattress on the floor; (8) foam mattress above the ground; } \\
\text { (9) springbed mattress on the floor; (10) springbed mattress above the ground; (11) other, } \\
\text { specify: }\end{array}$} \\
\hline
\end{tabular}




\section{Social Engagement}

Now, we would like to know more about the titles you hold in this village.

\begin{tabular}{|l|l|l|l|l|l|l|}
\hline QID & 1 & 2 & 3 \\
\hline & $\begin{array}{l}\text { Have you held a „title“ in } \\
\text { this village in the last 12 } \\
\text { months? (Code A) }\end{array}$ & $\begin{array}{l}\text { If QID 10.1 = 1-9: Since } \\
\text { when do/ did you hold } \\
\text { this title? (YYYY) }\end{array}$ & $\begin{array}{l}\text { If QID 10.1.1 = 1-9: } \\
\text { Election process? } \\
\text { (Code B) }\end{array}$ \\
\hline & & & & & & \\
\hline
\end{tabular}

Code A: (1)Kepala desa (2) Wakil kepala desa; (3) Sekertaris desa; (4) Kepala Dusun; (5) Kepala RT; (6) Kepala koperasi petani (7) Ketua kelompok petani; (8) Kepala (ketua) majlis taklim; (9) Sesepuh; (10) Kepala Imbarga adat (11) Ketua Karang Taruna; (12) Imam syarrat; (13) Mubaligh; (14) Kepala anggota politik (15) Hajis; (16) other, speci-

fy:

Code B: (1) inheritage; (2) appointed by kepala desa (3) elected by group; (4) elected by all villagers; (5) other, specify:

\begin{tabular}{|l|l|l|l|}
\hline QID & 4. & 5. & 6. \\
\hline & $\begin{array}{l}\text { Have you been a } \\
\text { member in the follow- } \\
\text { ing groups in the last } \\
\text { 12 months? } \\
\text { (1) Yes; (2) No }\end{array}$ & $\begin{array}{l}\text { How often have you } \\
\text { been to meetings in the } \\
\text { last 12 months (on av- } \\
\text { erage)? } \\
\text { Code A }\end{array}$ & $\begin{array}{l}\text { Since when are } \\
\text { you member } \\
\text { of this group? } \\
\text { YYYY) }\end{array}$ \\
\hline Koperasi Pertani & & & \\
\hline Kelompok Petani & & & \\
\hline Majlis taklim & & & \\
\hline Karang Taruna & & & \\
\hline Lembarga adat & & & \\
\hline $\begin{array}{l}\text { Eldest group Ke- } \\
\text { (ompok tetua }\end{array}$ & & & \\
\hline Syara` & & & \\
\hline Perangkat desa & $\begin{array}{l}\text { Pemerintah/ } \\
\text { dewan desa }\end{array}$ & & \\
\hline Kelompok politik & $\begin{array}{l}\text { Other, spe- } \\
\text { cify: }\end{array}$ & & \\
\hline Code A: (1) everyday; (2) weekly; (3) monthly; (4) once per 6 months; (5) once per year \\
\hline
\end{tabular}

\section{Environmental Perceptio}

1. Which card reflects (the best) you relationship with the nature? Number: 


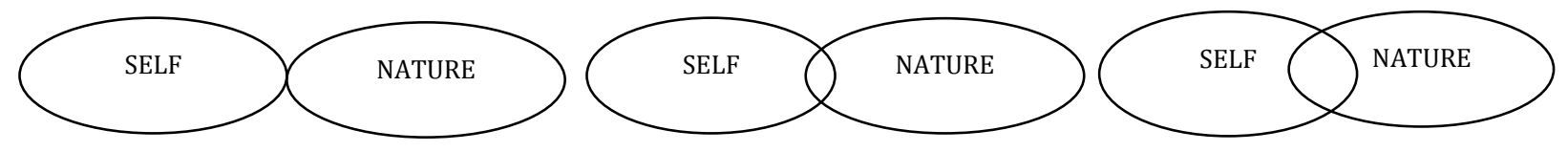

1

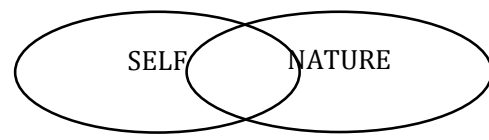

4

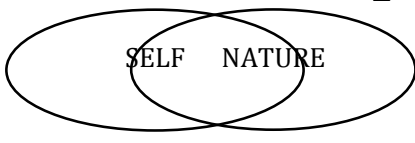

5
2

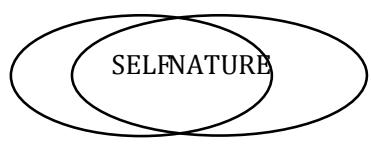

6
3

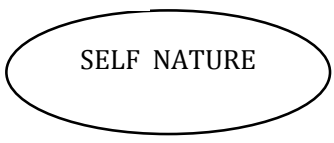

7

\section{Perception (Oil Palm, Rubber Plantation, Jungle Rubber)}

Here you can see three different production systems, which you might know (oil palm, rubber plantation, jungle rubber). Now, we are going to read out different question? Code: (1)Oil palm; (2) rubber plantation; (3) jungle rubber

\begin{tabular}{|l|l|l|l|l|}
\hline QID & Question & $\mathbf{1}^{\text {st }}$ & $\mathbf{2}^{\text {nd }}$ & $\mathbf{3}^{\text {rd }}$ \\
\hline 1. & $\begin{array}{l}\text { Which of the production systems do you find most beautiful } \\
\text { (second most beautiful and third most beautiful)? }\end{array}$ & & & \\
\hline 2. & $\begin{array}{l}\text { Which of the production systems do you find the most natural } \\
\text { (the second natural and the third natural)? }\end{array}$ & & & \\
\hline 3. & $\begin{array}{l}\text { Which of the production systems do you find the most profita- } \\
\text { ble (the second profitable and the third profitable)? }\end{array}$ & & \\
\hline 4. & $\begin{array}{l}\text { Which of the production systems do you associate the most with } \\
\text { the improved wellbeing of your family (the second and the } \\
\text { third)? }\end{array}$ & $\begin{array}{l}\text { Which of the production systems do you associate the most with } \\
\text { decreasing number of birds and mammals (the second and the } \\
\text { third)? }\end{array}$ & & \\
\hline 5. & $\begin{array}{l}\text { Which of the production systems do you associate the most with } \\
\text { increasing water scarcity (the second and the third)? }\end{array}$ & & & \\
\hline 7. & $\begin{array}{l}\text { Which of the production systems do you associate the most with } \\
\text { decreasing nutrients in the soil (the second and the third)? }\end{array}$ & & & \\
\hline
\end{tabular}

\section{Environmental events}

Over the last five years, was your household affected by the following events? How serious was your household affected by this event over last five years?

\begin{tabular}{|l|l|l|l|l|}
\hline QID & Event & \multicolumn{3}{|l|}{ Household was_affected by } \\
\hline & & Seriously & Slightly & Not at all \\
\hline 1. & Drought/Water scarcity & & & \\
\hline 2. & Flood/too much rain & & & \\
\hline 3. & Crop diseases & & & \\
\hline 4. & Erosion & & & \\
\hline 5. & Decreasing soil fertility & & & \\
\hline
\end{tabular}




\begin{tabular}{|l|l|l|l|}
\hline QID & Question & Answer & Code \\
\hline 6. & $\begin{array}{l}\text { Since you live in this village has the number of events } \\
\text { related to the environment (water scarcity; soil erosion; } \\
\text { drought; flooding) increased, decreased or stayed con- } \\
\text { stant? }\end{array}$ & $\begin{array}{l}\text { (1) increase; } \\
\text { (2) decrease; } \\
\text { (3) stayed } \\
\text { constant }\end{array}$ \\
\hline 7. & $\begin{array}{l}\text { Do you think environmental problems (erosion, floods, } \\
\text { soil fertility, and biodiversity loss) will become worse } \\
\text { for your village? }\end{array}$ & (1) Yes; (2) No \\
\hline
\end{tabular}

\section{Migration}

1. Has your household migrated from somewhere to this village?

(1) Yes; (2) No

If QID14.1=2, continue with QID14.8.

2. Did your household migrate as part of transmigrant programme?

(1) Yes; (2) No

\begin{tabular}{|c|c|c|c|c|}
\hline 3. & 4. & 5. & 6. & 7. \\
\hline $\begin{array}{l}\text { Place from where } \\
\text { the household } \\
\text { migrated to this } \\
\text { village: (Code } A)\end{array}$ & $\begin{array}{l}\text { Year of } \\
\text { tansmigra- } \\
\text { tion/migra } \\
\text { tion: }\end{array}$ & $\begin{array}{l}\text { Since } \\
\text { when does } \\
\text { your HH } \\
\text { live in this } \\
\text { village? }\end{array}$ & $\begin{array}{l}\text { Who was the head } \\
\text { of the household } \\
\text { at time of migra- } \\
\text { tion? (Code B) }\end{array}$ & $\begin{array}{l}\text { What was the ma- } \\
\text { jor source of in- } \\
\text { come before mi- } \\
\text { gration? } \\
\text { (Code C9) }\end{array}$ \\
\hline \multicolumn{5}{|c|}{$\begin{array}{l}\text { Code A: (1) Jambi province ; (2) Java ; (3) Sumatera North ; (4) Sumatera South ; (5) Kaliman- } \\
\text { tan ; (6) Sulawesi ; (7) other, specify: }\end{array}$} \\
\hline \multicolumn{5}{|c|}{$\begin{array}{l}\text { Code B: (1) current HH head, (2) father/mother of current HH head; (3) grandfather of cur- } \\
\text { rent HH head (4) other relatives of current HH head; (5) other, specify: }\end{array}$} \\
\hline \multicolumn{5}{|c|}{ Code C: (1)self-employed agriculture; (2) employed agriculture; (3) gaji buruh; (4)wiraswasta } \\
\hline
\end{tabular}

\begin{tabular}{|l|l|l|l|}
\hline QID & Question & Answer & Code \\
\hline 8. & What is your religion? & $\begin{array}{l}\text { (1) Islam; (2) Hindu; (3) Protestant; (4) Catholic; } \\
\text { (5) Pantekosta; (6) Buddha; (7) other, speci- } \\
\text { fy: }\end{array}$ \\
\hline 9. & What is you ethnicity? & $\begin{array}{l}\text { (1) Melayu; (2) Rimba; (3) Bugis; (4) Jawa; (5) } \\
\text { Sunda; (6) Batak; (7) Manado; (8) Minahasa; (9) } \\
\text { Poso; (10) Minang; (11) Bali; (12) Toraja; (13) } \\
\text { Aceh; (14) Makasar; (15) other, specify. }\end{array}$ \\
\hline
\end{tabular}




\section{Final Questions}

We are going to read out some statements related to the distribution of land in your village. We would like to know your opinion. Therefore please use this scale (strongly agree-strongly disagree).

\begin{tabular}{|l|l|l|l|l|l|}
\hline QID & Question & $\begin{array}{l}\text { Strongly } \\
\text { Agree }\end{array}$ & Agree & $\begin{array}{l}\text { Disag } \\
\text { ree }\end{array}$ & $\begin{array}{l}\text { Strongly } \\
\text { Disagree }\end{array}$ \\
\hline 1 & The purchase of land i soften illegal & & & & \\
\hline 2 & $\begin{array}{l}\text { The amount of land that someone owns } \\
\text { is a result of heritage. }\end{array}$ & & & & \\
\hline 3 & $\begin{array}{l}\text { The amount of land that someone own is } \\
\text { a result of hard work. }\end{array}$ & & & & \\
\hline 4 & $\begin{array}{l}\text { The amount of land that someone own is } \\
\text { a result of luck. }\end{array}$ & & & & \\
\hline 5 & Income should be distributed more equal. & & & & \\
\hline 6 & $\begin{array}{l}\text { Hard work does not generally bring success. } \\
\text { It is more a matter of luck and relations. }\end{array}$ & & & & \\
\hline 7 & $\begin{array}{l}\text { People can only get rich at the expenses of } \\
\text { others. }\end{array}$ & & & & \\
\hline 8 & $\begin{array}{l}\text { Most people that are rich have worked very } \\
\text { hard to achieve this. }\end{array}$ & & & & \\
\hline
\end{tabular}

\section{Thank you for your participation!}

